\author{
Universidade de São Paulo \\ Instituto de Física de São Carlos \\ Departamento de Física e Ciência dos Materiais
}

\title{
Efeitos do Tratamento da Madeira com Álcool Furfurílico combinado com Compostos de Boro
}

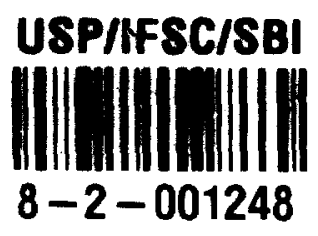

Salete Kiyoka Ozaki

Dissertação apresentada à Área Interunidades, da Universidade de São Paulo, para obtençăo do título de Mestre em Ciência e Engenharia de Materiais.

Orientador: Prof. Dr. Milton Ferreira de Souza Co-orientador: Prof. Dr. Yuji Imamura 


\section{Ozaki, Salete Kiyoka}

Efeitos do Tratamento da Madeira com Álcool Furfurílico combinado com Compostos de Boro/Salete Kiyoka Ozaki. - São Carlos, 1999.

$164 p$.

Dissertação(Mestrado) - Instituto de Física de São Carlos, Instituto de Química de São Carlos, Escola de Engenharia de São Carlos, 1998.

Orientador: Prof. Dr. Milton Ferreira de Souza

Co-orientador: Prof. Dr. Yuji Imamura

1.Estabilidade Dimensional

3. Fixação do Boro.
2. Resistência Biológica I. Título 


\section{Ciência e Engenharia de Materiais}

\section{UNIVERSIDADE DE SÃO PAULO}

Escola de Engenharia de São Carlos

CAIXA POSTAL - 369

CEP 13560-970 - São Carlos/SP - Brasil

Tel/Fax: (016) 273-9777

E-mail: erica@if.sc.usp.br

MEMBROS DA COMISSÃO JULGADORA DA DISSERTAÇÃO DE MESTRADO DE SALETE IKYIOKA OZAKI, APRESENTADA A ÁREA INTERUNDADES EM CIÊNCIA E ENGENHARIA DE MATERIAIS, DA EESC-IFSC-IQSC, UNIVERSIDADE DE SÃO PAULO, EM 21/1/1999.

\section{COMISSÃO JULGADORA:}

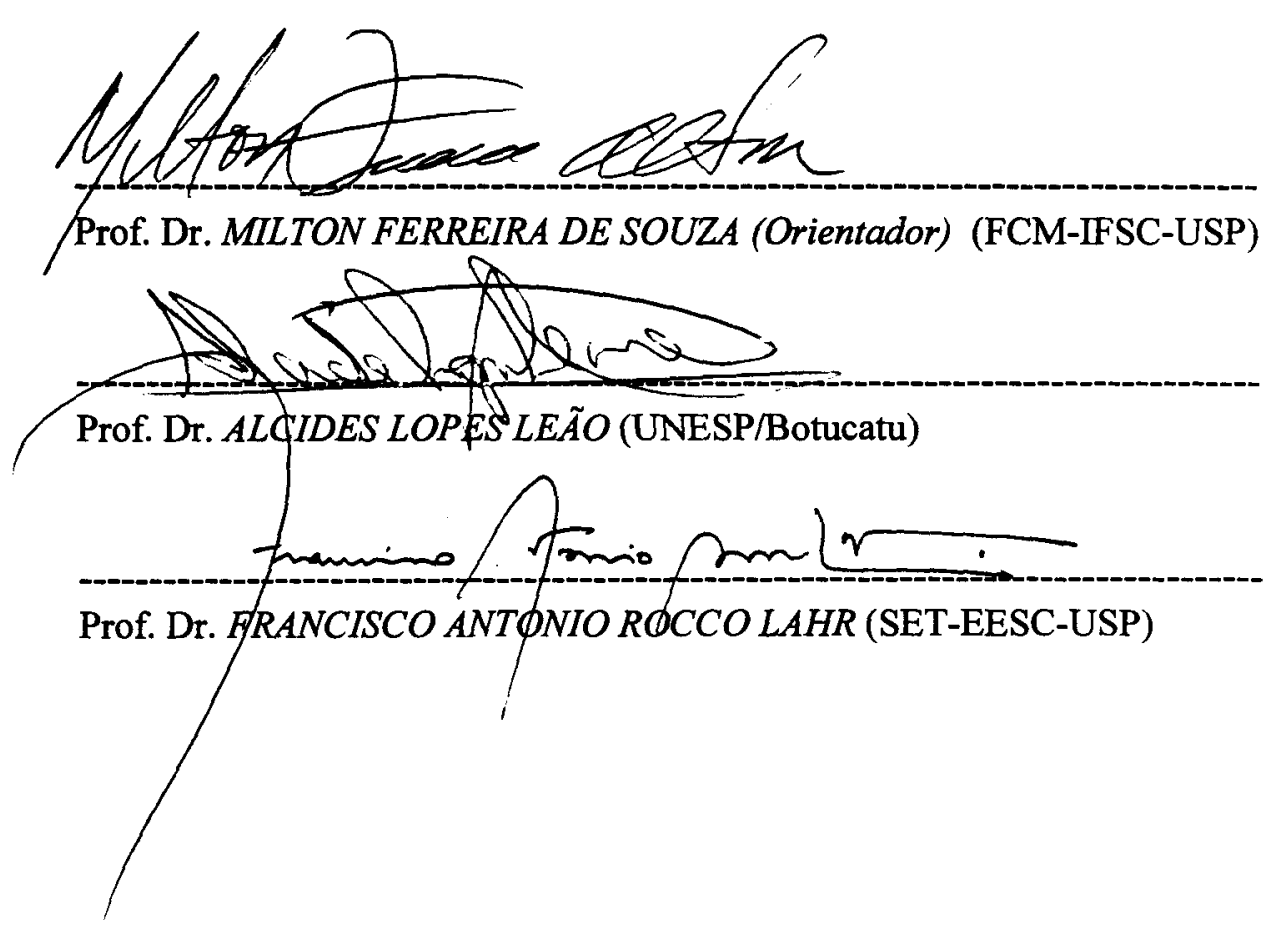




\section{Agradecimentos}

- Ao Prof. Dr. Milton Ferreira de Souza pela experiência e sabedoria com que conduz seus muitos trabalhos, acreditando sempre no homem. Seu incentivo, amizade e compreensão foram fundamentais para que este trabalho se concretizasse.

- Ao Prof. Dr. Yuji Imamura pela paciência e dedicação nas difíceis fases de adaptação a outra cultura e outro grupo de trabalho, e espírito de cooperação em possibilitar a execução de importantes estudos no Wood Research Institute.

- Ao pesquisador Sr. Mustafa K. Yalinkilic (professor da Black Sea Technical University Turquia, cursando doutorado no WRI - Kyoto University), cuja experiência e cooperação foram fundamentais no desenvolvimento deste trabalho.

- Ao Sr. Yashiro Yamamoto por me incentivar e muito contribuir para tornar realidade o sonho de estudar no exterior.

- À JICA - Japan International Cooperation Agency por ter possibilitado o desenvolvimento de importante etapa do trabalho num dos mais conceituados institutos de pesquisa de madeira do mundo.

- Ao Sr. Nishimura, responsável pelos estagiários do Centro de Osaka, pelo carinho e atenção em atender-nos.

- À Associação de Nikkeys de Yokohama e às professoras do curso de língua japonesa que não mediram esforços para que conseguissemos nos comunicar em japonês em um tempo muito curto.

- Aos professores do Departamento de Física da Universidade Federal de Mato Grosso: Sérgio Roberto de Paulo, Denilton Carlos Gaio e Romildo Gerônimo Ramos, pelo grande incentivo e apoio em superar muitas deficiências e acreditar em meu trabalho. 
- Aos professores do Departamento de Química da UFMT, especialmente Evaldo Ferraz de Oliveira, Edinaldo de Castro e Silva, Edevaldo V. Campos, Carlos Emílio Lopes e Eliana Freire Gaspar, pelo carinho e compreensão em todas as circunstâncias, e incentivar tanto o meu crescimento profissional como pessoal.

- Aos professores da Pós-Graduação na Área Interunidades em Física, Química e Engenharia, do Instituto de Física de São Carlos, Instituto de Química de São Carlos e Escola de Engenharia de São Carlos.

- Aos colegas técnicos do Departamento de Química da UFMT, pela amizade e grande cooperação tanto no gerenciamento do trabalho no laboratório como esclarecimentos e auxílios nos assuntos burocráticos.

- Ao professor Akio Adachi do Deterioration Control Laboratory - WRI - Kyoto University, pela sua gentil cooperação e atenção durante a preparação das amostras e do desenvolvimento dos testes.

- Aos professores do Wood Research Institute - Kyoto University, pelas valiosas discussões, sugestões e auxílios.

- Aos colegas: EeDing Wong (Malásia), Han Guang Ping (China), Lilibeth Pulido Novicio (Filipinas), Hwang (Coréia do Sul), Zhang Ming (China), Subyakto (Indonésia), Bambang Subyanto (Indonésia), Dede Hermawan (Indonésia), Koichi Murase (Japão), Kenji Umemura (Japão), Tamami Kawasaki (Japão), Nelson Pulido (Colombia), Ivan (Bulgária), Bossev (Bulgária), Ralf Hasdroph (Alemanha), Duc (Austrália), do campus de Uji, da Kyoto University, que tudo fizeram para que minha permanência no Japão fosse a mais proveitosa e prazeirosa possível.

- Aos colegas: Paulo dos Santos Batista, Jean Yamamoto, Eiji Harima, Robson S. Miranda, Paulo Henrique Aguirre, Roberto P. Vila Nova, Washington E. Magalhães, Inácio Regiani 
e Deusdedit Lineu Spavieri, que tornam o ambiente de trabalho saudável e produtivo.

- Às amigas Suely Oliveira Amorim e Maria Nazareth de Souza, companheiras sempre.

- Aos colegas de turma: Juzélia Souza Santos, Walquíria Marinho, Luciane Durante, Ellen K. Pantoja, Marcos F. Pantoja, Laerte Pinhedo, Adnauer Daltro, J. M. Henriques de Jesus, Manoel Gregório de Miranda Filho, Walterley Moura, Pedro Strobel, Gilson Francisco de Lima, Waldemir Rodrigues, João Luiz Cuiabano, pela amizade e alegria nos bons momentos, e companheirismo nos tempos difíceis.

- Ao professor Dener Gonçalves Prata, do Laboratório de Madeiras e Estruturas de Madeira (LaMEM), pela atenciosa colaboração nos primeiros esclarecimentos com a morfologia da madeira.

- Aos técnicos do Laboratório de Madeiras e Estruturas de Madeira (EESC) e do Laboratório de Microscopia Eletrônica (IFSC), pela valiosa colaboração no preparo das amostras e testes.

- Às secretárias do grupo de Óptica do IFSC, Isabel e Gláucia, e da Seção de Alunos, Wladerez e Érica, pela atenção e eficiência. 
Aos meus pais Hiromi e Emika, meu avô Minoru, irmãos e cunhadas, e meus sobrinhos, Fernanda $e$ Henrique, pelo amor, carinho $e$ compreensão em todos os momentos. 


\section{SUMÁRIO}

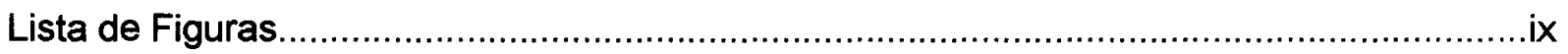

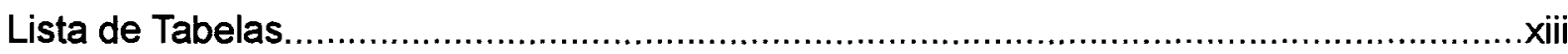

Lista de Abreviaturas e Símbolos.....................................................................................

Resumo

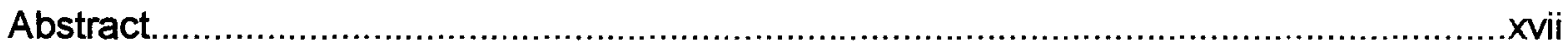

Introdução

Capítulo I - Revisão Bibliográfica

1.1 Composição Química e Análise da Madeira ........................................................

1.2 Variação Dimensional da Madeira...................................................................13

1.2.1 Porque ocorre a variação dimensional da madeira........................................13

1.2.2 Tratamento de Repelência à Água ................................................................

1.2.3 Tratamento de Estabilização Dimensional....................................................17

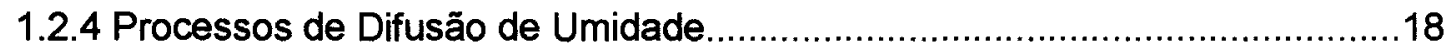

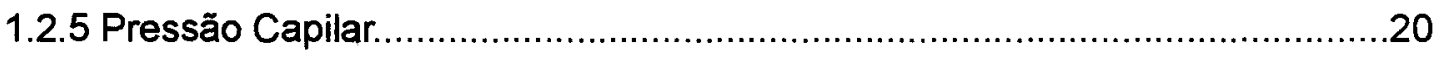

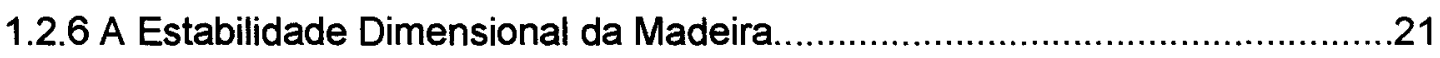

1.2.7 Tratamentos para melhorar a Estabilidade Dimensional da Madeira.............25

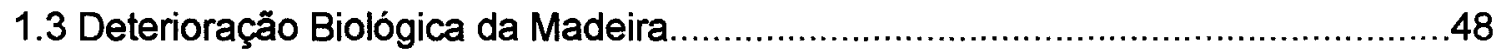

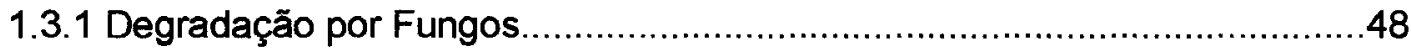

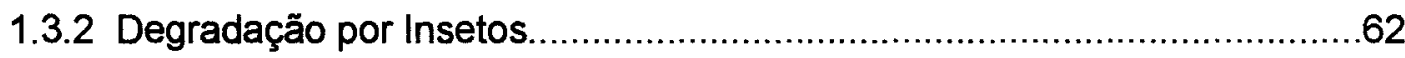

1.3.3 Degradação por Brocas Marinhas...........................................................65

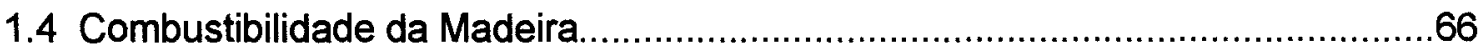

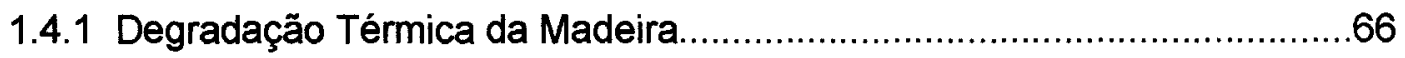

1.4.2 Definições de alguns Termos Importantes no Estudo de Materiais

Resistentes ou Retardantes de Fogo .............................................................69 


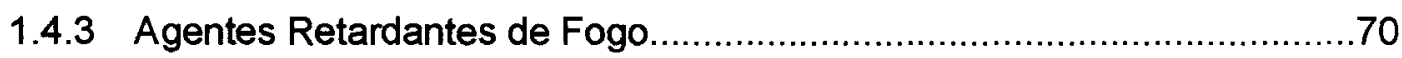

1.4.4 Mecanismo de Ação dos Retardantes de Fogo.....................................71

1.4.5 Testes de Resistência ao Fogo..........................................................

1.4.6 Toxicidade de Alguns Gases Despreendidos na Combustão..................76

1.5 Degradação por Raios Ultra-violetas ....................................................78

1.5.1 Degradação dos Componentes Estruturais da Madeira.........................78

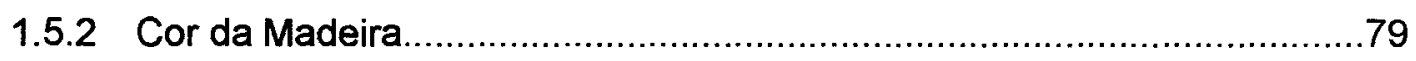

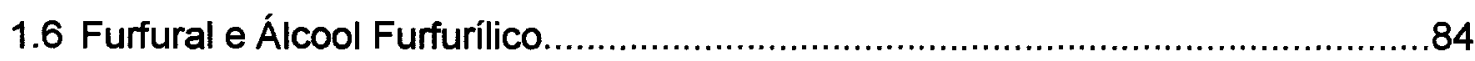

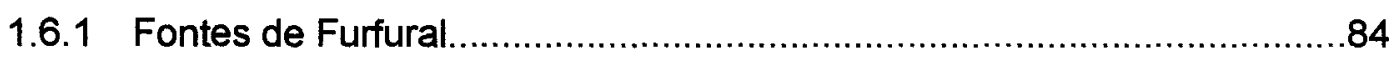

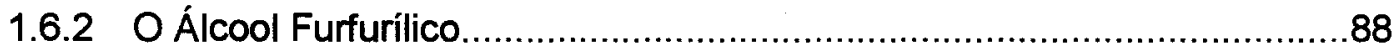

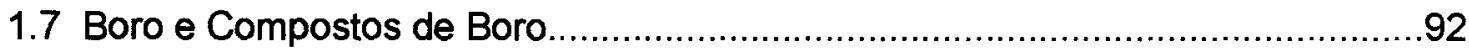

Capítulo II - Procedimentos experimentais

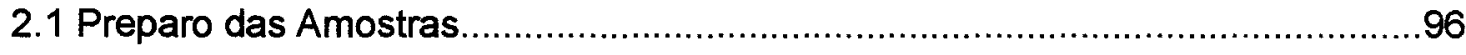

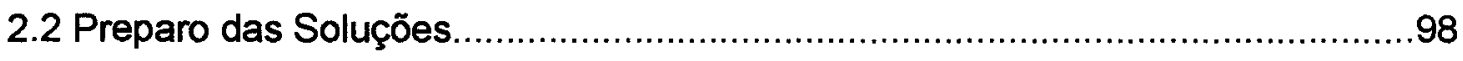

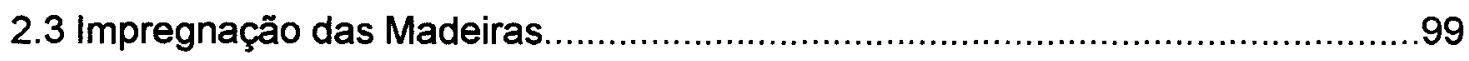

Capítulo III - Resultados e Discussão

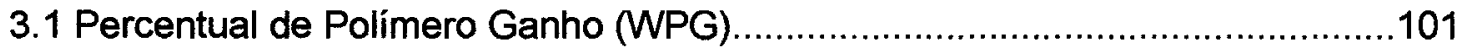

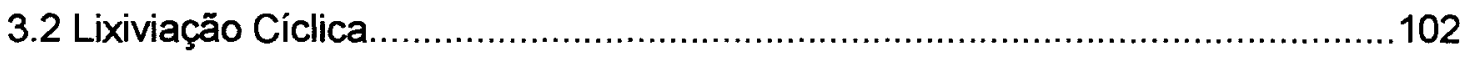

3.2.1 Análise dos Resíduos de Lixiviação Cíclica do Boro.............................105

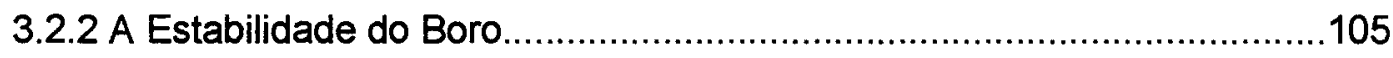

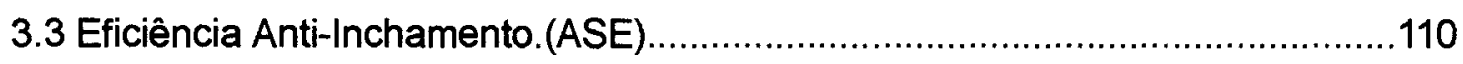

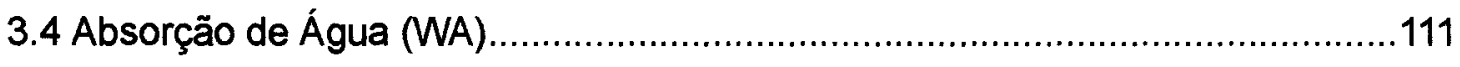

3.5 Eficiência de Exclusão de Umidade (MEE) ...............................................111

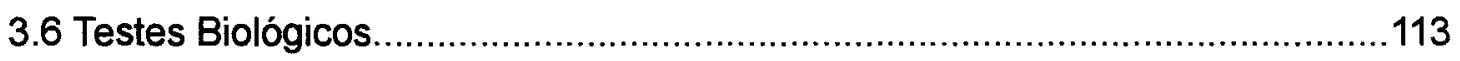

3.6.1 Teste de resistência ao Ataque de Térmitas.......................................114

3.6.2 Teste de Deterioração por Fungos................................................122 
3.7 Teste de Índice de Oxigênio. .133

3.8 Teste de Exposição às Condições Climáticas 143

Capítulo IV - Conclusões. .153

Referências Bibliográficas .157 Anexos 
Lista de Figuras

Figura 1- Esquema Geral dos Componentes Químicos na Madeira .5

Figura 2- Diagrama Esquemático da Orientação Microfibrilar.. 8

Figura 3- Distribuição de Lignina, Celulose e Hemicelulose através da Parede Celular.......9

Figura 4- Direções Longitudinal, Radial e Tangencial em relação aos anéis. 14

Figura 5- Relação de Inchamento com o Tempo para Madeira com e sem Tratamento......16

Figura 6- Relação de Inchamento com o Tempo para Madeira com e sem Tratamento......17

Figura 7- Relação de Inchamento com o Tempo para Madeira com e sem Tratamento......18

Figura 8- Interface Sólido-Líquido-Gás 19

Figura 9- Esquema llustrativo do Fenômeno da Fluência .24

Figura 10- Modelo das Modificações Químicas da Madeira .29

Figura 11- Proposta de Ligação entre Formaldeído e Grupos OH da Madeira. 31

Figura 12- Ligação de Anidrido Acético com Grupos $\mathrm{OH}$ da Madeira. 39

Figura 13- Ligação de Grupos OH com Etenona. .40

Figura 14- Ligação de Grupos $\mathrm{OH}$ com Cloreto de Acila. 40

Figura 15- Ligação de Grupos $\mathrm{OH}$ com Cetona .40

Figura 16- Ligação de lodeto de Metila com Grupos $\mathrm{OH}$ da Madeira.

Figura 17- Ligação de Cloreto de Alquila com Grupos OH da Madeira.

Figura 18- Ligação de Epóxido com Grupos $\mathrm{OH}$ da Madeira

Figura 19- Ligação de Isocianato com Grupos $\mathrm{OH}$ da Madeira .45

Figura 20- Ligação de Acrilonitrila com Grupos $\mathrm{OH}$ da Madeira. 46

Figura 21- Ligação de $\beta$-propiolactona com Grupos $\mathrm{OH}$ da Madeira. 47

Figura 22- Mecanismo de Degradação da Celulose por Fungos da Podridão Branca........52

Figura 23- Metabolização de Ácido Oxálico a partir de Ácido Oxaloacético. .54

Figura 24- Uma Parte do Espectro Eletromagnético. 80 
Figura 25- Conversão de Pentoses $(\mathrm{R}=\mathrm{H})$ a Furfural, e de Hexoses a Hidroximetilfurfural...85

Figura 26- Exemplos de Produtos obtidos da Fração de Açúcares da Hidrólise. .85

Figura 27- Polimerização do Furfural com a Propanona. .86

Figura 28- Provável estrutura de um Polímero Furânico Não Linear. .87

Figura 29- Polimerização do 5-Hidroximetil 2- furancarboxialdeído. .88

Figura 30- Conversão do Furfural a Álcool Furfurílico. .89

Figura 31- Estrutura do Álcool Furfurilico apresentando Inter-Cruzamentos. .89

Figura 32- Primeiro Estágio da Polimerização do Álcool Furfurílico. .90

Figura 33- Oligômero de FFA com Ligações Conjugadas. .90

Figura 34- Estágio Avançado da Polimerização do FFA. .91

Figura 35- Esquema Simplificado da Câmara de Impregnação. .100

Figura 36- Variação em Massa da Espécie Sugi ao longo de Dez Ciclos de Lixiviação.......102

Figura 37- Variação em Massa da Espécie Pinho ao longo de Dez Ciclos de Lixiviação.....103

Figura 38- Variação em Volume do Pinho ao longo de Dez Ciclos de Lixiviação. 103

Figura 39- Variação em Volume do Sugi ao longo de Dez Ciclos de Lixiviação 104

Figura 40- Cromatograma da Análise dos Residuos da Solução de FFA + BA. 107

Figura 41- Cromatograma da Análise dos Resíduos da Solução de FFA + BO 108

Figura 42- Cromatograma da Análise dos Resíduos da Solução de FFA + BI 109

Figura 43- Relação da Eficiência Anti-Inchamento (ASE) com o WPG 113

Figura 44- Amostra Assentada no Aparato para Exposição ao Ataque de Térmitas. 115

Figura 45- Evolução da Mortalidade de Térmitas ao longo de 6 semanas - Sugi. 115

Figura 46- Evolução da Mortalidade de Térmitas ao longo de 6 semanas - Pinho. 116

Figura 47- Perda de Massa (\%) da espécie Sugi após 6 semanas. 116

Figura 48- Perda de Massa (\%) da espécie Pinho após 6 semanas. .117

Figura 49- Aparência Visual do Pinho Submetido ao Teste de Resistência aos Térmitas..121 Figura 50- Aparência Visual do Sugi Submetido ao Teste de Resistência aos Térmitas....121 
Figura 51- Aparência Visual do Sugi Submetido ao Teste de Resistência aos Térmitas....122

Figura 52- Vidro Teste de Exposição ao Ataque de Fungos.

Figura 53- Perda de Massa(\%) do sugi submetido aos fungos da podridão parda. 127

Figura 54- Perda de Massa(\%) do sugi submetido aos fungos da podridão branca.

Figura 55- Perda de Massa(\%) do pinus submetido aos fungos da podridão parda. 128

Figura 56- Perda de Massa(\%) do pinus submetido aos fungos da podridão branca. 128

Figura 57- Micrografias de Madeiras Submetidas à Deterioração por Fungos. 130

Figura 58- Coluna de Teste de Índice de Oxigênio. .134

Figura 59- Índice de Oxigênio da espécie Sugi e Pinus. 136

Figura 60- Tempo de Queima das espécies sugi e pinus. 137

Figura 61- Micrografias de Madeiras Submetidas ao Teste de Índice de Oxigênio. 139

Figura 62- Aparência Visual do Sugi sem tratamento após Teste de Índice de Oxigênio....141

Figura 63- Aparência Visual do Sugi tratado com FFA + BA após Teste.

Figura 64- Aparência Visual do Pinho sem tratamento após Teste. 142

Figura 65- Aparência Visual do Pinho tratado com FFA + BA após Teste. 142

Figura 66- Representação do Sistema $L^{*} a^{*} b^{*}$

Figura 67- Detalhe da Representação das Cores nos Planos a* e b*.... 144

Figura 68- Representação Tridimensional das Cores no Sistema $L^{*} a^{*} b^{*}$ .145

Figura 69- Variação Total da Cor após 24 semanas de Exposição. 146

Figura 70- Variação da Cor da espécie Sugi Exposta às Condições Climáticas. 147

Figura 71- Variação da Cor da espécie Pinus Exposta às Condições Climáticas. 147

Figura 72- Aparência Visual de Amostras de Pinus tratadas com FFA. 148

Figura 73- Aparência Visual de Amostras de Pinus tratadas com FFA. 148

Figura 74- Aparência Visual de Amostras de Sugi tratadas com FFA. 149

Figura 75- Aparência Visual de Amostras de Sugi e Pinus tratadas com FFA. 149

Figura 76- Aparência Visual de Amostras de Sugi e Pinus tratadas com FFA. 150 
Figura 77- Aparência Visual de Amostras de Sugi e Pinho tratadas com FFA... 150

Figura 78- Aparência Visual de Amostras de Sugi e Pinho tratadas com FFA... 150

Figura 79- Aparência Visual de Amostras de Sugi e Pinho tratadas com FFA...... .151 
Lista de Tabelas

Tabela 1 Células das Coniferas. .6

Tabela 2 Energia de Dissociação de Algumas Ligações Químicas...................................74

Tabela 3 Relação das Soluções de Tratamento Empregadas.......................................99

Tabela 4 Gravidade Específica e Percentual de Polímero Ganho.................................104

Tabela 5 Concentração de Boro nas Soluções ........................................................105

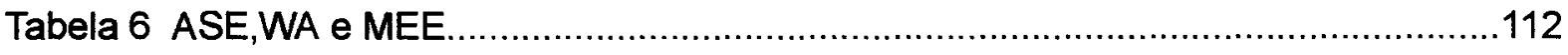

Tabela 7 Percentagem de Perda de Massa e Resistência à Deterioração Relativa...........125

Tabela 8 Percentagem de Perda de Massa e Resistência à Deterioração Relativa...........126

Tabela 9 WPG e Tempo de Queima das Espécies Submetidas ao Teste de Índice .........137

Tabela 10 Variação Total da Cor ao Final de 24 Semanas de Exposição..........................147 
Lista de Abreviaturas e Símbolos

FFA Álcool Furfurilico

FFA + BA Álcool Furfurílico combinado com Ácido Bórico

$\mathrm{FFA}+\mathrm{BO} \quad$ Álcool Furfurílico combinado com Borato de Amônio

FFA + BI Álcool Furfurílico combinado com Biborato de Amônio

WPG Percentagem de Polímero Ganho

ASE Eficiência Anti- Inchamento

ACE Eficiência Anti-Fluência

MOR Módulo de Ruptura

MOE Módulo de Elasticidade

Camada P Camada Primária

Camada S1 Camada Secundária Externa

Camada S2 Camada Secundária Central

Camada S3 Camada Secundária Interna

Camada W Camada Rugosa

ML Lamela Média

CCA Arsenato de Cobre Cromatado

CCB Sais de Cobre, Cromo e Boro

PCP Pentaclorofenol

ACA Arsenato de Cobre Amoniacal

ACC Cromato de Cobre Ácido

ACZA Arsenato de Zinco e Cobre Amoniacal

CZC Cloreto de Zinco Cromatado

FCAP Fenol Arsenato de Flúor e Cromo

IPBC Propinil Butil Carbamato de lodo

TBTO Tributil Oxido de Estanho

DMDHEU Dimetilol Dihidroxi Etileno Uréia

O.I. Índice de Oxigênio

BADO Ácido Bórico-Octoborato de Dissódio

DDAC Didecil Dimetil Cloreto de Amônio 
ambos sejam combinadas e melhoradas.

Impregnou-se duas espécies de coníferas muito populares, uma no Brasil e outra no Japão, com álcool furfurílico em combinação com compostos de boro e testou-se algumas de suas propriedades. Espécies de Coníferas "Japanese cedar" (Cryptomeria japonica D. Don.) - o sugi, e (Pinus caribaea var. hondurensis) - pinus - foram impregnadas com álcool furfurílico (FFA) pelo processo vácuo-encharcamento seguido da cura do FFA sob aquecimento. Compostos de boro: ácido bórico, borato de amônia e biborato de amônia foram adicionados à solução de impregnação. Espécies impregnadas foram submetidas aos testes de eficiência anti-inchamento, resistência aos térmitas, resistência aos microorganismos, resistência à flamabilidade e resistência às intempéries. Ao lado destes testes, os resíduos das soluções submetidas aos ciclos de lixiviação de acordo com as normas padrões JIS 9201 (1992) foram analisados através de cromatografia iônica com o objetivo de estudar métodos de fixação do boro na madeira.

Os resultados mostraram que a resina de FFA confere à madeira alta estabilidade dimensional. Resultados semelhantes são obtidos quando FFA é combinada com compostos de boro. A mobilidade do boro mostrou diferentes comportamentos em comparação com o tratamento com o ácido bórico, embora o boro ainda seja lixiviável. A madeira tratada com FFA combinada com compostos de boro apresentou grande resistência a ataques de térmitas e à deterioração biológica quando não submetida à lixiviação. Quando lixiviadas a resistência biológica diminui consideravelmente mas ainda assim é maior que a da madeira sem tratamento ou da tratada somente com ácido bórico.

O tratamento mostrou que a combinação aumentou a resistência da madeira contra a queima sem chama. A queima produz pouca fumaça e cinzas.

As combinações de tratamento não se mostraram eficazes para fixar a cor durante a exposição às condições climáticas. 


\section{Resumo}

As pentoses são subprodutos de vários rejeitos agrícolas tais como palha de arroz, palha e sabugo de milho, casca de aveia, bagaço da cana-de-açúcar, caroço de algodão, resíduos de madeira e outros, de onde se pode obter, por digestão com ácido forte, o furfural, e dele, por hidrogenação, o álcool furfurílico (FFA). A polimerização do FFA conduzindo a um produto inerte, resistente à corrosão, que tem sido utilizado principalmente como revestimento de mesas e bancadas de laboratório e de tanques industriais, é um produto negro que apresenta estrutura fortemente intercruzada. Porém, seu relativo alto custo tem constituído uma barreira para que suas aplicações se popularizem. Com o aproveitamento de resíduos industriais da produção de etanol, óleo de arroz, algodão, milho, e da indústria madeireira, espera-se a redução de seu custo de produção e, consequentemente, a ampliação de seu campo de aplicações principalmente por tratar-se de um polímero natural não derivado do petróleo.

Por outro lado, o país enfrenta sérias dificuldades no campo habitacional, uma delas sendo o elevado custo dos materiais de construção. Viabilizando-se o emprego de madeiras de reflorestamento para emprego em construção civil e industrial, por exemplo aumentando sua resistência ao ataque de fungos e de insetos, à propagação da chama e à variação dimensional, poderemos proporcionar um número maior de moradias sem, contudo, promover o desmatamento de reservas de madeiras nobres.

Neste trabalho tem-se como objetivos a obtenção de compósitos de madeira e polímero que apresentem vantagens sobre a madeira de reflorestamento sem tratamento, e o estudo de um meio de fixar o boro usando o álcool furfurílico para que as propriedades de 
ambos sejam combinadas e melhoradas.

Impregnou-se duas espécies de coníferas muito populares, uma no Brasil e outra no Japão, com álcool furfurílico em combinaçăo com compostos de boro e testou-se algumas de suas propriedades. Espécies de Coníferas "Japanese cedar" (Cryptomeria japonica D. Don.) - o sugi, e (Pinus caribaea var. hondurensis) - pinus - foram impregnadas com álcool furfurílico (FFA) pelo processo vácuo-encharcamento seguido da cura do FFA sob aquecimento. Compostos de boro: ácido bórico, borato de amônia e biborato de amônia foram adicionados à solução de impregnação. Espécies impregnadas foram submetidas aos testes de eficiência anti-inchamento, resistência aos térmitas, resistência aos microorganismos, resistência à flamabilidade e resistência às intempéries. Ao lado destes testes, os resíduos das soluções submetidas aos ciclos de lixiviação de acordo com as normas padrões JIS 9201 (1992) foram analisados através de cromatografia iônica com o objetivo de estudar métodos de fixação do boro na madeira.

Os resultados mostraram que a resina de FFA confere à madeira alta estabilidade dimensional. Resultados semelhantes são obtidos quando FFA é combinada com compostos de boro. A mobilidade do boro mostrou diferentes comportamentos em comparação com o tratamento com o ácido bórico, embora o boro ainda seja lixiviável. A madeira tratada com FFA combinada com compostos de boro apresentou grande resistência a ataques de térmitas e à deterioração biológica quando não submetida à lixiviação. Quando lixiviadas a resistência biológica diminui consideravelmente mas ainda assim é maior que a da madeira sem tratamento ou da tratada somente com ácido bórico.

O tratamento mostrou que a combinação aumentou a resistência da madeira contra a queima sem chama. A queima produz pouca fumaça e cinzas.

As combinaçōes de tratamento não se mostraram eficazes para fixar a cor durante a exposiçăo às condições climáticas. 


\section{Abstract}

Pentosans are by-products of many agricultural crops such as rice, corn and oat husks, comcobs, sugar cane bagasse, cotton seeds, wood wastes, etc. By digesting these by-products with strong acid furfural can be produced, which, in its turn, can be transformed into furfuryl alcohol through hydrogenation. Polymerization of furfuryl alcohol transforms it into an inert corrosion-resistant product that is used as a coating material for laboratory tables, workbenches and industrial tanks. Its relatively high cost, however, has so far been an obstacle to its widespread application. By taking advantage of industrial waste from ethanol distilleries and from the rice, cotton, corn oil and wood industries, it is expected to reduce the cost of furfuryl alcohol production and, thus, to increase its applications. This becomes an increasingly relevant objective when one considers the future scarcity of petroleum.

Brazil is also beset by a variety of housing-related problems, one of which is the high cost of construction materials. Increasing the resistance of reforested wood against termite and fungi attacks and enhancing its fireproof and anti-swelling characteristics will enable the country to increase housing and preclude further deforestation of hardwood forests.

Present work discusses the work involved in developing a wood-polymer composite with particular characteristics for improving the dimensional stability of wood, increasing its resistance against termite and fungi attacks, decreasing its flammability and enhancing its weathering resistance, for proposing the utilization of furfuryl alcohol as boron fixation agent.

Two species of very popular softwoods, one of them in Brazil, pine and the other in Japan, sugi were impregnated with poli-FFA. Sapwood blocks of Japanese cedar 
(Cryptomeria japonica D. Don.) and Caribbean pitch pine (Pinus caribaea var. hondurensis) were impregnated with furfuryl alcohol (FFA) by a vacuum-impregnation process followed by curing of FFA under heating. Boron compounds: boric acid, ammonium borate and ammonium biborate were mixed in the impregnation solution. Impregnated specimens were submitted to an anti-swelling efficiency (ASE) test, exposed to attack by termites and microorganisms, and subjected to a flame resistance and natural weathering test. Boron leachability was determined, along with ten cycles of weathering, according to JIS 9201 (1992), by ion chromatography (IC). Results indicated that FFA imparted high dimensional stability to wood when mixed with boron compounds. Boron mobility showed differentiated behavior in comparison to treatment with boric acid alone, although boron was still leachable. Wood specimens treated with a FFA-boron compound combination were quite resistant to termite attacks and to biological deterioration when they were not submitted to leaching cycles. When were submitted to leaching cycles, their biological resistance decreased significantly; however, it was still higher than in untreated wood or in wood treated only with boric acid.

The treatment proved to be effective as a glowing retardant. The combustion yields small amount of smoke and ash.

Treatments did not prove efficiency to avoid the color changes in outdoor exposure. 


\section{Introdução}

A utilização de madeira é um dos recursos mais atraentes de que o Brasil dispõe devido à sua extensão territorial, riqueza de recursos hídricos e por ter energia solar em abundância durante todas as estações do ano. Entre outras vantagens do uso da madeira estão sua renovabilidade, facilidade de processamento, ser má condutora de calor, ter alta razão resistência/densidade, bem como o fato de ser agradável ao tato e à visão. Porém apresenta alguns aspectos negativos entre os quais a instabilidade dimensional, baixa resistência biológica e à flamabilidade. Desde que a conscientização ecológica tornou-se palavra de ordem em todos os setores da

economia, a busca pela melhoria na qualidade de vida tem trazido à discussão propriedades como a degradabilidade e reciclabilidade. A associação de recursos renováveis como madeira e outros compósitos ligno-celulósicos têm constituído um dos mais importantes campos de pesquisa na ciência e engenharia de novos materiais.

Para melhorar tais propriedades da madeira, existem inúmeros preservativos no mercado. Porém, os únicos que tiveram sua eficiência realmente comprovada foram o creosoto, CCA (sais de cromo-cobre-arsênio) e PCP (pentaclorofenol). A consciência ambientalista vem levantando os problemas decorrentes do uso destes 
produtos sob o ponto de vista toxicológico, com o USA Environmental Protection Agency, chegando a proibir o uso de CCA e creosoto. Contudo, como as alternativas surgidas para substitui-los foram em vão, ou seja, preservativos de baixa toxicidade foram encontrados mas, ou a performance era bem inferior, ou o seu custo era muito elevado. Assim, o creosoto e o CCA tiveram seu banimento revogado (Pizzi 1993).

Os compostos de boro são largamente utilizados como preservativos de madeira contra deterioração biológica e como retardante de chama por apresentarem baixa toxicidade aos mamíferos, serem fáceis de aplicar, além de seu baixo custo. $A$ facilidade com que é lixiviada da madeira tratada, no entanto, não os recomenda para uso externo ou em contato com o solo.

As pentoses, que podem ser obtidas do aproveitamento de resíduos industriais da produção de etanol, óleos de algodão, de milho, de arroz e da própria indústria madeireira, dão, por digestão ácida, o furfural, e este, por hidrogenação, o álcool furfurílico (FFA). A impregnação de madeira com monômeros de FFA e a promoção da polimerização in situ pela ação catalítica de ácidos tem provado incrementar muitas de suas propriedades como a estabilidade dimensional, a resistência a ácidos e álcalis, a resistência biológica e à flamabilidade. Ácidos fortes podem promover a cura completa das resinas de álcool furfurílico mas, por outro lado, podem causar a degradação dos componentes das paredes celulares, o que resulta em perda de resistência mecânica da madeira (Dunlop; Peters 1953) ( Stamm 1977).

Neste trabalho tem-se como objetivos a obtenção de um compósito de madeira e polímero de álcool furfurílico, e o estudo dos efeitos dos diversos tratamentos do compósito com compostos de boro, usando o álcool furfurílico como agente de fixação, sobre as propriedades de estabilidade dimensional, resistência 
biológica e resistência à flamabilidade, que tanto um como outro apresentam isoladamente. 


\section{Capítulo I}

\section{Revisão Bibliográfica}

\subsection{Composição Química e Análise da Madeira}

A madeira é um compósito natural heterogêneo e anisotrópico, que pode ser entendido como uma associação de elementos químicos, que formam os elementos estruturais, arranjados em um sistema altamente organizado, que ergue as paredes celulares que a compõem. As células da madeira são compostas por substâncias de alto peso molecular, a celulose, hemicelulose (poliose) e lignina, e por substâncias de baixo peso molecular, os extrativos e a matéria inorgânica, conforme o esquema geral da figura 1 [(Fengel; Weneger 1989) (Saka 1993)]. A celulose é o esqueleto estrutural na forma de microfibrilas, a hemicelulose é a substância matriz presente entre as microfibrilas de celulose. A lignina é a substância que confere rigidez à parede celular, ligando as células entre si. Existe ainda uma grande e variada quantidade de água e extrativos, considerados como aditivos.

As substâncias macromoleculares estão presentes tanto em angiospermas como em gimnospermas. As proporções de polioses e lignina são diferentes em angiospermas (madeiras duras) e gimnospermas (madeiras moles), enquanto que a celulose é um componente praticamente uniforme em todas as espécies. As 
substâncias de baixo peso molecular estão relacionadas com a espécie, e variam em qualidade e quantidade (Fengel; Weneger 1989).

Esta classificação, angiospermas e gimnospermas, no entanto, não é muito usual entre os pesquisadores da área de madeira que adotam a seguinte nomenclatura: as madeiras duras são referidas como dicotiledôneas e também como folhosas, e as madeiras moles como coniferas. As coniferas possuem estruturas mais simples que as dicotiledôneas. Os traqueídeos nas coníferas e as fibras nas dicotiledôneas constituem a maior parte da parede celular e a elas pode ser creditada a maioria das propriedades físicas e químicas da madeira (Fengel; Weneger 1989). Em nosso estudo vamos abranger somente as coníferas por serem elas de rápido crescimento e baixo custo em relação à maioria das dicotiledôneas, e serem passiveis de impregnação com reagentes químicos para melhorar algumas propriedades e conservar outras [(Fengel; Weneger 1989) (Saka 1993)].

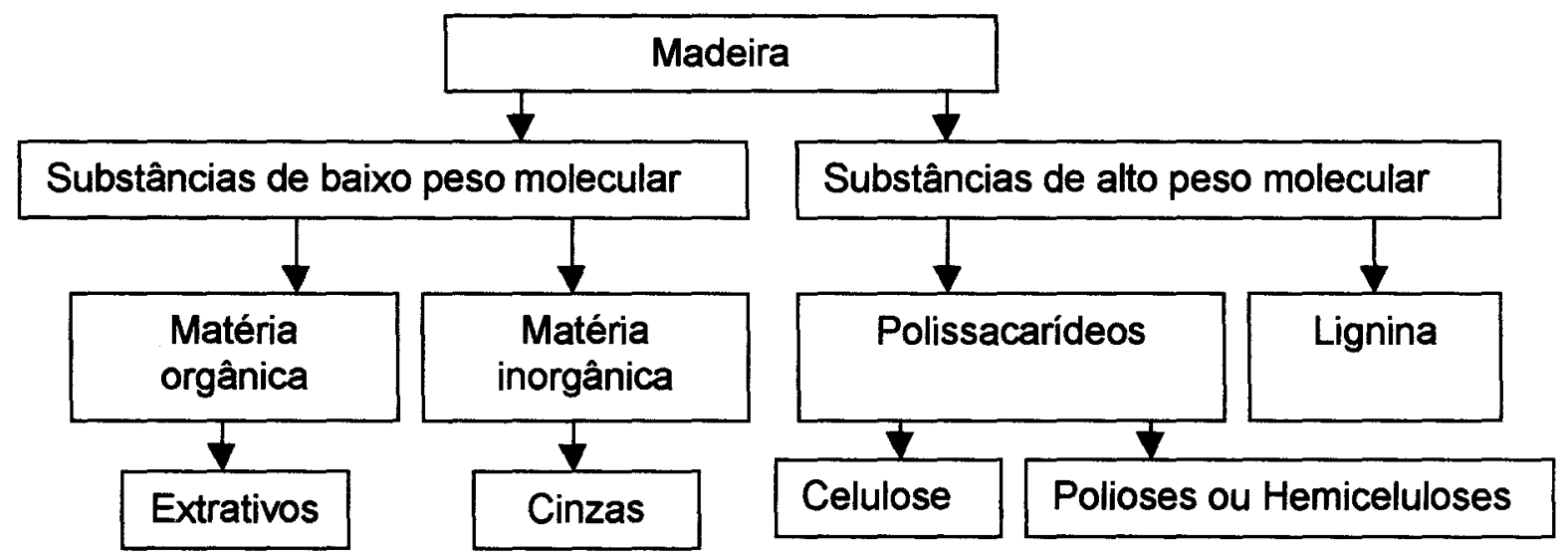

Figura 1- Esquema geral dos componentes químicos na madeira (Fengel; Weneger 1989).

A madeira é um meio capilar poroso. Os elementos que conduzem os fluidos são os traqueídeos longitudinais e os raios. No caso das coníferas $95 \%$ do volume da 
madeira é ocupada por traqueídeos longitudinais interconectados principalmente aos traqueideos radiais pelas pontuações aureoladas. $O$ restante do volume é ocupado pelas células radiais (Banks 1970). A tabela 1 apresenta os principais tipos de células das coníferas (Saka 1993).

Tabela 1 Células das Coníferas.

\begin{tabular}{|ll|}
\hline Eongitudinal & Transwersal \\
\hline Traqueídeo & Traqueídeo radial \\
\hline Traqueídeo fibrilar & \\
\hline Célula parenquimática axial & Célula parenquimática radial \\
\hline Célula epitelial & Célula epitelial radial \\
\hline
\end{tabular}

Os fluidos são capazes de se mover de traqueídeo para traqueídeo, e, em menor proporção, dos traqueídeos às células radiais utilizando as pontuações aureoladas (Smith; Banks apud Rowell; Banks 1985').

Os traqueideos longitudinais podem ser de dois tipos, conforme a estação do ano em que foram formadas. Os traqueídeos de verão possuem paredes celulares mais espessas, o lúmem (estruturas vazias, funcionando como reservatório de reagentes no processo de densificação) e o diâmetro das células são menores se comparados aos traqueídeos de primavera, além de apresentarem maior resistência ao fluxo de fluidos. Estes conjuntos de traqueídeos dispostos de forma circular ao longo do tronco podem ser vistos a olho nu, e determinam os anéis de crescimento ou anéis

"SMITH, D. N. R.; BANKS, W. B. apud ROWELL, R. M.;BANKS, W.B. Water Repellency and Dimensional Stability of Wood. General Technical Report FPL-50, USDA, Forest Service, Forest Products Laboratory, Madison, WI, 1985, 24p. 
anuais. O diâmetro dos traqueideos pode variar entre 15 e $80 \mu \mathrm{m}$ de acordo com a espécie, e o comprimento de 1200 a $7500 \mu \mathrm{m}$, resultando numa razão comprimento/diâmetro de $\sim 100$.

A estocagem e o transporte de carbohidratos são feitos pelas células parenquimáticas, principalmente as radiais. Existem ainda as células parenquimáticas longitudinais, as células epiteliais, cuja função é secretar, e circundam os canais resiniferos, e os parênquimas radiais. Os canais resiníferos são cavidades verticais e radiais presentes na maioria das coniferas (Fengel; Weneger 1989).

Segundo Bailey; Kerr apud Käärik (1978) e Wardrop; Harada "apud Saka (1993), as paredes celulares (que funcionam como reservatório químico de reagentes) são formadas por camadas concêntricas: a primária $(P)$ e a secundária $(S)$, sendo que a secundária apresenta três subcamadas - $S_{1}, S_{2}$ e $S_{3}$. A $S_{1}$ é a camada secundária externa. S2 é a central e S3 é a camada interna. Porém, muitos autores referem-se à camada S3 como a camada terciária (Fengel; Weneger 1989), ou ainda, a denominam de camada rugosa (W) (Sjöström 1981).

A camada primária é a parede cambial ou parede original formada pelo meristema. É formada durante o crescimento superficial da parede celular.

A camada secundária é formada durante o espessamento da parede celular. Em geral, a camada $S_{2}$ aumenta com o aumento da espessura da parede. E a camada rugosa $(\mathrm{W})$ constitui a superfície do lúmem. As asperezas desenvolvem-se quando a lignificação está se completando, sendo um material muito parecido com a lignina, mas

\footnotetext{
"BAILEY, I. W.; KERR, T. apud KÄÄRIK, A. Decomposition of Wood. In: KIRK, T. K.; HIGUCHI, T.; CHANG, $H$. $-m$. Lignin Biodegradation: Microbiology, Chemistry, and potentials Applications. Vol. I, CRC Press, Boca Raton, Florida, 1978, p. 129-174.

"WARDROP, A. B.; HARADA, H. apud SAKA, S. Structure and Chemical Composition of Wood as a Natural Composite Material. In: Recent Research on Wood and Wood-Based
} 
que contém ainda carbohidratos e substâncias pécticas (Fengel; Weneger 1989).

A figura 2 ilustra a orientação das microfibrilas na parede celular. Na camada $P$, as microfibrilas da celulose estão agregadas folgadamente e orientadas axialmente ao eixo da célula, no caso da superfície externa $(\mathrm{Po})$, e transversalmente na interna $\left(P_{1}\right)$. A camada $S_{1}$ tem orientação microfibrilar do tipo cruzado, alternando hélices $S$ e Z. S2 apresenta hélices $Z$ com alto grau de paralelismo. A camada $S_{3}$ é fina e é composta por hélices S. Existem lamelas de transição entre as superfícies internas de uma camada com as externas de outra. A mudança no ângulo microfibrilar é mais abrupta em $S_{23}$ que em $S_{12}$.

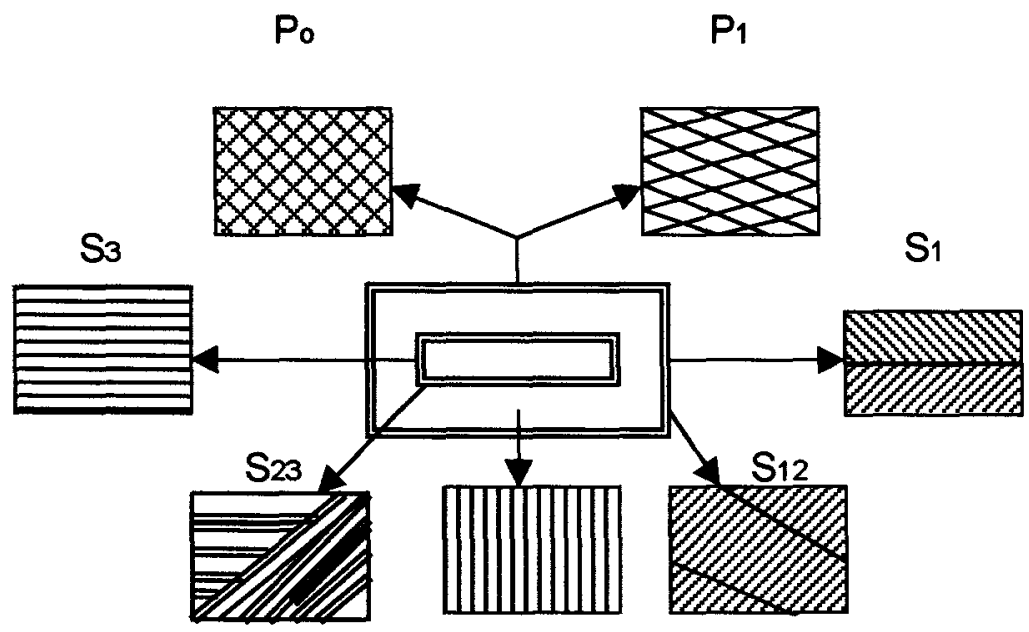

S2

Figura 2- Diagrama esquemático da orientação microfibrilar nas paredes celulares. Po e P1 são as superficies externa e interna da camada primária. S12 e S23 são camadas intermediárias entre as camadas $S 1$ e $S 2$ e entre S2 e S3, respectivamente (Saka 1993).

Entre as camadas da parede celular existe uma camada chamada lamela média (ML) ou camada intermediária (I), localizada entre as paredes $P$ de células adjacentes. A lamela média é uma fina camada entre células com a função de uni-las.

Materials. Current Japanese Materials Research, vol 11, Elsevier, London, New York, 1993, p. 
Ela quase não apresenta fibras, sendo formada por substâncias pécticas, podendo, eventualmente, tornar-se altamente lignificada. Devido à dificuldade de distinção entre ML e as duas paredes $P$ de células diferentes, o termo lamela média composta (CML) geralmente é usado para designar esta combinação (Saka 1993).

As concentrações de lignina, celulose e hemiceluloses variam de espécie para espécie e de camada para camada (Fengel; Weneger 1989).

$\mathrm{Na}$ figura 3 observa-se as variações nas concentrações de lignina, celulose e hemiceluloses nas diferentes camadas da parede celular do pinho Scots (Pinus silvestris).

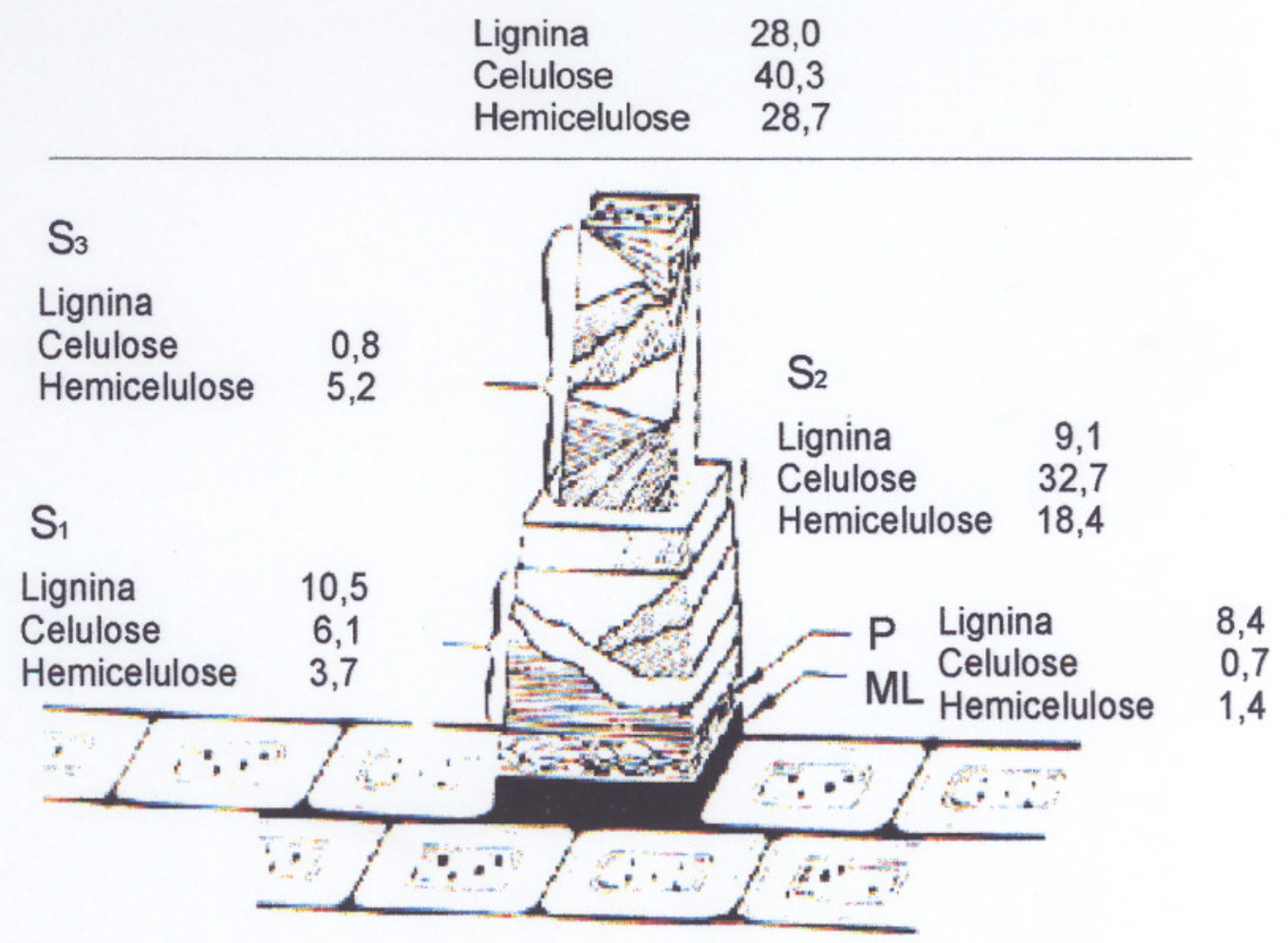

Figura 3- Distribuição de lignina, celulose e hemicelulose através da parede celular do pinho Scots (Rowell 1982). 
Estas variações nas concentrações de lignina, celulose e hemiceluloses exercem grande influência nas propriedades de cada espécie e até mesmo de cada camada da parede celular. Camadas com alta concentração de lignina são degradadas pelos fungos da podridão branca, e camadas com alto teor de celulose e hemiceluloses são facilmente degradados pelos fungos da podridão parda.

- A celulose pode ser caracterizada como um polímero linear de alto peso molecular constituído de unidades de anidroglucopiranoses. As unidades são ligadas por ligações $\beta-(1-4)$ glicosídicas. A cadeia é alongada e as unidades de glucose são arranjadas em um plano. As unidades de repetição da celulose são chamadas de celobiose, com comprimento de 1,03 nm. Devido à sua estrutura supramolecular, assim como suas propriedades químicas e físicas, é considerada o principal componente estrutural das paredes celulares dos vegetais. É organizada em fibrilas elementares (diâmetro de 1,2 a 4,8 nm) - associação de moléculas de celulose, contendo regiões ordenadas e não ordenadas - que se associam em feixes maiores com diâmetro de 10 a $25 \mathrm{~nm}$ chamadas microfibrilas. As regiões com cadeias de celulose orientadas são chamadas de cristalitos. A celulose representa $50 \%$ em média da madeira seca. Deste total, aproximadamente $65 \%$ é formada por celulose cristalina (Fengel; Weneger 1989).

- Hemiceluloses ou polioses - encontram-se em associação direta com a celulose na parede celular e funcionam como agentes de acoplamento entre a celulose e a lignina. Diferem da celulose na composição das unidades de açúcar, por possuírem cadeias moleculares muito mais curtas e cadeias laterais. Os principais grupos de açúcar anidro são: as hexoses - glucose, manose e galactose, as pentoses - xilose e arabinose, os ácidos hexurônicos e as deoxi-hexoses. A conversão de pentoses e 
hexoses em furfural e hidroximetilfurfural, respectivamente, está apresentada na figura 25. As cadeias principais de poliose podem consistir de unidades iguais (p.e. xilanas), ou de duas ou mais unidades diferentes (p. e. glucomanas). As pectinas são constituídas ou de galacturonanas, ou de galactanas ou de arabinanas. As angiospermas possuem maior quantidade de polioses (composta principalmente de unidades de xilose e grupos acetil) que as gimnospermas (composta principalmente de manose e galactose) (Fengel; Weneger 1989). A pentose mais importante é a xilose que pode ser produzida de angiospermas pela hidrólise com ácido fraco. Pentoses e hexoses resultam ainda (por hidrogenólise) em glicerol, etileno glicol e outros glicóis (Sjöström 1981). A figura 26 mostra alguns produtos de reação das pentoses e hexoses.

- Lignina - o seu conteúdo na madeira pode variar de 20 - 40\% (Fengel; Weneger 1989), e de $17-33 \%$ (Higuchi 1978). As moléculas de lignina são constituídas de um sistema aromático composto de unidades de fenilpropanos. Os precursores e construtores de todas as ligninas são: álcool p-cumaril, álcool coniferil e álcool sinapil. Gimnospermas possuem maior quantidade de lignina que angiospermas e são diferentemente estruturadas. Do ponto de vista morfológico, a lignina é uma substância amorfa localizada na lamela média e na parede secundária. Durante o desenvolvimento das células é incorporada como o último componente das paredes celulares, interpenetrando as fibrilas e reforçando as paredes celulares (Fengel; Weneger 1989).

- Substâncias poliméricas em menor quantidade - substâncias pécticas, amido, proteínas, que compõem quase $1 \%$ das células parenquimáticas, são encontradas 
principalmente nas regiões não processáveis da madeira como o câmbio e a casca (Fengel; Weneger 1989).

Substâncias de baixo peso molecular:

- Os extrativos são substâncias de baixo peso molecular, que podem ser extraídos por solventes polares e apolares, e têm grande influência nas propriedades e processabilidade da madeira. Alguns extrativos são tóxicos a fungos e bactérias, ou a cupins. Outros são odoríferos, bem como existem os que conferem cor. Também ocorrem as misturas de diferentes compostos que inibem a cristalização: terpenos, lignans, flavonóides, estilbenos, e outros aromáticos. Além destas substâncias, outras podem estar presentes nos extrativos: graxas, gorduras, esteróides, hidrocarbonetos (Fengel; Weneger 1989).

- A matéria inorgânica é constituida pelos sais minerais. É analisada como cinzas pela incineração da matéria orgânica a altas temperaturas. Os sais minerais estão presentes em percentuais de 0,2 a 0,5\% em madeira de zonas temperadas. Em madeiras de zonas tropicais os percentuais são bem maiores. Os principais componentes inorgânicos da madeira são: potássio, magnésio e cálcio, presentes nas madeiras de zonas temperadas. E potássio, magnésio, cálcio e sílica, presentes nas madeiras de zona tropical (Fengel; Weneger 1989). Usualmente a quantidade de sais minerais é maior no alburno que no cerne. As exceções são os casos da espécie Pinus em que os sais de magnésio e manganês tendem a concentrarem-se no cerne. A concentração de cálcio é maior nos anéis de crescimento dos primeiros anos de formação. Em madeiras descoloradas observou-se acumulações de carbonato de cálcio, principalmente (Hillis 1977). 


\subsection{Variação Dimensional da Madeira}

\subsubsection{Porque ocorre a Variação Dimensional da Madeira}

A parede celular da madeira é composta principalmente de polímeros com grupos hidroxilas ou outros grupos contendo oxigênio, que atraem umidade através das ligações de hidrogênio. A madeira sofre um aumento em volume quase sempre proporcional à quantidade de água adicionada (Stamm 1964). O inchamento vai aumentando até que a parede celular fique saturada de água. Este ponto é chamado de ponto de saturação da fibra, e varia de 20 a 50\% de ganho de massa (Feist; Tarkow* apud Rowell; Banks 1985). A água além deste ponto é água livre preenchendo o lúmem da célula e não contribui para aumentar o inchamento. Este processo é reversível. A madeira retrai assim que perde umidade a níveis abaixo do ponto de saturação da fibra.

Para cada umidade relativa $(\mathrm{RH})$ e temperatura ambiente, há um correspondente conteúdo de umidade de equilíbrio (EMC). O EMC correspondente a $100 \%$ de umidade relativa varia de 20 a 50\% e para a maioria das espécies é de 28 a $30 \%$. Neste conteúdo de umidade (no ponto de saturação da fibra) considera-se que a célula segura o máximo de água adsorvida.

A celulose e as hemiceluloses sendo mais higroscópicas que a lignina, são as principais responsáveis pela aquisição de umidade (Browning*apud Rowell; Banks

\footnotetext{
*FEIST, W. C.; TARKOW, H. apud ROWELL, R. M.;BANKS, W.B. Water Repellency and Dimensional Stability of Wood. General Technical Report FPL-50, USDA, Forest Service, Forest Products Laboratory, Madison, WI, 1985, 24p.

"BROWNING, B. L. apud ROWELL, R. M.;BANKS, W.B. Water Repellency and Dimensional Stability of Wood. General Technical Report FPL-50, USDA, Forest Service, Forest Products Laboratory, Madison, WI, 1985, 24p.
} 
1985). As hemiceluloses (não cristalinas por natureza), a porção não cristalina da celulose, as superfícies dos cristalitos da celulose, e uma pequena percentagem da lignina são as responsáveis pela aquisição de água pela madeira.

A madeira, tratando-se de um compósito anisotrópico, incha e contrai nas três direções: longitudinal (direção vertical), tangencial (paralela aos anéis anuais de crescimento) e radial (perpendicular aos anéis anuais de crescimento). Na figura 4 estão representadas estas direções. As variações na direção longitudinal são muito pequenas. Em geral, a maior variação ocorre na direção tangencial (de 2 a 15\% dependendo, entre outras razões, da densidade da madeira), e as variações na direção radial variam de 40 a $70 \%$ da variação tangencial (FPL*apud Rowell; Banks 1985).

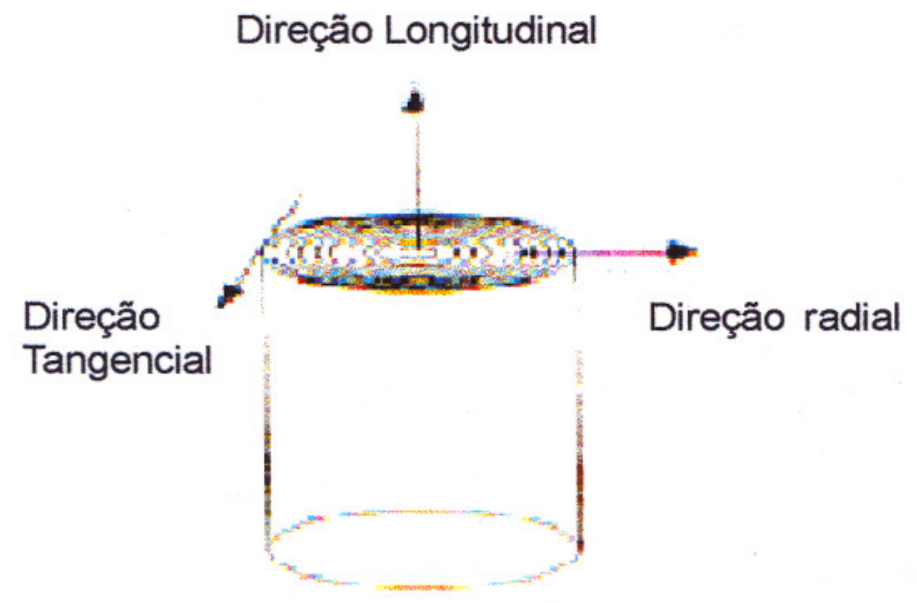

Figura 4- Direções longitudinal, radial e tangencial em relação aos anéis de crescimento.

A extensão do inchamento que ocorre na madeira é dependente da densidade para a maioria das espécies (Stamm 1964), com exceção do eucalipto e de madeiras

\footnotetext{
FOREST PRODUCTS LABORATORY Wood Handbook. Wood as a Engineering Material. Agric. Handbook No. 72, USDA, Forest Service, Washington, DC, 1974. apud ROWELL, R. M.;BANKS, W.B. Water Repellency and Dimensional Stability of Wood. General Technical Report FPL-50, USDA, Forest Service, Forest Products Laboratory, Madison, WI, 1985, 24p.
} 
nativas de florestas tropicais. O inchamento volumétrico percentual, $V$, é uma função da densidade seca $d\left(\mathrm{~g} / \mathrm{cm}^{3}\right)$, e o ponto de saturação da fibra $\mathrm{Kf}_{\mathrm{f}}\left(\mathrm{cm}^{3} / \mathrm{g} \%\right)$.

$$
V=K_{f} \cdot d
$$

Esta equação determina o inchamento volumétrico aproximado da madeira passando de um estado de madeira seca em estufa para o de ponto de saturação da fibra, e a retração volumétrica aproximada passando do ponto de saturação da fibra ao estado de madeira seca em estufa. Desvios desta relação são observados em espécies com alto teor de extrativos (Skaar "apud Rowell; Banks 1985).

Para a madeira inchar, água ou algum outro agente que cause o inchamento deve penetrar a parede celular. Esta penetração pode resultar de fluxo de massa ou da difusão de vapor d'água para o lúmem das células e daí para as paredes celulares, ou da difusão de águas aprisionadas dentro da parede celular (Stamm 1959*; 1960* apud Rowell; Banks 1985 ).

$O$ inchamento da madeira em contato com umidade exerce forças muito grandes, da ordem de 1630 atmosferas (Stamm 1964), devido à tensão superficial. Estas forças podem ser empregadas, por exemplo, para quebrar grandes rochas (Rowell; Banks 1985).

Alguns dos tratamentos para reduzir as interações madeira/água são os

\footnotetext{
" SKAAR, C. Water in Wood. Syracuse University Press, New York, 1972. apud ROWELL, R. M.;BANKS, W.B. Water Repellency and Dimensional Stability of Wood. General Technical Report FPL-50, USDA, Forest Service, Forest Products Laboratory, Madison, WI, 1985, 24p.

* STAMM, A. J. Bound Water Diffusion in the Fiber Direction. Forest Products Journal, vol. 9, p. 27-32, 1959. apud ROWELL, R. M.; BANKS, W. B. Water Repellency and Dimensional Stability of Wood. USDA, General Technical Report FPL-50, Forest Service, Forest Products Laboratory, Madison, WI, 1985. 24p.
}

"STAMM, A. J. Bound Water Diffusion in Across-the-Fiber Directions. Forest Products Journal, vol. 10, p. 524-528, 1960. apud ROWELL, R. M.; BANKS, W. B. Water Repellency and Dimensional Stability of Wood. USDA, General Technical Report FPL-50, Forest Service, Forest Products Laboratory, Madison, WI, 1985. 24p. 
conhecidos como: tratamento para conferir a repelência à água e de estabilização dimensional.

\subsubsection{Tratamento para conferir Repelência à Água}

Este tratamento reduz a taxa de absorção da umidade, mas ao final de um certo tempo a extensão de inchamento é quase a mesma que a da madeira sem tratamento (figura 5). O EMC permanece no mesmo nível. Este tipo de tratamento não aumenta a estabilidade dimensional.

Alguns exemplos deste tipo de tratamento consistem em mergulhar a madeira em cera ou silicone (Feist; Mraz*; Gray; Wheeler*; apud Rowell; Banks 1985).

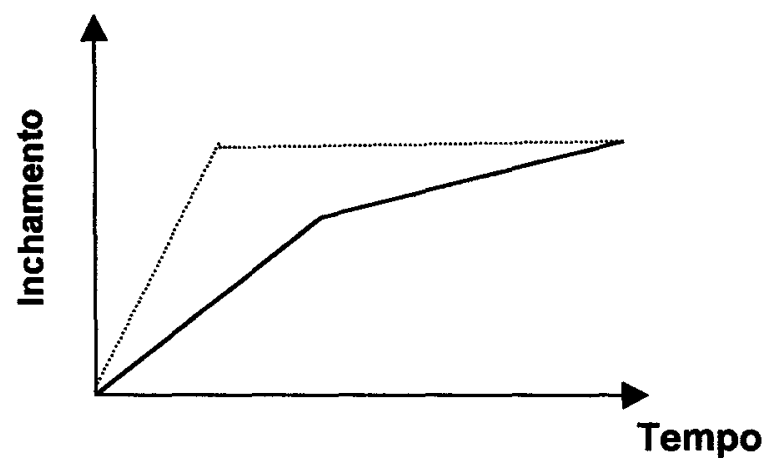

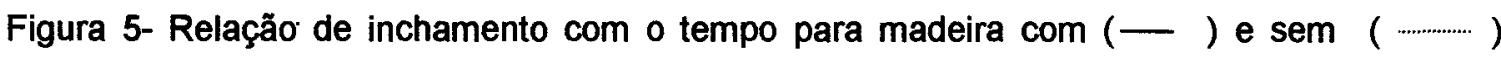
tratamento de repelência à água. Para a madeira tratada a taxa de absorção da umidade é reduzida, mas ao final de um certo tempo, a extensão do inchamento é praticamente a mesma da madeira sem tratamento.

"FEIST, W. C.; MRAZ, E. A. Wood Finishing: Water Repellents and Water Repellents Preservatives. Res. Note FPL-0124, USDA, Forest Service, Madison, WI, 1978. apud ROWELL, R. M.; BANKS, W. B. Water Repellency and Dimensional Stability of Wood. USDA, General Technical Report FPL-50, Forest Service, Forest Products Laboratory, Madison, WI, 1985. 24p.

GRAY, V. R.; WHEELER, N. E. Timber Water Proofing Agents. Timber Research and Development Association. Research Report C/RR/6, High Wycombe, England, 1959. apud ROWELL, R. M.; BANKS, W. B. Water Repellency and Dimensional Stability of Wood. USDA, General Technical Report FPL-50, Forest Service, Forest Products Laboratory, Madison, WI, 1985. 24p. 


\subsubsection{Tratamento de Estabilização Dimensional}

O tratamento de estabilização dimensional é definido como o tratamento para prevenir ou reduzir o inchamento e a retração da madeira resultante da quantidade de umidade absorvida. A estabilidade dimensional depende da quantidade e não da taxa com a qual a madeira absorve umidade. A figura 6 ilustra o efeito de um tratamento de estabilização dimensional.

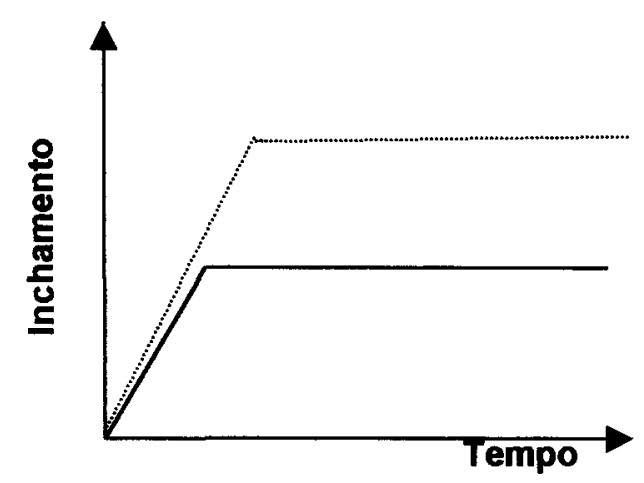

Figura 6- Relação de inchamento com o tempo para madeira com (— ) e sem (-........) tratamento para estabilização dimensional. A taxa de absorção de umidade é praticamente a mesma da madeira sem tratamento, mas a extensão do inchamento é bem reduzida.

A figura 7 mostra um gráfico típico relacionando inchamento com o tempo para madeira com e sem tratamento. A curva tracejada mostra como uma espécie sem tratamento absorve umidade rapidamente e incha até a quantidade máxima. A curva cheia mostra uma curva hipotética para uma espécie de madeira com tratamento de estabilização dimensional e de repelência à água. $O$ decréscimo na taxa de absorção de água indica aumento da repelência à água, enquanto que a reduzida extensão de inchamento indica maior estabilidade. 


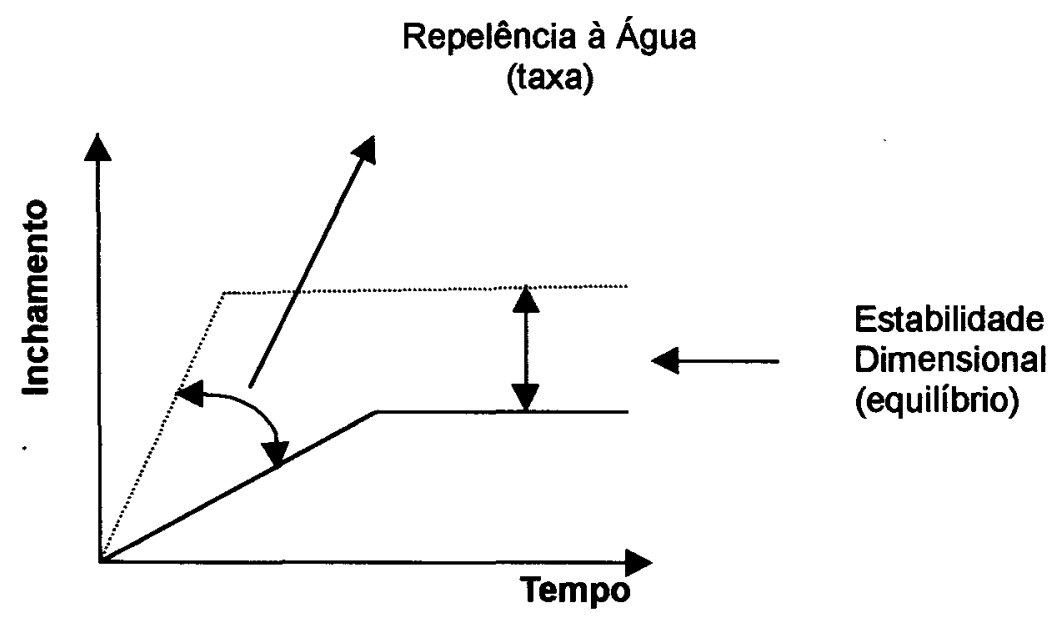

Figura 7- Relação de inchamento com o tempo para madeira com (_ ) e sem (....... ) tratamento de repelência à água e de estabilização dimensional. Este tratamento reduz tanto a taxa de absorção da umidade como a extensão de inchamento.

\subsubsection{Processos de Difusão de Umidade}

Quando um líquido penetra na madeira existem forças atrativas entre o líquido e o sólido em contato, como indicados nas figuras $8 \mathrm{~A}$ e 8B. Neste caso, a diferença de pressão entre as duas faces das superficies expostas ao ar pode ser expressa pela equação.

$$
P-P o=\gamma L V \cos \theta\left(\frac{1}{r_{1}}+\frac{1}{r_{2}}\right)
$$

onde

r1 e r2 são os principais raios de curvatura da interface líquido vapor e $\gamma$ Lv é a tensão interfacial líquido-vapor.

Uma outra representação para a tensão interfacial é considerar as forças associadas, como mostra a figura $8 \mathrm{C}$.

Quando a adesão do líquido ao sólido é igual ou maior que a coesão do 
líquido, uma gota de líquido implantada se espalha espontaneamente. Isto equivale a dizer que o ângulo entre o sólido e o líquido na interface sólido/líquido/vapor, chamado de ângulo de contato, é zero. Se a adesão sólido/líquido é menor que a coesão do líquido, a gota permanecerá na superfície fazendo um ângulo finito com a mesma. 0 ângulo de contato aumenta com o decréscimo da magnitude das forças de adesão em relação às forças de coesão do líquido. A equação de Young expressa estas relações:

$$
\gamma_{s v}=\gamma_{s L}+\gamma L v \cos \theta
$$

onde

$\gamma_{s v}=$ tensão interfacial sólido/vapor

$\gamma L v=$ tensão interfacial líquido/vapor

$\gamma_{\mathrm{SL}}=$ tensão interfacial líquido/sólido

$\theta=$ ângulo de contato

(A)

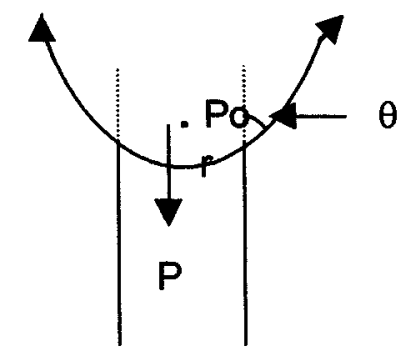

$\mathrm{P}<\mathrm{Po} \quad$ líquido
B)

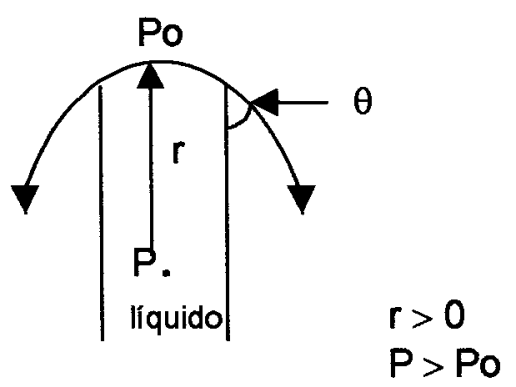

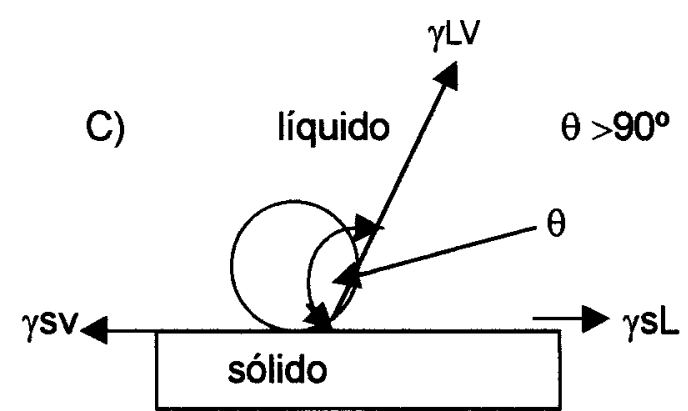

$\gamma s L$
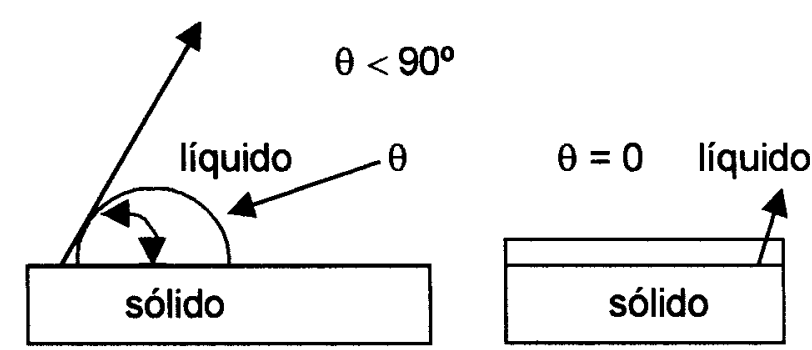

Figura 8- Interface sólido-líquido-vapor. A) A pressão interna do líquido $(P)$ é menor que a pressão atmosférica $(\mathrm{Po})$. B) $\mathrm{P}>\mathrm{Po}$. C) Ângulo de contato entre uma gota de líquido e uma superfície sólida. No primeiro caso, $\theta>90^{\circ}$. No segundo, $\theta<90^{\circ}$. No terceiro caso, $\theta=0^{\circ}$ 
(Souza; Souza 1998).

Em sistemas envolvendo água como a fase líquida, as superfícies formando ângulos de contato menores que $90^{\circ}$ são tidas como hidrofílicas e maiores que $90^{\circ}$ são ditas hidrofóbicas ou repelentes de água (Rowell; Banks 1985).

\subsubsection{Pressão Capilar}

A diferença de pressão $\mathrm{P}$ - Po, também chamada de pressão capilar da superfície curvada (Pc), é dada pela equação (4):

$$
P c=\frac{-2 \gamma L \cos \theta}{r}
$$

onde ré o raio do capilar.

O líquido entra espontaneamente através do tubo capilar para valores de $\theta$ menores que $90^{\circ}$. Quando $\theta$ é maior que $90^{\circ}$, deve ser aplicada uma pressão externa maior que Pc para forçar o líquido a entrar no capilar.

Os componentes estruturais das paredes celulares são ricos em $\mathrm{OH}$ alcoólicos primários e secundários, muitos deles capazes de formar ligações de hidrogênio com a água. A lignina é menos hidrofílica que a celulose e as hemiceluloses, mas, mesmo assim, tem uma considerável afinidade pela água (Christensen; Kelsey" apud Rowell; Banks 1985).

\footnotetext{
" CHRISTENSEN; KELSEY...The Sorption of Water Vapour by the Constituents of Wood. Holz als Roh und Werkstoff, vol. 17, p. 189-204, 1959. apud ROWELL, R. M.; BANKS, W. B. Water Repellency and Dimensional Stability of Wood. USDA, General Technical Report FPL-50, Forest Service, Forest Products Laboratory, Madison, WI, 1985. 24p.
} 


\subsubsection{A Estabilidade Dimensional da Madeira}

A estabilidade dimensional é atingida quando se consegue impedir os grupos $\mathrm{OH}$ da madeira, principalmente das hemiceluloses e da celulose, de formar ligações de hidrogênio com moléculas de água. Estas moléculas de água promovem o distanciamento entre as cadeias dos polímeros da madeira. Este distanciamento microscópico é o responsável, a nível macroscópico, pelo inchamento da madeira. Quando a madeira está sujeita a condições de menor umidade do ar, as moléculas de água ligadas por ligações de hidrogênio, abandonam suas posições e atingem novo equilíbrio dinâmico entre 0 ambiente circundante e os polímeros das paredes celulares. Isto causa a reaproximação das fibras da madeira (retração). A alternância entre a retração e o inchamento é mais comum em peças expostas às intempéries, podendo acarretar rupturas (Rowell; Banks 1985).

Uma variedade de termos é usada para descrever os níveis de estabilidade dimensional da madeira, entre eles podemos citar: a eficiência antiencolhimento, a percentagem de inchamento, a eficiência de estabilização dimensional, a eficiência anti-inchamento, e percentual de redução de inchamento. Independente do nome empregado, estes termos medem quanto (em percentagem) um tratamento influencia na propriedade da madeira de absorver umidade, em relação à madeira sem tratamento, livre de carga.

Ohmae, Norimoto e Minato (1997) fizeram uma relação entre as estruturas e propriedades dos tratamentos químicos sobre as madeiras, medindo a estabilidade dimensional em relação à madeira tratada antes do encharcamento com água, e também antes do tratamento químico. A Eficiência Anti-Inchamento (ASE) é definida como: 


$$
A S E=\frac{100(S u-S)}{S u}
$$

onde:

Su é o coeficiente volumétrico de inchamento da amostra sem tratamento químico, entre o estado seco em estufa e o estado encharcado com água;

S é o coeficiente da amostra com tratamento químico, nas mesmas condições da amostra sem tratamento acima.

E definiram ASE' como:

$$
A S E^{\prime}=\frac{100\left(S u-S^{\prime}\right)}{S u}
$$

onde:

S' é coeficiente volumétrico da amostra com tratamento químico calculado baseando-se nas dimensões das amostras secas, antes do tratamento.

Quando uma amostra apresenta valor de ASE' de $100 \%$ significa que as dimensões da amostra seca permanecem inalteradas não somente com o tratamento químico, mas também com o encharcamento com água após o tratamento. Um valor de ASE' de $0 \%$ significa que as dimensões da amostra tratada são iguais às das amostras sem tratamento no estado encharcado. Ou seja, o tratamento não tem efeito na estabilização dimensional. Exemplos são as deposições de sais inorgânicos, que não penetram nas paredes celulares, apenas formam depósitos no lúmem. Quando o valor de ASE' é negativo, sugere que o tratamento tem efeito oposto ao de conferir estabilidade dimensional. Uma das explicaçőes para este fenômeno é a redução do efeito de arqueamento da camada $S_{1}$ nas paredes celulares. Ou a contração do monômero durante a polimerização. Exemplo: tratamento com óxido de propileno (Norimoto; Gril 1993) (Ohmae; Norimoto 1997). 
A completa estabilização dimensional da madeira, isto é, valor de ASE de $100 \%$, é verificado no processo de petrificação. Com tratamentos químicos é difícil supor que isso vá ocorrer. Mas, para a maioria das aplicações, níveis bem menores que isso são suficientes (Rowell; Banks 1985).

A estabilidade dimensional relacionada com deformação induzida como a fluência ou depressão vibracional requer uma redução da viscosidade da matriz devido à absorção de umidade. Este efeito é denominado de efeito mecanossorptivo e pode ser medido pelo fator "eficiência anti-fluência" (ACE), definido por:

$$
A C E=\frac{\delta J u-\delta J}{\delta J u} X 100
$$

onde:

$\delta J$ é o aumento da flexibilidade (o quociente da deformação pela tensão) induzida pelo ciclo completo da umidade.

$\delta$ Ju é o mesmo valor acima, obtido da espécie sem tratamento.

A expressão usada para calcular $\delta \mathrm{J}$ é:

$$
\delta J=\frac{3 w t^{3}\left(f_{2}-f_{1}\right)}{F l^{3}}
$$

onde:

$w$ é a largura da amostra;

$t$ é a espessura da amostra (seca);

I é o vão;

F é a carga aplicada;

$f_{1}$ é a deflexão após a aplicação da carga; 
$f_{2}$ é a deflexão ao final do experimento.

$\delta J$ descreve o potencial para deformação induzida por tensão sob variação das condições de umidade. É o correspondente ao coeficiente volumétrico de inchamento S na deformação livre de carga.

O fenômeno da fluência pode ser entendido de uma maneira simples: quando moléculas de água são absorvidas, promovem a separação entre as cadeias de polímeros naturais da madeira, aumentando as dimensões no sentido perpendicular às fibras, diminuindo as forças de coesão entre elas (forças de Van der Walls). Isto resulta na facilidade das cadeias de deslizarem umas sobre as outras.

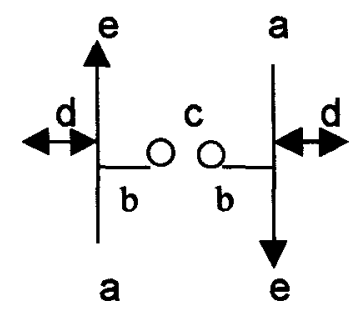

Figura 9- Esquema ilustrativo do fenômeno da fluência. $\mathrm{O}-$ grupo $\mathrm{OH}$ disponivel para ligação de hidrogênio. a - cadeia de polímero natural da madeira. b - parte da cadeia propensa à ligação de hidrogênio. c - ligação de hidrogênio entre uma cadeia e outra. d - direção da expansão do volume da matriz das cadeias. e -deslizamento da cadeia resultante da diminuição das forças de coesão entre uma e outra.

Quando o fator ACE é igual a $100 \%$ indica que a amostra não apresenta fluência. Valores de ACE negativos indicam que as amostras apresentam instabilidade mecanossorptivo (Norimoto; Gril 1993). 


\subsubsection{Tratamentos para melhorar a Estabilidade Dimensional da Madeira}

\subsection{7a) Seleção da Espécie}

A solução de tratamento pode penetrar virtualmente em todas as células (no caso de espécies permeáveis), ou pode penetrar somente alguns centímetros longitudinalmente e alguns milímetros radialmente, podendo ainda ficar restrita às zonas de células de crescimento tardio (no caso de espécies pouco permeáveis).

Existem espécies de madeira que possuem baixo coeficiente de expansão de umidade. Uma das mais conhecidas é a teca (Tectona grandis), muita empregada para a construção de barcos (Rowell; Banks 1985).

Além desta variação observada entre espécies, também ocorrem diferenças entre o cerne e o alburno (Redding* apud Rowell; Banks 1985). A determinação da estabilidade dimensional é feita comparando-se o coeficiente de inchamento volumétrico da madeira tratada em relação à não tratada. Estes valores precisam ser medidos em uma mesma região da madeira, pois variam dependendo da proporção de madeira de crescimento tardio para a de crescimento juvenil.

Outro fator muito importante constitui-se nas dimensões da amostra. Se muito pequena, erros nas medidas podem resultar em desvios padrão altos e os valores de eficiência anti-inchamento (ASE) se tornariam sem significado.

Além disso, a madeira incha e retrai de 40 a 70 vezes mais na direção tangencial que na radial, e de 30 a 100 vezes mais na direção radial e tangencial que

\footnotetext{
* REDDING, L. W. Resistance of Timbers to Impregnation with Creosote. Department of Environment, Forest Products research Bulletin No. 53, Her Majesty's Stationery office, 1971. apud ROWELL, R. M.; BANKS, W. B. Water Repellency and Dimensional Stability of Wood. USDA, General Technical Report FPL-50, Forest Service, Forest Products Laboratory, Madison, WI, 1985. 24p.
} 
na longitudinal (figura 4). Assim, determinar o corte aproveitando o máximo da direção longitudinal e mínima da direção tangencial minimiza os efeitos do inchamento e retração da madeira.

\subsection{7b) Redução de Higroscopicidade}

Reduzir a tendência da madeira de capturar água seria remover os grupos hidroxilas dos polímeros da parede celular para que estes não se liguem à água. A remoção destes grupos seria possivel através de redução, mas isso destruiria a madeira.

Os tratamentos térmicos são conduzidos com o objetivo de degradar os componentes mais higroscópicos da madeira, as hemiceluloses, produzindo polímeros insolúveis, aumentando a estabilidade dimensional e diminuindo a resistência mecânica. (Seborg et al. ; Stamm et al." apud Rowell; Banks 1985).

\subsection{7c) Tratamentos Físicos}

Os tratamentos físicos constituem-se de coberturas externas com cera, ou qualquer outro agente hidrófobo, geralmente seguidas de aplicação de pressão, que

\footnotetext{
SEBORG, R. M.; TARKOW, H.;STAMM, A. J. Effect of Heat upon the Dimensional Stabilization of Wood. Journal of the Forest Products Research Society, vol. 4(5), 3(3), p. 59-67, 1953. apud ROWELL, R. M.; BANKS, W. B. Water Repellency and Dimensional Stability of Wood. USDA, General Technical Report FPL-50, Forest Service, Forest Products Laboratory, Madison, Wl, 1985. 24p.

- STAMM, A. J. Thermal Degradation of Wood and Cellulose. Industrial and Engineering Chemistry, vol. 48(3), 413-17, 1956 apud ROWELL, R. M.; BANKS, W. B. Water Repellency
} 
recobre os poros da madeira, impedindo a penetração da umidade. É um processo simples, de ligação do tipo não químico. Os trabalhos mais conhecidos utilizaram parafina (Feist; Mraz; Gray; Wheeler apud Rowell; Banks 1985).

\subsection{7d) Tratamentos Químicos}

Os reagentes devem ser capazes de reagir com grupos hidroxilas da madeira sob condições neutras (ácidos fortes causam extensiva degradação da madeira), a temperaturas abaixo de $120^{\circ} \mathrm{C}$ (acima desta temperatura os componentes estruturais da madeira começam a degradar), e fracamente alcalinas. O sistema químico deve ser simples e capaz de inchar a estrutura da madeira para facilitar a penetração. As ligações devem ser estáveis, e a madeira tratada deve conservar as propriedades desejáveis da madeira sem tratamento e melhorar ou eliminar as indesejáveis (Rowell 1982).

A impregnação da madeira com soluções dimensionalmente estabilizadores depende do fluxo da solução através da estrutura celular. O uso de soluções impregnantes sofre influência ainda da redistribuição da solução durante a evaporação do solvente depois do tratamento (Banks; Carragher" apud Rowell; Banks 1985).

Estas soluções são aplicadas por diversos meios: imersão, impregnação a vácuo, impregnação a vácuo seguido de pressão, ou outros. A literatura é rica em

and Dimensional Stability of Wood. USDA, General Technical Report FPL-50, Forest Service, Forest Products Laboratory, Madison, WI, 1985. 24p.

BANKS, W. B.; CARRAGHER, J. G. The Cellular Distribution of Paraffin Wax in Water Repellent Treated Wood. Records of the Annual Convention, British Wood Preservation Association, Cambridge, London, July 2-5, 1984 apud ROWELL, R. M.; BANKS, W. B. Water Repellency and Dimensional Stability of Wood. USDA, General Technical Report FPL-50, Forest Service, Forest Products Laboratory, Madison, Wl, 1985. 24p. 
publicações de variados tratamentos tanto de repelência à água como de estabilização dimensional (Borging; Corbett*; Banks*; apud Rowell; Banks 1985).

Os tratamentos químicos se dividem em:
a) intercruzamento
b) densificação

Norimoto e Gril (1993) propuseram um modelo simplificado para explicar as modificações que ocorrem na madeira com os tratamentos químicos composto de três categorias a nivel celular e oito a nível molecular. Supondo, para maior simplicidade, que a parede celular tenha seção reta retangular, a série $\mathbf{A}$ representa as modificações a nível celular. (I) modificação somente da parede celular; (II) deposição na superfície do lúmem: (III) preenchimento do lúmem. A série B representa as modificações a nível molecular: Os círculos vazios representam dois grupos $\mathrm{OH}$ aptos a fazerem ligações de hidrogênio. Os círculos pequenos e cheios representam a substituição por moléculas de baixo peso molecular, e os círculos cheios grandes representam moléculas de alto peso molecular. As ligações covalentes são representadas por um traço. O traço não contínuo significa ligação fraca.

- BORGIN, K.; CORBETT, K. Stability and Weathering properties of Wood Treated with Various Oils, Waxes and Resins. Plastics, Paint and Rubber, vol. 14(3), p. 69-72; (4), p.69-72; (5), P. 61-66, 1970 apud ROWELL, R. M.; BANKS, W. B. Water Repellency and Dimensional Stability of Wood. USDA, General Technical Report FPL-50, Forest Service, Forest Products Laboratory, Madison, WI, 1985. 24p.

"BANKS, W. B. The Role of Water Repellents in the Protection of Timber. Records of the Annual Convention, British Wood Preservation Association, Cambridge, London, July 6-9, 1971 apud ROWELL, R. M.; BANKS, W. B. Water Repellency and Dimensional Stability of Wood. USDA, General Technical Report FPL-50, Forest Service, Forest Products Laboratory, Madison, WI, 1985. 24p. 
Com a introdução da espécie química de tratamento, esta poderá reagir com os componentes da parede celular (AI), ou reagir somente com os componentes da superfície do lúmem celular (All), ou ainda permanecer ou preencher completamente o lúmem da célula (AllI). O tipo Al é pouco aplicado nos casos de prevenção de biodeterioração, com exceção da acetilação. Mais comuns nestes casos são os do tipo All da qual faz parte o CCA. O tratamento do tipo Alll no qual os reagentes não interagem com os componentes da parede celular, não são recomendados sob o ponto de vista da poluição ambiental porque produtos tóxicos podem ser lixiviados para o meio ambiente. Este tipo de tratamento é representado na série B pelos números 7 e 8 .

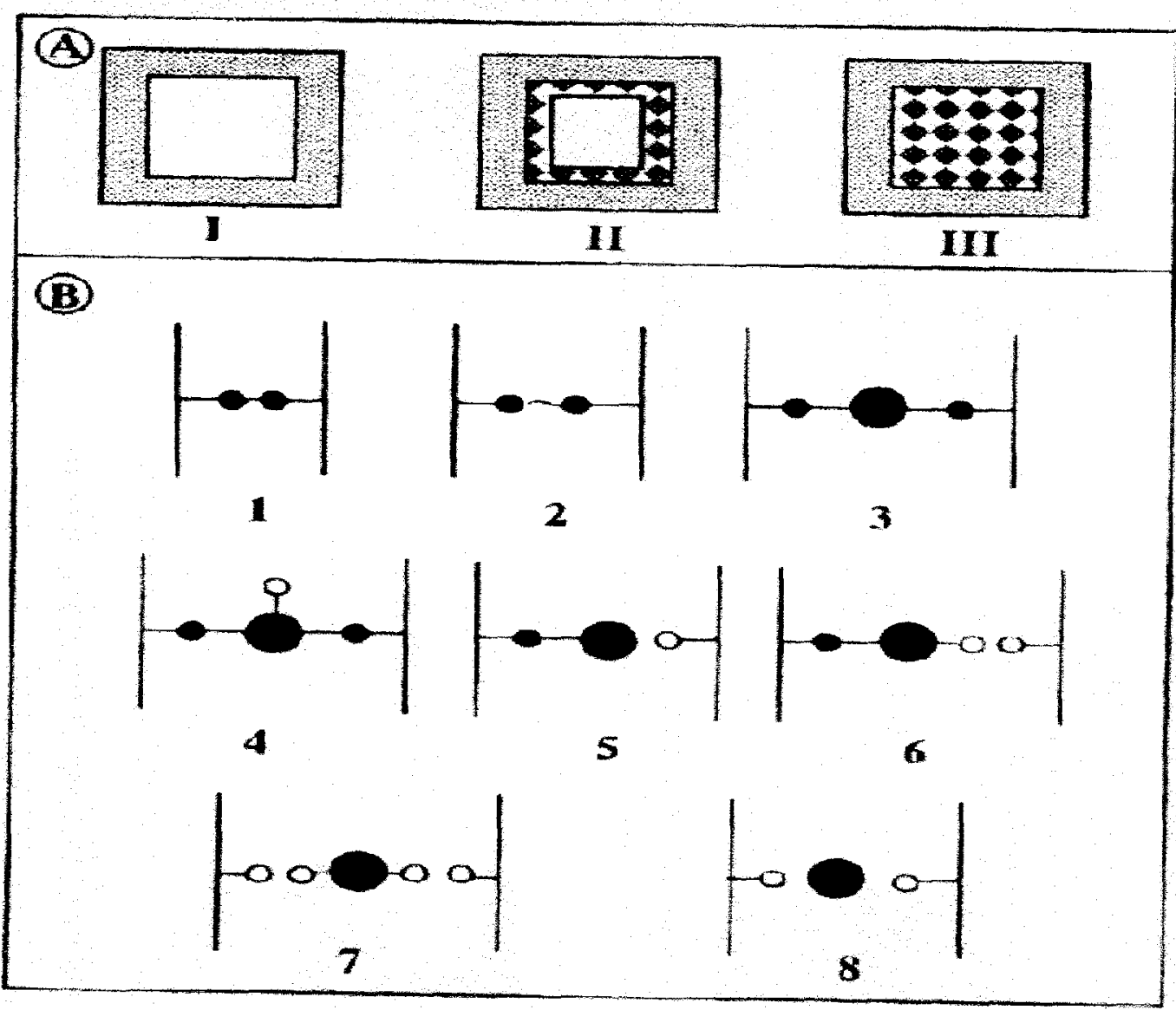

Figura 10- Modelo das modificações químicas da madeira, segundo Norimoto e Gril (1993). A série $\mathbf{A}$ representa as modificações a nível celular. A série $\mathbf{B}$ representa as modificações a nível molecular: Os círculos vazios representam dois grupos $\mathrm{OH}$ aptos a fazerem ligações de 
hidrogênio. Os círculos pequenos e cheios representam a substituição por moléculas de baixo peso molecular, e os círculos cheios grandes representam moléculas de alto peso molecular. As ligaçōes covalentes são representadas por um traço. $O$ traço não contínuo significa ligação fraca.

Na situação B1 é feito um típico tratamento para conferir maior estabilidade dimensional à madeira com vapores de formaldeído. Na situação B2 o tratamento é feito com formaldeído na fase líquida e a maior distância entre as cadeias indica que houve inchamento. Contudo, os efeitos prejudiciais do formaldeido ao corpo humano já foram objeto de muito estudo resultando na procura de reagentes alternativos.

Em diversas situações o tratamento químico pode promover o intercruzamento como nos casos de B1 a B4. Na situação B3 o reagente é hidrófobo e na B4 é hidrófilo, isto é, atrai moléculas de água. Reagentes típicos do tipo B3 são os aldeidos difuncionais tais como o glioxal e o glutaraldeído. Um reagente típico do tipo B4 é o DMDHEU (dimetilol-dihidroxi-etileno uréia).

Em B5 e B6 as ligações são estáveis somente de um lado. A acetilação pertence ao tipo B5 e confere à madeira alta resistência à variação volumétrica e ao ataque biológico, que é atribuído ao fato de diminuir o conteúdo de umidade da madeira $e$ à introdução de grupos inertes que previnem a degradação dos componentes da madeira pelo sistema enzimático. Em B7 e B8 os círculos grandes e cheios representam os agentes densificadores, que preenchem somente o lúmem da célula, não formando ligações fortes.

Segundo Yusuf (1996), tratamentos preservativos como o CCA (sais de cromo, cobre e arsênio) pertencem ao tipo II. Seus sais são permeáveis aos poros da superfície do lúmem e das paredes da célula. Quando se faz impregnação com polímeros de alto peso molecular estas se depositam somente no lúmem das células e 
não oferecem resistência ao ataque de fungos porque não se depositam nem modificam a parede celular. E também não proporcionam estabilidade dimensional.

\section{a) Reações de Intercruzamento Químico da Madeira:}

Quando as unidades estruturais da parede celular da madeira são ligadas entre si, o intercruzamento proporciona um impedimento estérico às moléculas de água. Estas reações de intercruzamento podem ocorrer entre grupos $\mathrm{OH}$ de celulose, hemicelulose ou lignina, da mesma cadeia ou de cadeias diferentes. E geralmente é catalisada por ácidos fortes (Rowell 1987).

\section{a.(1) Reação com Formaldeído}

A reação dos grupos $\mathrm{OH}$ das paredes celulares com formaldeído (formalização) se dá em duas etapas, sendo que na primeira ocorre a formação de um hemiacetal e, na segunda, de um acetal.

$$
\begin{aligned}
& \mathrm{WOOD}-\mathrm{OH}+\mathrm{H}-\stackrel{\mathrm{O}}{\mathrm{C}}-\mathrm{H} \longrightarrow \text { WOOD }-\mathrm{O}-\left.\right|_{\mathrm{H}} ^{\stackrel{\mathrm{OH}}{l}} \stackrel{\mathrm{HOD}-\mathrm{OH}}{\longrightarrow} \\
& \text { WOOD- } \mathrm{O}-\mathrm{CH}_{2}-\mathrm{O}-\text { WOOD }
\end{aligned}
$$

Figura 11- Proposta de ligação entre formaldeído e grupos $\mathrm{OH}$ da madeira, formando um hemiacetal na primeira etapa e na segunda, um acetal.

O tratamento com formaldeído torna a madeira quebradiça, devido às 
unidades de intercruzamento (cadeias curtas inflexiveis do tipo -O-C-O-). Se a cadeia interna fosse longa, teria mais flexibilidade, porém, isto reduziria a estabilidade dimensional, pois estaria permitindo a fluência (Rowell 1982). Em trabalho anterior, Rowell (1978) reportou bons resultados em eficiência anti-inchamento (ASE) com baixas percentagens de ganho de polímero (WPG), embora tenha verificado diminuição de resistência mecânica (@10\%).

Comparando resultados de estabilidade dimensional e resistência ao ataque de fungos e térmitas, Yusuf (1996) comprovou que a formalização na fase de vapor é muito mais eficaz do que na fase líquida, porém, do ponto de vista ambiental, a fase liquida é vantajosa por ser conduzida à temperatura ambiente e por não promover sérias perdas de resistência mecânica da madeira. Norimoto e Gril (1993) reportam altos valores de resistência à fluência nos casos de formalização na fase de vapor e o módulo de ruptura (MOR) à flexão longitudinal melhora no tratamento com $\mathrm{SO}_{2}$ como catalisador. Quando $\mathrm{HCl}$ é usado como catalisador, o MOR é reduzido.

\section{b) Tratamentos de Densificação da Madeira}

O tratamento de densificação promove a estabilidade dimensional ocupando os sítios acessíveis a ligações com a água. Penetrando nas paredes celulares, o volume da substância química empregada ocupa os sítios acessíveis que seriam ocupados pela água. Para que a substância ocupe todos os sítios acessíveis à água, as moléculas da substância devem ser de tamanho comparável ao da água e também devem causar o inchamento como ela (Rowell et al. 1976). 
Os tratamentos de densificação podem ser classificados em:
b.1 Não ligado - lixiviável
b.2 Não ligado - não lixiviável
b.3 Ligado - não lixiviável

\section{b.1 Não ligado - lixiviável}

\section{b.1.1) Deposição de Sais}

O tratamento com $\mathrm{BaPO}_{4}$ e $\mathrm{BaHPO}_{4}$ resulta em uma pequena melhora de ASE, mas em redução de $\mathrm{ACE}$. A resistência contra ataques de fungos e térmitas não é melhorada (Norimoto; Gril 1993). Outros sais comumente utilizados são os cloretos de manganês, de sódio, de bário, de magnésio e de lítio; o tiocianato de potássio e o iodeto de potássio, que causam um inchamento maior que a água se o pH for maior que oito (Stamm* apud Rowell; Banks 1985). Em todos estes tratamentos, a estabilidade dimensional é inicialmente alta, acima de $70 \%$. Entretanto, como são facilmente lixiviados com água, a eficiência cai abruptamente depois de pouco tempo (Rowell; Banks 1985).

\section{b.1.2) Polietileno Glicol}

O tratamento com polietileno glicol (PEG) desempenha bem no início, mas, devido a ser ele próprio um reagente hidrófilo, em apenas 24 horas de mergulho em

\footnotetext{
"STAMM, A. J. Effect of inorganic Salts upon the Swelling and the Shrinking of Wood. Journal of American Chemical Society, vol. 56, p. 1195-1204, 1934. apud ROWELL, R. M.; BANKS, W. B. Water Repellency and Dimensional Stability of Wood. USDA, General Technical Report FPL-50, Forest Service, Forest Products Laboratory, Madison, WI, 1985. 24p.
} 
água, sofre grande perda por lixiviação e sua eficiência diminui significativamente (Rowell 1982).

Em geral, a impregnação com PEG é feita por imersão da madeira verde em solução aquosa entre 30 e $50 \%$, onde o PEG é trocado pela água das paredes celulares, e depois deixada para secar à temperatura ambiente. É utilizado para tratamento de objetos que necessitam de secagem sem sofrer danos, por exemplo, impregnar troncos verdes de madeira evitando o rachamento durante a secagem (Stamm* apud Rowell; Banks 1985). Não se liga às paredes celulares da madeira, apenas preenchendo o lúmen destas (Rowell; Banks 1985; Rowell; Konkol 1987). Com WPG de $110 \%$, obteve-se $81 \%$ de ASE, porém, com eficiência anti-fluência (ACE) altamente negativa ( $\cong-200 \%$ ) (Norimoto; Gril 1993).

\section{b.2 Não ligado - não lixiviável}

O tratamento da madeira com estas soluçőes origina um compósito densificado onde os produtos químicos da solução de impregnação não ficam ligados aos componentes da parede celular, mas formam polímeros insolúveis que podem ou não ser lixiviados pela água.

- STAMM, A. J. Thermal Degradation of Wood and Cellulose. Industrial and Engineering Chemistry, vol. 48(3), 413-17, 1956. apud ROWELL, R. M.; BANKS, W. B. Water Repellency and Dimensional Stability of Wood. USDA, General Technical Report FPL-50, Forest Service, Forest Products Laboratory, Madison, W, 1985. 24p. 


\section{b.2.1) Uréia-Formaldeído}

A impregnação com esta resina também melhora as propriedades da madeira como a dureza, compressão, flexão estática e resistência à abrasão. Mas, apesar de diminuir o inchamento e a absorção máxima de água, não é muito resistente à água, devendo ser evitado em aplicações extemas (Galperin et al. 1995).

\section{b.2.2) Fenol-Formaldeido}

A impregnação com esta resina aumenta a densidade, melhora a dureza, a resistência à compressão perpendicular às fibras, 0 inchamento na direção tangencial e a máxima absorção de água. Porém, a resistência à abrasão é reduzida. A estabilidade dimensional é melhorada, bem como a eficiência anti-fluência (ACE) (Norimoto; Gril 1993). A flexão estática permanece inalterada. A resistência ao impacto à flexão é significativamente pior que na madeira sem tratamento (Galperin et al. 1995; Rowell; Konkol 1987; Rowell; Banks 1985). O tratamento confere maior resistência ao ataque de fungos e térmitas, e a ácidos (Rowell; Konkol 1987; Ryu et al. 1992). A impregnação é feita com solução aquosa da resina com baixo peso molecular $(\cong 300)$, em madeira verde, seguida de cura por aquecimento. Com 25 a $40 \%$ de WPG obtémse ASE de 60 a $70 \%$ (Stamm; Seborg* apud Rowell; Banks 1985). Quando a madeira tratada com esta resina é submetida à alta pressão durante o processo de cura obtém-

\footnotetext{
'STAMM, A. J.; SEBORG, R. M. Resin-treated Wood (Impreg). Rep. 1380.USDA, 1943. apud ROWELL, R. M.; BANKS, W. B. Water Repellency and Dimensional Stability of Wood. USDA, General Technical Report FPL-50, Forest Service, Forest Products Laboratory, Madison, WI, 1985. 24p.
} 
se um "compreg", com ASE de 95\% (Seborg; Stamm" apud Rowell; Banks 1985). "Compreg" é muito resistente ao apodrecimento, ao ataque de térmitas e aos furadores marinhos. A resistência elétrica e a ataques ácidos é comparada à madeira não tratada. Todas as propriedades de resistência mecânica são melhoradas à exceção da flexão ao impacto (Rowell; Konkol 1987) (Rowell; Banks 1985) (Kumar 1994).

\section{b.2.3) Estireno}

A impregnação com estireno é feita utilizando um solvente que promove o inchamento (sistema dioxano-água ou metanol-água) da madeira. Os monômeros penetram na parede celular e se polimerizam. É necessário utilizar um catalisador, o peróxido de benzoíla, que é misturado com o monômero no momento da impregnação (Gomes 1996) (Galperin et al. 1995) (Kumar 1994) (Hazer et al. 1993). A polimerização pela radiação leva a polímeros grafitizados, densificando as paredes celulares (Rowell; Banks 1985). As resistências mecânicas à tração, à flexão estática e à compressão apresentaram melhoras significativas com ganho de peso entre 70 e $140 \%$. Mas não apresentou significativo aumento na estabilidade dimensional (Gomes 1996).

\section{b.2.4) Metacrilato de Metila (MMA)}

Este tratamento é considerado tanto de estabilização dimensional como também de repelência à água. Os polímeros, preenchendo os poros, funcionam como

\footnotetext{
SEBORG, R. M.; STAMM, A J. Effect of Resin Treatment and Compression upon the Properties of Wood. Report 1383, USDA, 1945. apud ROWELL, R. M.; BANKS, W. B. Water Repellency and Dimensional Stability of Wood. USDA, General Technical Report FPL-50, Forest Service, Forest Products Laboratory, Madison, WI, 1985. 24p.
} 
um tampão, retardando quase ao mínimo a taxa com que a madeira absorve água (Rowell 1982). Os monômeros, apesar de introduzidos em pouca quantidade no lúmen devido à sua natureza hidrofóbica, contraem durante a polimerização. O compósito final é repelente à água, mas tanto o valor da ASE como o da ACE são próximos de zero. O tratamento promove grande aumento de densidade. E a qualidade superficial da madeira melhora sensivelmente, razão pela qual é muito empregado em fabricação de móveis, artigos esportivos e objetos de adorno (Norimoto; Gril 1993; Ohmae; Norimoto 1997).

\section{b.2.5) Cera}

A impregnação da madeira com cera de parafina misturada com preservativos é empregada com a finalidade de prevenir trincamentos e conferir a repelência à água.

O tratamento consiste em trocar a água da parede celular da madeira pela cera. O primeiro estágio é efetuado fervendo a madeira em solvente orgânico solúvel em água, com ponto de ebulição acima do da água, p. e. éter etilenoglicol monoetil (Cellosolve) com $\mathrm{PE}=135^{\circ} \mathrm{C}$. Logo, o solvente substituirá a água com pequena mudança de volume. Em seguida, a cera fundida substitui o solvente, sendo que a cera deve ter ponto de fusão mais elevado que o ponto de ebulição do solvente. A cera não substitui todas as moléculas de água devido ao tamanho de suas moléculas ser maior que o da água. Com este tratamento, a madeira fica repelente à água, porém dificulta colagens e acabamentos. A cera impede fisicamente o acesso da água aos sítios $\mathrm{OH}$ da madeira (Rowell; Banks 1985; Rowell; Konkol 1987). O tratamento também confere resistência à biodegradação (Norimoto; Gril 1993). 


\section{b.3 Ligado-não lixiviável}

Este tratamento densifica a parede celular com ligações químicas permanentes. Os reagentes devem ser capazes de reagir com grupos hidroxilas da madeira sob condiçōes neutras ou levemente alcalinas e temperaturas em torno de $120^{\circ} \mathrm{C}$. A molécula completa deve reagir rapidamente e formar ligações químicas estáveis. Estes reagentes podem ser divididos em duas classes: as de adição de sítio único e as de adição de polimerização.

\section{b.3a) Adição de sítio único}

b.3a.1) Acetilação

É a modificação química da madeira mais estudada. A ligação permanente com os grupos $\mathrm{OH}$ das paredes celulares resulta em grande eficiência na estabilidade dimensional. Verifica-se também a diminuição da penetração capilar.

b.3a. 1.1) com anidrido

A melhor condição de acetilação é usar o anidrido acético sem catalisador, a $100-130^{\circ} \mathrm{C}, \mathrm{e}$, como solvente, o xileno. Quando a acetilação é feita com anidrido acético forma-se ácido acético que deve ser imediatamente retirado da madeira, pois pode provocar a reversão da esterificação, e a corrosão de metais usados como elementos de ligação. Com isso perde-se $50 \%$ do reagente. Outra opção é destruir o 
ácido acético in situ com óxido de etileno ou acetileno, o que leva á formação de outro éster. $O$ ácido acético pode ainda ser neutralizado com octadecilamina resultando em um repelente à água. Pode-se fazer a acetilação em presença de anilina, que reage com o ácido desprendido formando um biocida, com adicional proteção à madeira. Também se pode usar piridina com cloreto de fósforo como catalisador.

Entretanto, os anidridos propiônico, butírico, trifluoroacético, ftálico e maleico também são utilizados (Goldstein et al. 1961). Para o anidrido ftálico usa-se dimetilformamida como solvente. Em geral, para um ganho percentual de peso de $20 \%$ consegue-se uma melhoria na estabilidade dimensional em torno de $70 \%$ (Risi; Arseneau* apud Rowell; Banks 1985). Quando a acetilação é feita com anidridos cíclicos (maleico, ftálico) a estrutura cíclica se abre, reagindo com a hidroxila da madeira e formando na outra extremidade um outro grupo hidroxila, apto a reagir novamente ou apto a formar ligação de hidrogênio com a água. $O$ tratamento com anidrido ftálico e epicloridrina confere à madeira excelente resistência às intempéries e à biodegradação.<smiles>CCOC(=O)OC(C)=O</smiles>

Figura 12- Ligação de anidrido acético com grupos $\mathrm{OH}$ da madeira.

\footnotetext{
"RISI, J.; ARSENEAU, D. F. Dimensional Stabilization of Wood. IV. Allylation. Forest Products Journal, vol. 7, p. 293-95, 1957 apud ROWELL, R. M.; BANKS, W. B. Water Repellency and Dimensional Stability of Wood. USDA, General Technical Report FPL-50, Forest Service, Forest Products Laboratory, Madison, WI, 1985. 24p.
} 
b.3a.1.2) com ceteno

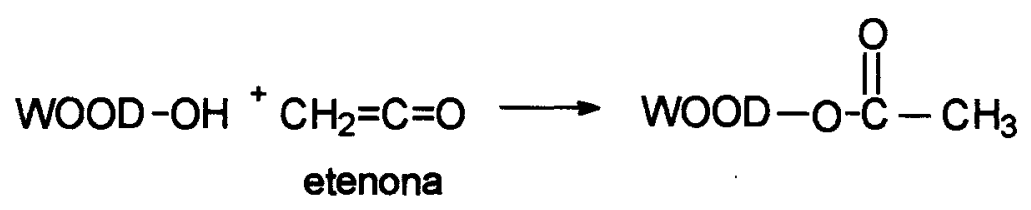

Figura 13- Ligação de grupos $\mathrm{OH}$ com etenona.

b.3a. 1.3) com cloreto de acila

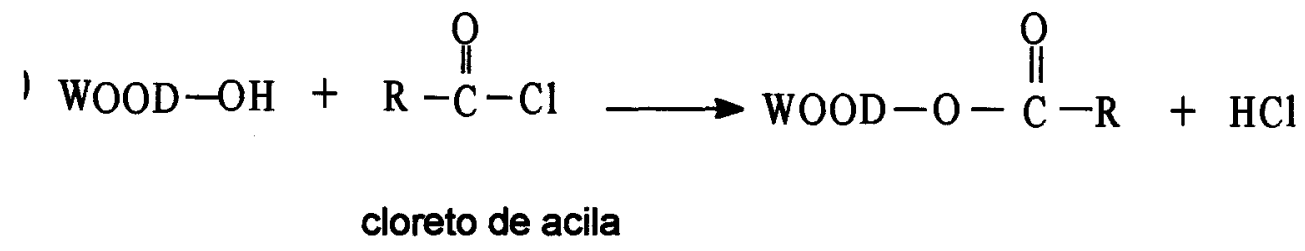

Figura 14- Ligação de grupos $\mathrm{OH}$ com cloreto de acila.

b.3a. 1.4) com cetona

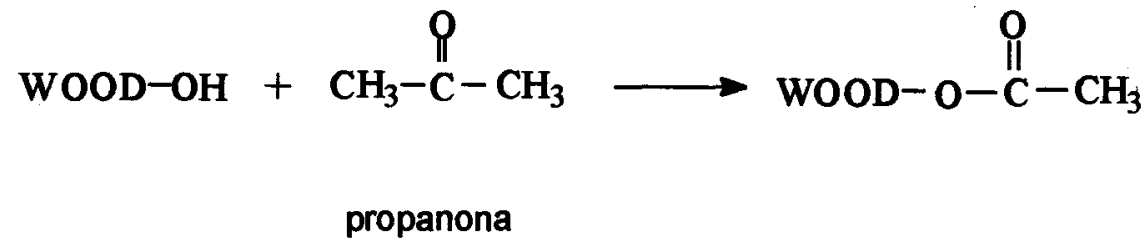

Figura 15- Ligação de grupos $\mathrm{OH}$ com cetona.

A madeira acetilada apresenta boa resistência ao ataque de fungos do apodrecimento, mas é ineficaz contra os demais fungos. Tem boa resistência aos térmitas subterrâneos e às brocas marinhas, mas não é melhor que o tratamento com CCA e creosoto. O tratamento também promove o melhoramento da estabilidade do 
MOR e MOE (módulo de elasticidade). E, sendo um bom agente de estabilização dimensional que não apresenta toxicidade, é utilizado em banheiras e revestimentos de pisos e paredes de locais de banho (Norimoto; Gril 1993).

\section{b.3a. 2) Metilação}

A reação da madeira com sulfato de dimetila ou iodeto de metila resulta em eterificação dos polímeros da parede celular.

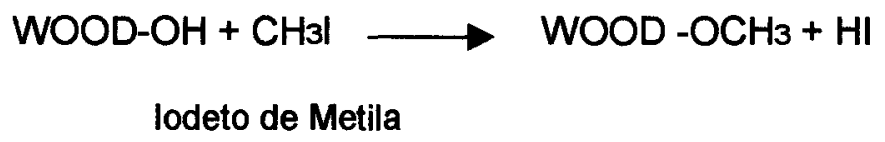

Figura 16- Ligação de iodeto de metila com grupos $\mathrm{OH}$ da madeira.

Metilações feitas repetidas vezes podem aumentar o ganho de peso em até $20 \%$ com melhora na estabilidade dimensional de até $60 \%$ (Rudkin apud Rowell; Banks 1985).

b.3a. 3) Alquilação

$$
\mathrm{WOOD}-\mathrm{OH}+\mathrm{R}-\mathrm{Cl} \longrightarrow \mathrm{WOOD}-\mathrm{O}-\mathrm{R}+\mathrm{HCl}
$$

Figura 17- Ligação de cloreto de alquila com grupos $\mathrm{OH}$ da madeira.

\footnotetext{
"RUDKIN, A.W. The Role of the Hydroxyl Group in the Gluing of Wood. Australian Journal of Applied Science, vol. 1, p. 270-83, 1950. apud ROWELL, R. M.; BANKS, W. B. Water Repellency and Dimensional Stability of Wood. USDA, General Technical Report FPL-50, Forest Service, Forest Products Laboratory, Madison, WI, 1985. 24p.
} 
Reações com cloretos de alquila são realizadas usando-se normalmente piridina ou cloreto de alumínio como catalisadores, com melhoria na estabilidade dimensional. Porém, o ácido clorídrico formado como subproduto pode acarretar degradação das cadeias de celulose, com perda de resistência mecânica. Outro problema verificado é a solubilidade da resina formada, sendo facilmente lixiviada. A reação da madeira com cloreto de alquila em piridina (Kenaga et al". apud Rowell; Banks 1985) promoveu uma ASE inicial elevada, mas com ciclos de secagem e mergulho em água, o valor da ASE que, neste caso, é devido à formação de polímeros de cloreto de alquil piridínio que é facilmente lixiviável, vai sendo reduzido (Risi; Arseneau apud Rowell; Banks 1985).

b.3a. 4) Aldeídos

Acetaldeido (Tarkow; Stamm* apud Rowell; Banks 1985) e benzaldeído (Tarkow; Stamm; Weaver et al." apud Rowell; Banks 1985) usando ácido nitrico ou cloreto de zinco como catalisador resultaram em bom valor de ASE para o acetaldeído, mas de apenas $40 \%$ com benzaldeído.

\footnotetext{
"KENAGA, D. L.; SPROULL, R. C.; ESSLINGER, J. Preliminary Experiments on Dimensional Stabilization of Wood by Allylation. Southern Lumberman, vol. 180, p. 45, 1950. apud ROWELL, R. M.; BANKS, W. B. Water Repellency and Dimensional Stability of Wood. USDA, General Technical Report FPL-50, Forest Service, Forest Products Laboratory, Madison, WI, 1985. 24p.

* TARKOW, H.; STAMM, A. J. Effect of Formaldehyde Treatments upon e Dimensional Stabilization of Wood. Journal of the Forest Products Research Society, vol. 3(3), p. 33-7, 1953. apud ROWELL, R. M.; BANKS, W. B. Water Repellency and Dimensional Stability of Wood. USDA, General Technical Report FPL-50, Forest Senvice, Forest Products Laboratory, Madison, WI, 1985. 24p.

"WEAVER, J. W.; NIELSON, J. F.; GOLDSTEIN, I. S. Dimensional Stabilization of Wood with Aldehydes and Related Compounds. Forest Products Journal, vol. 10, p. 306-10, 1960. apud ROWELL, R. M.; BANKS, W. B. Water Repellency and Dimensional Stability of Wood. USDA, General Technical Report FPL-50, Forest Service, Forest Products Laboratory, Madison, WI, 1985. 24p.
} 
Glioxal, glutaraldeído e $\alpha$-hidroxiadipaldeído mostraram $50 \%$ de ASE com $20 \%$ de WPG (Weaver et al. apud Rowell; Banks 1985). Ao tratar a madeira com glioxal usando $\mathrm{SO}_{2}$ como catalisador, Yasuda e Minato (1995) obtiveram 70\% de ASE com $20 \%$ de WPG. Usando glioxal + glicol obtiveram $77 \%$ de ASE com $\cong 20 \%$ de WPG.

Ácido ftalaldeídico em acetona catalisada com ácido p-tolueno sulfônico resultou em $40 \%$ de ASE com $34 \%$ de WPG (Weaver et al. apud Rowell; Banks 1985). Quando curado a $100^{\circ} \mathrm{C}$, de 16 a 24 horas, sem catalisador, resultou em 50 a $70 \%$ de ASE (Kenaga* apud Rowell; Banks 1985).Furfural, acetato de glicol, heptaldeido e cloro acetaldeído resultaram em 15 a 25\% de WPG para, no máximo, $40 \%$ de ASE (Weaver et al. apud Rowell; Banks 1985).

\section{b.3b) Adição de Polimerização}

\section{b.3b. 1) Epóxidos}

Um novo grupo hidroxila é formado e pode se ligar com um outro grupo epóxido, produzindo a polimerização. A reação entre epóxido e madeira pode ser catalisada por base fraca. Devido à natureza iônica da reação, McMillin apud Rowell; Banks 1985 reporta $60 \%$ de ASE com $20 \%$ de WPG, usando óxido de etileno

* KENAGA, D. L Stabilized Wood. US Patent 2,811,470, 1957. apud ROWELL, R. M.; BANKS, W. B. Water Repellency and Dimensional Stability of Wood. USDA, General Technical Report FPL-50, Forest Service, Forest Products Laboratory, Madison, WI, 1985. 24p.

"MCMILLIN, C. W. Dimensional Stabilization with Polymerizable Vapor of Ethylene Oxide. DForest Products Journal, vol. 13, p. 56-61, 1963. apud ROWELL, R. M.; BANKS, W. B. Water Repellency and Dimensional Stability of Wood. USDA, General Technical Report FPL-50, Forest Service, Forest Products Laboratory, Madison, WI, 1985. 24p. 
catalisado com trietilamina. Com $22 \%$ de WPG, menos de $1 \%$ de retraimento ocorre com a madeira (Aktiebolag* apud Rowell; Banks 1985).

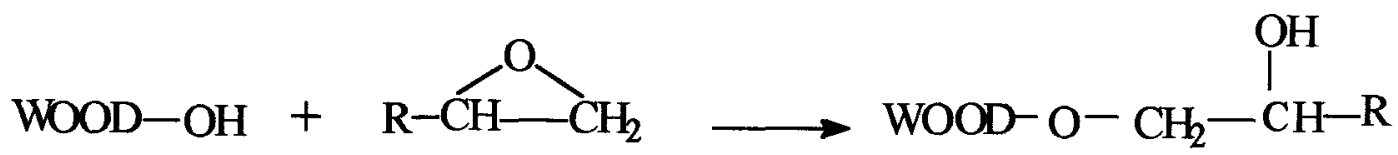

Figura 18- Ligação de epóxido com grupos $\mathrm{OH}$ da madeira.

A impregnação é feita com a resina com baixo grau de polimerização, e depois se promove a cura com um endurecedor durante 5 a 6 horas em temperatura ambiente. É mais usado em laminados por que é de difícil penetração. Diminui a taxa de absorção de água, uma vez que cria uma barreira nas paredes internas impedindo a entrada da água. Aumenta a dureza. A reação é rápida e há formação de cadeias curtas. Com um ganho de 20 a $30 \%$ em peso consegue-se de 50 a $70 \%$ de estabilidade dimensional. Os epóxidos reagem e incham a parede celular e continuam a inchar até causar o rompimento da estrutura da célula. A água pode, então, reagir com grupos $\mathrm{OH}$ agora expostos pela ruptura. Neste estágio, com certeza, há perda da estabilidade dimensional (Rowell et al. 1976).

b.3b. 2) Isocianatos

$\mathrm{Na}$ reação de isocianato com grupos hidroxilas da madeira é formado um éster que contém nitrogênio. Reações de isocianato de etila, de n-butila, de t-butila, em

* AKTIEBOLAG, M. D.; Wood Impregnation with Gaseous Ethylene Oxide. French Patent 1,408,170. 1965. apud ROWELL, R. M.; BANKS, W. B. Water Repellency and 
dimetilformamida resultaram em $67 \%$ de ASE com $31 \%$ de WPG (Clermont; Bender apud Rowell; Banks 1985).

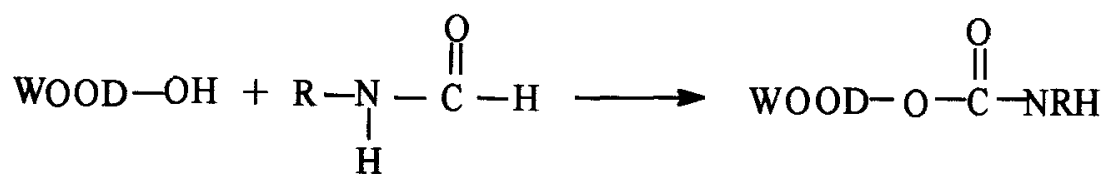

Figura 19- Ligação de isocianato com grupos $\mathrm{OH}$ da madeira.

A madeira isocianatada torna-se resistente a fungos e sua resistência à flexão e compressão também é aumentada. Mas sua resistência à abrasão e à fratura diminui.

As reações da madeira com isocianatos são geralmente muito rápidas e produzem ligações uretanas muito estáveis. A lignina reage muito mais rapidamente que os polissacarídeos. Se a impregnação resultar em WPG além de $30 \%$, novas superficies começam a ser expostas, causando ruptura das paredes celulares, diminuindo a estabilidade dimensional. A máxima estabilidade dimensional (70\%) é atingida com 16 a $28 \%$ de ganho de peso. Verificou-se também boa resistência ao ataque de térmitas. Apesar da alta velocidade da reação, nem todos os grupos hidroxilas disponiveis reagem, mesmo com alto ganho percentual de peso. (Rowell; Ellis 1979).

Isocianatos de baixo peso molecular reagem com as paredes celulares, porém os de alto peso molecular tendem a somente preencher o lúmem das células.

Dimensional Stability of Wood. USDA, General Technical Report FPL-50, Forest Service, Forest Products Laboratory, Madison, WI, 1985. 24p.

"CLERMONT, L. P.; BENDER, F. Effect of Swelling Agents and Catalysts on Acetylation of Wood. Forest Products Journal, vol. 7, p.167-70, 1957. apud ROWELL, R. M.; BANKS, W. B. Water Repellency and Dimensional Stability of Wood. USDA, General Technical Report FPL-50, Forest Service, Forest Products Laboratory, Madison, WI, 1985. 24p. 
b.3b. 3) Acrilonitrila

Reagindo-se acrilonitrila em metanol seguida de exposição a $10^{7}$ rads de radiação ionizante consegue-se $40 \%$ de ASE com $29 \%$ de WPG. A baixa estabilidade dimensional pode ser devido à reação da acrilonitrila com o metanol formando polímeros no lúmem ao invés de nas paredes celulares.

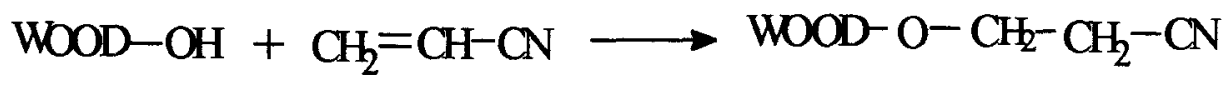

Figura 20- Ligação de acrilonitrila com grupos $\mathrm{OH}$ da madeira.

Usando-se hidróxido de sódio $(\mathrm{NaOH})$ como catalisador, melhora-se a estabilidade dimensional em até $60 \%$ com ganho de peso de $30 \%$. No entanto, se for utilizado hidróxido de amônio $(\mathrm{NH} 4 \mathrm{OH})$ como catalisador forma-se um polímero solúvel em água na parede da célula, que é lixiviável. Houve aumento da estabilidade dimensional e da resistência à biodeterioração. Entretanto, verificou-se diminuição da resistência mecânica da madeira (Kenaga apud Rowell; Banks 1985).

b.3b. 4) $\beta$-propiolactona

Dois produtos são possiveis dependendo do $\mathrm{pH}$ da reação.

Em meio ácido a reage com a madeira formando um éter.

Em meio básico forma-se um éster. 
Altas concentrações de $\beta$-propiolactona causam alto grau de inchamento, resultando em delaminação e ruptura. Com $30 \%$ de WPG a madeira apresenta $60 \%$ de ASE (Goldstein *apud Rowell; Banks 1985).

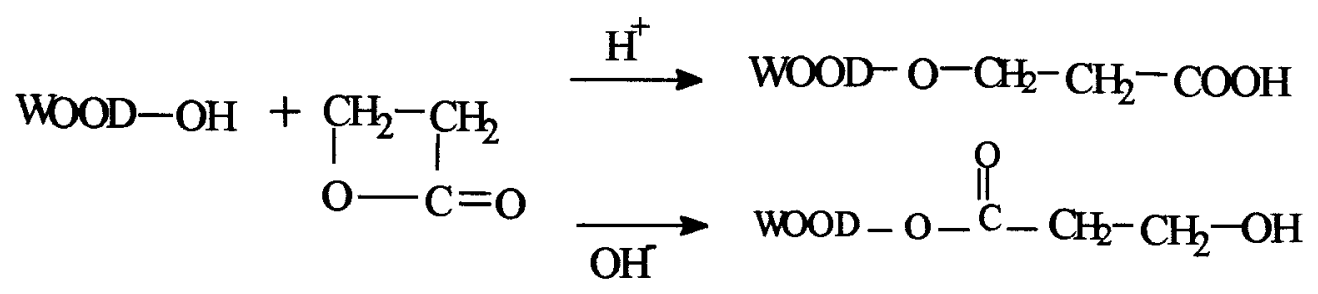

Figura 21- Ligação de $\beta$-propiolactona com grupos $\mathrm{OH}$ da madeira.

* GOLDSTEIN, I. S. Improving Fungus Resistance and Dimensional Stability of Wood by Treatment with $\beta$-propiolactone. US Patent 2,931,741, 1960. apud ROWELL, R. M.; BANKS, W. B. Water Repellency and Dimensional Stability of Wood. USDA, General Technical Report FPL50, Forest Service, Forest Products Laboratory, Madison, WI, 1985. 24p. 


\subsection{Deterioração Biológica da Madeira}

A madeira é um recurso natural biodegradável. Fungos e insetos efetuam a degradação sem a qual a Terra estaria tomada por madeira usada. O problema é que estes degradadores não distinguem entre árvores tombadas na floresta, madeira fora de serviço e madeira em serviço.

A madeira é degradada biologicamente porque organismos reconhecem os polímeros polissacarídicos na parede celular e têm um sistema enzimático altamente específico capaz de hidrolisar estes polímeros em unidades digeríveis (Rowell 1982). A madeira constitui um substrato que pode ser metabolizado pelos fungos degradadores e outros microorganismos. Os carbohidratos hidrofílicos e a lignina hidrofóbica constituem fontes de energia para estes organismos degradadores (Shimada 1993).

Os principais organismos de degradação da madeira são:

1) Fungos Apodrecedores

2) Insetos Xilófagos

3) Brocas Marinhas

\subsubsection{Degradação por Fungos}

A holocelulose (celulose e hemicelulose) e a lignina, que juntas compõem o corpo estrutural da madeira, são degradadas por enzimas secretadas pelos fungos e bactérias em compostos simples tais como açúcares, que podem ser absorvidos e metabolizados por organismos degradadores (Scheffer 1973). 
O mecanismo de resistência aos ataques biológicos, em parte, é devido à distribuição de reagentes nos polímeros da parede celular causando o bloqueamento dos sítios enzimaticamente reativos. Os sítios mais reativos da madeira são os grupos hidroxilas presentes tanto na celulose como na hemicelulose e na lignina. A modificação da lignina não parece ter um papel significativo no mecanismo de proteção aos ataques de microorganismos. A resistência mecânica da madeira é devido aos polímeros de alto peso molecular (polissacarideos) da celulose e da hemicelulose, e da lignina. Quando estas são degradadas, a madeira perde resistência (Rowell 1982).

As enzimas se ligam ao substrato pela atração entre seus grupos funcionais e os grupos funcionais do substrato. Em geral, um grupo carboxílico da enzima se liga a um grupo hidroxila do substrato, causando subsequentes reações catalisadas:

- Orientação dos átomos do substrato para facilitar as reações.

- Catálise ácido-base envolvendo resíduos de aminoácidos próximos aos sitios reativos do substrato.

- Catálise covalente, em que os ataques ao substrato por grupos nucleofilicos ou eletrofílicos das enzimas aceleram a reação.

- Catálise por distorção conformacional do substrato, de modo que a reação subsequente é facilitada pela liberação de forças conformacionais induzidas da enzima.

As madeiras mais resistentes aos ataques microbiológicos possuem extrativos que lhes servem de preservativos naturais.

A maioria das manchas, mofo, bolor e apodrecimento são causados por fungos. Os fungos penetram e se alastram na madeira na forma de fio ou filamento chamado de hifa que consiste de várias células conectadas nas suas terminações. 
Os fungos apodrecedores são vegetais microscópicos desprovidos de clorofila. São parasitas incapazes de sintetizar seu próprio alimento. Elas prescindem de materiais orgânicos que são encontrados nos produtos armazenados nas cavidades celulares ou nos próprios constituintes celulares da madeira.

Os fungos degradadores da madeira pertencem a três categorias:

1) Fungo da Podridão Branca ("white rot fungi")

2) Fungo da Podridão Parda ("brown rot fungi")

3) Fungo da Podridão Mole ("soft rot fungi")

\subsection{1a) Fungo da Podridão Branca ("white rot fungi")}

Os Fungos da Podridão Branca ("white-rot fungi") atacam principalmente a lignina. São os maiores decompositores da lignina, mas atacam também a celulose em estágio posterior. Pertencem ao grupo dos basidiomicetos, os chamados cogumelos. Eles deixam a madeira esbranquiçada e esponjosa devido à hidrólise da lignina que confere a cor escura à madeira. Causam perda de peso e resistência.

As enzimas LiP (lignina peroxidase), lacase e MnP (manganês peroxidase) oxidam somente as porções fenólicas da lignina e catalisam as subsequentes polimerizações da lignina. A LiP catalisa a oxidação dependente de um elétron do peróxido de hidrogênio $\left(\mathrm{H}_{2} \mathrm{O}_{2}\right)$, de uma variedade de radicais. A MnP oxida substratos fenólicos a radicais fenóxi de maneira similar a LiP na presença de $\mathrm{H}_{2} \mathrm{O}_{2}$. A degradação e a transformação da lignina através destas enzimas têm potenciais aplicações na indústria:

- A delignificação da madeira, palhas e bagaços agroindustriais, para aumentar a digestibilidade de raçōes pelos ruminantes; 
- A delignificação de cavacos de madeira para reduzir o consumo de energia e o consumo de reagentes na polpação pelo processo kraft;

- Modificação de ligninas isoladas para a produção de determinadas ligninas com propriedades específicas (Shimada 1993).

Os fungos da podridão branca produzem um estreitamento progressivo da parede celular secundária $\left(\mathrm{S}_{3}\right)$, começando pelo lúmem e se estendendo em direção à lamela média. Após a decomposição completa da lamela média começam a atacar a celulose. A camada mais resistente aos fungos da podridão branca é a S3. Há dois tipos de fungos: aqueles que decompõem lignina e celulose simultaneamente; e aqueles que decompõem a lignina preferencialmente nos primeiros estágios da deterioração. $O$ efeito de sua degradação parece uniforme em cada célula e de uma célula para outra.

Os efeitos de redução da resistência mecânica estão intimamente ligados com os danos aparentes.

A ação das enzimas celulolíticas de um fungo da podridão branca se restringe à superfície da parede celular, enquanto que as do fungo da podridão parda são capazes de penetrar e agir no interior da parede celular. Ambos parecem capazes de produzir enzimas na extremidade da hifa que é por onde se inicia a abertura das cavidades. O mecanismo de penetração está relacionado com a habilidade do fungo em degradar moléculas, e também com a formação de cavidades (Wilcox 1973).

A degradação da celulose pelos fungos da podridão branca é chamada sistema celulase e foi proposto por Wood e McCrae (Shimada e Takahashi 1991).

No estágio $A$, enzimas endo-celulase $(C x)$ atacam aleatoriamente regiões amorfas do substrato de celulose para preparar os sítios reativos para as enzimas exocelulase (C1). 
Em $B$, as enzimas $C 1$ dividem as unidades exo-wise de celobiose.

No estágio C esta seqüência se repete e as porçōes de celulose são clivadas.

(D) As celobioses e os celo-oligo sacarídeos formados são hidrolisados a glucose pela enzima $\beta$-glucosidase.
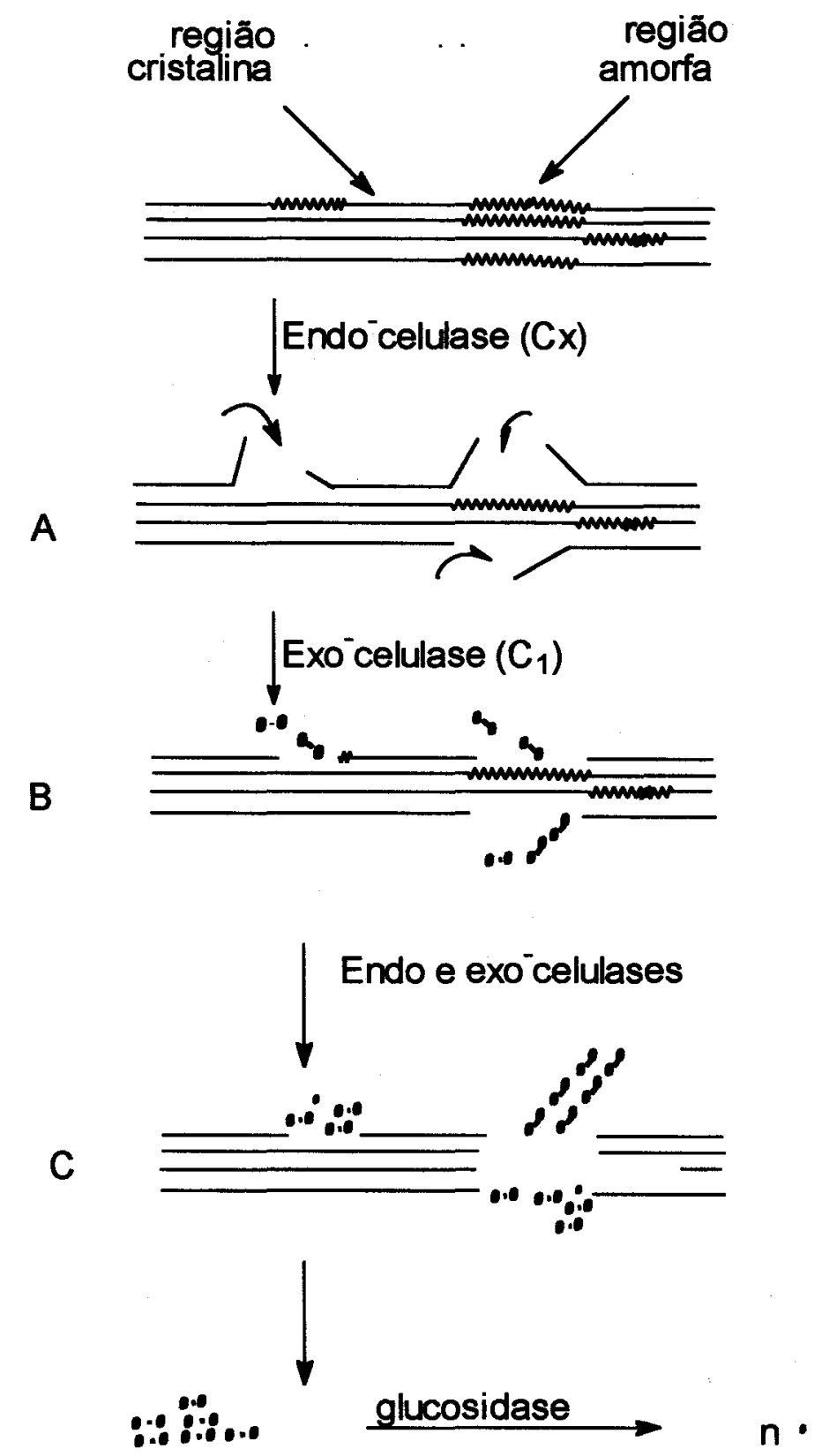

Figura 22- Mecanismo da degradação da celulose pelos fungos da podridão branca (Shimada 1993). 


\subsection{1b) Fungo da Podridåo Parda ("brown rot fungi")}

Os Fungos da Podridão Parda ("brown-rot fungi") atacam a celulose e as hemiceluloses, causando o colapso da parede celular da madeira. Têm preferência pelas gimnospermas. Os fungos da podridăo branca também atacam a celulose, porém, nos primeiros estágios, a degradação pelos fungos da podridão parda é efetuada com muito mais rapidez. Pertencem ao grupo dos basidiomicetos. Deixam a madeira parda, pois não degradam a lignina, com rachaduras perpendiculares e ao longo das fibras. Causam perda de peso e resistência.

A camada $S_{1}$ tem densidade maior que a $S_{2}$ e resiste tanto aos ataques de fungos da podridão branca como da parda.

A camada $S_{2}$ tem maior resistência às enzimas destruidoras de lignina do que às destruidoras de celulose. Por isso, é a menos resistente aos fungos da podridão parda.

A camada S3 é resistente aos fungos da podridão branca, mas não o é para os da parda.

A lamela média é a região mais resistente a ambos.

O mecanismo de degradação da celulose pelos fungos da podridão parda não é o mesmo dos fungos da podridão branca, visto que eles não produzem a exocelulase. E também pelo fato dela ocorrer em regiões cristalinas. Também foi descartada a hipótese da reação do tipo Fenton (Koenig* apud Shimada 1993) porque os radicais $\mathrm{OH}$ são oxidantes muito fortes e não atacariam seletivamente a celulose,

\footnotetext{
"KOENIG, J. W. Wood and Fiber, vol. 6, p. 66, 1974. Apud SHIMADA, M. Biochemical Mechanisms for the Biodegradation of Wood. In: SHIRAISHI, N.; KAJITA, H.; NORIMOTO, M. eds. Recent Research on Wood and Wood-Based Materials. Current Japanese Materials Research, vol. 11, p. 207-22, Elsevier, London, 1993.
} 
atacariam também a lignina. Porém, isto não ocorre. Além disso, a decomposição pelo sistema Fenton é inibida pelo ácido oxálico, que é um importante metabólito fisiológico dos fungos da podridão parda. Shimada et al. (1991) isolaram uma enzima (a oxaloacetase) que catalisa a hidrólise do ácido oxaloacético a ácido oxálico e ácido acético. O ácido oxálico é utilizado como um agente hidrolítico pelos fungos da podridão parda para atacar as cadeias de celulose e hemicelulose durante o processo de degradação.

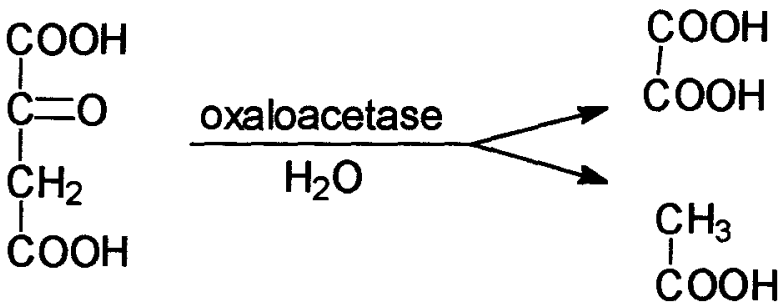

Figura 23- Metabolização de ácido oxálico a partir de ácido oxaloacético catalisada por oxaloacetase (Shimada et al. 1991).

O ataque dos fungos da podridão parda não ocorre de maneira uniforme, eles se esparramam pela parede celular e é incompleta em qualquer localização. No entanto, os efeitos da degradação por eles promovida não são mostrados na razão direta dos efeitos visuais. A perda de resistência excede em muito os efeitos visuais aparentes (Wilcox 1973).

\subsection{1c) Fungo da Podridão Mole ("soft rot fungi"):}

Os fungos da podridão mole ("soft rot fungi") são do tipo ascomicetos. Atacam a superfície da madeira (até $20 \mathrm{~mm}$ de profundidade), causam perda de peso e 
resistência. A madeira fica mole quando úmida e, ao secar, apresenta cor escura, com várias fissuras. A deterioração por este tipo de fungo é caracterizada por fisiologia e ecologia distinta. Ela causa a lenta degradação pela ação das intempéries, um pequeno aumento na solubilidade em álcalis (semelhante aos fungos da podridão branca), são incapazes de metabolizar a lignina extensivamente (como os fungos da podridão parda), e causam fissuras na pintura.

Primeiro foram combatidos com creosoto. Depois os tratamentos do tipo fluoreto-cromo-arsênico demonstraram melhores resultados (Scheffer 1973).

\subsection{1d) Fungos Manchadores ("stain"):}

As manchas resultam principalmente da cor escura da hifa do próprio fungo que pode ser vista recobrindo camadas da superfície da madeira, mas também deixam manchas na madeira devido aos pigmentos por eles liberados.

Os fungos manchadores são do tipo ascomicetos. Eles atacam o amido e os açúcares presentes no lúmem das células. A infecção ocorre rapidamente e a madeira não perde peso nem resistência.

A mancha causada por íon ferro acarreta a mudança de cor da madeira do cinza pálido ao preto azulado. A reação entre o ferro e o tanino, formando o tanato de ferro, causa o escurecimento da madeira. A formação do tanato de cobre causa a descoloração vermelha.

Uma boa proteção contra este tipo de fungo é manter a madeira com baixo teor de umidade. No início dos anos 40 era usado hexacloreto de benzeno com pentaclorofenato de sódio para reduzir manchas e prevenir o ataque de insetos 
(Scheffer 1973). O tratamento com bifluoreto de amônio através de difusão simples tem mostrado ser eficiente para prevenir o aparecimento de manchas (Scheffer 1973).

\subsection{1e) Fungos Emboloradores ("mold"):}

Geralmente são do tipo ascomicetos, penetram fundo na madeira e emboloram a superfície devido à produção de esporos. Deixam a madeira com aspecto algodoado cuja coloração varia do branco ao preto.

Os fungos manchadores e embololadores não causam a degradação da madeira, porém, prejudicam o acabamento.

\subsection{1f) Fatores que Influenciam na Proliferação de Fungos:}

Os fatores que influenciam no aparecimento e proliferação de fungos são, entre outros: umidade, presença de oxigênio, conteúdo de nitrogênio, $\mathrm{pH}$, temperatura, tamanho e difusibilidade de enzimas em relação à estrutura capilar, cristalinidade da celulose, conformação e rigidez estérica dos polímeros naturais da madeira, interrelações entre as estruturas poliméricas, e os grupos substituintes nos polímeros (Smulski 1996). A degradação microbial só ocorre se existir um adequado suprimento de água, a presença de oxigênio e uma temperatura favorável. A faixa ideal de temperatura para que os fungos se proliferem é de $\cong 21$ a $32^{\circ} \mathrm{C}$; a degradação é muito lenta a temperaturas abaixo de $10^{\circ} \mathrm{C}$, e completamente inibida perto de 0 e de $38^{\circ} \mathrm{C}$ (Scheffer 1973). 
O meio mais eficaz de proteger a madeira em serviço contra degradação biológica é mantê-la em lugar seco, sem contato com a umidade. Quanto à temperatura, mesmo em temperaturas de congelamento muitos fungos não morrem, apenas hibemam. Geralmente a madeira utilizada em interiores possui umidade de 4 a $16 \%$, estando, portanto, protegida do ataque dos fungos. Para ser atrativa aos fungos, a madeira precisa apresentar umidade em torno de $18 \%$ continuamente.

Para a madeira cuja finalidade é uso externo, isto é, exposta às variações climáticas, a proteção contra a natural biodeterioração seria o emprego do ceme das madeiras naturalmente resistentes à deterioração como, por exemplo, cedros vermelhos, pinhos vermelhos e carvalhos brancos. Estas espécies possuem extrativos não atrativos aos fungos. Porém, o estoque destas espécies não é infinito e o tratamento químico de madeiras mais comuns imitando-as, pode ser a alternativa, já que não se pode assegurar o não contato com a umidade. Os preservativos tomam a madeira tóxica aos organismos de degradação da madeira, ou modificam seus componentes para que os microorganismos não reconheçam suas fontes nutritivas, fazendo com que a madeira fique resistente aos seus ataques. Talvez a melhor proteção seja encontrar um fungo que penetre profundamente na madeira e promova a inibição dos fungos degradadores através da produção de reagentes antibióticos, ou da remoção dos açúcares e amido utilizados por eles como fontes energéticas (Wilcox 1973).

\subsection{1g) Tratamentos para Prevenir a Degradação por Fungos}

O mais antigo preservativo que se tem conhecimento é o óleo de cedro com que os egípcios untavam os objetos de madeira funerários. Para proteger as paredes 
das moradias empregou-se argilas, óleos e cinzas. Industrialmente, os americanos foram os pioneiros no uso do creosoto para preservar madeiras não duráveis das linhas de trem, postes e pontes, no início de 1850. O processo empregado é o da célula cheia ou processo Bethell (Smulski 1996). O processo Bethell ainda é o mais utilizado para a impregnação convencional de preservativos hidrossolúveis. Para o tratamento com preservativos lipossolúveis, o processo Rüping-Lowry é normalmente empregado.

creosoto é altamente eficiente contra fungos, insetos e brocas marinhas. Este tratamento confere, em média, uma sobrevida de 30 anos. De origem orgânica, ele é degradável, tem cor que varia do preto ao marrom e exala fortes vapores. Produtos creosotados não aceitam pintura, devendo ser selados com resinas de epoxi, uretanas ou outros (Smulski 1996). Além destas desvantagens, inflamações dermatológicas foram a ele creditados além de apresentar substâncias carcinogênicas (Takahashi 1993).

No início de 1900 foram empregados os carbonatos e bicarbonatos de sódio, e os derivados mercuriais solúveis em água (Scheffer 1973).

$\mathrm{Na}$ década de 30 o borax e os fenóis clorados dominaram o mercado de preservativos. Os compostos de boro apresentam baixo impacto ambiental mas é facilmente lixiviado da madeira. e os organo-clorados apresentam efeitos colaterais devido à acumulação residual.

Os anos 40 foram denominados de "era dos penta", com o pentaclorofenol (PCP) e seus derivados substituindo o creosoto no tratamento de postes, linhas de trem e paredes de madeira por proporcionar uma superfície clara e pintável, utilizandose solventes orgânicos como o isobutano liquefeito. Prolonga a vida útil da peça por 20 anos. Porém, mesmo empregando-se selantes como verniz e esmalte, pode mover-se 
em direção ao solo onde seus resíduos não degradáveis a ele se ligam. Além disso, aumentam a combustibilidade da madeira.

Outros preservativos lipossolúveis vêm substituindo os "pentas", como o propinil butil carbamato de iodo (IPBC), o naftenato de cobre e zinco e o tributil óxido de estanho (TBTO) (Smulski 1996). Porém, a opinião pública acerca dos problemas de toxicidade e impacto ambiental tem forçado a retirada de mercado de muitos preservativos, incluindo os hidrocarbonetos clorados, O TBTO, e ○ PCP no Japão (Takahashi 1993).

Os preservativos hidrossolúveis são numerosos: CCA (arsenato de cobre cromatado), ACA (arsenato de cobre amoniacal), ACC (cromato de cobre ácido), CZC (cloreto de zinco cromatado), ACZA (arsenato de zinco e cobre amoniacal) e FCAP (fenol arsenato de flúor e cromo). Todos apresentam mecanismos semelhantes, e, à exceção do CZC e FCAP, não são lixiviáveis. O zinco e o cobre conferem resistência aos fungos. $\mathrm{O}$ arsênico protege contra $\mathrm{O}$ ataque das térmitas e dos fungos resistentes ao cobre. A amônia (ACA e ACZA) auxilia ao cobre, arsênico e zinco a penetrar profundamente na madeira.

O CCA começou a ser utilizado nos anos 30. Existem 3 formulações: A, B e C, variando as concentrações de $\mathrm{Cr}$, Cu e As. O preferido é o tipo $\mathrm{C}$, a forma óxida. Esta forma apresenta vantagens como a resistência à corrente elétrica superior à madeira sem tratamento, o que a toma adequada para emprego em postes de distribuição e transmissão de energia elétrica. A madeira tratada com CCA adquire cor esverdeada que pode ser pintada, envernizada, encerada ou laqueada, podendo ser manuseada normalmente, pois não exala odores, nem vapores irritantes. Por esta razão são utilizadas em construções de playground, instalações para animais e estacas para plantas (Smulski 1996). 
O CCA é eficiente contra fungos e térmitas, assim como contra as brocas marinhas. Ele só não torna a madeira completamente imune aos insetos que não a ingerem como as formigas carpinteiras. E contra os fungos manchadores. Madeiras tratadas quando empilhadas úmidas, são susceptíveis a alojar mofo e fungos manchadores em sua superficie. Ele é solúvel durante o processo de impregnação, do tipo célula cheia modificada, tornando-se insolúvel após o tratamento. Por isso o CCA não é lixiviado da madeira em serviço, e não despreende vapores durante a impregnação (Smulski 1996). Estudos de outros autores, porém, afirmam que a lixiviação ocorre e as conseqüências da contaminação são desastrosas do ponto de vista ambiental.

Pizzi (1981) afirma que o complexo $\mathrm{Cr}^{6+}$ /lignina confere a repelência à água e melhora a estabilidade dimensional da madeira. $\mathrm{E} \circ \mathrm{Cr}^{5+}$ deve estar presente principalmente na lamela média e na parede secundária $\left(\mathrm{S}_{3}\right)$, que são ricas em lignina. Como as coniferas possuem em média de 60 a $90 \%$ de sua lignina concentrada na lamela média, isto explica a eficácia do tratamento em coníferas como preservativo contra fungos e térmitas. Porém, $\circ \mathrm{Cr}^{6+}$ sofre redução a $\mathrm{Cr}^{3+}$ e este pode ser lixiviado. Este é o maior problema, pois a solução de tratamento pode contaminar tanto o solo como também outras plantas locais.

Wehr (1985) tratando moirões roliços com CCA, CCB (sais de cobre, cromo e boro) e FCAP, concluiu que o tratamento mais problemático é o com CCA, tanto pelo processo de impregnação sem pressão como para o processo da substituição da seiva. Os problemas mais críticos encontrados foram: o desbalanceamento do $\mathrm{pH}$ e lixiviação da solução, baixa penetração e distribuição não uniforme da solução impregnante. 
Fuse apud Takahashi (1993) alerta para a toxicidade das cinzas do $\mathrm{Cr}^{6+}$ e dos gases do ácido arsenioso quando a madeira tratada for queimada após o tempo de vida útil.

A substituição do arsênio e do cromo por fósforo, boro, flúor ou zinco tem sido testados como altemativas ao uso do CCA devido a apresentarem menos riscos à saúde humana e ao meio ambiente. Compostos de alquilamônio (ACC) prometiam resultados comparáveis aos do CCA. Sua baixa toxicidade e alta performance contra ataques de térmitas, assim como em combinação com cobre e outros agentes para melhorar sua eficiência contra biodeterioração foi muito apreciada. Porém, testes efetuados não o recomendam para uso em contato com o solo. Recentemente, um derivado do ACC, o didecil dimetil cloreto de amônio (DDAC) foi aprovado no Japão como um ativo ingrediente de formulações fungicidas e termicidas (Takahashi 1993).

O BAE (equivalente de ácido bórico) de $0.53 \%$ é suficiente para proteger a madeira da ação do fungo da podridão parda (Williams; Parresol "apud Leão 1997). Takahashi et al. (1989) afirmam que a relação ASE X WL devido à degradação por fungos para formalização e acetilação é a de que $50 \%$ de ASE toma a perda de massa desprezivel quando submetidos à degradação pelo fungo Coriolus versicolor, e para o Tyromyces palustris è necessário $60 \%$ de ASE.

\footnotetext{
"FUSE, G. Mokuzai Gakkaishi, vol 34, p. 709, 1988. Apud TAKAHASHI, M. Wood Preserving Techniques to Prevent Biodeterioration. In: SHIRAISHI, N.; KAJITA, H.; NORIMOTO, M. eds. Recent Research on Wood and Wood-Based Materials. Current Japanese Materials Research, vol. 11, p. 207-22, Elsevier, London, 1993.
}

WILLIAMS, L. H.; PARRESOL, B. R. Borate Diffusion into red Oak Sapwood Lumber: An initial Assesment. Forest Products Journal, vol 41(5), p.45-8, 1991. apud LEÃO, A. L. Fire Retardants in Lignocellulosics Composites. In: LEÃO, A. L. ; CARVALHO, F. X.; FROLLINI, E. eds. Lignocellulosic - Plastics Composites. USP/Unesp, São Paulo, 1997. 


\subsubsection{Degradação por Insetos}

Besouros, térmitas, formigas carpinteiras, brocas ou carunchos constituem os maiores degradadores da madeira. Muitos deles estão associados a fungos. Eles atacam primeiro, promovendo um desbaste da casca, abrindo caminho para o ataque dos fungos.

O cerne é mais resistente aos ataques dos insetos por uma razão filogenética. Ele possui mais extrativos que o alburno. Alguns extrativos foram isolados e caracterizados como tóxicos a alguns insetos, dentre eles estão os fenóis e os taninos.

As formigas carpinteiras não ingerem a madeira. Elas cavam túneis simplesmente para se alojarem. Atacam escavando as partes apodrecidas e depois se estendem a outras regiōes. Isso, porém, causa a perda da resistência da madeira. Com o aumento da colônia, aumenta 0 ataque e, após alguns anos, a peça se toma inutilizada.

Os cupins ou térmitas são insetos da ordem dos isópteros, vivem em colônias, são insetos sociais, lucívagos (vivem na ausência de luz), e atacam a madeira internamente tanto para se alojarem como também a ingerem como alimento. Efetuam a digestão da madeira com auxílio de protozoários que vivem nos seus intestinos.

Podem ser divididos em três grupos:

1) Cupins de solo ou subterrâneo:

Fazem sua residência no solo, construindo galerias até o local onde está a madeira. Mas podem construir caminhos de argila em forma de tubo nos quais as condições de umidade são mantidas e assim atacar estruturas de madeira que não se encontram em contato com o solo. Necessitam de elevado teor de umidade para viver porque seu corpo não possui 
revestimento de quitina e perde água quando exposto ao ar seco. Preferem as regiöes de clima temperado.

2) Cupins de madeira úmida:

Atacam a madeira úmida, no estágio inicial de apodrecimento. Depois deste primeiro ataque podem se estender para peças não atacadas por fungos.

3) Cupins de madeira seca:

Atacam a madeira seca ou com baixo teor de umidade $(6-16 \%)$. Sua necessidade de água é extremamente baixa. Preferem regiões de clima quente, áreas sub-tropicais e tropicais.

Térmitas são capazes de reduzir mecanicamente a barreira de lignina a partículas suficientemente pequenas de modo que os microorganismos presentes em seu intestino sejam capazes de removê-la para degradar os carbohidratos que thes servem de nutrientes. Minato et al. (1992) fizeram determinações de resistência ao ataque de térmitas para madeira tratada com formaldeído, separando soldados de operários. Os operários abastecem os soldados, e se eles não obtém os nutrientes de que necessitam, os soldados tendem a se enfraquecer mais rapidamente. Para operários submetidos ao teste sem nada de que pudessem se alimentar, isto é, estado de inanição, a mortalidade em seis semanas atingiu niveis de $40 \%$, chegando a $80 \%$ em nove semanas. Em alguns tratamentos com formaldeido, o comportamento foi similar aos operários forçados à inanição. 
Yoshimura (1995) investigou o sistema digestivo do Coptotermes formosanus e evidenciou a presença de sistemas de protozoários simbióticos. O principal deles é o Pseudotrichonympha grassi que depolimeriza a maior parte da celulose depois da parcial decomposição pelos térmitas. No caso da madeira submetida a tratamento, os térmitas a ingerem e a transferem a seus intestinos. Porém, se ela for resistente ao seu sistema celulolítico, os térmitas, não sendo capazes de obter nenhum nutriente através da quebra de suas moléculas, acabam por perder sua vitalidade. Outros protozoários presentes na fauna intestinal são Holomastigotoides hartmani e Spirotrichonympha leidyi (Yoshimura 1995; Imamura; Nishimoto 1985).

O mecanismo pode ser descrito em duas fases principais:

- a degradação parcial de fragmentos da madeira ingerida, principalmente de regiōes não cristalinas da celulose, pelas enzimas presentes no intestinos dos térmitas.

- A decomposição final dos fragmentos parcialmente degradados pela fauna intestinal.

Kang et. al. (1994) identificaram o maior componente termicida em extratos de Litsea coreana Leveille (kagonoki, em japonês) como sesquirosefurano.

Broca ou Caruncho é o nome genérico de uma grande quantidade de larvas e insetos adultos da ordem dos coleópteros que atacam a madeira verde e seca.

O equivalente de ácido bórico (BAE) de $0.2 \%$ é suficiente para controlar a ação do besouro em postes elétricos (Williams; Parresol apud Leão 1997). 


\subsubsection{Furadores ou Brocas Marinhas}

Furadores ou Brocas Marinhas são vários moluscos e crustáceos que atacam a madeira em contato com a água do mar, navios, piers e outras estruturas de madeira em água salgada. Os moluscos pertencem geralmente aos gêneros Bankia e Teredo e os crustáceos são geralmente do gênero Limnoria.

Por muito tempo acreditou-se que a resistência à ação dos furadores marinhos apresentada por certas madeiras australianas fosse devido à alta concentração de sílica em seu cerne que deveria constituir uma barreira física aos ataques. Silva e Hillis (1980) porém, encontraram outras espécies em que a concentração de sílica era nula ou muito baixa, e mesmo assim apresentavam resistência à ação dos furadores marinhos. A presença de extrativos orgânicos foi determinada como a principal causa.

O primeiro tratamento utilizado para combater as brocas marinhas consistiu de uma cobertura de cobre.

Os tratamentos mais eficazes conhecidos são: CCA, CCA + creosoto, creosoto + alcatrão de hulha e a adição de tributil óxido de estanho (TBTO) e dieldrin a creosoto (Scheffer 1973). 


\subsection{Combustibilidade da Madeira}

\subsubsection{Degradação Térmica da Madeira}

A degradação térmica da madeira ocorre em duas rotas diferentes, com um ponto de transposição em $\cong 300^{\circ} \mathrm{C}$. A primeira rota ocorre a temperaturas mais baixas e envolve a redução do grau de polimerização, o aparecimento de radicais livres, a eliminação de água, a formação de carbonilas, carboxilas e grupos hidroperóxidos, a evolução de $\mathrm{CO}$ e $\mathrm{CO}_{2}$, e a produção de carvão.

A segunda é a rota dominante e ocorre a temperaturas acima de $300^{\circ} \mathrm{C}$. As reações iniciam-se com depolimerização, seguida de reações de formação de carvão que dominam a produção de cinzas e gases, e fissão e desproporcionação (Shafizadeh"; Levan* apud Leão 1997).

A continuação da pirólise vai liberar compostos carbonílicos, carboxílicos, oleofínicos, água, $\mathrm{CO}$ e $\mathrm{CO}_{2}$. Estas reações são seguidas de desproporcionação, descarboxilação e descarbonilação (Shafizadeh apud Leão 1997).

A degradação térmica da madeira também pode ser classificada pelos regimes de temperaturas em que cada reação predomina.

Nesta classificação a degradação térmica compreende três fases:

1) ponto de chama $\left(225-260^{\circ} \mathrm{C}\right)$ - definido como o ponto onde a decomposição dos gases vai ocorrer na presença de uma fonte de ignição.

\footnotetext{
* SHAFIZADEH, F. The Chemistry of Pyrolysis and Combustion. apud LEÃO, A. L. Fire Retardants in Lignocellulosics Composites. In: LEÃO, A. L. ; CARVALHO, F. X.; FROLLINI, E. eds. Lignocellulosic - Plastics Composites. USP/Unesp, São Paulo, 1997.

* LEVAN, S. L. Thermal Degradation. apud LEÃO, A. L. Fire Retardants in Lignocellulosics Composites. In: LEÃO, A. L. ; CARVALHO, F. X.; FROLLINI, E. eds. Lignocellulosic Plastics Composites. USP/Unesp, São Paulo, 1997.
} 
2) ponto de queima $\left(260-290^{\circ} \mathrm{C}\right)$ - onde as reações ocorrem com uma chama estável.

3) ponto flamejante $\left(330-470^{\circ} \mathrm{C}\right)$ - que ocorre como ignição espontânea, quando a madeira explode em combustão (Schaffer* apud Leão 1997).

Quando a combustão é completa, o balanço estequiométrico da madeira e dos carbohidratos é dado pelas seguintes equações (Tran* apud Leão 1997):

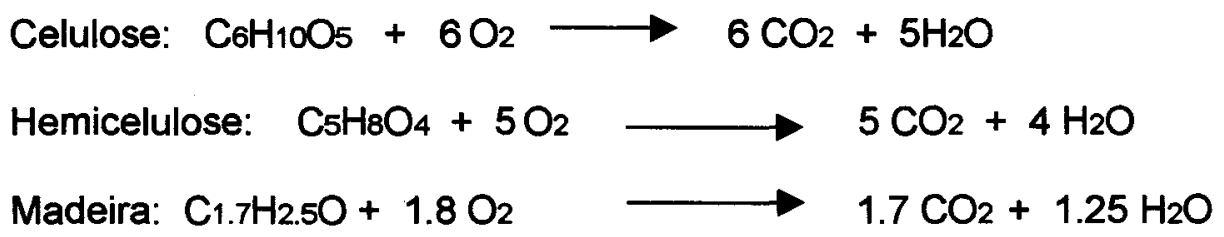

A decomposição térmica da madeira na presença de oxigênio se inicia com a liberação de água $\left(\cong 100^{\circ} \mathrm{C}\right)$. A madeira exposta por longos períodos de tempo a temperaturas acima de $63^{\circ} \mathrm{C}$ pode promover a combustão espontânea (Leão 1997). A auto ignição da madeira ocorre nas temperaturas de 195 a $206^{\circ} \mathrm{C}$ (Tuve* apud Leão

" SCHAFFER,E. L. Effect of Fire Retardant Impregnations on Wood Charring Rate. JFF/Journal of Fire Retardant Chemistry, vol. 1(1), p. 96-109, 1974. apud LEÃO, A. L. Fire Retardants in Lignocellulosics Composites. In: LEÃO, A. L. ; CARVALHO, F. X.; FROLLINI, E. eds. Lignocellulosic - Plastics Composites. USP/Unesp, São Paulo, 1997.

- TRAN, H. C. Rate of Heat and Smoke Release of Wood in na Ohio State University Calorimeter. Fire and Materials, vol. 12, p. 143-151, 1988. apud LEÃO, A. L. Fire Retardants in Lignocellulosics Composites. In: LEÄO, A. L. ; CARVALHO, F. X.; FROLLINI, E. eds. Lignocellulosic - Plastics Composites. USP/Unesp, São Paulo, 1997.

" TUVE, R. L. Principles of Fire Protection Chemistry. National Fire Protecion Association. 1976. apud LEÃO, A. L. Fire Retardants in Lignocellulosics Composites. In: LEÃO, A. L. ; CARVALHO, F. X.; FROLLINI, E. eds. Lignocellulosic - Plastics Composites. USP/Unesp, São Paulo, 1997. 
1997). A degradação da lignina começa a $160^{\circ} \mathrm{C}$, da hemicelulose a $180^{\circ} \mathrm{C}$, e da celulose a $280^{\circ} \mathrm{C}$ (Hurst; Jones* apud Leão 1997).

Embora a degradação da lignina comece primeiro, seus produtos de decomposição são os últimos remanescentes na forma de carvão. A maioria do carbono fixado no carvão é proveniente da lignina. Sua degradação produz fenóis da clivagem de ligações C-C e ligações éter, resultando em maior quantidade de carvão que a celulose. A desidratação a $200^{\circ} \mathrm{C}$ é a primeira reação de degradação. A clivagem das ligações aril-alquil-éter ocorre entre 150 e $300^{\circ} \mathrm{C}$. A $300^{\circ} \mathrm{C}$, as cadeias laterais alifáticas dos anéis aromáticos começam a se dividir. A clivagem das ligações C-C ocorre entre 370 e $400^{\circ} \mathrm{C}$ (Levan apud Leão 1997). A temperatura de ignição para gimnospermas no estado seco varia de $350-365^{\circ} \mathrm{C}$. Para as angiospermas varia de $300-310^{\circ} \mathrm{C}$. Esta diferença é atribuída ao maior conteúdo de lignina nas gimnospermas (Janssens* apud Leão 1997).

Goldstein (1961) afirma que na pirólise são evolvidos gases inflamáveis como o CO, metano, formaldeído, etanol, ácido fórmico e ácido acético. Também estão incluídos carvões altamente inflamáveis contendo furfural e levoglucosana (1,6 anidrobeta-D-glucopiranose), produtos da decomposição da celulose, e fragmentos de anéis aromáticos tais como fenóis, xilenóis, guaiacóis, cresóis e catecóis, produtos da decomposição da lignina. A carbonização se torna completa entre 400 e $500^{\circ} \mathrm{C}$, e

\footnotetext{
" HURST, N. W.; JONES, T. A. A Review of Products Evolved from Heat Coal, Wood and PVC. Fire and Materials. Vol. 9 (1), p. 1-9, 1985. apud LEÄO, A. L. Fire Retardants in Lignocellulosics Composites. In: LEÄO, A. L. ; CARVALHO, F. X.; FROLLINI, E. eds. Lignocellulosic - Plastics Composites. USP/Unesp, São Paulo, 1997.

* JANSSENS, M. Rate of Heat Release of Wood Products. Fire Safety Journal, vol. 17(3), p. 217-38, 1991. apud LEÃO, A. L. Fire Retardants in Lignocellulosics Composites. In: LEÃO, A. L. ; CARVALHO, F. X.; FROLLINI, E. eds. Lignocellulosic - Plastics Composites. USP/Unesp, São Paulo, 1997.
} 
desenvolve-se a estrutura cristalina do grafite. A lignina pirolisa a temperaturas mais elevadas e a hemicelulose a temperaturas mais baixas (Su et al.1997).

A celulose é responsável principalmente pela formação de voláteis inflamáveis. As hemiceluloses são menos estáveis que a celulose, e libera maior quantidade de gases não inflamáveis e menor quantidade de piche (Shafizadeh apud Leão 1997). A maioria do ácido acético formado na pirólise da madeira é devido à reação de acetilação da hemicelulose. As hemiceluloses de angiospermas são menos estáveis devido à alta concentração de xilanas, que são menos estáveis ao fogo. As pentoses são menos estáveis que as hexoses para reações de hidrólise e desidratação (Levan apud Leão 1997).

A perda de resistência nos primeiros estágios da degradação térmica é provavelmente causada pela decomposição das hemiceluloses (Shafizadeh apud Leão 1997).

\subsubsection{Definição de alguns Termos Importantes no Estudo de Materiais Resistentes ou Retardantes de Fogo}

Algumas definições são importantes para o estudo de substâncias que têm a propriedade de resistir ao fogo ou retardar sua ação.

- combustão: um meio de queimar; processo de unir quimicamente com excesso de oxigênio, produzindo luz e calor.

- pirólise: é a decomposição de materiais sob a ação do calor. 
- incandescência ("glowing"): a combustão direta de combustiveis sólidos com quantidade de oxigênio restrito. Neste caso, o material sólido toma-se incandescente como resultado do calor envolvido.

-chama ("flaming"): é a combustão na fase gasosa, com a geração de chama. Isto ocorre quando o material sob combustão é um gás.

- brasa sem chama ("smoldering"): é o processo onde as reações de decomposição térmica da combustão são mantidas a nivel muito baixo; as reações podem ser iniciadas a qualquer ponto como ondas de propagação. Geralmente ocorre sem chamas, e algumas vezes sem incandescência ou mesmo sem a liberação de fumaça. Ex. cigarro queimando.

- materiais à prova de fogo: são substâncias que, mesmo sob longa exposição ao fogo ou ao calor, não são queimados (amianto, por exemplo).

- materiais retardantes ao fogo: são substâncias que podem retardar o fogo a um limite de tempo, ou reduzir as calorias emitidas pela fonte de calor.

Coberturas superficiais de agentes resistentes ao fogo provaram fornecer melhor proteção que as coberturas superficiais de agentes retardantes de fogo (Leão 1997).

\subsubsection{Agentes Retardantes de Fogo}

Agentes que retardam a ação do fogo são adicionados à madeira através de sais impregnantes para aumentar a formação de carvão a baixas temperaturas e diminuir a formação de piche e gases voláteis (Kollmann et al. 1975).

Agentes retardantes de fogo são divididos em dois grupos: 
1) Aditivos: são aqueles que interagem com o substrato somente por processos físicos. Exemplos: fosfatos, compostos de amônio, alumina hidratada, amino resinas, cloreto de zinco, compostos de boro, e outros.

2) Reativos: são aqueles que reagem quimicamente com a estrutura polimérica básica. Exemplos: anidrido tetraftálico, polióis halogenados, polióis fósforohalogenados, bisfenóis halogenados, ácidos clorêndicos, e outros.

\subsubsection{Mecanismo de Ação dos Retardantes de Fogo}

Os retardantes de fogo são adicionados à madeira pelas impregnações de sais inorgânicos para aumentar a formação de carvão e diminuir a formação de piche e gases voláteis (Kollmann et al. 1975). O mecanismo geral, segundo Eickner* (apud Leão 1997), é o seguinte:

1) cria-se uma camada líquida ou vítrea, formando uma barreira que impede a troca de ar e produtos inflamáveis na zona de combustão;

2) forma-se coberturas ou espumas que isolam a superfície e retarda a pirólise pela interceptação do ar;

3) aumenta-se a condutividade térmica permitindo a dissipação de calor mais rápida do que é fornecido pela fonte de ignição;

4) criam-se modificações químicas e físicas que absorvem calor;

\footnotetext{
EICKNER, H. W. Wood and Wood Products. In: Fire Safety Aspects of Polymeric Materials. Vol 1, Materials: State of the Art. Nat. Mat. Adv. Board. Publ. NMAB 318-1. National Academy of Science, 1977. apud LEÃO, A. L. Fire Retardants in Lignocellulosics Composites. In: LEÃO, A. L. ; CARVALHO, F. X.; FROLLINI, E. eds. Lignocellulosic Plastics Composites. USP/Unesp, São Paulo, 1997.
} 
5) formam-se gases não flamáveis que diluem os gases inflamáveis, formando-se menos misturas gasosas inflamáveis, reduzindo a matéria combustível;

6) modifica-se o mecanismo da pirólise para liberar radicais livres que quebram a cadeia de combustão;

7) abaixa-se a temperatura para a pirólise e promove-se maior formação de carvão, o que reduz a formação de produtos inflamáveis como o piche e os gases.

Para a redução da propagação da chama, o nivel de retenção de reagentes é importante. Placas tratadas com ácido bórico não são fortemente influenciadas pelo nível de retenção como nos tratamentos com boratos ou fosfatos de amônio.

Nos estágios iniciais da combustão, os primeiros 15 minutos são quase que completamente dominados pelas chamas, com relativamente pouca queima sem chama. Geralmente os retardantes de queima sem chama são efetivos porque inibem a oxidação $\mathrm{CO}$ a CO2 (Leão 1997).

As resinas de Álcool Furfurílico são largamente empregadas como retardantes de fogo [(Bozer; Brown 1972) (Bozer et al. 1977) (Londrigan et al. 1977)].

O anel pseudo aromático carboniza quando exposto ao fogo ou a altas temperaturas, formando uma densa carbonização. Quando é forçada a queimar pela introdução de fonte externa de ignição, pequena quantidade de fumaça é evolvida. Esta propriedade está relacionada com a grande quantidade de carbono da resina, e ao baixo peso molecular dos produtos voláteis evolvidos na pirólise. A grande quantidade de carbono da resina, durante a decomposição térmica, produz grande quantidade de produtos carbonáceos na superfície do compósito, isolando o esqueleto 
da resina da superfície inflamante, interferindo na difusão do oxigênio no substrato inflamado. Desta maneira, a temperatura fica reduzida, a taxa da pirólise também se reduz, e a combustão fica limitada às reações gasosas com produtos voláteis de baixo peso molecular. A combustão é limpa e produz pouca fumaça (Leitheiser et al. 1978).

Os compostos de boro são caracterizados por seu baixo custo, baixa toxicidade, mínima pressão de vapor e por não apresentar efeitos deletérios à madeira. São empregados como retardantes de fogo não apenas para materiais celulósicos como também para lignocelulósicos. São efetivos em suprimir a queima sem chama (mas incandescente). As amostras tratadas com ácido bórico ou ácido tetrafluorobórico, ou, ainda, com sais de borato de amônio, não causam a supressão da ignição ou da chama flamejante (Su et al.1997).

O ácido bórico é considerado um bom agente retardante de fogo. Sua adição faz a madeira requerer maior quantidade de $O_{2}$ para a ignição (Yalinkilic 1997). Funciona como inibidor de propagação de chama e da queima sem chama. Com a mesma quantidade de $\mathrm{O}_{2}$, a madeira tratada queima por tempo bem menor que a madeira sem tratamento. A causa é atribuida às ligações do tipo B-O, B-N, B-C, serem mais estáveis e, por isso requerem maior quantidade de energia para se dissociarem (Yalinkilic 1997). A tabela 2 fornece a energia de dissociação de algumas ligações comuns.

Ligações do tipo $\mathrm{B}-\mathrm{O}, \mathrm{Al}-\mathrm{O}$ e $\mathrm{P}-\mathrm{N}$ têm excelente estabilidade térmica, porém, hidrolisam rapidamente quando aquecidos ao ar.

Polímeros que contém $\mathrm{Fe}$ ou $\mathrm{Ti}$ são geralmente pirofóricos, isto é, contêm seus próprios catalisadores de oxidação (na cadeia). 
Tabela 2 Energia de dissociação de algumas ligações químicas (Gerrard 1961).

\begin{tabular}{|c|c|}
\hline Ligação & Energia (Kcal/mol) \\
\hline C-C & 83 \\
\hline S-S & 51 \\
\hline O-O & 33 \\
\hline Si-Si & 42 \\
\hline P-P & 51 \\
\hline As-As & 32 \\
\hline B-O & 130 \\
\hline Si-O & 89 \\
\hline P-O & 84 \\
\hline B-N & 100 \\
\hline P-N & 50 \\
\hline P-C & 62 \\
\hline
\end{tabular}

O bórax também é considerado eficiente como retardante de fogo tanto usado separado ou em conjunto com ácido bórico.

A combinação de fosfato de amônio e bórax toma materiais celulósicos à prova de fogo. Outros sais de boro são igualmente eficazes quando usados em combinação com o ácido bórico. Um dos mais conhecidos é o acido bórico-octoborato de dissódio (BADO), que não promove redução na resistência mecânica do material. $A$ combinação de ácido sulfúrico, um composto de boro e sulfato de amônio promove a resistência ao fogo similar ao tratamento com ácido bórico para materiais celulósicos. Porém, um dos aspectos negativos das madeiras tratadas com compostos de boro é o efeito de continuar a queima sem chama e sem incandescência ("after glow") (Draganov* apud Leão 1997). Os fosfatos e sulfatos de amônio são retardantes de chama.

A eterificação e a esterificação resultam em aumento da estabilidade termal.

\footnotetext{
"DRAGANOV, S. M. Fire Retardant Composition and Method of Rendering Cellulosic Materials Fire-Retardant. U. S. Patent Office, 4,132,635. 1979. apud LEÃO, A. L. Fire Retardants in Lignocellulosics Composites. In: LEÃO, A. L. ; CARVALHO, F. X.; FROLLINI, E. eds. Lignocellulosic - Plastics Composites. USP/Unesp, São Paulo, 1997.
} 
Soluções aquosas de sais $\left(\mathrm{BaCl}_{2} \mathrm{e}\right.$, em seguida, $\left.\left(\mathrm{NH}_{4}\right)_{2} \mathrm{HPO}_{4}\right)$ são utilizadas para mergulhar a madeira. Após a secagem, eles se depositam nas paredes celulares. Este tratamento é empregado com a finalidade de conferir propriedades anti-chama à madeira.

Compostos de amônio são compativeis com bórax ou ácido bórico e conferem maior penetrabilidade dos agentes retardantes de fogo (Scheffer; Vankleeck apud Leão 1997).

Agentes extintores de fogo são baseados em sua maioria em compostos de brometo, cloreto e fluoreto, tais como: $\mathrm{CF}_{3} \mathrm{Br}, \mathrm{CH}_{2} \mathrm{BrCl}, \mathrm{CF}_{2} \mathrm{BrCl}, \mathrm{CF}_{2} \mathrm{Br}$, $\mathrm{CF}_{2} \mathrm{BR}$ $\mathrm{CF}_{2} \mathrm{Br}$, embora sejam muito tóxicos (Leão 1997).

Em 1990, Levan; Winandy* apud Leão 1997 efetuaram estudos que indicam que a combinação de agentes retardantes de fogo com condições ambientais desfavoráveis como altas temperaturas e altos níveis de conteúdo de umidade da madeira, causam a diminuição da resistência mecânica da madeira.

\subsubsection{Testes de Resistência ao Fogo}

Existem duas categorias de testes:

* SCHEFFER, C. A.; VANKLEECK, A. The Decay Resistance of Wood Impregnated with FireRetarding Ammonium Salts. In: American Wood Preservers Association Annual Meeting, 1945. apud LEÃO, A. L. Fire Retardants in Lignocellulosics Composites. In: LEÃO, A. L. ; CARVALHO, F. X.; FROLLINI, E. eds. Lignocellulosic-Plastics Composites. USP/Unesp, São Paulo, 1997.

" LEVAN,S. L.; WINANDY, J. E. Effects of Fire Retardant Treatments on Wood Strength. A Review. Wood and Fiber Science. Vol. 22(1), p. 113-131, 1990. apud LEÃO, A. L. Fire Retardants in Lignocellulosics Composites. In: LEÃO, A. L. ; CARVALHO, F. X.; FROLLINI, E. eds. Lignocellulosic - Plastics Composites. USP/Unesp, São Paulo, 1997. 
- reação ao fogo (inflamabilidade) - definido pelo modo como o material ou agente reage sob aquecimento ou fogo. Este grupo inclui os testes de ignitabilidade, propagação da chama, taxa de liberação de calor (HRR), e produtos de combustão, tais como fumaça com fumos tóxicos, e, geralmente é aplicado a substâncias tóxicas;

- resistência ou tolerância ao fogo - está relacionado principalmente à prevenção da propagação da chama num determinado limite espacial (sala) e/ou como um material submetido à carga se comporta numa situação de incêndio.

\subsubsection{Toxicidade de Alguns Gases Despreendidos na Combustão}

A maioria das mortes causadas por acidentes com fogo é devida à asfixiação, principalmente por monóxido de carbono e cianeto de hidrogênio.

A concentração de oxigênio abaixo de $17 \%$ causa asfixiação, descoordenação muscular e perda da habilidade de pensar. Abaixo de $6 \%$ causa a morte. A baixas temperaturas, a morte ocorre no intervalo de 6 a 8 minutos, mostrando que para materiais retardantes de fogo, uns poucos minutos pode ser crucial (Gallagher apud Leão 1997).

89\% das mortes causadas por fogo são devidas à inalação de gases tóxicos, principalmente $\mathrm{CO}, \mathrm{CO}_{2}$, aldeídos, óxidos de nitrogênio, cianeto de hidrogênio, dióxido de enxofre, amônia, ácido acético, formaldeído, acetona, furfural, fenóis, cresóis,

" GALLAGHER, E. L. Residential Fire Safety Prevention, Detection, Survival and Escape. Fire Equipment Manufacturers Association, Inc. Arlington, VA, 113p., 1977. apud LEÃO, A. L. Fire Retardants in Lignocellulosics Composites. In: LEÃO, A. L. ; CARVALHO, F. X.; FROLLINI, E. eds. Lignocellulosic - Plastics Composites. USP/Unesp, São Paulo, 1997. 
alcanos, alcenos e hidrocarbonetos aromáticos. $11 \%$ são devidas a queimaduras (Gallagher; Hurst; Jones apud Leão 1997).

O perigo potencial do CO comparado a outros gases é que a hemoglobina tem mais afinidade por ele que por oxigênio, resultando em menor disponibilidade de hemoglobina $(\mathrm{Hb})$ para o transporte de oxigênio.

$$
\mathrm{CO}+\mathrm{HbO}_{2} \longrightarrow \mathrm{COHb}+\mathrm{O}_{2}
$$

Onde:

$\mathrm{HbO}_{2}$ é a oxihemoglobina e $\mathrm{COHb}$ é a carboxihemoglobina.

Madeiras tratadas com agentes retardantes de fogo à base de sais ou ácidos liberam água, piruvaldeído, ácido acético, furfural e um derivado furanoso. Enquanto que a madeira sem tratamento libera, no mínimo, 59 compostos (podendo chegar a 300) (Levan apud Leão 1997). 


\subsection{Degradação por Raios Ultra-violetas}

\subsubsection{Degradação dos Componentes Estruturais da Madeira}

A madeira é um material biológico que é decomposta pelos microorganismos e reage quimicamente quando em contato com metais, ácidos e álcalis. Por possuir estrutura porosa, substâncias solúveis ou sais podem ser depositados em seu lúmem durante o curso de seu crescimento ou depois de cortado. Estes depósitos podem mudar sua cor (Hon; Minemura 1991). Quando exposta às condições climáticas sofre degradação pelos raios ultravioleta. Isso é devido primariamente às variações que ocorrem na lignina, tanto em concentração como em composição (Kainis*; Feist; Hon * apud Evans; Thay; Schmazlz 1996). É ela a principal responsável pelas variações de cor que ocorrem na madeira. O processo de delignificação é extremamente rápido. Exposições às intempéries de curto tempo podem causar substancial delignificação superficial em coníferas (Evans et al. 1996). Como a lignina age como um antioxidante e adesivo, unindo as fibras de celulose, quando suas unidades sofrem variações, toda a superfície da madeira sofre degradação. A lignina pode sofrer demetilação, oxidação

"KALNIS, M. A. Surface Characteristics of Wood as They Affect the Durability of Finishes. Part II. Photochemical Degradation of Wood. USDA, Report 57, p. 23-60, Forest Products Laboratory, Madison, WI, 1966. apud EVANS, P. D.: THAY, P. D.; SCHMALZL, K. L. Degradation of Wood Surfaces During Natural Weathering. Effects on Lignin and Cellulose and on the Adhesion of Acrylic Latex Primers. Wood science and Technology, vol. 30, p. 411-22, 1996.

"FEIST, W. C.; HON, D. - S Chemistry of Weathering and Protection. In: ROWELL, R. M. ed. The Chemistry of Solid Wood. Advance in Chemistry Series, 207, p. 401-51, American Chemical Society, Washington, DC, 1984. apud EVANS, P. D.: THAY, P. D.; SCHMALZL, K. L. Degradation of Wood Surfaces During Natural Weathering. Effects on Lignin and Cellulose and on the Adhesion of Acrylic Latex Primers. Wood science and Technology, vol. 30, p. 411-22, 1996. 
e depolimerização, gerando produtos ácidos na superfície da madeira (Rowell et al. 1981).

A superfície da madeira é caracterizada pela suavidade ao toque e por um certo grau de maciez, e sua serviceabilidade é dependente da resistência à abrasão.

A celulose é menos susceptivel à degradação por raios UV que a lignina. A água lixivia a superfície da madeira durante a chuva e expõe novas unidades de lignina, causando significativa perda de material superficial durante a exposição. Os carbohidratos sofrem depolimerização, desidrogenação, dehidroximetilação e oxidação, com aumento de conteúdo de ácido urônico (Rowell et al. 1981). A resistência mecânica da madeira está relacionada com as propriedades da celulose e a diminuição da resistência está relacionada com a redução da viscosidade da holocelulose e do grau de polimerização médio (Evans; Schmalzl 1989).

Outros fatores que influenciam a degradação superficial são o congelamento e descongelamento da água adsorvida, abrasão ou ações mecânicas, tais como o vento, areia e sujeiras. Pequenas partículas como a areia podem se alojar nas trincas da superfície e, através de processos de inchamento e retração, enfraquecer as fibras em contato com elas (Rowell et al. 1981).

\subsubsection{Cor da Madeira}

A luz visível, que produz a sensação visual para os olhos humanos está compreendida entre 380 e 789 nm; a luz UV está abaixo ( $\cong$ entre 250 e $400 \mathrm{~nm}$ ) e a infravermelha (IR) está acima, como pode ser visto no espectro eletromagnético. 
Comprimento de Onda $\lambda(\mathrm{m})$

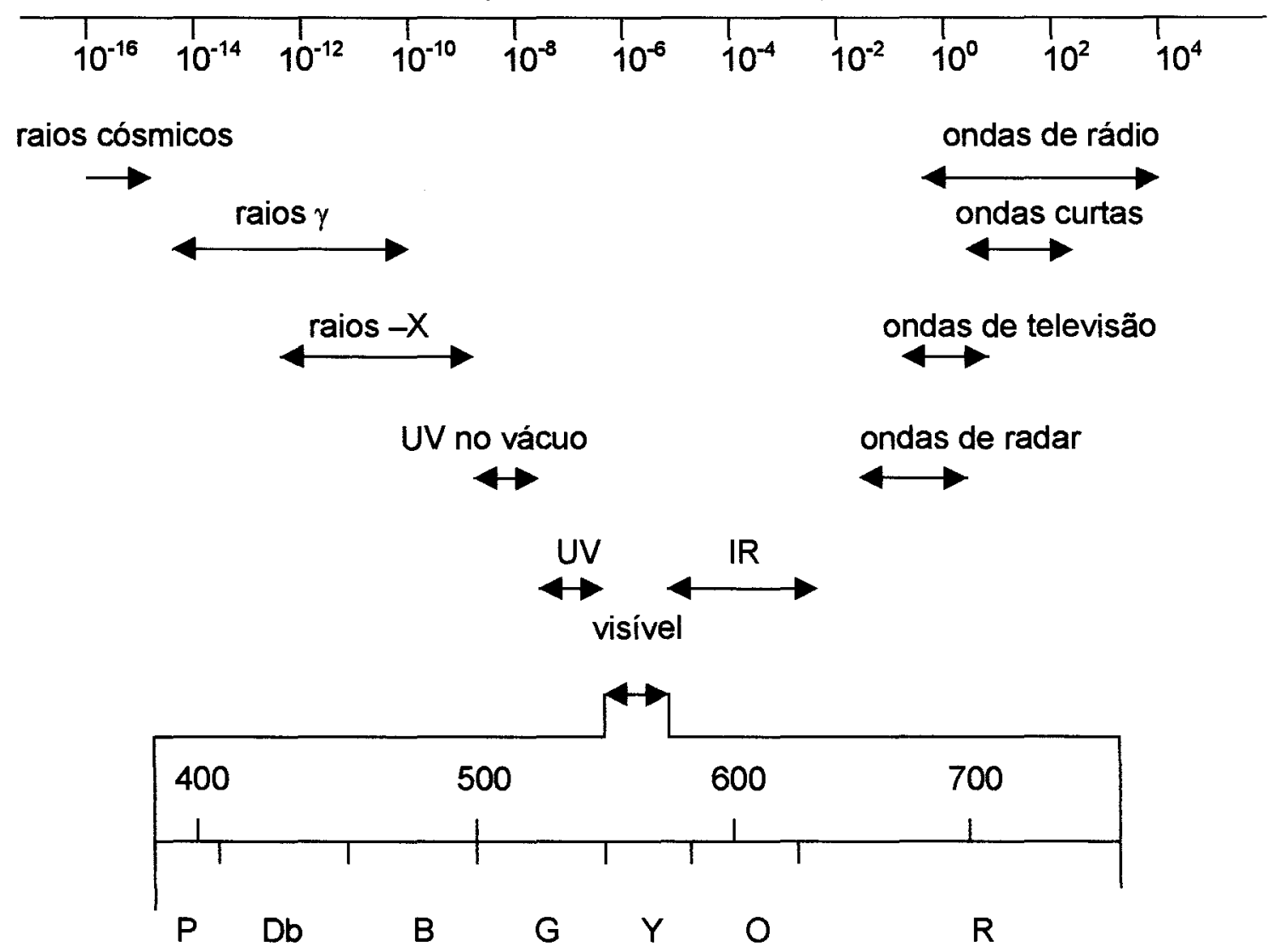

Figura 24- Uma parte do espectro eletromagnético mostrando a relação da região visivel com outros tipos de radiação. $P=$ violeta $\quad D b=a z u l$ escuro $B=a z u l \quad G=v e r d e \quad Y=a m a r e l o$ O=alaranjado R=vermelho (Hon; Minemura 1991).

A curva de reflexão na região visivel é o meio mais acurado de representar a cor do material. A representação numérica é útil nestes casos. A representação numérica é baseada na comparação da espécie colorida com uma escala padrão de cor, e então é classificada e numerada. Um outro meio é baseado na qualidade tricromática, que significa que qualquer cor pode ser obtida da mistura de outras três cores. É usado um sistema de especificação da cor para determinar a qualidade tricromática. 
A madeira absorve luz visível. Consequentemente, podemos ver as cores da madeira como sendo vermelho, marrom, amarelo, etc. Sua superfície não é uniforme. Suas várias células possuem volumes diferentes e isto causa delicadas diferenças de cor (Hon; Minemura 1991)

Celulose e hemicelulose não absorvem luz visível. As ligninas absorvem comprimentos de onda abaixo de $500 \mathrm{~nm}$. Muitas madeiras podem absorver além deste comprimento de onda devido à presença de substâncias fenólicas tais como taninos, flavonóides, estilbeno, lignan e quinona. Nas coníferas, a cor da lignina pode ser atribuída à benzoquinona fenil substituída e copolímeros desidrogenativos de coniferil aldeído (Pew; Conners 1971). Um grupo de átomos tendo um elétron T tal como uma ligação insaturada $(\mathrm{C}=\mathrm{C}, \mathrm{C}=\mathrm{O}, \mathrm{C}=\mathrm{NH},-\mathrm{N}=\mathrm{N}-$ ) é chamada de cromóforo. Esses elétrons podem alcançar facilmente um estado excitado. Moléculas contendo muitos agrupamentos insaturados conjugados apresentam os orbitais moleculares sobrepostos sobre estes grupos. O alto nivel de delocalização dos elétrons produz a diminuição da energia requerida para as transições eletrônicas. Os grupos hidroxilas, $\mathrm{COOH}$ e -OR são auxocromos, o que significa que assistem a ação dos cromóforos intensificando a coloração ou capacitando a absorção de luz de comprimentos de onda maiores (Hon; Minemura 1991). O bloqueamento de hidroxilas fenólicas por metilação, acetilação ou benzilação confere estabilidade de cor aos materiais lignocelulósicos. As modificações químicas da parede celular da madeira além de conferir resistência ao intemperismo, também reduzem a higroscopicidade dos componentes carbohidratos, diminuindo os ciclos de inchamento/retração. Melhorando a estabilidade dimensional, a madeira adquire maior estabilidade de suas fibras superficiais e, consequentemente, maior resistência ao trincamento (Rowell et al. 1981). 
Toda madeira muda de cor com radiação ultravioleta. Muitas coniferas escurecem com a irradiação de luz. O curso (se a cor se torna mais saturada ou se ocorre a descoloração) e a taxa da variação da cor, porém, variam com a espécie. Grandes mudanças de cor significam maior descoloração. Uma intensiva descoloração é atribuída aos extrativos contidos no cerne (Hon; Minemura 1991).

Abe et al. (1994) mediram a variação de cor do cerne do sugi após algumas horas depois da árvore ser derrubada, encontrando variações de:

$$
\begin{array}{lll}
L^{*}=50,59 & \text { a } & L^{*}=34,36 \\
a^{*}=18,43 & \text { a } & a^{*}=2,81 \\
b^{*}=25,15 & \text { a } & b^{*}=5,07
\end{array}
$$

(os significados de $L^{*}, a^{\star}$ e $b^{\star}$ são discutidos na página 145).

As cores variaram de marrom avermelhado para preto. As causas por eles apontadas foram extrativos presentes no cerne do sugi que reagem com o oxigênio atmosférico em condições fracamente alcalinas. Também afirmam que amônia e quaisquer enzimas não têm participação na variação da cor.

Testes de exposição às condições climáticas podem ser naturais ou artificiais.

A exposição natural é conduzida com as amostras expostas naturalmente às variações climáticas, num ângulo de $45^{\circ}$, num período de 23 a 24 semanas.

A exposição artificial simula as variações climáticas, utilizando a irradiação de luz artificial e aspersão de água.

Hon e Minemura (1991) realizaram teste de aceleração de intemperismo, com luz de arco de carbono, durante 100 horas. Para o sugi foram encontrados os resultados: $\Delta E=4,8$ e $a=9,0 \%$. Yusuf (1996) submeteu LVLs ("Laminated Veneer Lumber") tratados com glioxal, glutaraldeído e DMDHEU, à exposição natural e à luz de arco de carbono, por 720 horas. Enquanto que na exposição natural observou-se 
variação brusca da cor das amostras nas primeiras dez semanas, os resultados obtidos na exposição artificial foram mais constantes, mostrando um incremento em $\Delta E$ com alguma constância até $\mathbf{4 8 0}$ horas de teste período.

Rowell, Feist e Ellis (1981) realizaram testes acelerados com 90 ciclos de 20 horas de irradiação de luz, e 360 horas de aspersão de água destilada. O tempo de exposição foi expresso como horas de exposição à luz. Verificaram que a combinação de óxido de butileno ou metil isocianato (modificam a parede celular) com metil metacrilato (preenche o lúmem) conferiu a estabilização da lignina, e adicional estabilidade dimensional.

Acabamentos transparentes tais como vernizes podem proteger contra umidade, mas não contra a degradação por raios UV. Os tratamentos superficiais com $\mathrm{Cr}^{6+}$ mostraram-se eficientes contra degradação superficial e conferem repelência à água (Rowell et al. 1981).

Para restaurar a cor da madeira descolorada, um dos métodos empregados é a decomposição das estruturas cromofóricas do sistema com alvejantes tais como peróxido de hidrogênio ou clorato de sódio. Peroxoboratos também apresentam esta propriedade. Eles absorvem luz UV e emitem luz visivel (Lee 1996). Outro método é o lixamento da superfície. Tratamentos superficiais assim como o emprego de tintas e pigmentos são eficazes porque a descoloração geralmente é limitada à camada superficial (Hon; Minemura 1991). 


\subsection{Furfural e Álcool Furfurilico}

\subsubsection{Fontes de Furfural}

O álcool furfurílico (FFA) é preparado a partir de fontes sacarídicas renováveis como palha e sabugo de milho, casca de aveia, palha de arroz, caroço de algodão, bagaço de cana-de-açúcar, casca e grão tostado de café, resíduos de madeira, etc.

Os polissacarídeos da madeira são hidrolisados por ácidos ou enzimas a açúcares com rendimento de $50-55 \%$ do seu conteúdo na madeira seca, dependendo da espécie da madeira. As hemiceluloses são convertidas quase que completamente, enquanto que grandes quantidades de celulose permanecem na solução sem serem hidrolisadas.

A digestão dos resíduos agrícolas, bem como dos rejeitos da indústria madeireira, com ácido forte, a elevadas temperaturas, converte as pentoses em furfural (2-furfuraldeído ou 2-furancarboxialdeído). Esta hidrólise ocorre em duas etapas com xilose como produto intermediário, ou em apenas uma etapa (fig. 25). E converte as hexoses a hidroximetilfurfural produzindo ainda outros subprodutos como ácido fórmico e ácido levulínico.

O furfural é usado como solvente industrial e como matéria-prima para a produção de inúmeros outros reagentes derivados e polímeros. 

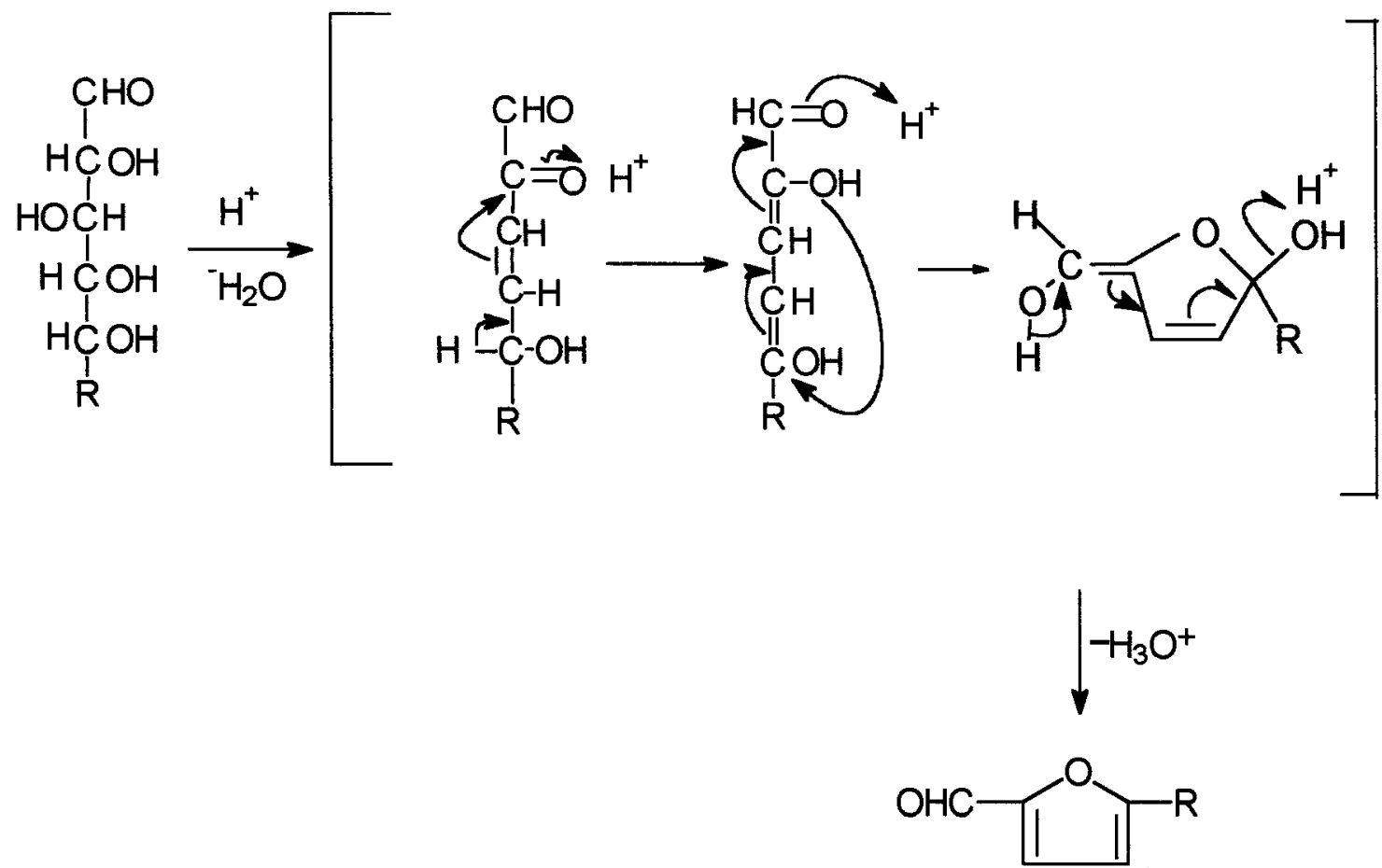

Figura 25- Conversão de pentoses $(R=H)$ a furfural, e de hexoses $\left(R=\mathrm{CH}_{2} \mathrm{OH}\right)$ a hidroximetilfurfural (Käärik 1978).

Em condições mais drásticas, hexoses e pentoses, por hidrogenólise, resultam em glicerol, etileno glicol e outros glicóis. A figura 26 ilustra os produtos da hidrólise das hexoses e pentoses.

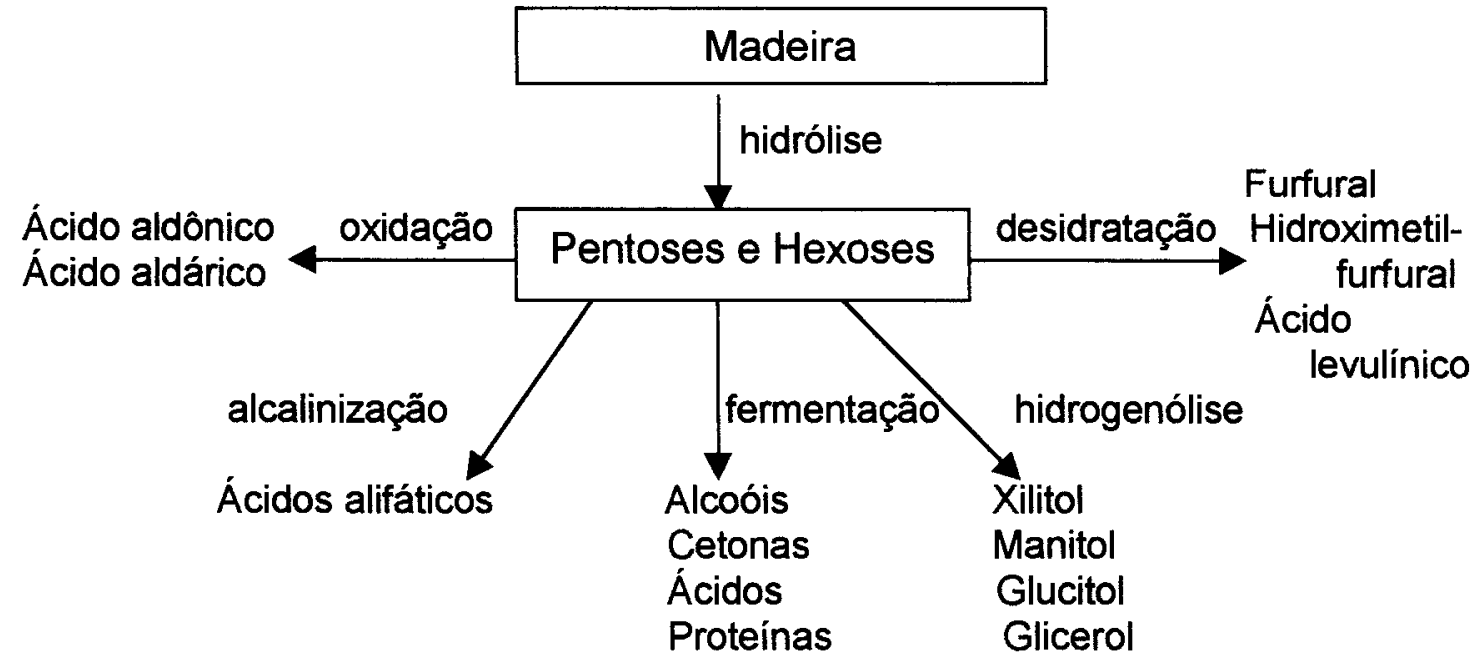

Figura 26- Exemplos de produtos obtidos da fração de açúcares da hidrólise da madeira (Sjöström 1981). 
Após a hidrólise, a madeira maciça resultante é composta principalmente de lignina (Sjöström 1981).

As resinas de furfural apresentam aplicações limitadas como pós de absorção. Porém, quando furfural polimeriza com uma cetona em meio alcalino, dois produtos são majoritariamente obtidos: o 2-furfurilideno metil cetona e seu homólogo difurânico. Estes polímeros, resultantes de uma dupla condensação, são usados para a obtenção, via catálise ácida, de resinas negras insolúveis.

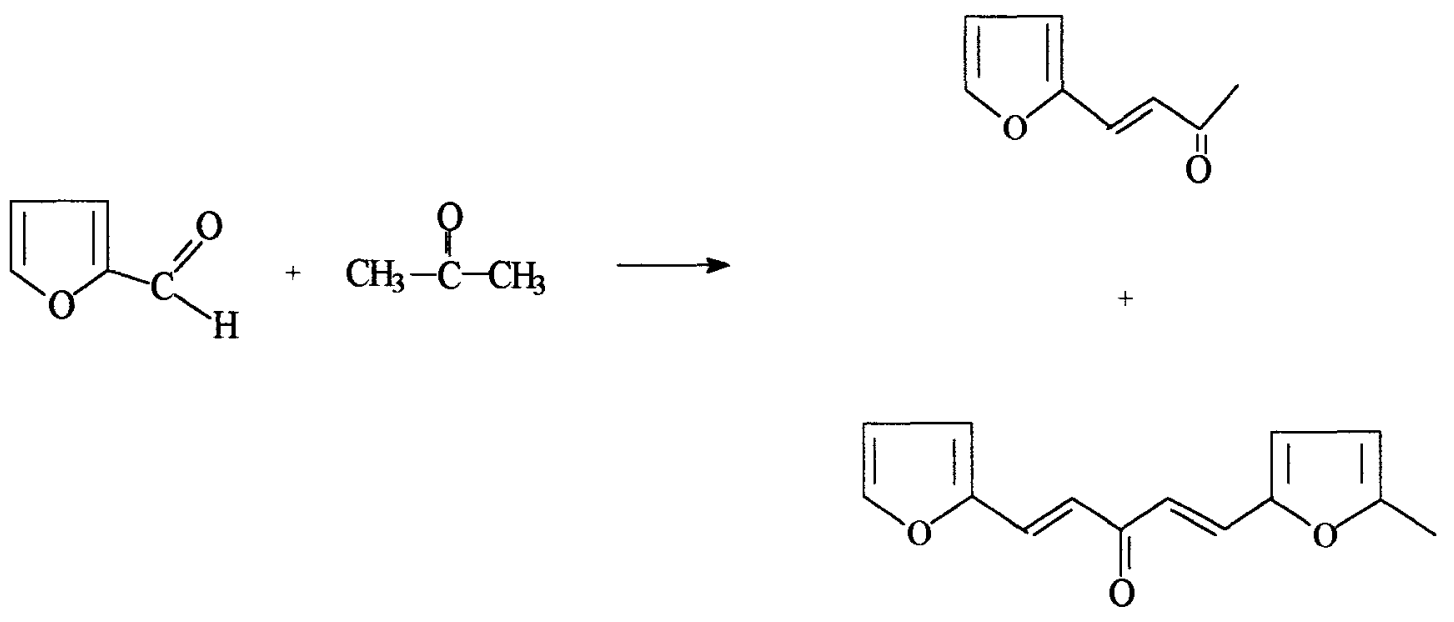

Figura 27- Polimerização do furfural com propanona.

Estas resinas têm aplicações como adesivos e revestimentos resistentes à corrosão.

Os principais mecanismos nestas reações envolvem as insaturações nos dois compostos externos aos anéis furânicos. Mas, reações de condensação envolvendo grupos carbonila e substituição eletrofilica ao $C_{5}$ também ocorrem, embora em menor extensão. Uma provável estrutura desses polímeros é a seguinte: 


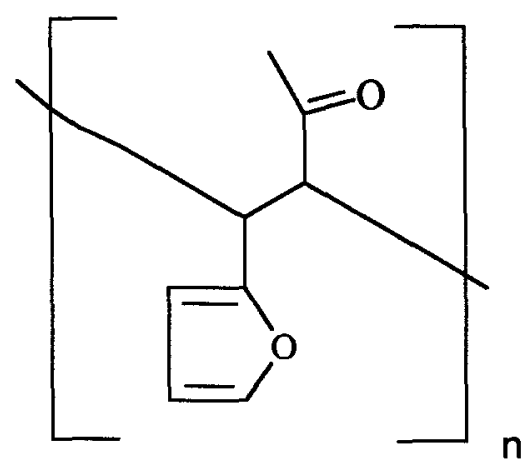

Figura 28- Provável estrutura de um polímero furânico não linear.

O hidroximetilfurfural é preparado a partir das hexoses, em tratamento térmico por curto tempo, catalisada por ácido. É utilizada extração por solvente para separá-lo do ácido levulínico. Este, por sua vez, é separado do ácido fórmico por aquecimento com ácidos. O ácido fórmico é liberado e o ácido levulínico forma $\alpha$ e $\beta$-angélica lactonas.

Furfural e 5-hidroximetil 2-furancarboxialdeído pertencem à primeira geração de compostos furânicos, exaustivamente estudados antes da primeira guerra mundial como uma fonte alternativa de monômeros preparados a partir de rejeitos agrícolas, quando se acreditava num risco de escassez de petróleo.

Embora tanto no caso do furfural como do 5-hidroximetil 2-furancarboxialdeído evidências sugerem uma série de reações de condensação como descrito na fig. 28 , também é possivel que sejam formados estruturas com hidrogênio terciário tornandose particularmente móveis. Estes, por sua vez, podem abandonar estes oligômeros ramificados e gerar radicais que são fortemente estabilizados pela extensão da conjugação, como é mostrado na figura 29. 

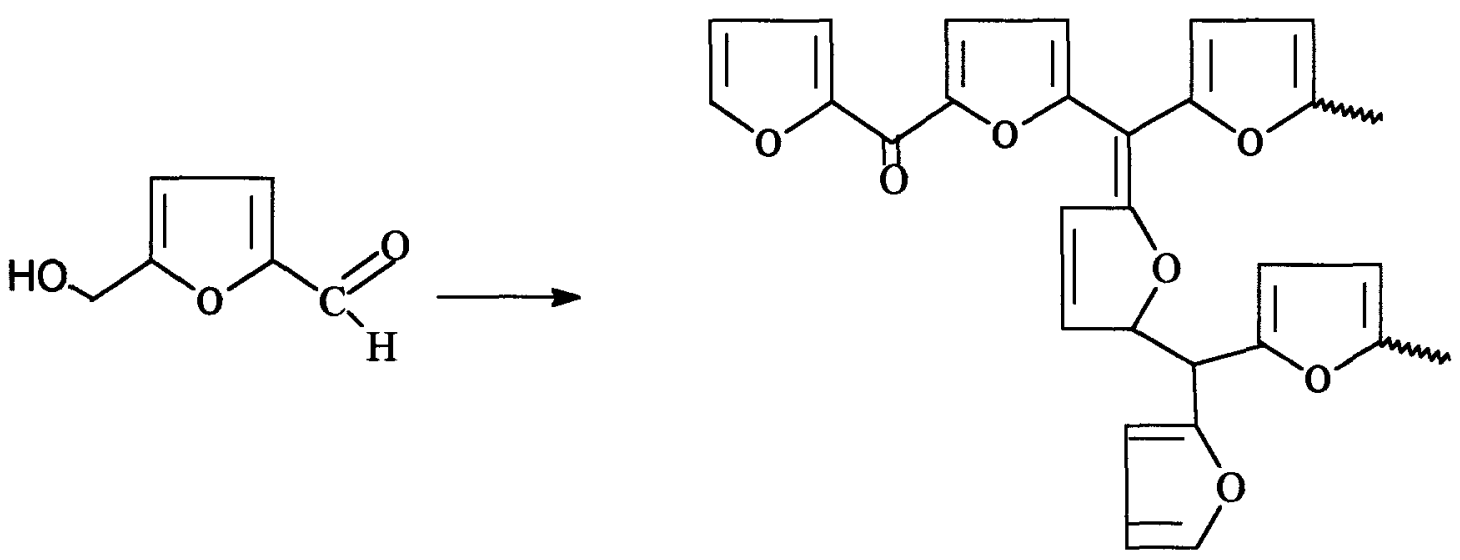

Figura 29- Polimerização do 5-hidroximetil 2-furancarboxialdeído.

É possivel que estas reaçōes ocorram em polimerizaçōes do furfural catalisadas por ácido ou base. Um hidrogênio móvel, como o hidrogênio terciário ligado a três anéis furânicos, pode, não somente ser abstraído na forma de um radical livre $\left(\mathrm{H}^{\circ}\right)$, como também na forma de $\mathrm{H}^{+}$(meio ácido) ou $\mathrm{H}^{-}$(meio básico). O 5-hidroximetil 2furancarboxialdeído é muito sensivel a este tipo de reação, o que confirma que o $\mathrm{H} 5$ desempenha um importante papel nos mecanismos de condensação, e não os átomos de $\mathrm{H}_{3}$ e $\mathrm{H}_{4}$ (Gandini; Belgacem 1996).

\subsubsection{O Álcool Furfurílico}

A hidrogenação converte furfural em álcool furfurílico. $O$ alto teor de furfural extraido a partir destes materiais secos justifica sua exploração comercial. $O$ álcool furfurílico polimeriza-se quando submetido a condições acídicas (figura 30), e este processo envolve uma série de transformaçães que, dependendo das condições experimentais, levam a um produto negro, termofixo, que apresenta inter-cruzamentos, 
resistente aos ácidos e aos álcalis (figura 31).

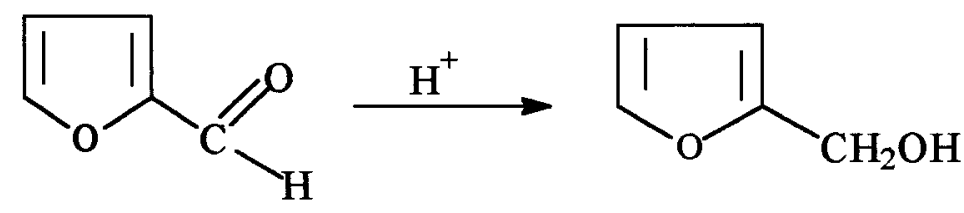

Furfural

Álcool Furfurílico

Figura 30- Conversão do furfural a álcool furfurílico.

Resinas de álcool furfurílico têm sido utilizadas como preservativos de madeira, fungicidas, inseticidas e retardantes de chama.

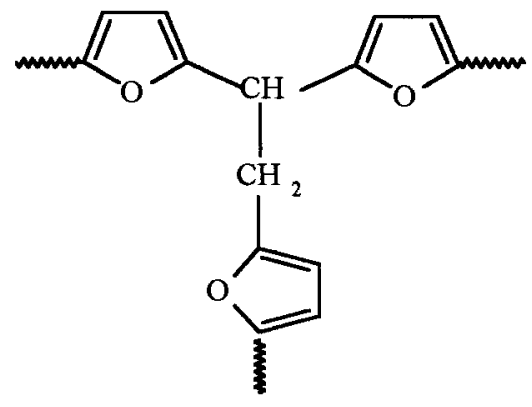

Figura 31- Estrutura de poli álcool furfurílico apresentando intercruzamentos.

As resinas de FFA são preparadas pelo homo-polimerização do FFA ou pela co-polimerização do FFA com formaldeído. O mecanismo responsável pelo processo de polimerização consiste em sua primeira etapa de reação de condensação entre grupos $\mathrm{OH}$ de um lado e um átomo $\mathrm{H}_{5}$ de um anel furânico (cabeça-cauda) ou um outro grupo $\mathrm{OH}$ (cabeça-cabeça). 

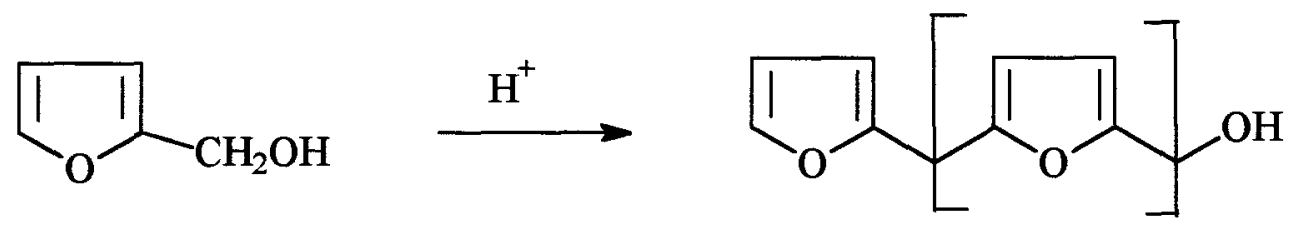

Figura 32- Primeiro estágio da polimerização do álcool furfurílico catalisada por ácido forte.

De acordo com Batista (1998), a polimerização do álcool furfurílico em tubos capilares mostrou que um dos oligômeros formados tem a estrutura descrita abaixo e possui coloração verde. Devido às conjugações, este polímero apresenta propriedade de condução elétrica.<smiles>CCC(C)(CC)c1ccc(/C=c2\cc/c(=C\c3ccc(/C=c4\cc/c(=C\c5ccc(C(C)(CC)CC)o5)o4)o3)o2)o1</smiles>

Figura 33- Oligômero de FFA com ligações conjugadas.

Os oligômeros formados podem conter os dois tipos de cadeias, as metilênicas e as dimetilenoxídicas. Os mecanismos envolvidos neste processo não são totalmente conhecidos e mostram uma reação lenta no inicio que se toma fortemente exotérmica e muito veloz a partir de um certo ponto. Evidências constatam que em condições ácidas as cadeias dimetilenoxídicas têm tendência a perder formaldeído e reverter às metilênicas, e, com um tempo de cura muito longo e à altas temperaturas as ligações dimetilenoxídicas podem se romper. Esta é a razão das ligações metilênicas serem mais freqüentes, como pode ser observado pela figura 34 (Gandini; Belgacem 1996). 


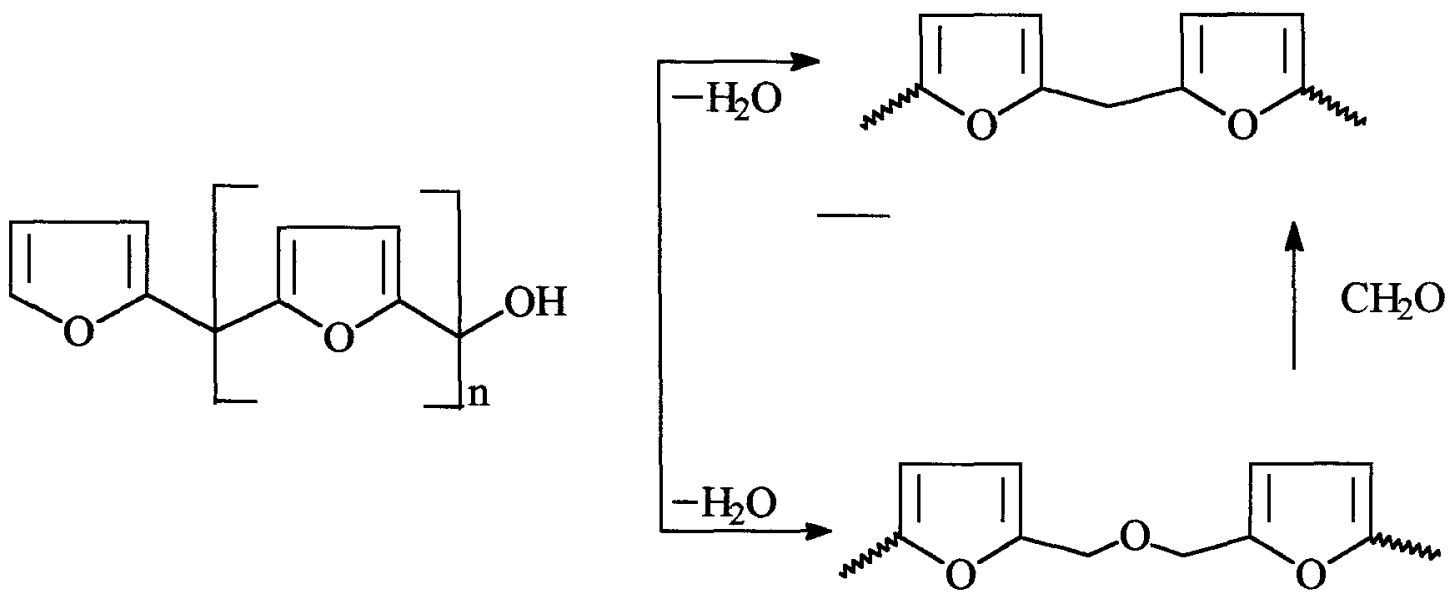

Figura 34- Estágio avançado da polimerização do álcool furfurílico

Durante a polimerização também é produzido água, ácido levulínico e outros fragmentos de resinas tais como poli metil álcool furfurílico entre outros. As reações de condensação entre os grupos metilênicos tendem a estruturas inter-cruzadas. Estas estruturas dão propriedades de resistência aos materiais compósitos (Gandini; Belgacem 1996). Os polímeros assim formados possuem alta viscosidade e são relativamente pouco reativos, resistentes a ácidos e a álcalis e comprovado0s retardantes de fogo (Leitheiser et al. 1978).

Ryu, Imamura e Takahashi (1992) observaram que o acréscimo no WPG das amostras tratadas com FFA aumentou a resistência destas ao ataque de térmitas. 0 pré-tratamento com ácido bórico e posterior tratamento com FFA tornou-as ainda mais resistentes, e demonstrou não ser influenciada pelo WPG do FFA, sugerindo que a ação termicida era devida à ação do boro residual. Os resultados foram melhores que os obtidos para a madeira acetilada, porém, similares aos obtidos para madeiras tratadas com resina de fenol-formaldeído. O teste de resistência aos fungos degradadores mostrou resultados levemente inferiores aos tratamentos com acetilação e com fenol-formaldeido. 


\subsection{Boro e Compostos de Boro}

Pizzi e Baecker (1996) afirmaram que há apenas um preservativo de madeira capaz de agir tanto como inseticida e fungicida como também como retardante de chama, e facilmente aceito por apresentar baixa toxicidade aos mamíferos e baixo impacto ambiental. Este preservativo é o boro.

O emprego do boro como preservativo para madeira apresenta muitas vantagens em relação à resistência ao ataque de térmitas se comparado, p. e. aos compostos de fósforo. Uma pequena quantidade de boro fixada nas amostras lixiviadas é suficiente para retardar a atividade das térmitas (Yalinkilic 1996). Compostos de boro são conhecidos por serem eficazes em sua ação de retardantes de fogo (Laks; Manning 1994). Materiais tratados com boro mostraram tempo de ignição quase duas vezes mais lentos se comparados às mesmas amostras sem tratamento (Su et al. 1997). Além disso, é fácil de manusear e possui alta difusibilidade, o que o torna aplicável no tratamento de madeira de baixa permeabilidade. Sua difusibilidade resulta da não fixação às paredes celulares e é, ao mesmo tempo, a responsável pela facilidade com que sofre lixiviação com um mínimo de umidade presente (Blew; Williams apud Peylo; Willeitner 1995). A difusão do boro aumenta com o aumento da umidade e torna-se muita rápida a níveis acima de $100 \%$. Porém, ela ocorre mesmo

\footnotetext{
" * BLEW, J. O. Comparison of Preservatives in Mississipi Fencepost Study after 10 Years of Service. AWPA 43, p. 26-41. apud PEYLO, A.; WILLEITNER, H. The Problem of Reducing the Leachability of Boron by Water Repellents. Holzforschung, vol. 49, p. 211-16, 1995.

"WILLIAMS, A. I. The Extraction and Determination of Disodium Octaborate in Sitka Spruce. Analyst, vol. 93, p. 111-15. apud PEYLO, A.; WILLEITNER, H. The Problem of Reducing the Leachability of Boron by Water Repellents. Holzforschung, vol. 49, p. 211-16, 1995.
} 
com baixos niveis, abaixo de $20 \%$ (Dirol*; Morell et al. ${ }^{*}$ apud Peylo; Willeitner 1995). A alta difusibilidade do boro e a forte tendência a sofrer lixiviação tem causado restrições ao seu emprego em tratamento de madeiras para uso em contato com solo (Yalinkilic et al. 1996; 1997; 1998). O fato de o boro sofrer lixiviação não está relacionado com o fluxo de água nas células visto que os íons borato se difundem através de gradiente de concentração, com um mínimo de conteúdo de umidade, no interior das paredes celulares. Para prevenir a lixiviação do boro os tratamentos que preenchem o lúmem das células não são eficientes. Peylo; Willeitner (1995) sugerem que a melhor maneira de evitar que o boro seja lixiviado é o tratamento superficial com uma cobertura não higroscópica tão densa quanto possível.

O ácido bórico forma complexo com grupos 1-metoxi 2-hidroxi benzeno e 1,2dimetoxibenzeno da lignina (Kubel; Pizzi* apud Pizzi; Baecker 1996) e com grupos 1,2dihidroxibenzeno dos taninos (Antikainen; Oksanen*; Slabbert* apud Pizzi; Baecker

* DIROL, D. Borate Diffusion in Wood from Rods Liquid Product. Application to Laminated Beams. Doc. IRGNGG 3482, 1988. apud PEYLO, A.; WILLEITNER, $H$. The Problem of Reducing the Leachability of Boron by Water Repellents. Holzforschung, vol. 49, p. 211-16, 1995.

* " MORELL, J. J.; SEXTON, C. M.; PRESTON, A. F. Effect of Moisture Content of Douglas fir Heartwood on Longitudinal Diffusion of Boron from Fused Borate Rods. Forest Products Journal, vol. 40(4), p. 37-40, 1990. apud PEYLO, A.; WILLEITNER, $H$. The Problem of Reducing the Leachability of Boron by Water Repellents. Holzforschung, vol. 49, p. 211-16, 1995.

" * KUBEL, H.; PIZZI, A. The Chemistry and Kinetic Behaviour of Cu-Cr-As/B Wood

Preservatives. Part V. Holzforsch. Holzvewert, 34 (4), p. 75-83,1982.

"KUBEL, H.; PIZZI, A. The Chemistry and Kinetic Behaviour of Cu-Cr-As/B Wood Preservatives. Part VI. Holzforsch. Holzvewert, 34 (5), p. 84-86,1982. Apud PIZZI, A.; BAECKER, A. A New Boron Fixation Mechanism for Environmental Friendly Wood Preservatives. Holzforschung, vol. 50, p. 507-10, 1996.

ANTIKAINEN, P. J.; OKSANEN, $H$. On the Oxidation Chelates of Ortho Diphenols. Acta Chem. Scand. 22: 2867-2871, 1968. apud PIZZI, A.; BAECKER, A. A New Boron Fixation Mechanism for Environmental Friendly Wood Preservatives. Holzforschung, vol. 50, p. 507$10,1996$.

* " SLABBERT, N. P. Metal Complexes of Black Wattle Tannins and Related Model Polyphenols. Ph.D. thesis. Rhodes University, Grahamstown, South Africa, 1972. Apud PIZZI, A.; 
1996). Sendo um ácido moderadamente solúvel $\left(0,93 \mathrm{M}\right.$ a $\left.25^{\circ} \mathrm{C}\right)$, é um ácido de Lewis muito fraco, podendo promover a auto condensação dos polímeros (Jolly 1966). Porém, diversas tentativas de complexá-lo com polímeros auto intercruzados não provaram ser capazes de diminuir sua lixiviação significativamente.

O ácido bórico é uma fonte de $\mathrm{B}_{2} \mathrm{O}_{3}$ livre de metal e é usado em uma variedade de produtos industriais (Peylo; Willeitner 1995).

Yalinkilic (1997) observou em estudos termo-gravimétricos que o ácido bórico reduziu a temperatura de decomposição de 300 para $280^{\circ} \mathrm{C}$ para madeiras tratadas com $4,4 \%$ de ácido bórico. A temperatura da pirólise da celulose também foi reduzida, significando a formação de menor quantidade de resíduos carbonizados.

Ao tratar a madeira com um polímero (FFA) que provavelmente ocupa os sítios ativos das paredes celulares, formando ligações intercruzadas, a adição de boro na forma de ácido bórico e boratos de amônio foi pensada para tentar uma melhor fixação do boro na forma de complexos com o polímero intercruzado. O emprego do FFA aumenta a estabilidade dimensional da madeira e também promove a sua densificação. Espera-se que os complexos FFA-boro aumentem a fixação do boro na madeira, sem, contudo, estacionar totalmente sua mobilidade, pois o boro somente é eficiente como fungicida e inseticida se estiver livre e descomplexado (Yalinkilic 1996) (Merck *apud Peylo; Willeitner 1995).

Se o FFA funcionar como agente de fixação do boro, é possível que o boro esteja interagindo com grupos hidroxilas da madeira, se ligando fracamente ou ficando

BAECKER, A. A New Boron Fixation Mechanism for Environmental Friendly Wood Preservatives. Holzforschung, vol. 50, p. 507-10, 1996.

* " MERCK. Die Chemische Analyse von Wasser. 13. Auflage, Merck, Darmstadt, 241p., 1989. Apud PEYLO, A.; WILLEITNER, $H$. The Problem of Reducing the Leachability of Boron by Water Repellents. Holzforschung, vol. 49, p. 211-16, 1995. 
aprisionado pela rede intercruzada formada pelas cadeias de FFA e polímeros da madeira. Complexos de borato podem ser formados com grupos hidroxilas da holocelulose e da lignina pois o ácido bórico reage com polialcoóis, especialmente os que possuem grupos hidroxilas em átomos de carbonos vizinhos, formando complexos.

Estas interações entre grupos $\mathrm{OH}$ - boro e grupos $\mathrm{OH}$ - FFA são consideradas eficientes para melhorar a estabilidade dimensional. $O$ incremento da resistência biológica também é esperado devido ao efeito de bloqueamento dos sítios enzimaticamente reativos da celulose, fazendo com que os fungos e insetos não reconheçam estes sítios, e também da não disponibilização dos grupos $\mathrm{OH}$ para formar ligações de hidrogênio com moléculas de água. $O$ baixo conteúdo de umidade inibe a ação dos organismos degradadores da madeira.

A definição pelo uso do borato e biborato de amônio está relacionada com a facilidade com que o íon amônio se liga à resina penetrando profundamente e em grande quantidade nas paredes celulares.

Além disso, compostos de amônio contribuem para aumentar a resistência à deterioração (Scheffer; Vankleeck apud Leão 1997). No Japão, didecildimetil cloreto de amônio (DDAC) foi recentemente aprovado como um ingrediente ativo como fungicida e termicida por possuir baixa toxicidade (Takahashi 1993).

Esta revisão bibliográfica básica foi necessária para fundamentar o entendimento das propriedades da madeira que se pretende avaliar com as madeiras tratadas com Álcool Furfurilico em combinação com Compostos de Boro. 


\section{Capítulo II}

\section{Procedimentos Experimentais}

\subsection{Preparo das Amostras}

Amostras de "Japanese cedar" (Cryptomeria japonica D. Don)- sugi - e pinus (Pinus caribaea MORELET var hondurensis BAR et GOLF) foram preparadas nas dimensões de $20 \mathrm{~mm}$ ( tangencial) $\times 20 \mathrm{~mm}$ (radial) $\times 10 \mathrm{~mm}$ (longitudinal). A densidade aparente seca média e o conteúdo de umidade seco ao ar do sugi são 0.30 $\mathrm{g} / \mathrm{cm}^{3}$ e $10.32 \%$ respectivamente. O teor médio de holocelulose é de $73.3 \%$; de lignina de $32.3 \%$ e de resina varia de 2.6 a $3.1 \%$. Os anéis de crescimento das amostras de sugi são de $3 \mathrm{~mm}$ a $5 \mathrm{~mm}$ de espessura (Wood Industry Handbook). A densidade aparente seca média do pinus é $0.53 \mathrm{~g} / \mathrm{cm}^{3}$ (Bortoletti $\mathrm{Jr}$. 1993). O pinus possui teores médios de $65.8 \%$ de holocelulose, $31.8 \%$ de lignina e de 2.0 a $3.0 \%$ de resina. Até a idade de 15 anos não apresenta cerne diferenciado. Apresenta baixa resistência natural a organismos xilófagos. Este pinus é bastante permeável e facilmente tratável quimicamente (Wehr 1985). Abaixo estão apresentados os valores de resistência à compressão normal, à tração normal às fibras e ao cisalhamento (Bortoletto 1993). 
Flexão

Módulo de Resistência (daN/cm²) Módulo de Elasticidade (daN $/ \mathrm{cm}^{2}$ )

$\begin{array}{ccc}\text { Seca }(12 \%) & 625 \pm 216 & 90508 \pm 32343 \\ \text { verde } & 433 \pm 128 & 76561 \pm 27425\end{array}$

\section{Compressão Paralela}

Módulo de Resistência (daN/cm ${ }^{2}$ ) Módulo de Elasticidade (daN/cm ${ }^{2}$ )
Seca (\%)
$423 \pm 129$
$95949 \pm 46005$
verde
$207 \pm 67$
$69542 \pm 45211$

\section{Compressão Normal}

Módulo de Resistência (daN/cm²) Módulo de Elasticidade (daN/cm ${ }^{2}$ )
Seca $(\%)$
$50 \pm 12$
$5010 \pm 1167$
Verde
$28 \pm 6$
$2793 \pm 652$

\section{Tração Paralela}

Módulo de Resistência (daN/cm²) Módulo de Elasticidade (daN/ $\mathrm{cm}^{2}$ )

$\operatorname{Seca}(12 \%)$

$503 \pm 238$

$98335 \pm 50658$

Verde

$546 \pm 228$

$98258 \pm 54601$

\section{Tração Normal}

Módulo de Resistência (daN/ $\mathrm{cm}^{2}$ ) Módulo de Elasticidade (daN/cm²)

$\operatorname{Seca}(12 \%)$

$26 \pm 8$

$546 \pm 185$ 
verde

\section{Resistência ao Cisalhamento (daN/cm²)}

$\begin{array}{lr}\text { Seca }(12 \%) & 130 \pm 27 \\ \text { Verde } & 71 \pm 14\end{array}$

Desta forma, é considerado de baixa resistência mecânica.

As amostras foram secas em estufa a $100^{\circ} \mathrm{C}$ por 48 horas o que, segundo Fengel; Weneger (1989), assegura que a madeira apresente boa estabilidade de seus componentes. À temperaturas mais elevadas, o conteúdo de polissacarídeos decresce rapidamente e acima de $150^{\circ} \mathrm{C}$ o conteúdo de lignina aumenta. Depois de retiradas da estufa as amostras foram mantidas em dessecador até massa constante. As massas e as dimensões foram, então, medidas.

\subsection{Preparo das Soluções}

Soluções de FFA, ácido bórico (BA) e FFA combinado com borato de amônio (BO), biborato de amônio $(\mathrm{BI})$ e ácido bórico (BA) foram preparadas conforme as concentrações constantes na tabela (3). As concentrações foram definidas após testes de polimerização conduzidos separadamente. 
Tabela 3 - Relação das soluções de tratamento empregadas.

\begin{tabular}{|c|c|c|c|c|c|}
\hline $\begin{array}{l}\text { CÓDIGO DA } \\
\text { SOLUÇÃO DE } \\
\text { TRATAMENTO }\end{array}$ & $\begin{array}{l}\text { COMPOSIÇÃO DA } \\
\text { SOLUÇÃO DE } \\
\text { TRATAMENTO }\end{array}$ & $\begin{array}{c}\text { RAZÃO } \\
\text { DA } \\
\text { MISTURA }\end{array}$ & $\begin{array}{l}\text { RAZÃO } \\
\text { MOLAR } \\
(\% \text { MOL) }\end{array}$ & $\begin{array}{c}{[\mathrm{B}]} \\
(\mathrm{PPM})\end{array}$ & $\begin{array}{l}\mathrm{PHA} \\
25^{\circ} \mathrm{C}\end{array}$ \\
\hline$B A$ & $\begin{array}{c}\text { ÁCIDO BÓRICO } \\
1 \%(W M)\end{array}$ & & & 1743.50 & 5.27 \\
\hline FFA & $\begin{array}{c}\text { ÁLCOOL } \\
\text { FURFURÍLICO }\end{array}$ & PURO & & - & 5.01 \\
\hline$F F A+B I$ & $\begin{array}{c}\text { Álcool Furfurilico + } \\
\text { Biborato de Amônio } \\
\left(\mathrm{NH}_{4}\right) 2 \mathrm{~B} 4 \mathrm{O}_{7} .4 \mathrm{H}_{2} \mathrm{O} \\
0,25 \mathrm{~mol} / \mathrm{l} \\
\end{array}$ & $20: 3$ & 99.770: 0.229 & 1405.30 & 8.66 \\
\hline $\mathrm{FFA}+\mathrm{BO}$ & $\begin{array}{c}\text { Álcool Furfurílico + } \\
\text { Borato de Amônio } \\
(\mathrm{NH} 4) 2 \mathrm{O} .5 \mathrm{~B} 2 \mathrm{O}_{3} .8 \mathrm{H}_{2} \mathrm{O} \\
0.25 \mathrm{~mol} / \mathrm{l} \\
\end{array}$ & $20: 3$ & 99.524: 0.476 & 3513.25 & 7.78 \\
\hline$F F A+B A$ & $\begin{array}{c}\text { Álcool Furfurílico + } \\
\text { Ácido Bórico (H3BO3) } \\
0.5 \mathrm{~mol} / \mathrm{l}\end{array}$ & $3: 1$ & 98.572: 1.428 & 1351.21 & 4.32 \\
\hline
\end{tabular}

\subsection{Impregnação das madeiras}

Após efetuadas a secagem em estufa e as medidas, as amostras foram impregnadas com as soluções constantes na tabela 3 através do método que utiliza vácuo e encharcamento. As amostras a serem impregnadas foram colocadas em um dessecador a vácuo conectado a uma bomba e um funil de separação por onde foi introduzida a solução de impregnação (conforme esquema da figura 35). Foram submetidas a vácuo por 45 minutos. A solução de impregnação foi, então, admitida sobre as amostras lentamente e, após fechar a entrada, seguiu-se o encharcamento da solução por outros 60 minutos sob vácuo. Ao término do processo, o excesso da 
solução de impregnação foi drenado para fora do recipiente que o contém. As amostras foram deixadas em temperatura ambiente por uma hora e depois foram embrulhadas em papel alumínio e deixadas à temperatura ambiente por 24 horas. Após estes cuidados, elas foram colocadas na estufa a $80^{\circ} \mathrm{C}$ por 12 horas. A temperatura foi, então, incrementada gradualmente à razão de $5^{\circ} \mathrm{C} / \mathrm{h}$ até alcançar $120^{\circ} \mathrm{C}$, que é aproximadamente a temperatura na qual ocorre a polimerização do FFA. Nesta temperatura elas permaneceram por 12 horas. Após este período, o papel alumínio foi removido e as amostras retornaram à estufa onde a temperatura foi abaixada para $80^{\circ} \mathrm{C}$, ficando por 2 horas. Seguiu-se o incremento gradual na mesma razão acima até atingir $120^{\circ} \mathrm{C}$, temperatura na qual permaneceram por 2 horas. Estes cuidados são necessários para garantir a cura completa do polímero ao mesmo tempo em que promove a remoção de todo excesso. Ao final do processo de cura, as amostras foram retiradas da estufa e mantidas no dessecador até que atingissem massa constante. Massas e dimensões foram medidas e o ganho percentual de polímero foi calculado.

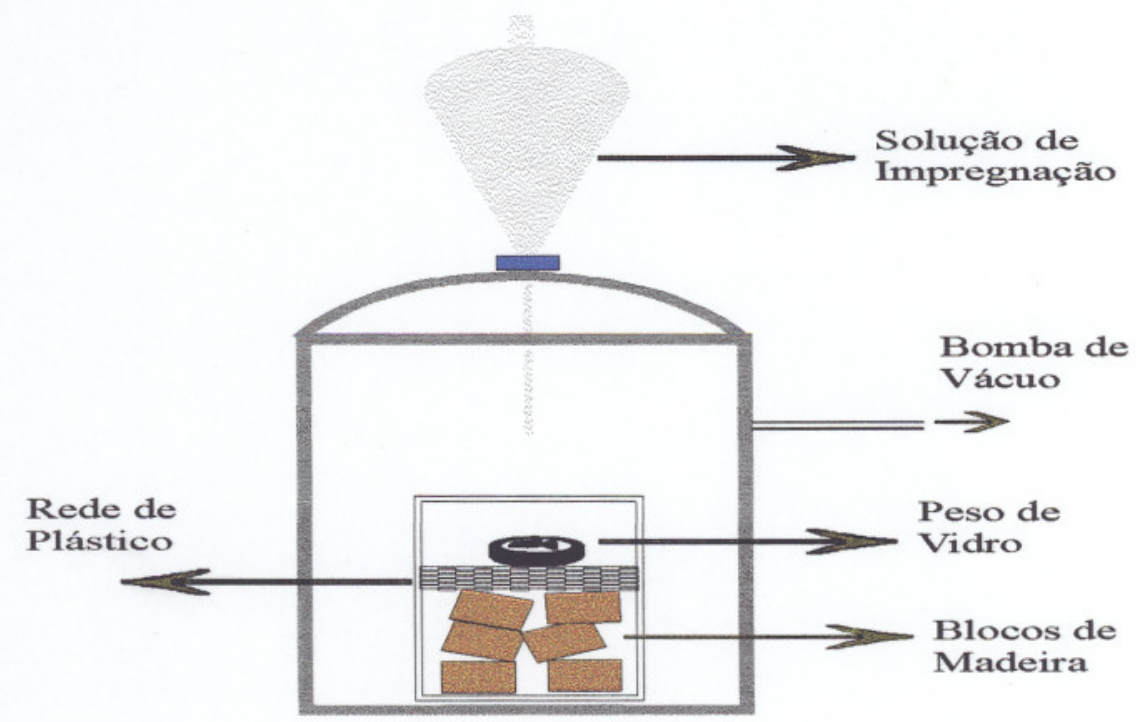

Figura 35- Esquema simplificado da Câmara de Impregnação. 


\section{Capítulo III}

\section{Resultados e Discussão}

\subsection{Percentual de Polímero Ganho (WPG)}

Os percentuais de polímero ganho das amostras devido à impregnação química foram calculados segundo a fórmula:

$$
\text { WPG }(\% \text { em massa })=\frac{W t-W_{0}}{W_{0}} \times 100,
$$

Onde Wt é a massa da amostra após o tratamento e Wo é a massa inicial da amostra seca na estufa, antes do tratamento. 


\subsection{Lixiviação Cíclica}

Amostras tratadas e sem tratamento foram secas a $100^{\circ} \mathrm{C}$ por 24 horas e mantidas no dessecador até massa constante. O teste de lixiviação cíclica foi conduzido de acordo com o "Japanese Industrial Standard" JIS A 9201-1991. Após medir as massas e dimensões, as amostras foram mergulhadas em água destilada com um volume equivalente a dez vezes o volume delas. Foram agitadas por um agitador magnético por 8 horas $(400-500 \mathrm{rpm})$ à temperatura ambiente. Ocasionalmente foi aplicado vácuo por 30 minutos para remover o ar contido nas amostras. Depois de remover a água, as amostras foram levadas à estufa onde permaneceram por 16 horas a $60^{\circ} \mathrm{C}$. Este processo cíclico de imersão e volatilização foi repetido por dez vezes, medindo-se as massas e dimensões a cada ciclo nas condições úmida e seca. As figuras 36 a 39 mostram as variações em massa e volume das amostras submetidas a este tratamento cíclico. A tabela 4 mostra a variação de densidade e de WPG das amostras antes e após serem submetidas à lixiviação cíclica.

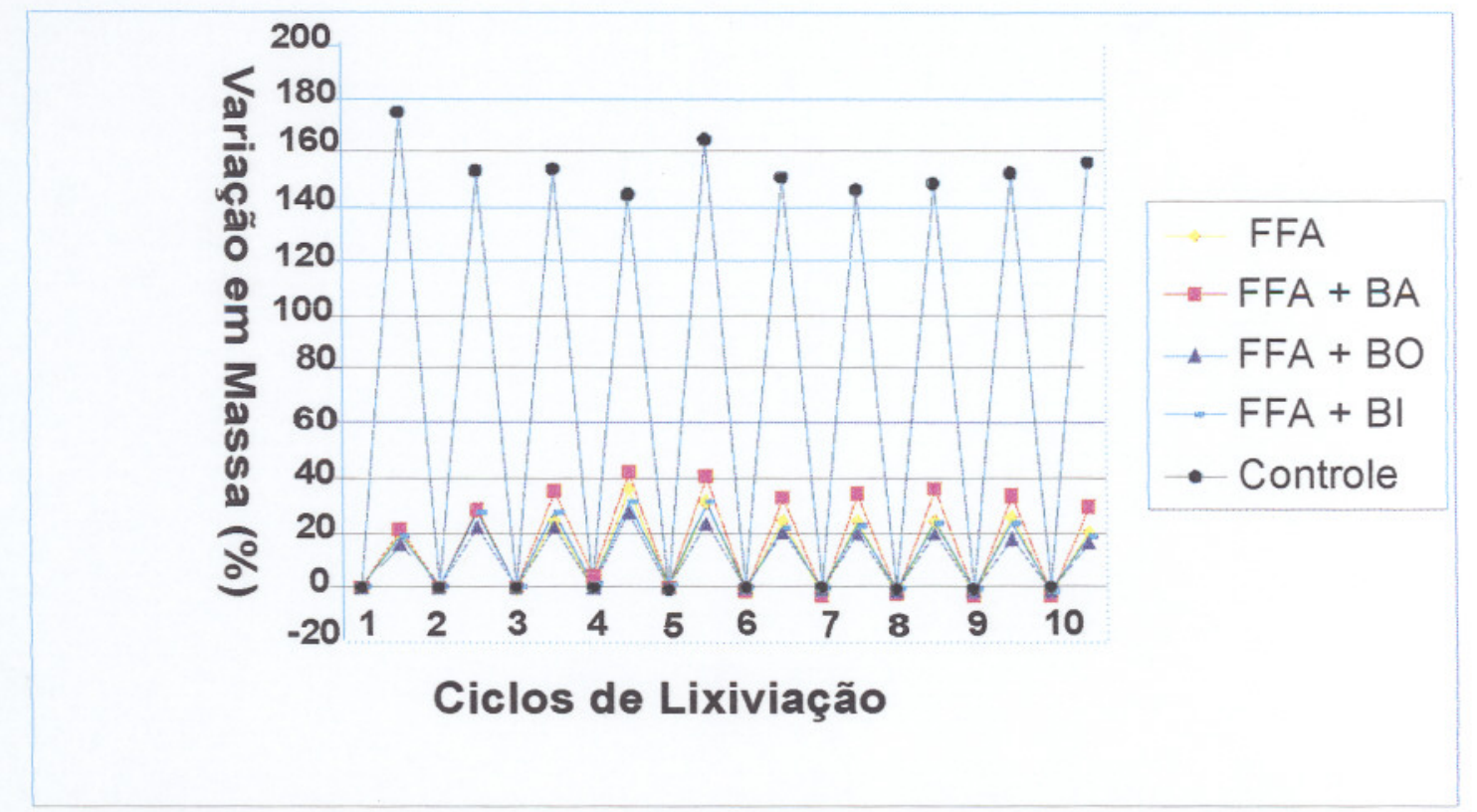

Figura 36- Variação em Massa da espécie Sugi ao longo de dez Ciclos de Lixiviação. 


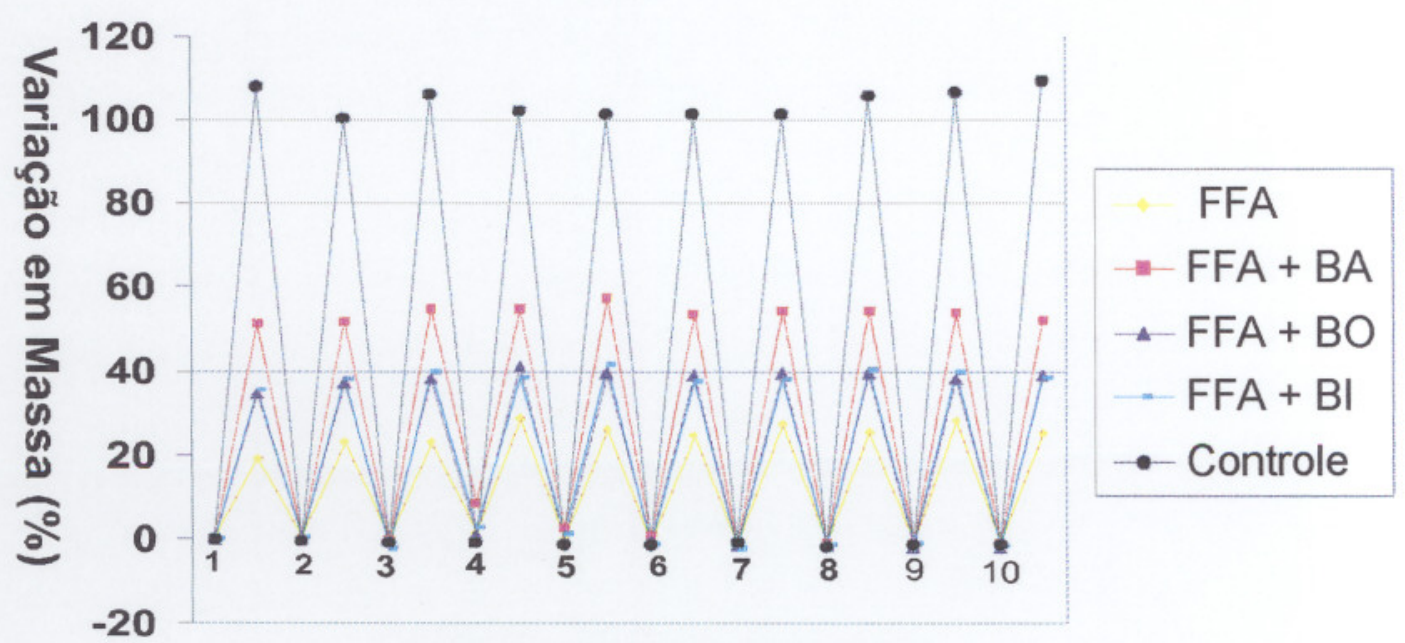

Ciclos de Lixiviação

Figura 37- Variação em Massa da espécie Pinus ao longo de dez Ciclos de Lixiviação.

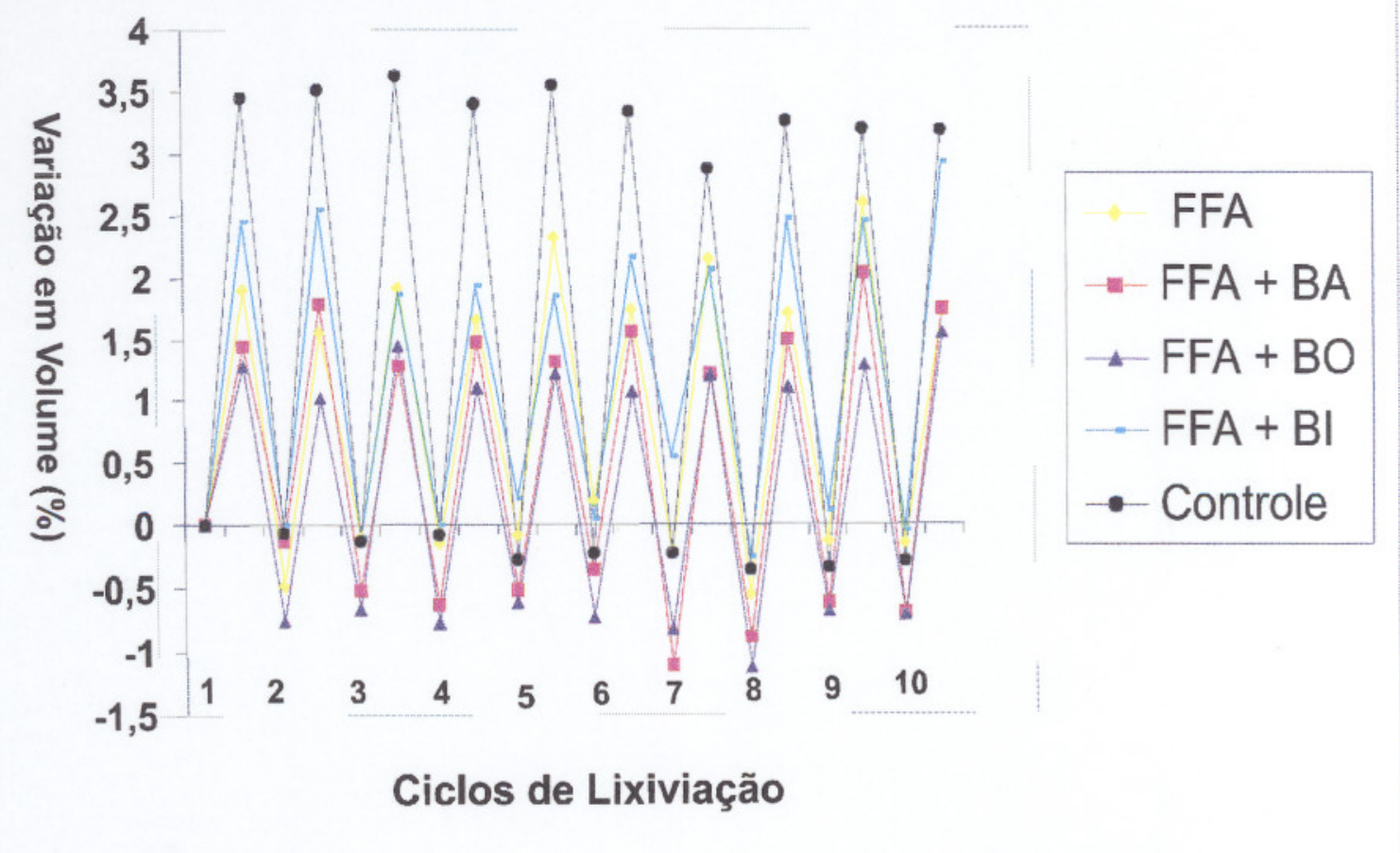

Figura 38- Variação em Volume do Pinus de acordo com os ciclos de lixiviação. 


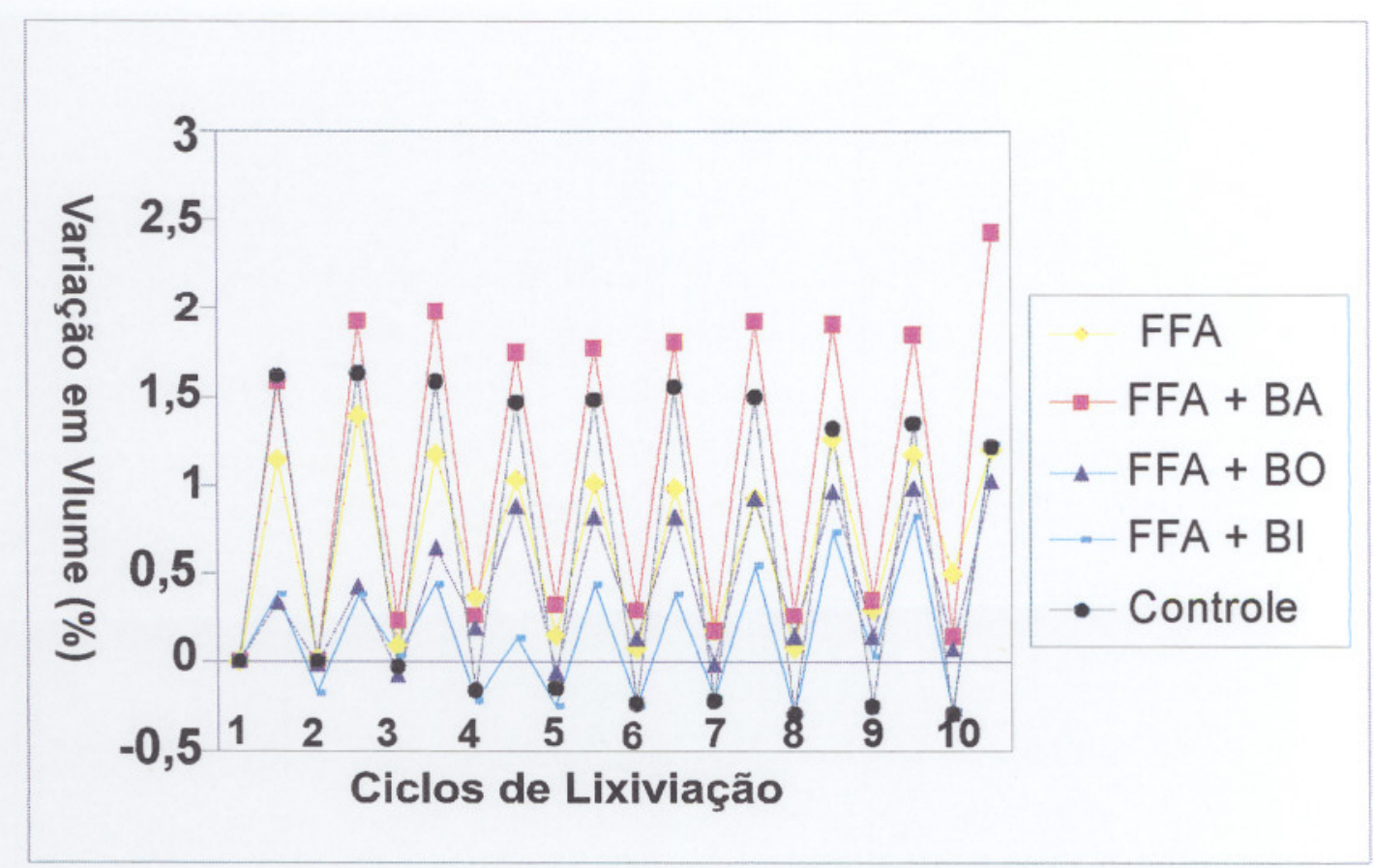

Figura 39- Variação em Volume do Sugi de acordo com os ciclos de lixiviação.

Tabela 4 Gravidade Específica e Ganho Percentual de Polímero (WPG).

\begin{tabular}{|c|c|c|c|c|c|}
\hline & & \multicolumn{2}{|l|}{$\mathrm{D}$} & \multicolumn{2}{|c|}{$(\mathrm{WPG})^{\mathrm{a}}$} \\
\hline $\begin{array}{l}\text { Código de } \\
\text { Tratamento }\end{array}$ & $\begin{array}{c}\text { Espécie } \\
\text { Madeira }\end{array}$ & $\begin{array}{l}\mathrm{g} / \mathrm{cm}^{3} \\
\text { Média } \pm \mathrm{SD}^{\mathrm{b}} \\
\text { Pré lixiviação }\end{array}$ & $\begin{array}{c}\mathrm{g} / \mathrm{cm}^{3} \\
\text { Média } \pm S D^{b} \\
\text { Pós lixiviação }\end{array}$ & $\begin{array}{c}\%(\text { em massa) } \\
\text { Média } \pm S D^{b} \\
\text { Pré lixiviação }\end{array}$ & $\begin{array}{l}\%(\text { em massa) } \\
\text { Média } \pm \text { SD }^{\circ} \\
\text { Pós lixiviação }\end{array}$ \\
\hline Controle & Sugi & $0.30 \pm 0.00$ & $0.29 \pm 0.00$ & & \\
\hline BA & Sugi & $0.31 \pm 0.00$ & $0.26 \pm 0.00$ & $6.54 \pm 0.47$ & $-2.89 \pm 0.15$ \\
\hline FFA & Sugi & $0.54 \pm 0.01$ & $0.52 \pm 0.01$ & $122.07 \pm 27.96$ & $114.80 \pm 27.23$ \\
\hline$F F A+B A$ & Sugi & $0.54 \pm 0.02$ & $0.51 \pm 0.01$ & $78.20 \pm 14.34$ & $69.38 \pm 14.51$ \\
\hline $\mathrm{FFA}+\mathrm{BO}$ & Sugi & $0.58 \pm 0.02$ & $0.56 \pm 0.02$ & $131.57 \pm 38.27$ & $127.04 \pm 37.48$ \\
\hline $\mathrm{FFA}+\mathrm{BI}$ & Sugi & $0.52 \pm 0.01$ & $0.51 \pm 0.01$ & $109.57 \pm 27.47$ & $106.11 \pm 27.35$ \\
\hline Controle & Pinho & $0.46 \pm 0.01$ & $0.44 \pm 0.01$ & & \\
\hline BA & Pinus & $0.47 \pm 0.01$ & $0.32 \pm 0.01$ & $4.32 \pm 0.74$ & $-4.16 \pm 0.32$ \\
\hline FFA & Pinus & $0.71 \pm 0.03$ & $0.69 \pm 0.09$ & $81.55 \pm 11.75$ & $76.65 \pm 11.75$ \\
\hline$F F A+B A$ & Pinus & $0.52 \pm 0.02$ & $0.51 \pm 0.02$ & $41.39 \pm 9.61$ & $36.59 \pm 10.44$ \\
\hline $\mathrm{FFA}+\mathrm{BO}$ & Pinus & $0.60 \pm 0.03$ & $0.59 \pm 0.04$ & $61.47 \pm 12.81$ & $56.85 \pm 13.74$ \\
\hline $\mathrm{FFA}+\mathrm{BI}$ & Pinus & $0.62 \pm 0.08$ & $0.60 \pm 0.07$ & $50.36 \pm 6.38$ & $45.96 \pm 6.51$ \\
\hline
\end{tabular}




\subsubsection{Análise dos Resíduos da Lixiviação Cíclica do Boro}

Ao término de 10 ciclos as soluções contendo o material lixiviado são analisadas e a concentração de boro em cada solução foi determinada por cromatografia iônica [lon Chromatographic (IC) Analyzer (Yokogawa Hokushin Electric, IC 500 P)], equipado com coluna de exclusão de íon. As condições analíticas do IC foram as seguintes: injeção da amostra: 100 $\mu$; coluna: SC55-052+SC55-252; temperatura: $40^{\circ} \mathrm{C}$; efluente: $1 \mathrm{mM} \mathrm{H} 2 \mathrm{SO}_{4}$; taxa de fluxo: $1 \mathrm{ml} / \mathrm{min}$; e detector de indice refrativo (Erma, Inc., ERC-7511).

\subsubsection{A estabilidade do boro}

Tabela 5. Concentrações de boro, detectadas por cromatografia iônica, durante a lixiviação cíclica.

Ciclo Concentração boro (ppm)

\begin{tabular}{|l|l|l|l|l|}
\hline & $\mathrm{BA}$ & $\mathrm{FFA}+\mathrm{BA}$ & $\mathrm{FFA}+\mathrm{BI}$ & $\mathrm{FFA}+\mathrm{BO}$ \\
\hline 1 & $512.0(29.36 \%)$ & $375.7(27.80 \%)$ & $99.51(7.08 \%)$ & $120.31(3.42 \%)$ \\
\hline 2 & $22.8(1.31 \%)$ & $300.9(22.27 \%)$ & $64.88(4.62 \%)$ & $115.90(3.29 \%)$ \\
\hline 3 & $17.0(0.97 \%)$ & $173.7(12.85 \%)$ & $71.43(5.08 \%)$ & $93.63(2.66 \%)$ \\
\hline 4 & ND & $113.2(8.38 \%)$ & $53.05(3.77 \%)$ & $85.70(2.445 \%)$ \\
\hline 5 & ND & $65.88(4.87 \%)$ & $47.96(3.41 \%)$ & $71.14(2.03 \%)$ \\
\hline 6 & ND & $44.7(3.31 \%)$ & $31.17(2.22 \%)$ & $31.38(0.89 \%)$ \\
\hline 7 & ND & $45.5(3.37 \%)$ & $25.02(1.78 \%)$ & $34.24(0.97 \%)$ \\
\hline 8 & ND & $40.08(2.96 \%)$ & $30.34(2.16 \%)$ & $36.50(1.04 \%)$ \\
\hline 9 & ND & $38.3(2.83 \%)$ & $30.00(2.14 \%)$ & $38.73(1.10 \%)$ \\
\hline 10 & ND & $37.1(2.74 \%)$ & $25.72(1.83 \%)$ & $32.78(0.93 \%)$ \\
\hline Total & $31.64 \%$ & $91.38 \%$ & $34.09 \%$ & $18.79 \%$ \\
\hline
\end{tabular}

ND: Não detectável. Valores entre parênteses indicam a percentagem de boro relativo à quantidade adicionada nas espécies de madeira durante a impregnação. 
A variação em massa do estado seco para o encharcado, tanto para o sugi como para o pinho, tratados e sem tratamento, foi mais acentuada que a variação em volume. A maior variação foi verificada nas amostras sem tratamento. Entre as duas espécies, o sugi variou mais. Devido à menor densidade do sugi, ele contém maior quantidade de lúmem que armazena maior quantidade de água.

A variação em volume foi bem menor em percentagem, e também as diferenças entre amostras tratadas e sem tratamento não foram muito acentuadas. Ao contrário, no caso do sugi, as amostras tratadas com FFA + BA sofreram variações maiores que as amostras sem tratamento. Em ambos os casos, pinus e sugi, os volumes subsequentes foram maiores que o volume seco inicial. A explicação para tal fato é a perda, durante a lixiviação, de muitos extrativos e substâncias solúveis

A análise por cromatografia iônica mostrou que as combinações FFA-BO e FFA-BI não são capazes de fixar o boro na madeira mas mostrou que retardam a mobilidade do boro da madeira para a solução e apresentou uma indicação de que houve a formação de complexos entre boro e FFA ou entre boro e grupos $\mathrm{OH}$ da madeira. $\mathrm{O}$ aparecimento de um outro pico referente a composto de boro após o sexto ciclo nas soluções lixiviadas de FFA + BO e após o sétimo ciclo nas soluções lixiviadas de $\mathrm{FFA}+\mathrm{BI}$, pode ser devido à formação de um complexo de boro com o FFA que por ser formado durante ou depois do processo de cura é mais estável que os primeiros complexos formados, ou pode, ainda, ser devido ao boro descomplexado que estivesse apenas aprisionado pelo FFA. Com a solubilização de oligômeros de baixo peso molecular de FFA, os compostos de boro foram liberados para a solução. Como sua liberação é dependente da solubilização do FFA, o processo é lento, diferente do caso do FFA + BA, onde, ao final de dez ciclos, mais de $90 \%$ do boro adicionado já havia sofrido lixiviação. 
Os cromatogramas das análises das soluções de FFA-compostos de boro após os dez ciclos de lixiviação são mostrados nas figuras 40, 41 e 42 .
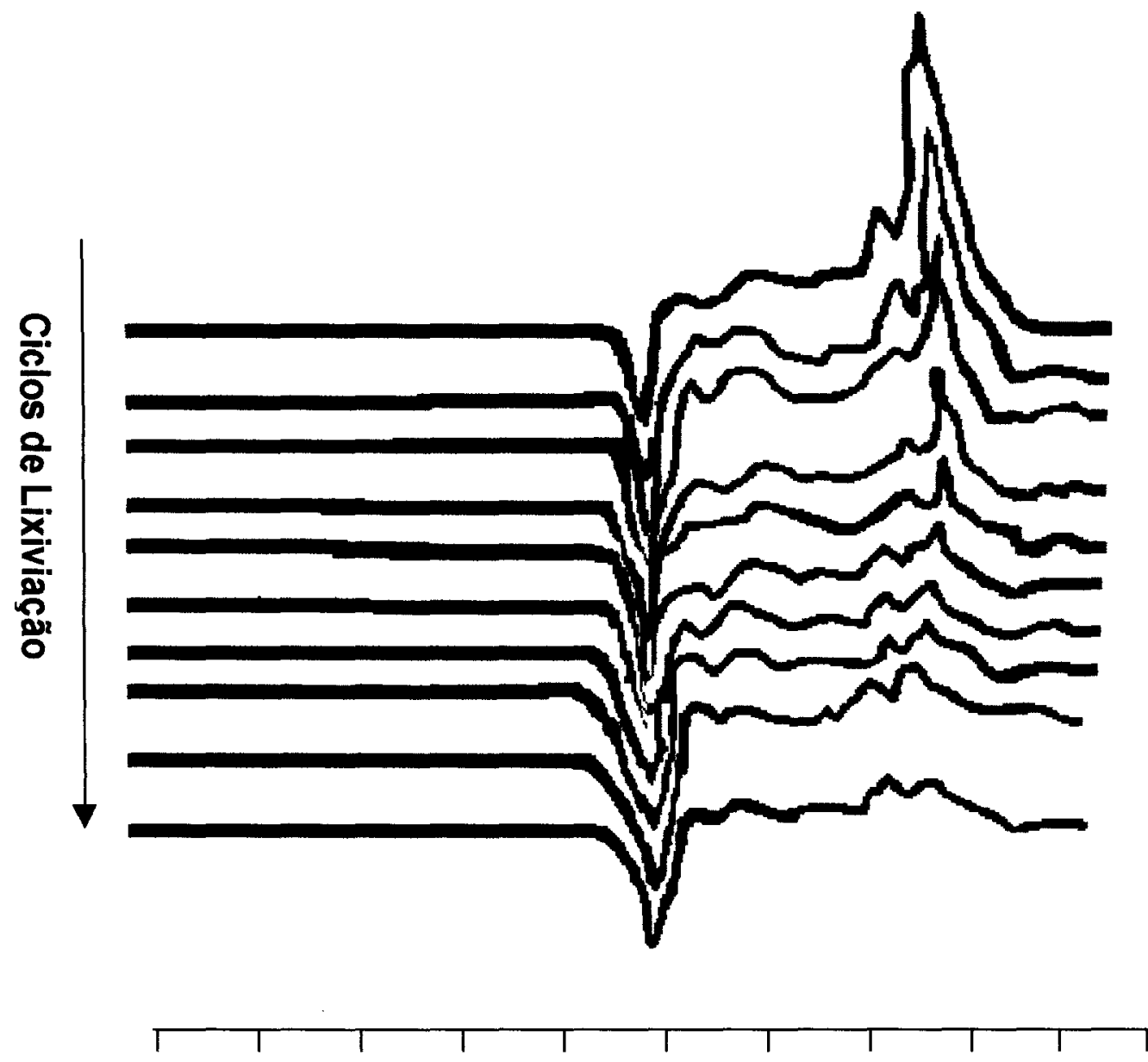

\section{Tempo (min)}

Figura 40- Cromatograma da análise dos resíduos da solução FFA + BA ao longo dos dez ciclos de lixiviação conduzidos de acordo com os padrões da JIS 9201-1992. 

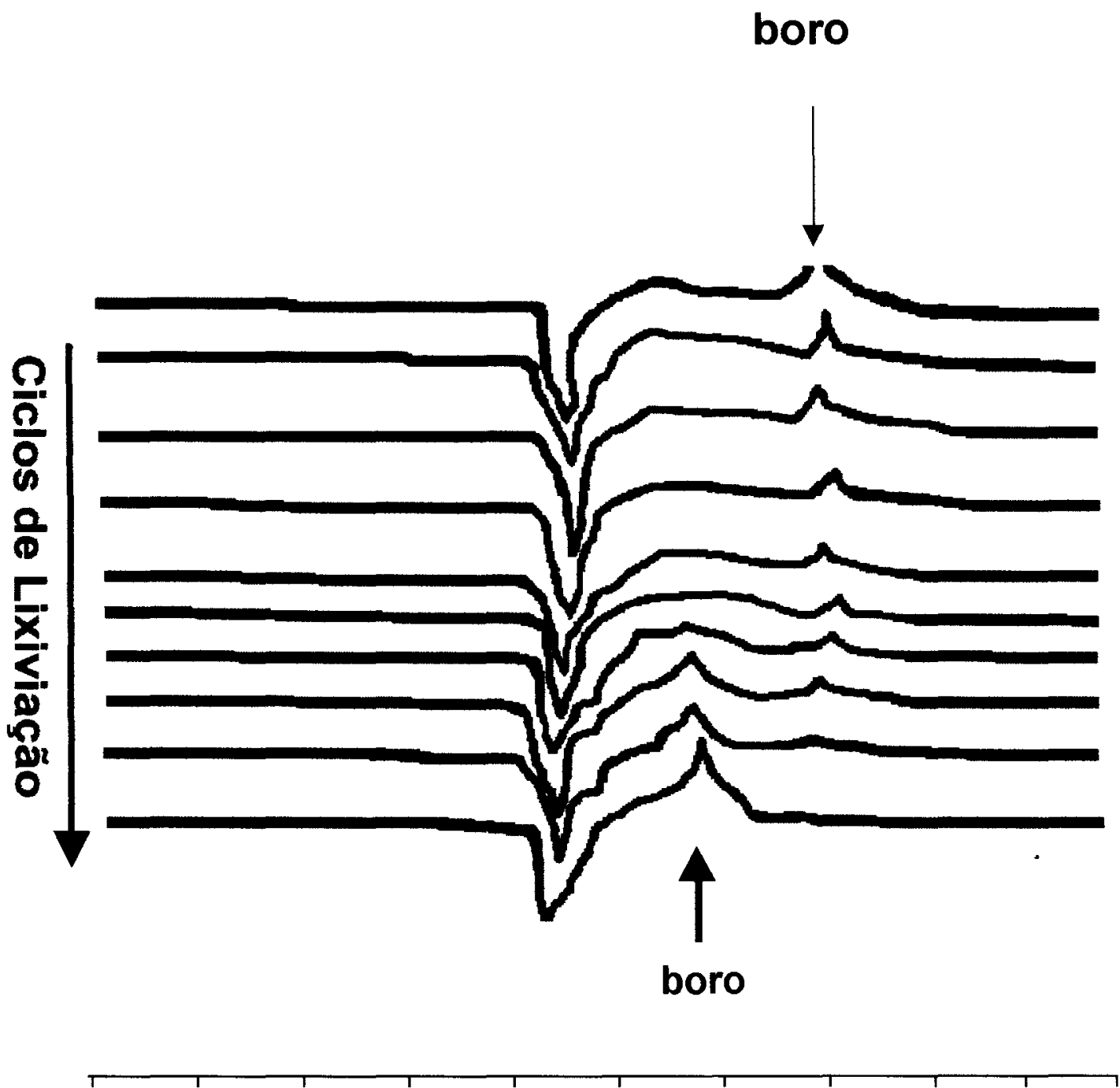

Tempo (min)

Figura 41- Cromatograma da análise dos resíduos da solução FFA + BI ao longo dos dez ciclos de lixiviação conduzidos de acordo com os padrões da JIS 9201-1992. 

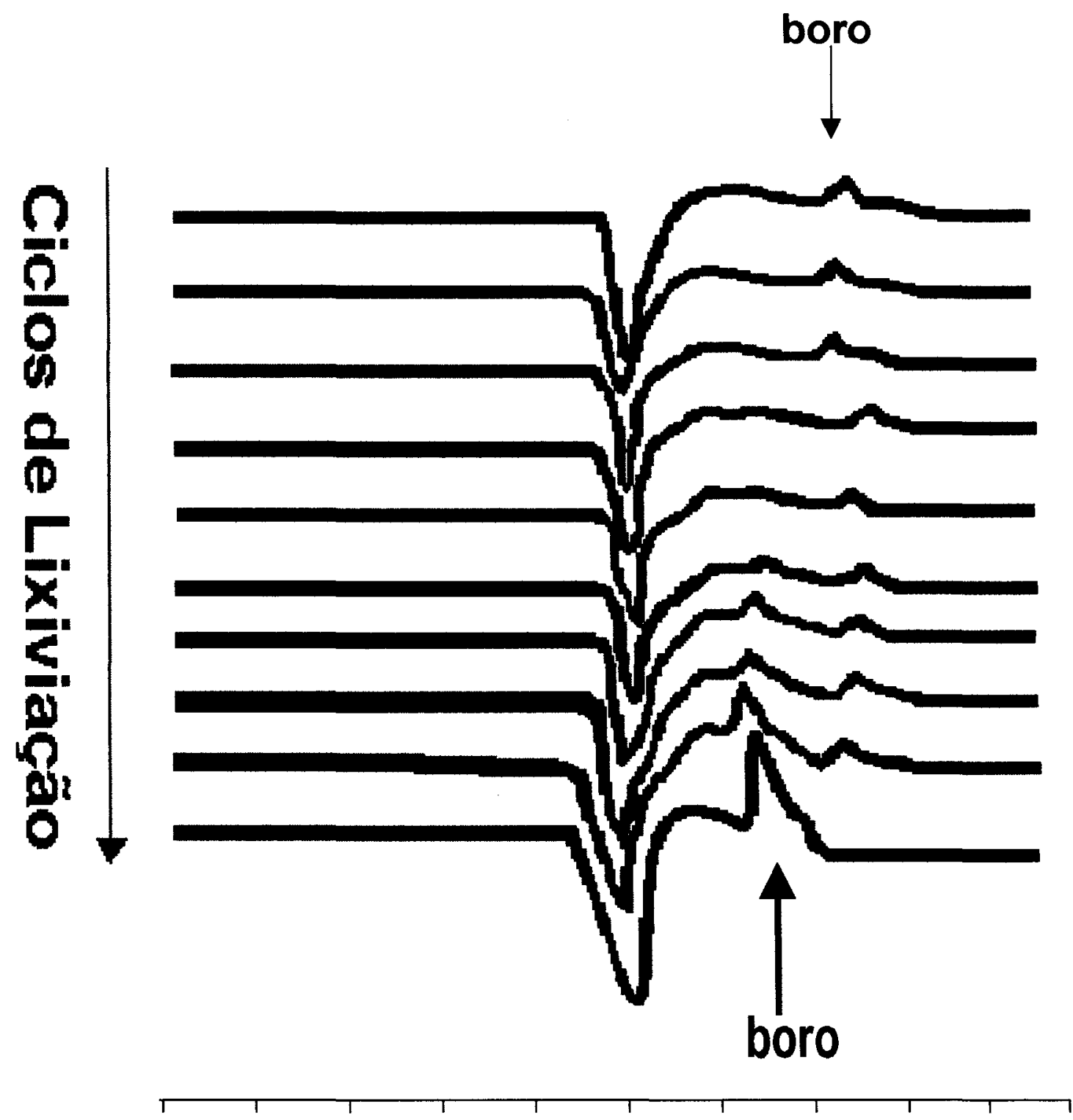

\section{Tempo (min)}

Figura 42- Cromatograma da análise dos resíduos da solução FFA + BO ao longo dos dez ciclos de lixiviação conduzidos de acordo com os padrões da JIS 9201-1992. 


\subsection{Eficiência Anti-Inchamento (ASE)}

A eficiência anti-inchamento livre de carga foi calculada após o tratamento cíclico, através da seguinte fórmula,

$$
A S E(\%)=\frac{S u-S}{S u} \times 100
$$

Onde

Su é o coeficiente volumétrico de inchamento da madeira sem tratamento e S é o coeficiente volumétrico de inchamento da madeira tratada.

Os coeficientes volumétricos de inchamento são calculados através da fórmula,

$$
S(\%)=\frac{V_{2-} V_{1}}{V_{1}} \times 100
$$

Onde

$V_{2}$ é o volume da amostra após mergulhada na água e agitada por 8 horas, e

$V_{1}$ é o volume da amostra inicial seca na estufa a $60^{\circ} \mathrm{C}$ por 16 horas e antes de mergulhá-la na água. 


\subsection{Absorção de Água (WA)}

As amostras foram mergulhadas em volume de água destilada dez vezes o seu próprio volume e submetidas a vácuo até que todas estivessem submergidas. Foram deixadas submersas por 24 horas e depois colocadas na estufa a $60^{\circ} \mathrm{C}$ por três dias. As massas e os volumes de dez amostras de cada tratamento foram medidos antes e depois da exposição à água. A capacidade de retenção de água foi considerada como sendo a diferença percentual de absorção de água da madeira baseada nas massas medidas antes e após a exposição à água.

$$
W A(\%)=\frac{W w-W i}{W i} \times 100
$$

onde WW é a massa úmida após a imersão e Wi é a massa inicial antes de submergir na água.

\subsection{Eficiência de Exclusão de Umidade (MEE)}

A MEE expressa a percentagem de redução de WA da madeira tratada em relação à madeira sem tratamento, calculada baseando-se na absorção de água (WA) da madeira tratada e sem tratamento expostas ao mesmo teste de imersão anterior, segundo a fórmula: 


$$
\operatorname{MEE}(\%)=\left[1-\left(\frac{W a t}{W a c}\right)\right] \times 100
$$

Onde

Wat é a absorção de água da madeira tratada e Wac é a absorção de água da madeira sem tratamento.

Os resultados de ASE, WA e MEE estão apresentados na tabela 6.

Tabela 6 Eficiência Anti-Inchamento (ASE), Capacidade de Absorção de Água (WA) e Eficiência de Exclusão de Umidade (MEE) para os diversos tratamentos.

\begin{tabular}{lllll}
\hline Código de & Espécie & ASE (\%) & WA (\%) & MEE(\%) \\
Tratamento & de Madeira & & \\
\hline Controle & Sugi & & $180.75(6.3)$ & \\
BA & Sugi & $-3.20(2.3)$ & $109.64(6.2)$ & $39.34(7.2)$ \\
FFA & Sugi & $85.45(10.5)$ & $20.69(3.5)$ & $88.60(8.5)$ \\
FFA + BA & Sugi & $70.16(6.9)$ & $29.76(5.6)$ & $83.50(10.3)$ \\
FFA + BO & Sugi & $87.30(8.7)$ & $16.88(4.5)$ & $90.70(7.8)$ \\
FFA + BI & Sugi & $84.83(7.8)$ & $19.09(3.9)$ & $89.40(8.1)$ \\
Controle & Pinus & & $97.93(3.2)$ & \\
BA & Pinus & $-9.69(4.7)$ & $123.29(5.5)$ & $-25.89(6.4)$ \\
FFA & Pinus & $84.42(10.2)$ & $25.02(7.6)$ & $74.50(6.8)$ \\
FFA + BA & Pinus & $84.24(9.9)$ & $52.16(2.5)$ & $46.70(3.2)$ \\
FFA + BO & Pinus & $86.05(10.4)$ & $38.94(5.6)$ & $60.20(6.2)$ \\
FFA + BI & Pinus & $73.55(7.9)$ & $38.51(6.1)$ & $60.70(3.3)$ \\
\hline
\end{tabular}

Valores entre parênteses indicam o desvio padrão relacionado à média de dez medidas.

Amostras de sugi apresentaram melhores resultados para MEE quando tratados com as combinações FFA-compostos de boro ( $\mathrm{BA}, \mathrm{BI}$ e $\mathrm{BO}$ ) do que as amostras de pinus. Em ambos os casos, a Eficiência Anti-Inchamento (ASE) calculada foi considerada muito boa. O único resultado desvantajoso verificado foi o já esperado 
tratamento somente com o ácido bórico.

O gráfico da figura 43 relaciona a eficiência anti-inchamento (ASE) com o percentual de polímero ganho (WPG).

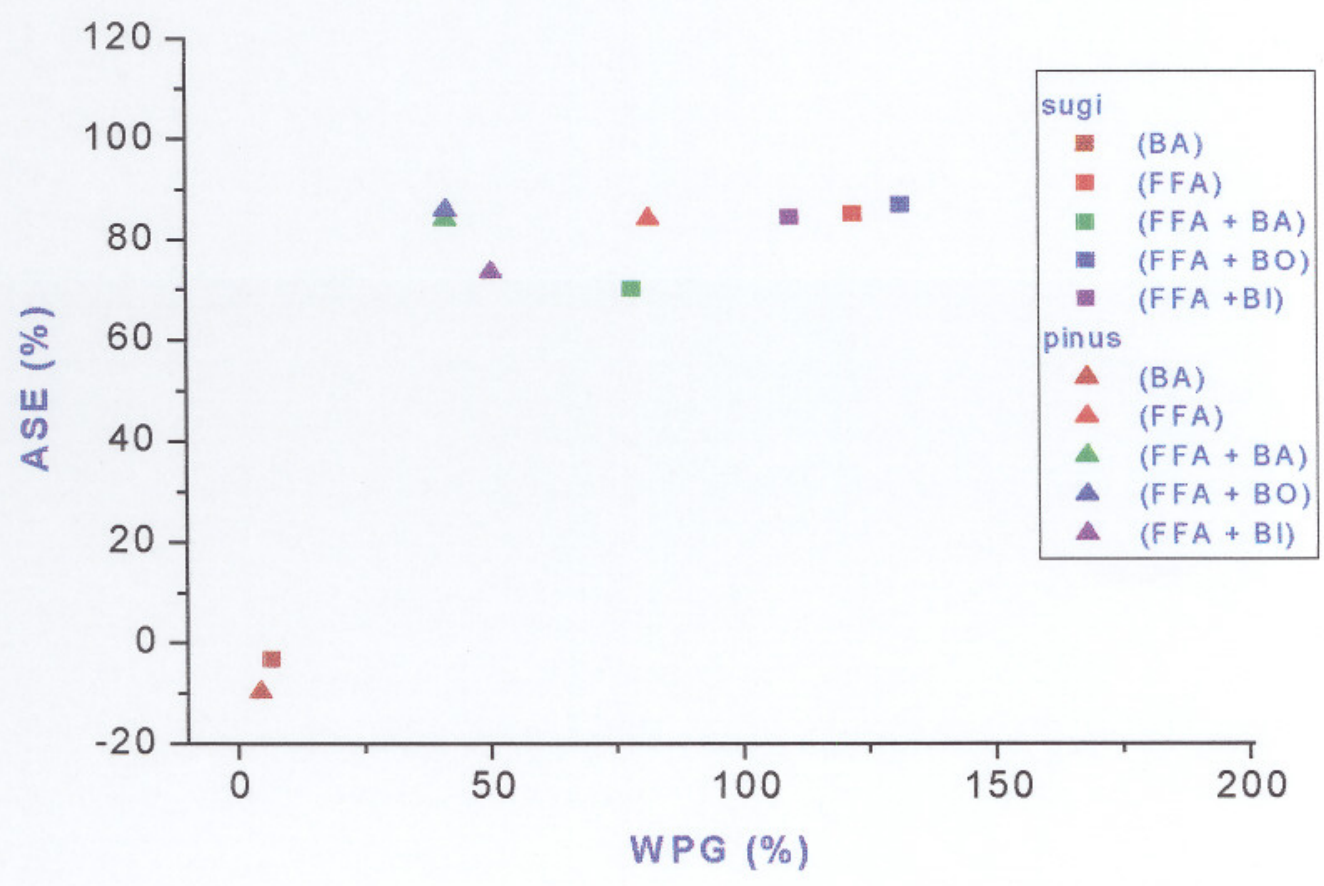

Figura 43- Relação da eficiência anti-inchamento (ASE) com o ganho percentual de polímero (WPG) para o sugi e o pinus, com os diversos tratamentos.

\subsection{Testes Biológicos}

Testes de resistência aos ataques de térmitas e de fungos foram conduzidos no Laboratório de Controle de Deterioração do Instituto de Pesquisas de Madeira, da Universidade de Kyoto, para avaliar a performance dos tratamentos com BA, FFA e FFA combinado com compostos de boro em relação à madeira sem tratamento. 


\subsubsection{Teste de Resistência ao ataque de Térmitas}

Amostras não submetidas e submetidas à lixiviação foram expostas ao ataque do destrutivo térmita subterrâneo Coptotermes formosanus Shiraki, de acordo com o Padrão JWPA No. 11-1 (1992), da Japanese Wood Preservation Association.

Cada amostra $\left[20(\mathrm{~T}) \times 20(\mathrm{R}) \times 10(\mathrm{~L}) \mathrm{mm}^{3}\right]$ foi colocada no centro de um recipiente cilíndrico de acrilico ( $80 \mathrm{~mm}$ de diâmetro interno e $60 \mathrm{~mm}$ de altura) com uma das bases vedadas com plaster de Paris (gesso), formando um fundo poroso de $5 \mathrm{~mm}$ de espessura (conforme figura 44). Neste recipiente cilíndrico de acrílico foram colocados 150 térmitas operários e 15 térmitas soldados, recolhidos aleatoriamente da colônia mantida no Laboratório de Controle de Deterioração, no campus de Uji, da Universidade de Kyoto - Japão. Cada recipiente de acrílico assim preparado foi depositado numa caixa bem tampada, forrada com algodão umedecido com água destilada para que os térmitas tenham suprimento de água ao longo do período de duração do teste. Estas caixas contendo os recipientes foram separadas segundo dois critérios:

a) pelo tipo de tratamento, e

b) se as amostras tinham sido lixiviadas ou não.

As caixas foram depositadas numa sala climatizada $\left(28^{\circ} \mathrm{C}\right.$ e $\left.\mathrm{RH}>80 \%\right)$, sem incidência de luz, por seis semanas, para teste de alimentação forçada.

A mortalidade dos térmitas e os danos visíveis foram determinados semanalmente. Ao final do período de teste, após efetuar uma cuidadosa limpeza, as amostras foram secas por 24 horas à temperatura ambiente e em estufa, por 24 horas, a $100^{\circ} \mathrm{C}$. A perda de massa de cada amostra foi determinada baseando-se na 
diferença entre as massas inicial e final, secas em estufa. Para cada tratamento foram utilizadas quatro replicatas.

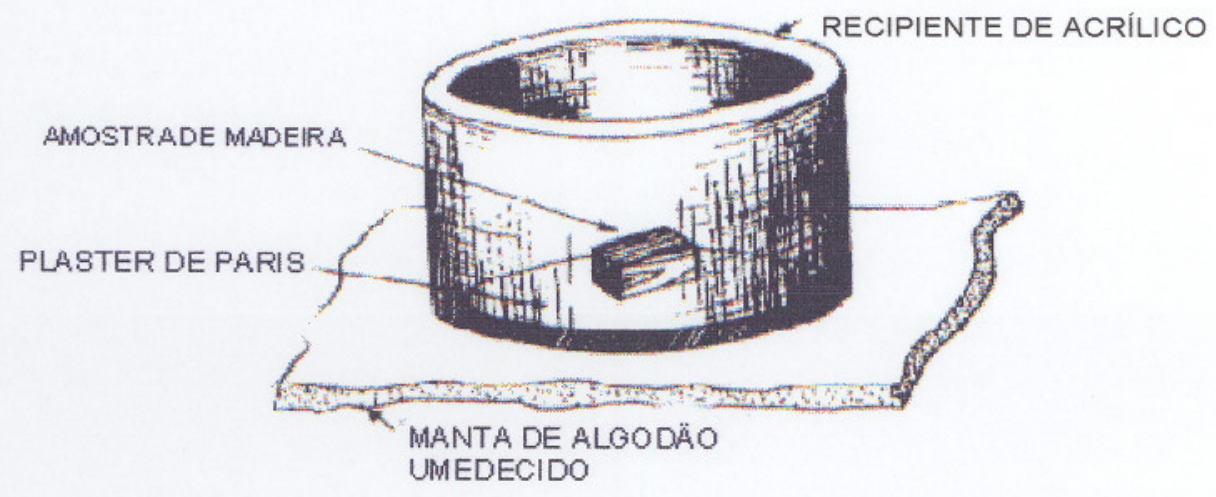

Figura 44- Amostra assentada no aparelho para exposição ao ataque dos térmitas subterrâneos Coptotermes formosanus Shiraki, de acordo com o padrão JWPA 11-1 (1992).

Os resultados são mostrados nas figuras 45 a 48 .

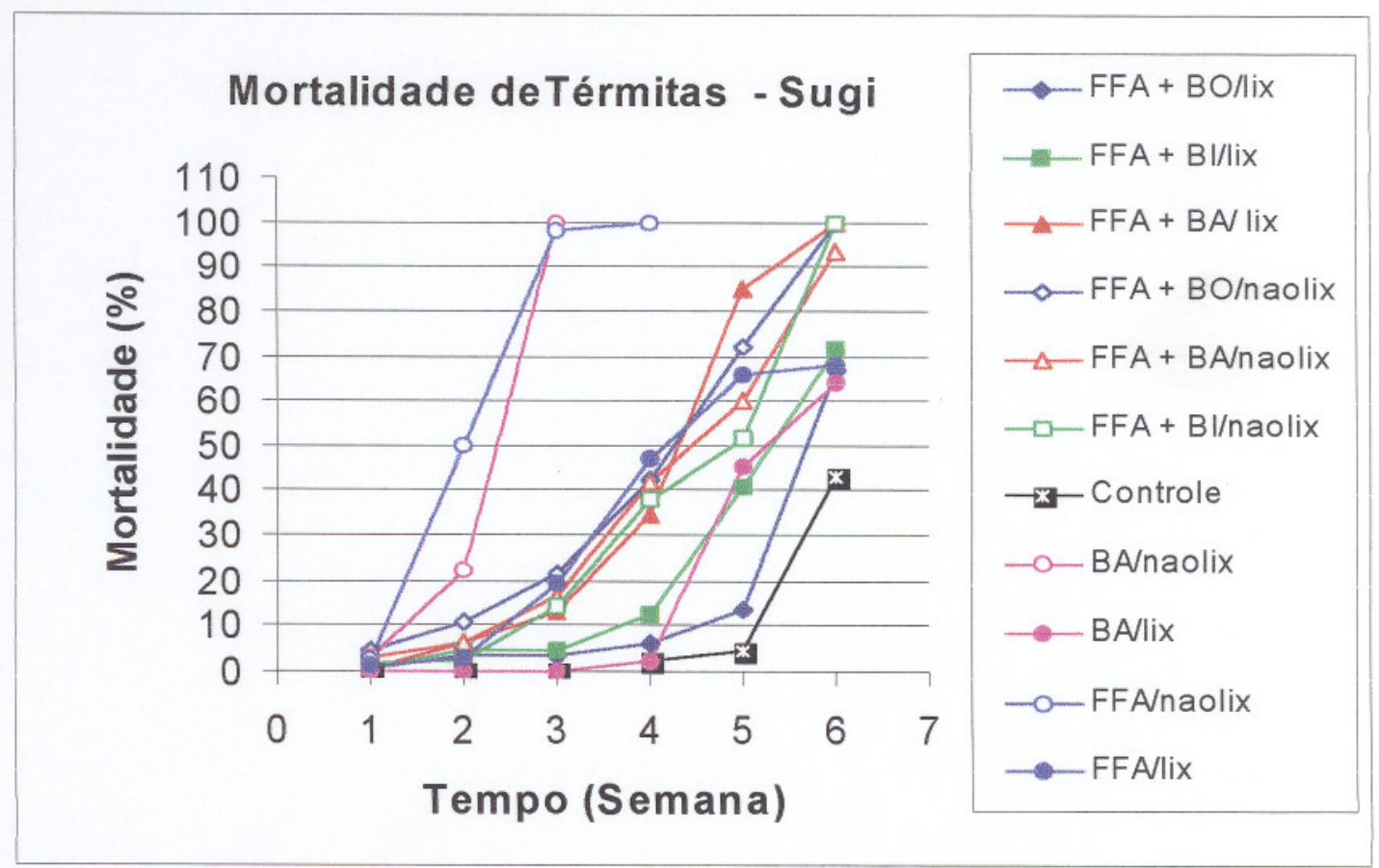

Figura 45- Evolução da Mortalidade de Térmitas ao longo de seis semanas de teste da espécie Sugi. 


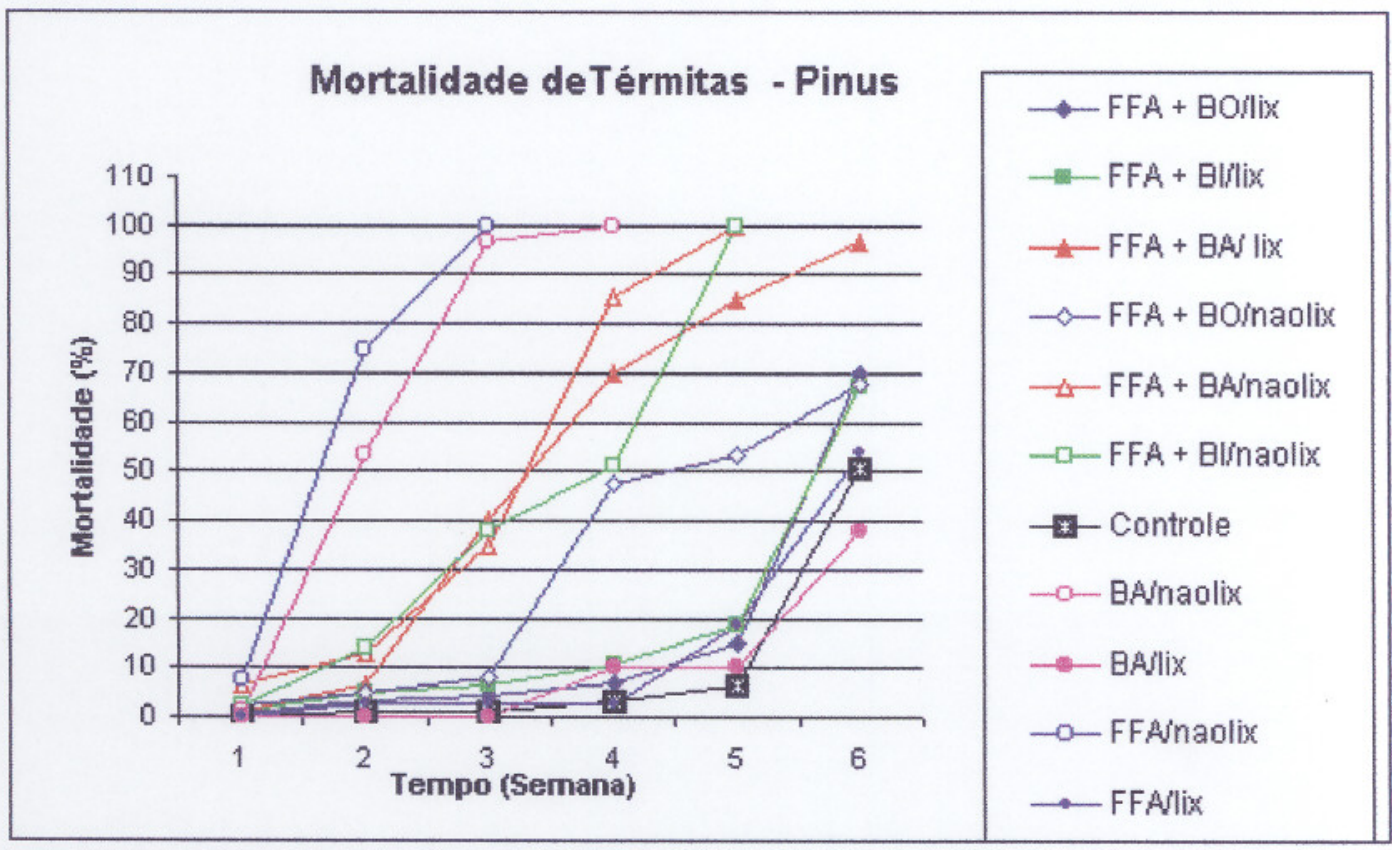

Figura 46- Evolução da Mortalidade de Térmitas ao longo de seis semanas de teste da espécie Pinus.

\section{Sugi}

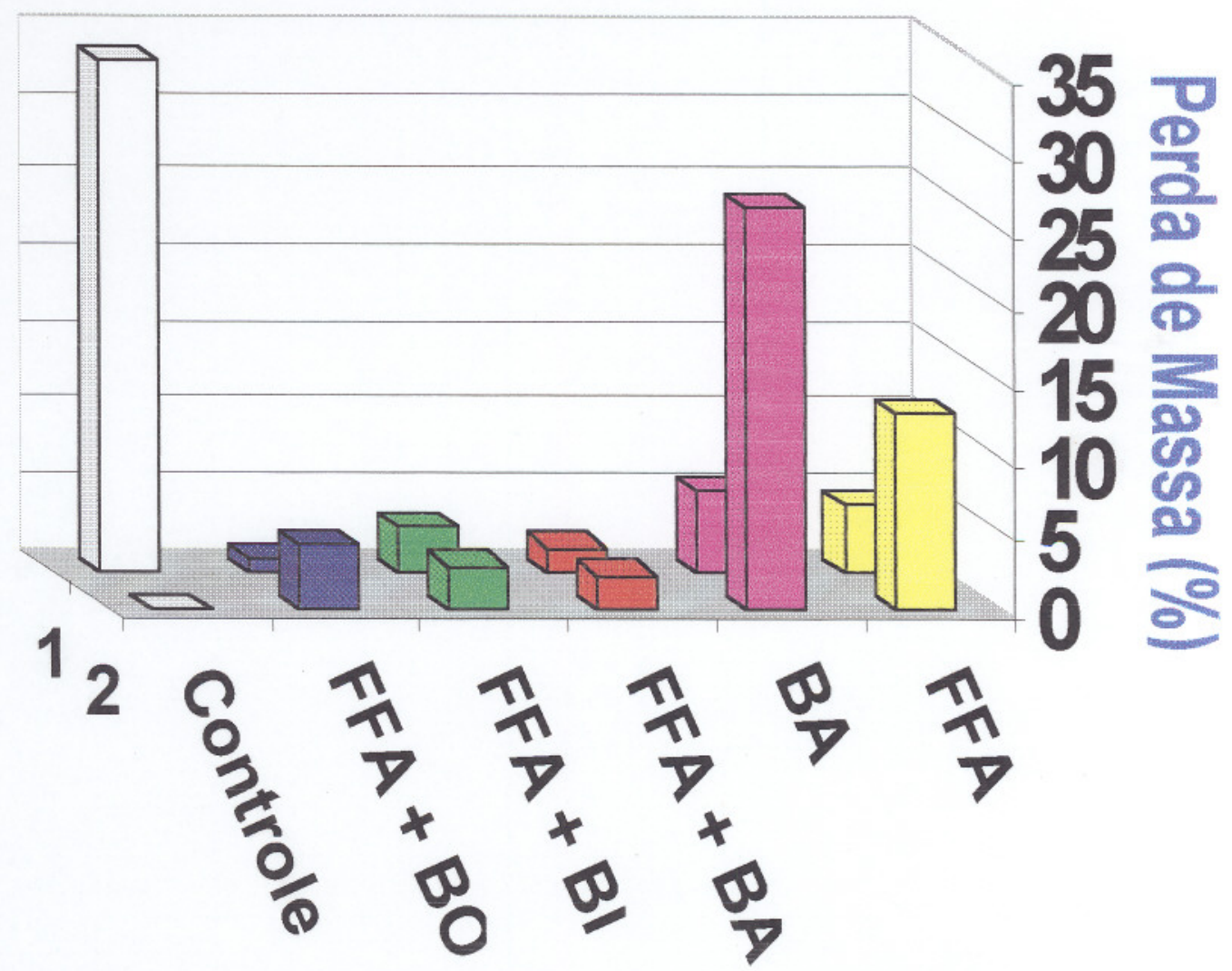

Figura 47- Perda de Massa (\%) da espécie Sugi após seis semanas de teste. 


\section{Pinus}

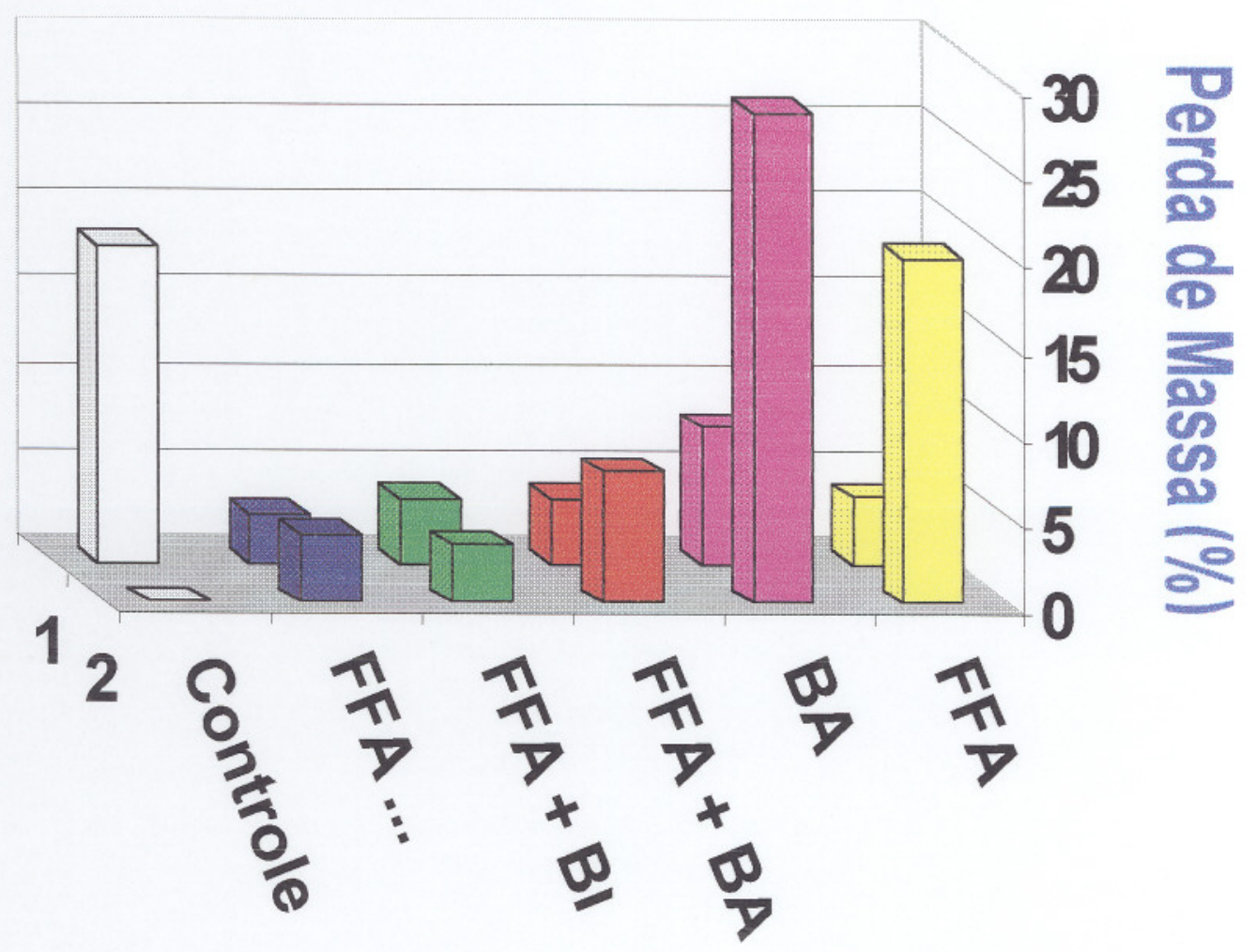

Figura 48- Perda de Massa (\%) da espécie Pinus após seis semanas de teste.

A mortalidade dos térmitas é mostrada nas figuras 45 e 46 . Todas as amostras tratadas mostraram um grande aumento na resistência ao ataque dos térmitas em relação às não tratadas, sugerindo um bom desempenho destes tratamentos. Contudo, a lixiviação cíclica resultou em acentuada redução na percentagem da mortalidade dos térmitas ainda que estes níveis sejam mais altos que os das amostras sem tratamento.

O tratamento somente com ácido bórico, nas amostras não submetidas à lixiviação, apresentou elevada taxa de mortalidade, o mesmo ocorrendo com o tratamento somente com FFA não submetido à lixiviação. Ambos apresentaram elevada taxa de mortalidade após três semanas de teste. $O$ tratamento somente com 
BA não impede que os térmitas ataquem a madeira, causando grande perda de massa, como mostram as figuras 47 e 48 . As amostras submetidas à lixiviação apresentaram perda de massa bem mais elevadas que as não submetidas à lixiviação, porém, considerando que a mortalidade no segundo caso atingiu quase $100 \%$ em três semanas, a perda foi significativa em comparação com outros resultados. Podemos afirmar que a morte dos térmitas é causada pela ingestão do BA, e, pela ação tóxica deste em seu intestino. Pela tabela 5 constata-se que o BA sofre grande lixiviação nos primeiros ciclos e depois estaciona. Mais de $30 \%$ do boro presente na solução de tratamento é lixiviado nos três primeiros ciclos. Os outros quase $70 \%$ de boro ficaram ligados aos polímeros naturais da madeira ou aprisionados por elas, não sendo mais detectado nos ciclos subsequentes. Nota-se também que o boro ligado ou aprisionado não apresentou mais eficiência como termicida.

Amostras tratadas somente com FFA quando lixiviadas têm seu desempenho comparável aos outros tratamentos combinados de FFA, não submetidos à lixiviação.

A combinação FFA + BO apresentou alta resistência do sugi aos térmitas quando não submetido à lixiviação. Mas, quando submetido à lixiviação, o tratamento com a combinação FFA + BA apresentou os melhores resultados, alcançando resultados comparáveis aos das amostras não submetidas à lixiviação, tanto no caso do sugi como no caso do pinus. Em ambos os casos a perda de massa foi bem menor que as amostras sem tratamento.

$\mathrm{O}$ tratamento com FFA $+\mathrm{Bl}$ apresentou melhor desempenho com o pinus quando não submetido à lixiviação. Em cinco semanas atingiu $100 \%$ de mortalidade dos térmitas, enquanto que, nas mesmas condições, com o sugi, foi atingido $50 \%$ de 
mortalidade. A perda de massa teve as mesmas proporções com amostras submetidas e não submetidas à lixiviação, o que significa que a lixiviação não torna a madeira mais digerível aos térmitas.

Pela tabela 5 verifica-se que a liberação do boro nos dois casos (FFA + BO e $\mathrm{FFA}+\mathrm{BI}$ ) é mais lenta desde o início. Houve um maior aprisionamento do boro entre as cadeias de polímeros ligados de FFA e madeira, ou o boro estava complexado. Após o sexto ou sétimo ciclo há um aumento da liberação do boro, provavelmente originado dos complexos mais estáveis que os liberados anteriormente.

Ao contrário dos casos anteriores, a liberação do boro da solução FFA + BA deu-se em grandes concentrações no início, diminuindo nos ciclos subsequentes. Contudo, continua em concentrações significativas até o décimo ciclo, levando-nos a supor que continuaria sendo liberado para a solução na mesma taxa até que todo o boro fosse lixiviado. Uma pequena percentagem remanescente foi suficiente para proporcionar o efeito termicida mesmo às amostras submetidas à lixiviação. Significa que o boro estava aprisionado pelas cadeias mas não estava complexado.

Em relação às amostras de pinus tratadas, submetidas à lixiviação, a percentagem de mortalidade de térmitas apresentou um considerável incremento após cinco semanas de teste enquanto que as amostras de sugi apresentaram um incremento gradual a partir de semanas anteriores.

As figuras 49 a 51 confirmam que as amostras tratadas com as combinações FFA-compostos de boro não foram vigorosamente atacadas pelos térmitas, aparentemente. Isto porque os térmitas costumam se alojar mais internamente, devido à temperatura e à ausência de luz, podendo causar grande degradação sem demonstrá-lo em toda a sua extensão. Porém, tanto nos casos de sugi como de 
pinus, apenas pequenas quantidades superficiais de algumas amostras submetidas à lixiviação foram beliscadas. Amostras não submetidas à lixiviação não apresentaram marcas consideráveis. Em ambos os casos, a percentagem de perda de massa foi muito baixa em comparação às amostras sem tratamento. Contudo, no caso do tratamento somente com BA, as amostras submetidas à lixiviação foram severamente danificadas, sendo que no caso do pinus a perda de massa foi maior que as amostras sem tratamento. Esta aparente disparidade no resultado pode ser creditada ao fato de não ter-se submetido as amostras sem tratamento à lixiviação cíclica, porque este processo, por si só, causa lixiviação de compostos solúveis e/ou voláteis dos componentes estruturais da madeira. Principalmente porque, se compararmos as duas espécies sem tratamento, no caso do sugi, a perda de massa foi bem maior que no caso do pinus. As amostras de sugi sem tratamento foram severamente danificadas talvez devido ao fato de sua densidade ser mais baixa que a do pinus. Por isso, a figura 47 mostra que todas as combinações foram eficientes em prevenir o ataque das térmitas ao sugi. $E$ a figura 48 mostra que os tratamentos somente com FFA e somente com BA, quando submetidos à lixiviação, não são eficientes para prevenir 0 ataque das térmitas ao pinus pois causam perda maior que a madeira sem tratamento. 


\section{Controle}
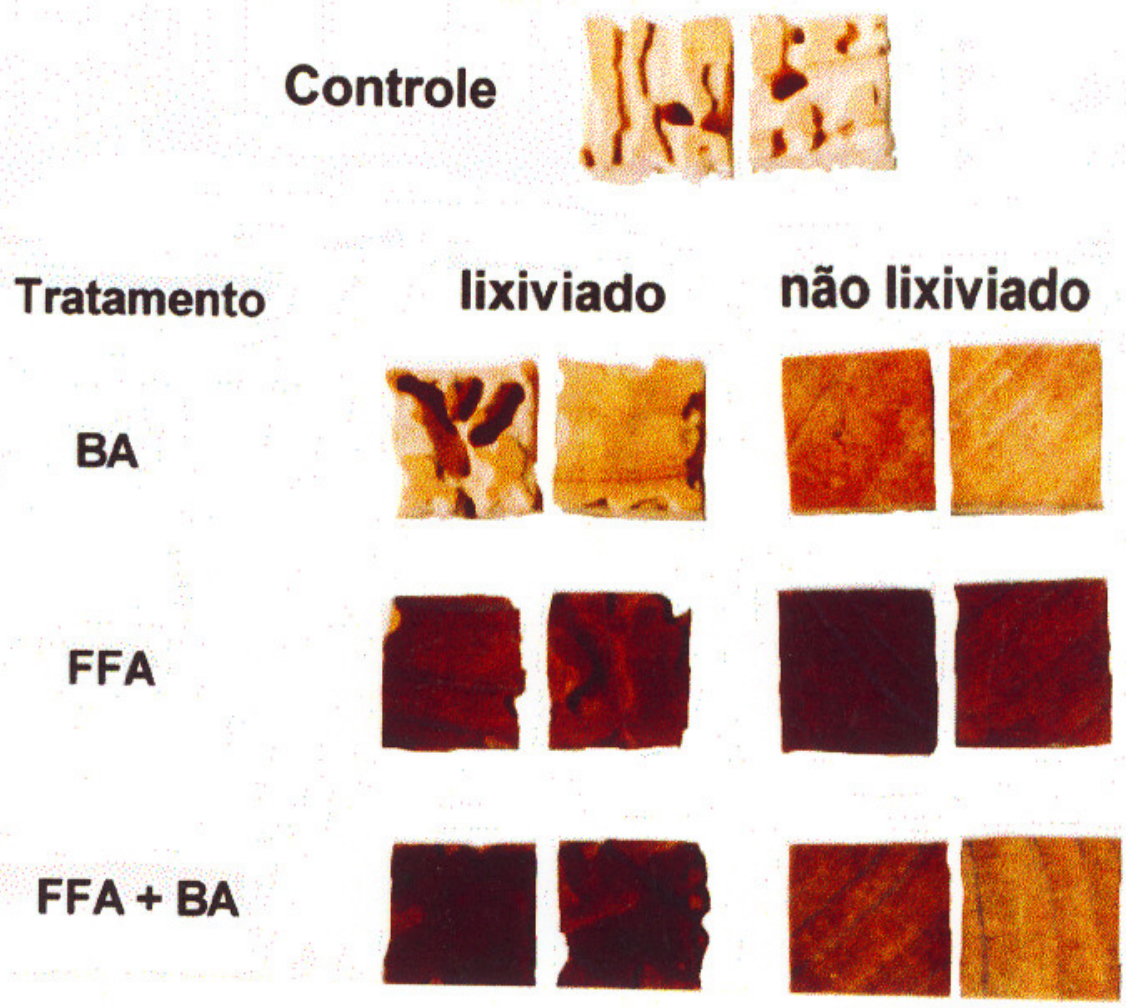

Figura 49- Aparência visual do Pinus submetido ao teste de resistência aos térmitas.

Controle

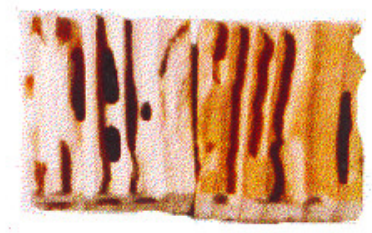

Tratamento

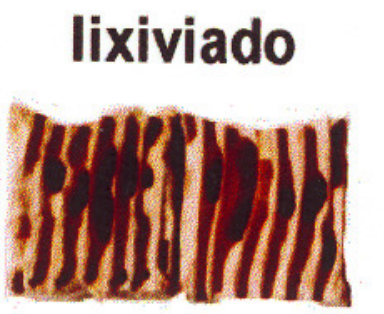

não lixiviado

BA

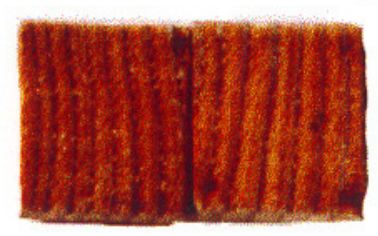

FFA
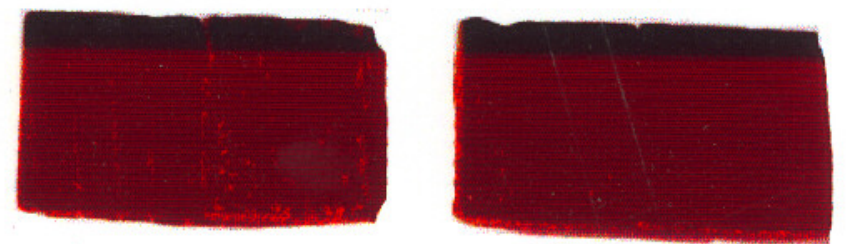

Figura 50- Aparência visual do Sugi submetido ao teste de resistência aos térmitas. 


\section{$\mathrm{FFA}+\mathrm{BA}$}

$\mathrm{FFA}+\mathrm{BO}$
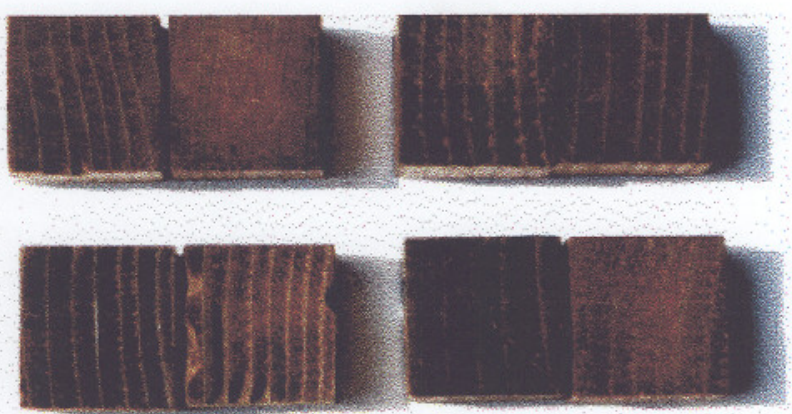

$\mathrm{FFA}+\mathrm{BI}$

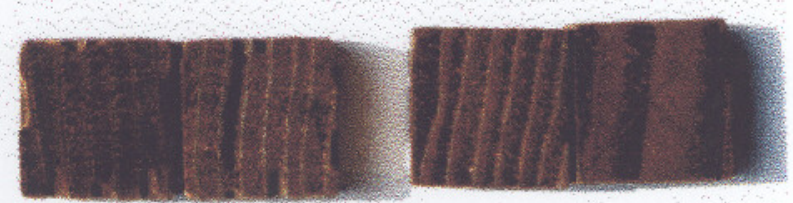

Figura 51- Aparência visual do Sugi submetido ao teste de resistência às térmitas.

\subsubsection{Teste de Deterioração por Fungos}

O teste de deterioração foi conduzido de acordo com os Padrões JWPA ("Japan Wood Preservation Association") № 3-1992 e JIS (Japan Industrial Standard) Z 21191977. Foi usado um fungo de podridão parda, Tyromyces palustris (Berk. et Curt.) Murr. [FFPRI 0507: número de cessão do fungo do Forestry and Forest Products Research Institute, Tsukuba, Japan], aqui referido como TYP, e um fungo de podridão branca, Coriolus versicolor (L. ex Fr.) Quél. [FFPRI 1030], aqui referido como COV.

As amostras foram secas em estufa a $100^{\circ} \mathrm{C}$ por 24 horas e mantidas no dessecador até massa constante. Suas massas foram medidas antes de serem seladas e esterilizadas com óxido de etileno gasoso. $250 \mathrm{~g}$ de areia de quartzo foram colocadas em cada vidro-teste (figura 52). Os vidros foram estabilizados por 3 dias. Após isto, foram esterilizados e inoculados com o meio de cultura $(80 \mathrm{ml}$ da solução 
nutriente para teste com TYP e $85 \mathrm{ml}$ para teste com COV). Todas estas operações foram efetuadas em ambiente cuidadosamente esterilizado.

Os vidros testes foram depositados em sala condicionada a $26^{\circ} \mathrm{C}$ por 10 dias para que a micélia fungal se desenvolvesse. Observamos se houve ou não a contaminação por outros fungos.

Três amostras foram colocadas em cada vidro-teste contendo o meio de cultura e foram inoculadas com solução estoque de cultura de COV (4ml) e TYP(4ml).

O meio de cultura foi preparado da seguinte maneira:

\begin{tabular}{lc}
$\mathrm{MgSO}_{4} 7 \mathrm{H}_{2} \mathrm{O}$ & $2,0 \mathrm{~g}$ \\
$\mathrm{KH}_{2} \mathrm{PO}_{4}$ & $3,0 \mathrm{~g}$ \\
Glucose & $25,0 \mathrm{~g}$ \\
\hline Extrato de Malte & $10,0 \mathrm{~g}$ \\
\hline Peptona & $5,0 \mathrm{~g}$ \\
\hline Água destilada & $1000 \mathrm{ml}$
\end{tabular}

Os vidros testes foram depositados novamente na sala condicionada a $26^{\circ} \mathrm{C}$ por 12 semanas. Nove amostras foram utilizadas para cada nivel de tratamento: Coriolus versicolor (COV), Tyromyces palustris (TYP). Para as amostras submetidas ao ataque do fungo Tyromyces palustris (TYP) foi colocada uma rede plástica para que os blocos de madeira não ficassem em contato permanente com a suspensão fungal. 


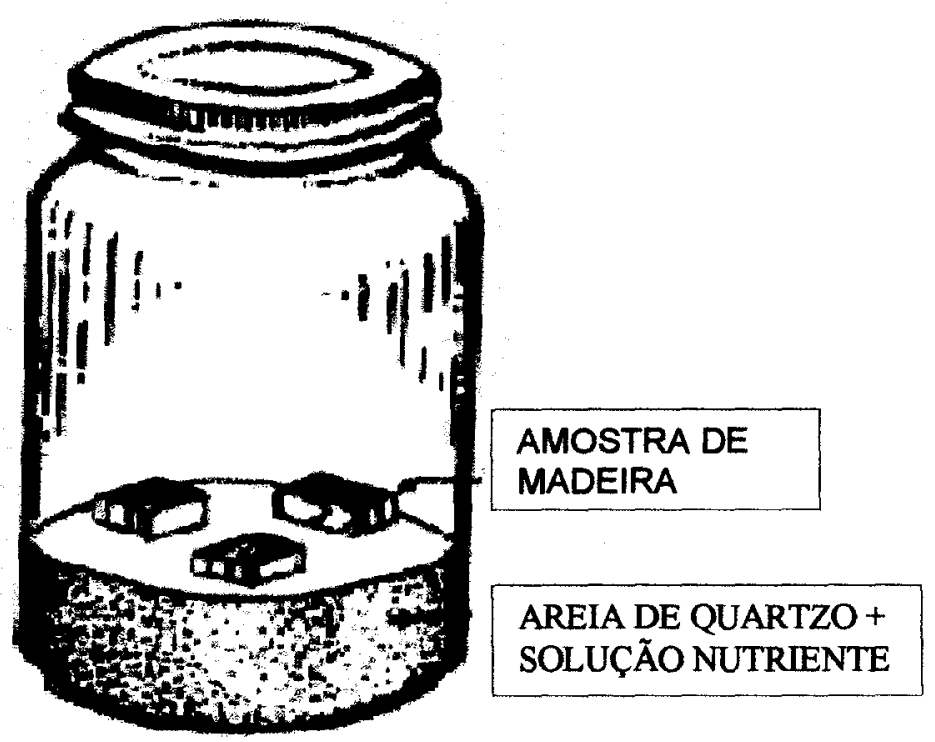

Figura 52- Vidro teste de exposição ao ataque de fungos.

Após o período de teste, as amostras foram retiradas e lavadas cuidadosamente, retirando-se os materiais aderidos à superfície ou depositados no interior da amostra, com uma escova macia. Secaram-se à temperatura ambiente por 24 horas, e depois foram colocadas em estufa a $100^{\circ} \mathrm{C}$ por outras 24 horas. As massas foram, então, medidas, e a extensão do ataque dos fungos foi calculada baseando-se na percentagem de massa perdida. A resistência à deterioração relativa foi calculada através da seguinte fórmula:

Resistência à Deterioração Relativa $(\mathrm{RDR})=\frac{A}{A o}$

Onde $A_{0}=100-$ percentagem de perda de massa corrigida do controle;

$A=100$ - percentagem de perda de massa corrigida da amostra.

Os resultados estão apresentados nas tabela 7 e 8 , e nos gráficos das figuras53 a 56. 
Tabela 7 Percentagem de Perda de Massa e Resistência à Deterioração Relativa de espécies de Sugi submetidas ao Teste de Resistência ao ataque de Fungos.

\begin{tabular}{|c|c|c|c|c|c||}
\hline Tratamento & Lixiviação & Fungo & WPG (\%) & $\begin{array}{c}\text { Perda de Massa } \\
(\%)\end{array}$ & $\begin{array}{c}\text { Resistência à } \\
\text { Deterioração } \\
\text { relativa }\end{array}$ \\
\hline Controle & Não & COV & & $48.57(12.1)$ & \\
\hline Controle & Não & TYP & & $40.03(9.0)$ & 1.43 \\
\hline FFA & Sim & TYP & $123.01(34.1)$ & $13.65(1.4)$ & 1.71 \\
\hline FFA & Sim & COV & $95.04(40.6)$ & $11.89(0.5)$ & 1.52 \\
\hline FFA & Não & TYP & $143.41(37.6)$ & $8.80(0.6)$ & 1.76 \\
\hline FFA & Não & COV & $114.16(37.2)$ & $9.35(0.4)$ & 1.00 \\
\hline BA & Sim & TYP & $0.12(0.1)$ & $39.86(4.4)$ & 0.95 \\
\hline BA & Sim & COV & $0.12(0.2)$ & $51.00(0.17)$ & 1.65 \\
\hline BA & Não & TYP & $6.5(0.4)$ & $1.11(0.2)$ & 1.92 \\
\hline BA & Não & COV & $6.2(0.8)$ & $1.20(0.5)$ & 1.33 \\
\hline FFA + BA & Sim & TYP & $69.34(12.4)$ & $19.93(6.0)$ & 1.55 \\
\hline FFA + BA & Sim & COV & $67.82(11.9)$ & $20.42(7.1)$ & 1.60 \\
\hline FFA + BA & Não & TYP & $78.60(13.7)$ & $3.81(1.3)$ & 1.87 \\
\hline FFA + BA & Não & COV & $77.57(12.9)$ & $3.90(0.9)$ & 1.36 \\
\hline FFA + BO & Sim & TYP & $84.01(20.1)$ & $18.22(4.5)$ & 1.56 \\
\hline FFA + BO & Sim & COV & $82.76(17.4)$ & $19.71(3.9)$ & 1.58 \\
\hline FFA + BO & Não & TYP & $86.77(19.2)$ & $5.14(1.6)$ & 1.84 \\
\hline FFA + BO & Não & COV & $81.17(23.9)$ & $5.22(2.0)$ & 1.35 \\
\hline FFA + BI & Sim & TYP & $76.73(14.3)$ & $19.31(5.2)$ & 1.55 \\
\hline FFA + BI & Sim & COV & $75.64(11.9)$ & $20.40(4.9)$ & 1.57 \\
\hline FFA + BI & Não & TYP & $80.85(13.3)$ & $5.64(1.7)$ & 1.83 \\
\hline FFA + BI & Não & COV & $81.32(14.2)$ & $5.82(1.8)$ & \\
\hline Vaa & & \\
\hline
\end{tabular}

Valores entre parênteses significam o desvio padrão da média de 9 amostras de cada teste. 
Tabela 8 Percentagem de Perda de Massa e Resistência à Deterioração Relativa de espécies de Pinus submetidas ao Teste de Resistência ao ataque de Fungos.

\begin{tabular}{|c|c|c|c|c|c|}
\hline Tratamento & Lixiviação & Fungo & WPG (\%) & \multirow{2}{*}{$\begin{array}{c}\text { Perda de Massa } \\
(\%)\end{array}$} & \multirow{2}{*}{$\begin{array}{c}\text { Resistência à } \\
\text { Deterioração } \\
\text { relativa }\end{array}$} \\
\hline & & & & & \\
\hline Controle & Não & TYP & & 43.18 & \\
\hline Controle & Não & $\mathrm{COV}$ & & 42.56 & \\
\hline FFA & Sim & TYP & $78.88(18.3)$ & $11.45(2.1)$ & 1.56 \\
\hline FFA & Sim & $\mathrm{COV}$ & $76.87(15.6)$ & $12.00(0.8)$ & 1.53 \\
\hline FFA & Não & TYP & $84.57(10.3)$ & $8.33(0.8)$ & 1.61 \\
\hline FFA & Não & COV & $85.29(10.9)$ & $9.69(0.9)$ & 1.57 \\
\hline $\mathrm{BA}$ & Sim & TYP & $0.2(0.3)$ & $45.32(5.8)$ & 0.96 \\
\hline $\mathrm{BA}$ & Sim & COV & $0.03(0.3)$ & $49.30(6.2)$ & 0.88 \\
\hline $\mathrm{BA}$ & Não & TYP & $4.31(0.6)$ & $1.20(0.3)$ & 1.74 \\
\hline$B A$ & Não & $\mathrm{COV}$ & $4.29(0.5)$ & $1.12(0.3)$ & 1.72 \\
\hline $\mathrm{FFA}+\mathrm{BA}$ & Sim & TYP & $38.01(6.2)$ & $15.93(4.4)$ & 1.48 \\
\hline $\mathrm{FFA}+\mathrm{BA}$ & Sim & $\mathrm{COV}$ & $35.96(6.8)$ & $16.75(3.8)$ & 1.45 \\
\hline $\mathrm{FFA}+\mathrm{BA}$ & Não & TYP & $47.69(13.5)$ & $1.24(0.3)$ & 1.74 \\
\hline $\mathrm{FFA}+\mathrm{BA}$ & Não & $\mathrm{COV}$ & $46.02(9.9)$ & $1.64(0.3)$ & 1.71 \\
\hline $\mathrm{FFA}+\mathrm{BO}$ & Sim & TYP & $45.86(6.3)$ & $16.53(3.2)$ & 1.47 \\
\hline $\mathrm{FFA}+\mathrm{BO}$ & Sim & $\mathrm{COV}$ & $46.26(6.0)$ & $17.27(2.9)$ & 1.44 \\
\hline $\mathrm{FFA}+\mathrm{BO}$ & Não & TYP & $39.94(8.8)$ & $4.35(0.9)$ & 1.68 \\
\hline $\mathrm{FFA}+\mathrm{BO}$ & Não & COV & $40.02(8.6)$ & $4.41(0.8)$ & 1.66 \\
\hline $\mathrm{FFA}+\mathrm{BI}$ & Sim & TYP & $28.49(8.2)$ & $14.56(3.5)$ & 1.50 \\
\hline $\mathrm{FFA}+\mathrm{BI}$ & Sim & $\mathrm{COV}$ & $30.07(7.6)$ & $15.36(4.2)$ & 1.47 \\
\hline $\mathrm{FFA}+\mathrm{BI}$ & Não & TYP & $33.82(5.2)$ & $2.90(0.4)$ & 1.71 \\
\hline $\mathrm{FFA}+\mathrm{BI}$ & Não & $\mathrm{COV}$ & $31.21(5.3)$ & $3.08(1.2)$ & 1.69 \\
\hline
\end{tabular}




\section{Perda de Massa (\%) -sugi (TYP)}

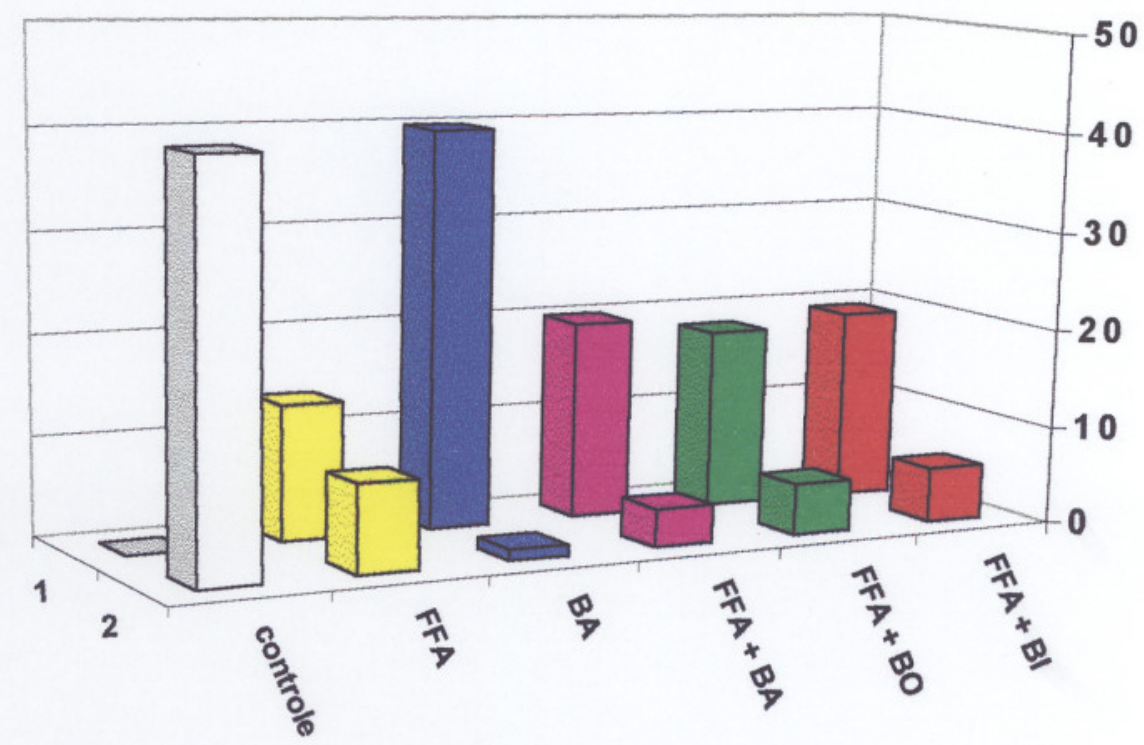

Figura 53- Perda de massa (\%) do sugi submetido aos fungos da podridão parda.

\section{Perda de Massa (\%) - sugi (COV)}

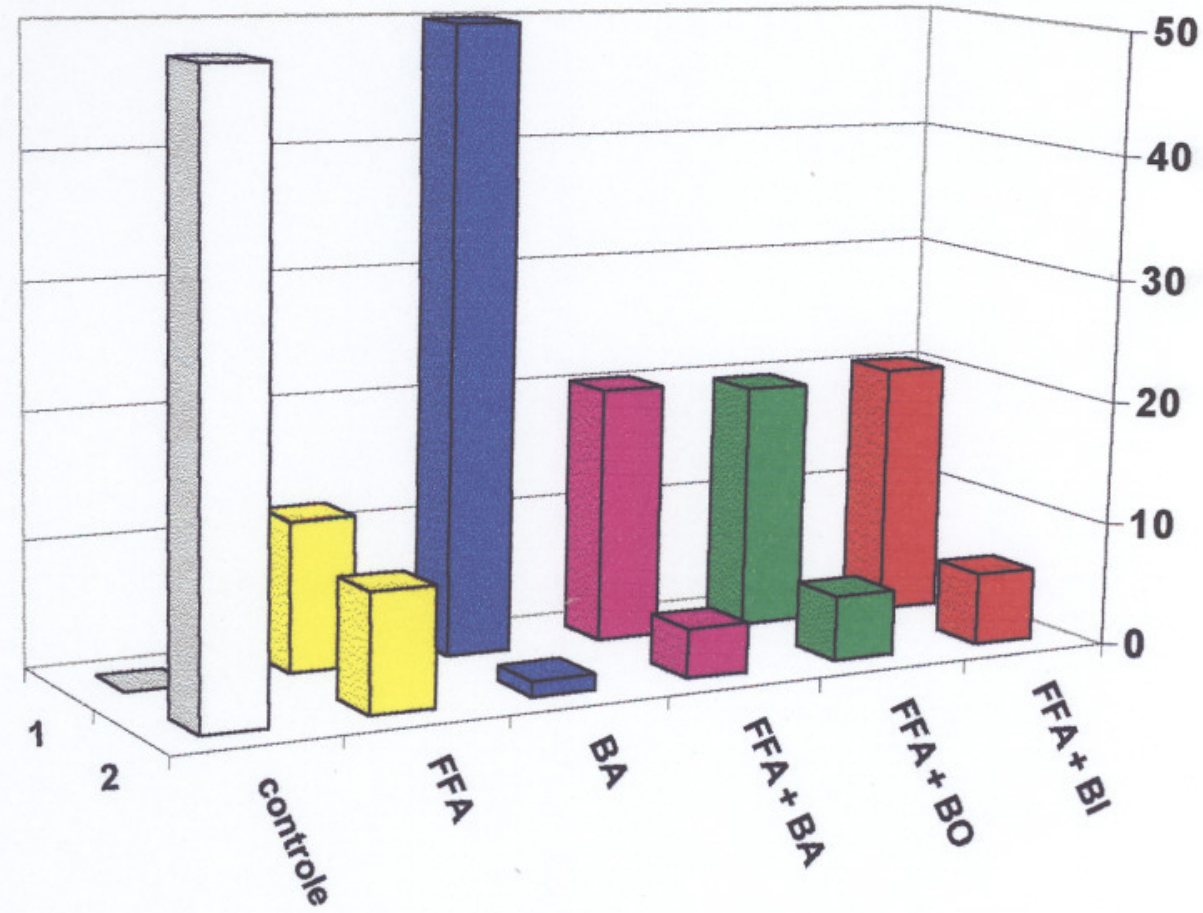

Figura 54- Perda de massa (\%) do sugi submetido aos fungos da podridão branca. 


\section{Perda de Massa (\%) - pinus (TYP)}

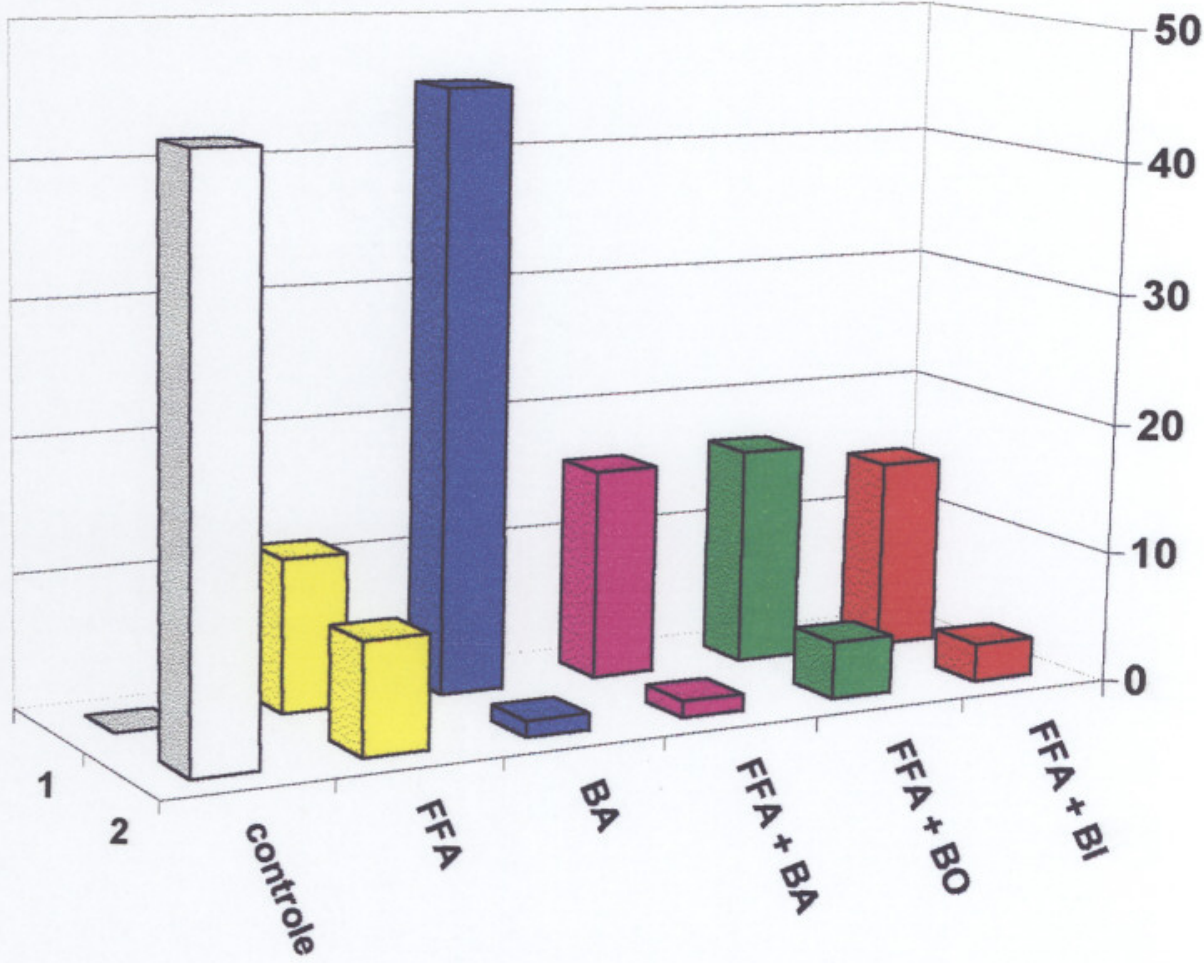

Figura 55- Perda de massa (\%) do pinus submetido aos fungos da podridão parda.

\section{Perda de Massa (\%) - pinus (cov)}

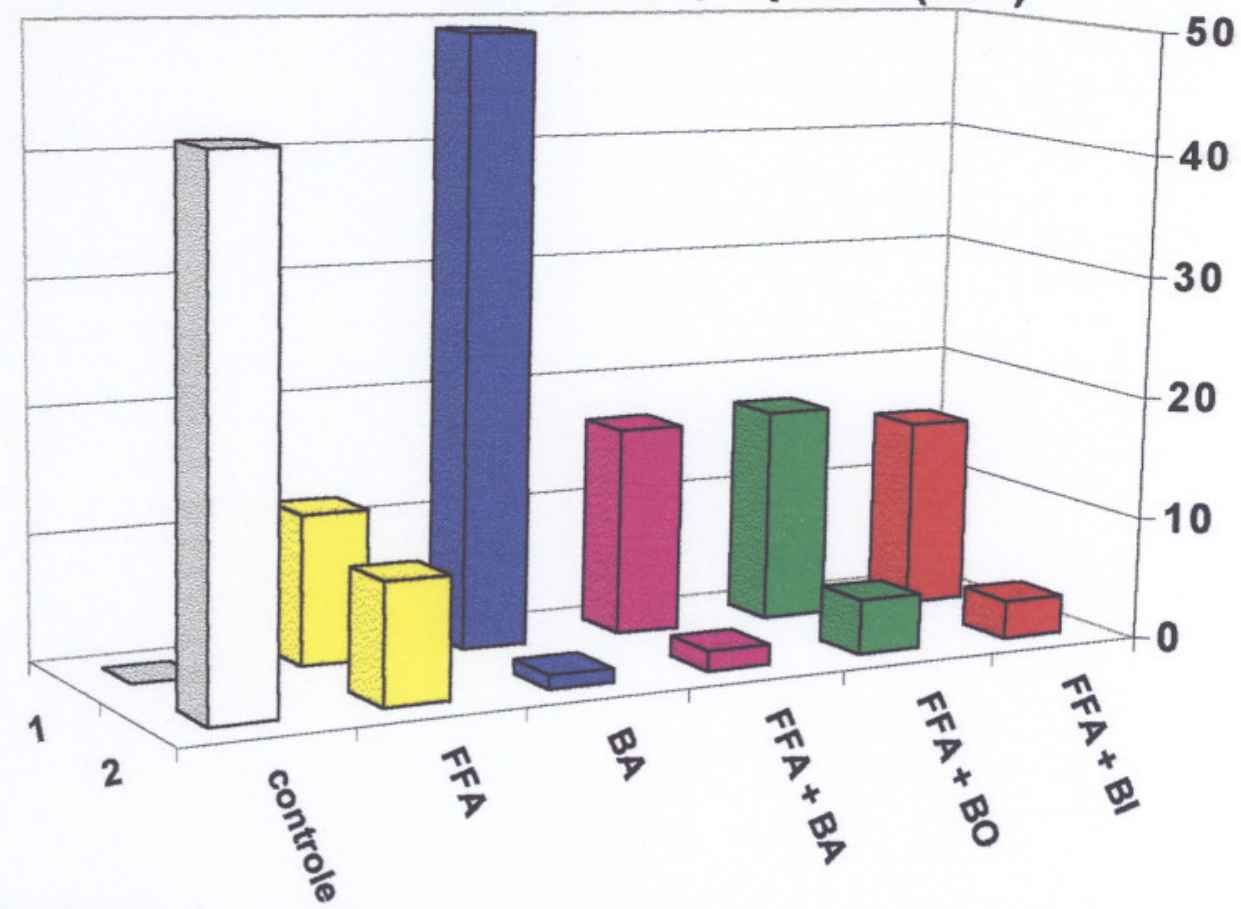

Figura 56- Perda de massa (\%) do pinus submetido aos fungos da podridão parda. 


\section{Observações no Microscópio Eletrônico de Varredura-}

Amostras tratadas e sem tratamento foram submetidas à observações no microscópio eletrônico de varredura. Seções muito finas do plano radial das amostras foram cortadas utilizando-se lâmina especial. As amostras foram recobertas com um filme de ouro. As observações foram efetuadas por um microscópio da Hitachi Modelo S-500 SEM, do Instituto de Pesquisas de Madeira (Wood Research Institute), da Universidade de Kyoto. As imagens estão apresentadas na figura 57. Tanto em amostras tratadas com nas amostras sem tratamento foi possível observar os danos promovidos pelos fungos.

As amostras de sugi apresentaram resistência à deterioração relativa levemente superior aos fungos da podridão branca Coriolus versicolor (COV). O COV causou maior perda de peso ao sugi sem tratamento, ou seja, foi mais atacado.

As amostras de pinus apresentaram resistência à deterioração relativa superior ao fungo da podridão parda TYP.

O pinus sem tratamento foi mais atacado pelos fungos TYP.

Podemos concluir que os tratamentos utilizados foram eficazes em retardar ou estacionar a degradação da madeira pelos fungos, principalmente quando não submetidas ao processo de lixiviação. Dentre os tratamentos avaliados os resultados apresentados pelo FFA foi surpreendente pois tanto as amostras não lixiviadas como as submetidas à lixiviação apresentaram alta taxa de RDR.

Não submetidas à lixiviação, o tratamento somente com BA apresentou a melhor resistência relativa, seguido pelo tratamento $F F A+B A, F F A+B O, F F A+B I$, por último o tratamento somente com FFA. 
Quando submetidas à lixiviação, o tratamento somente com FFA apresentou a melhor resistência relativa, seguido pelo tratamento $F F A+B O, F F A+B A, F F A+B I$ e BA.
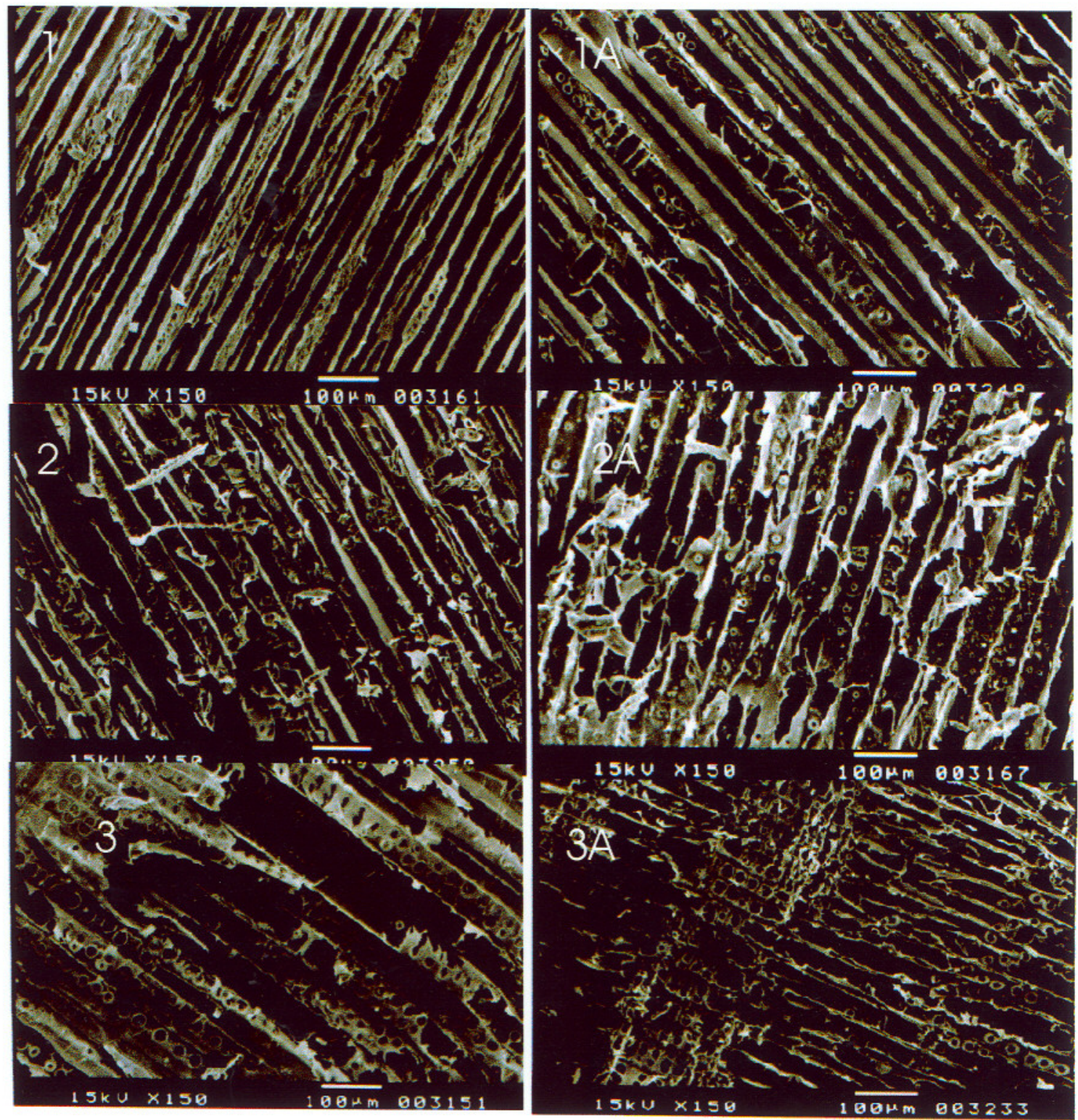

Figura 57- Micrografias de madeiras submetidas à deterioração por fungos.

1 Sugi $(F F A+B I)$ submetido a TYP

2 Sugi $(F F A+B I)-C O V$

3 Pinus (FFA + BA) - TYP
$1 \mathrm{~A}$ Sugi (sem tratamento) - TYP

2A Sugi (sem tratamento) - COV

3 A Pinus (sem tratamento) - TYP 
O efeito da lixiviação é sentido fortemente pelo tratamento somente com BA.

Os compostos de boro agem principalmente sobre os fungos da podridão parda. Todas as amostras tratadas mostraram evidências de terem sido mais atacadas pelos fungos da podridão branca principalmente nas amostras lixiviadas. $\mathrm{A}$ única exceção foi o caso do sugi tratado somente com FFA, onde o TYP causou maior perda de peso.

O mecanismo pode ser explicado pelo intercruzamento entre o polímero de FFA e os polímeros naturais da madeira, ocorrido do lúmem para a superfície, o que impediu a ação dos TYP que metabolizam somente as frações de carbohidratos da madeira. O processo se inicia com o ataque dos COV, degradadores da lignina, à camada S3 primeiro, e , em seguida, à lamela média, antes de iniciar o ataque à camada $S_{2}$. Porém, a camada $S_{3}$ é a mais pobre em lignina (figura 3) e a lamela média é a mais resistente tanto ao COV como ao TYP. E os fungos da podridão parda (TYP) só podem iniciar o seu ataque depois que os fungos da podridão branca tenham degradado a lignina pois esta mantém as cadeias de celulose unidas. COV e TYP atacam a camada $S_{2}$ conjuntamente. A camada $S_{2}$ é a mais rica rica em celulose e hemiceluloses. E é menos resistente aos fungos da podridão parda. Essa seqüência causou o enfraquecimento dos TYP.

Em relação aos controles, a percentagem de perda de peso foi dez vezes maior, em média, que a das amostras tratadas.

Pelas micrografias da figura 57 observa-se que os fungos da podridão parda não produzem uma degradação de maneira uniforme e os efeitos visuais não traduzem a extensão de seus danos pois causam grande redução na resistência mecânica sem contudo, aparentar grande devastação. 
Os fungos da podridão branca, ao contrário, apresentam os efeitos da degradação sofrida intimamente ligados aos efeitos visuais. Nota-se que houve a degradação dos polímeros, a formação de cavidades e a formação de colônias de fungos. 


\subsection{Teste de Índice de Oxigênio}

\section{Preparo da Amostra}

Amostras de sugi e pinus medindo $120 \mathrm{~mm}(\mathrm{~L}) \times 6.5 \mathrm{~mm}(\mathrm{R}) \times 0.23 \mathrm{~mm}(\mathrm{~T})$ foram impregnadas com as combinações de FFA-composto de boro, segundo a tabela 3. As amostras tanto de pinus quanto de sugi foram submetidas à lixiviação cíclica de acordo com a Norma Técnica JIS A 9201-1991, com dez ciclos de lixiviação usando água deionizada, avolumado como sendo 10 vezes o volume das amostras testadas para remover os materiais solúveis em água, seguido de evaporação dos resíduos voláteis.

\section{Teste de Índice de Oxigênio}

As amostras impregnadas foram submetidas ao teste de incombustibilidade segundo uma combinação das Normas Técnicas ASTM D 2863-77 - Measuring the Minimum Oxygen Concentration to Support Candle-like Combustion of Plastics (Oxygen Index), em anexo, e JIS A 7201-1976 - Testing Method for Flammability of Polymeric Materials Using the Oxygen Index Method.

O Índice de Oxigênio é definido como a concentração mínima de oxigênio expresso como percentagem de volume, em uma mistura de oxigênio e nitrogênio fluindo através de uma coluna de vidro, que suporta a combustão flamejante de um material polimérico, à temperatura ambiente, sob as concentraçōes aqui definidas. 0 equilíbrio é estabelecido pela relação entre o calor gerado da combustão da amostra 
e o calor perdido para as vizinhanças, que pode ser determinado pelo tempo de combustão ou pelo comprimento da amostra queimada. A coluna de teste é mostrada na figura 58.

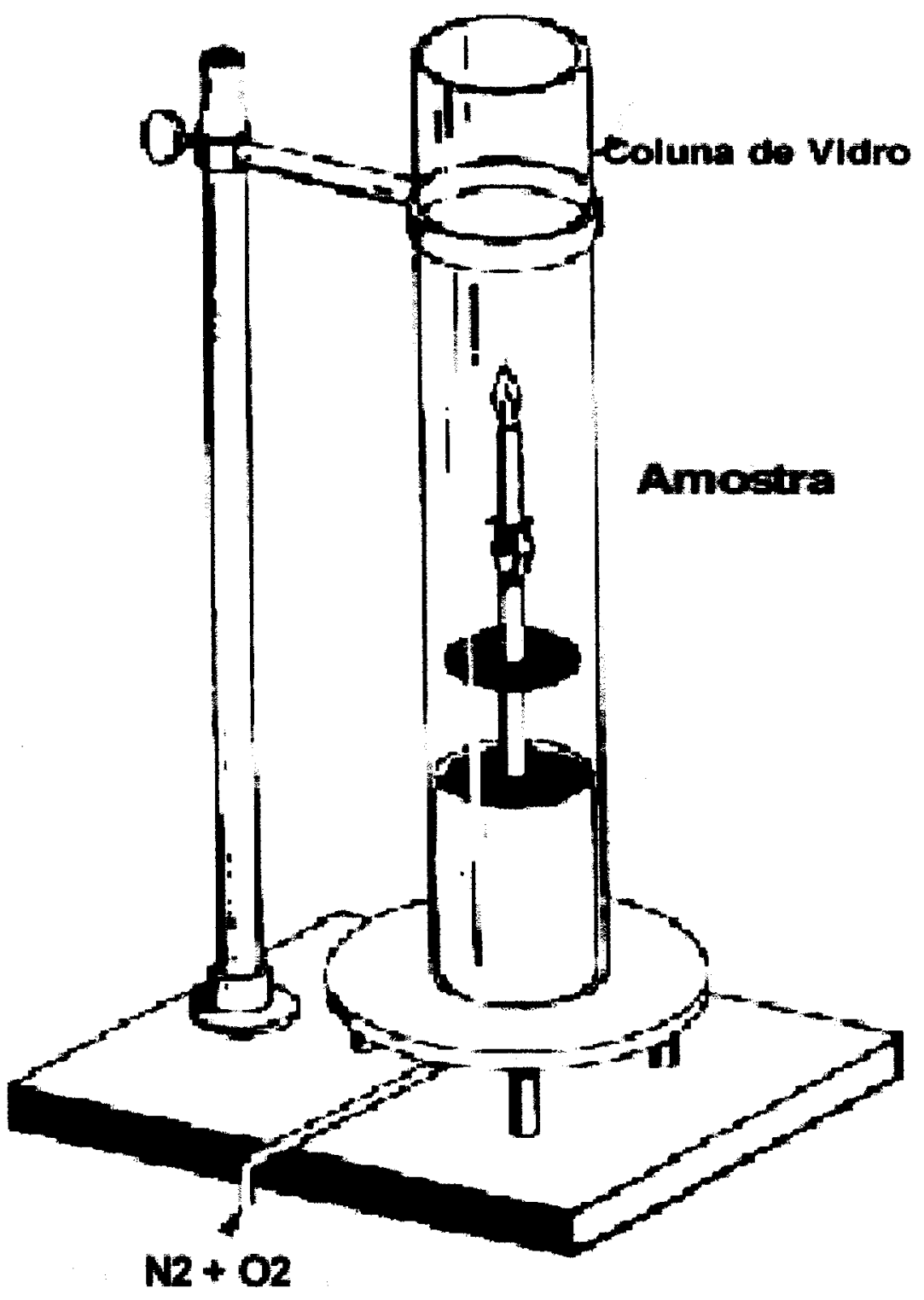

Figura 58- Coluna de teste de Índice de Oxigênio de acordo com o padrão JIS A 9201(1991). 
Queimou-se uma amostra de cada madeira sem tratamento ao ar para avaliar o tempo de queima. Ficando evidenciado que ela queima rapidamente, determinou-se $18 \%$ como sendo a concentração inicial de oxigênio. Pela tabela contida na Norma JIS K 7201 determinou-se a concentração de nitrogênio a ser utilizada para a concentração de oxigênio inicialmente selecionada. Ajustou-se estas concentrações de gases através de válvulas. A seguir, ajustou-se os fluxos de oxigênio e de nitrogênio através da coluna de vidro ( $4 \pm 1 \mathrm{~cm} / \mathrm{s}$ ). Deixou-se a mistura de gases fluir por 30 segundos para purgar o sistema.

A amostra foi presa verticalmente no suporte central da coluna de vidro, com o topo da amostra aproximadamente $100 \mathrm{~mm}$ abaixo do topo da coluna. Foi ateado fogo usando um queimador na parte superior da amostra. Aguardou-se até que a chama se tomasse firme e retirou-se a fonte de ignição. Iniciou-se a cronometragem imediatamente, marcando o tempo em que a chama se manteve acesa e a brasa esteve viva. Repetiu-se esta operação cinco vezes com cada amostra, cortando a ponta da amostra queimada.

Ao ajustar-se uma nova amostra no suporte, repetia-se todas as operações. Se a quantidade de oxigênio não fosse suficiente para suportar a chama como o de uma vela queimando, selecionava-se uma nova concentração para ela e também para o nitrogênio, conforme a tabela, purgava-se novamente o sistema e tomava-se a ignitá-lo.

\section{Cálculos}

Os cálculos do Índice de Oxigênio $(n)$ foram efetuados utilizando-se a seguinte equação: 


$$
n, \%=\left(100 \times \mathrm{O}_{2}\right) /\left(\mathrm{O}_{2}+\mathrm{N}_{2}\right)
$$

onde :

$\mathrm{O}_{2}$ = fluxo volumétrico de Oxigênio, $\mathrm{cm}^{3} / \mathrm{s}$, na concentração determinada durante os procedimentos de ajuste do aparato para o teste.

$\mathrm{N}_{2}=$ correspondente taxa de fluxo volumétrico de nitrogênio, $\mathrm{cm}^{3} / \mathrm{s}$.

Os resultados são apresentados nas figuras 59 e 60 e na tabela 9.

\section{Índice de Oxigênio}

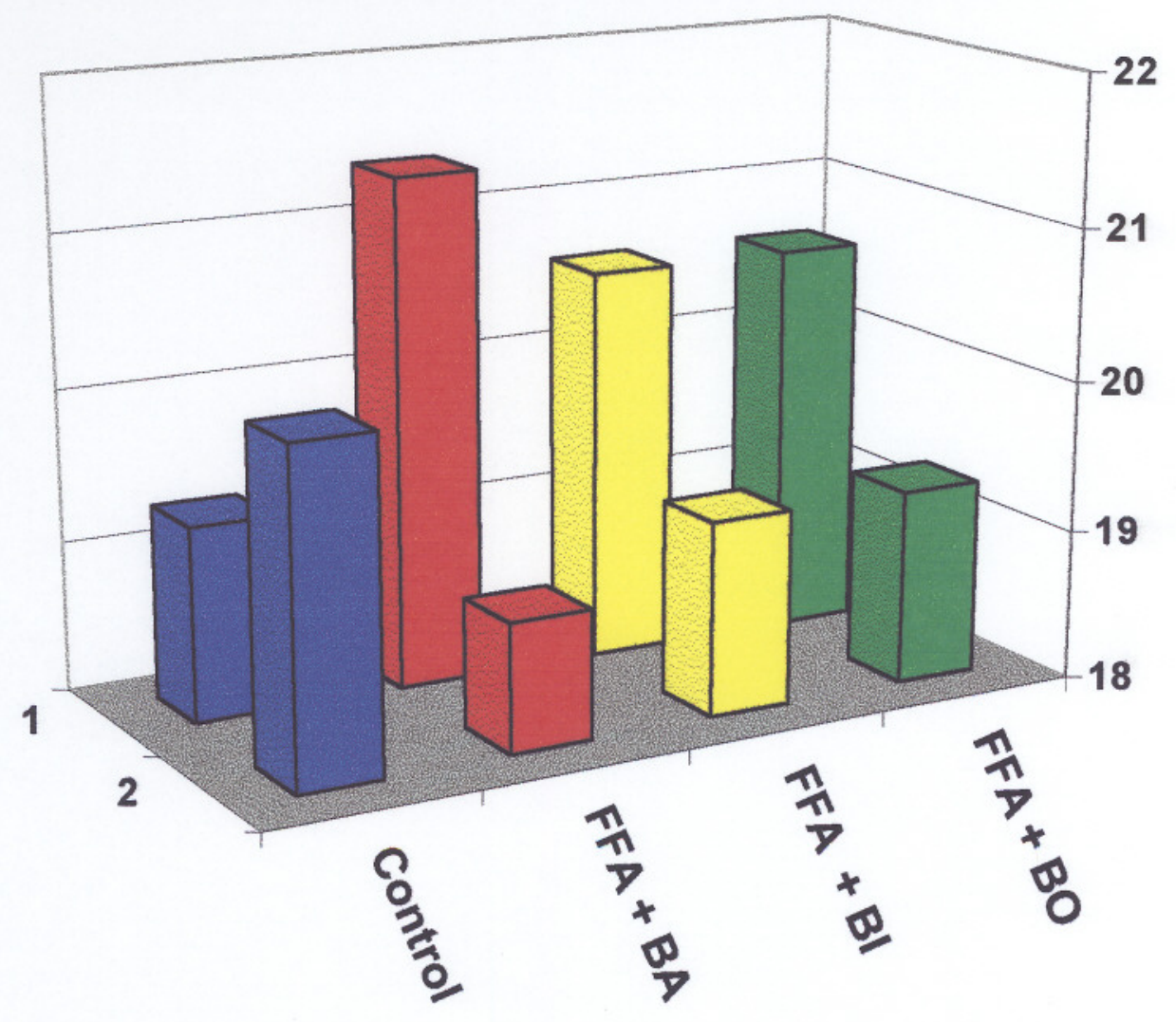

Figura 59- Índice de Oxigênio das espécies sugi (1) e pinus (2). 
Tabela 9- WPG e Tempo de queima das espécies submetidas ao teste de Índice de Oxigênio.

\begin{tabular}{|c|c|c|c|}
\hline Espécie & Tratamento & WPG (\%) & Tempo de queima (s) \\
\hline Sugi & Controle & & 42 \\
\hline Sugi & FFA + BA & $36,27 \pm 7,74$ & 9 \\
\hline Sugi & FFA + BI & $36,40 \pm 5,7$ & 10 \\
\hline Sugi & FFA + BO & $37,75 \pm 6,9$ & 54 \\
\hline Pinus & Controle & & 25 \\
\hline Pinus & FFA + BA & $31,95 \pm 4,8$ & 27 \\
\hline Pinus & FFA + BI & $35,55 \pm 5,4$ & 31 \\
\hline Pinus & FFA + BO & $36,33 \pm 4,5$ & \\
\hline
\end{tabular}

\section{Tempo de Queima (s)}

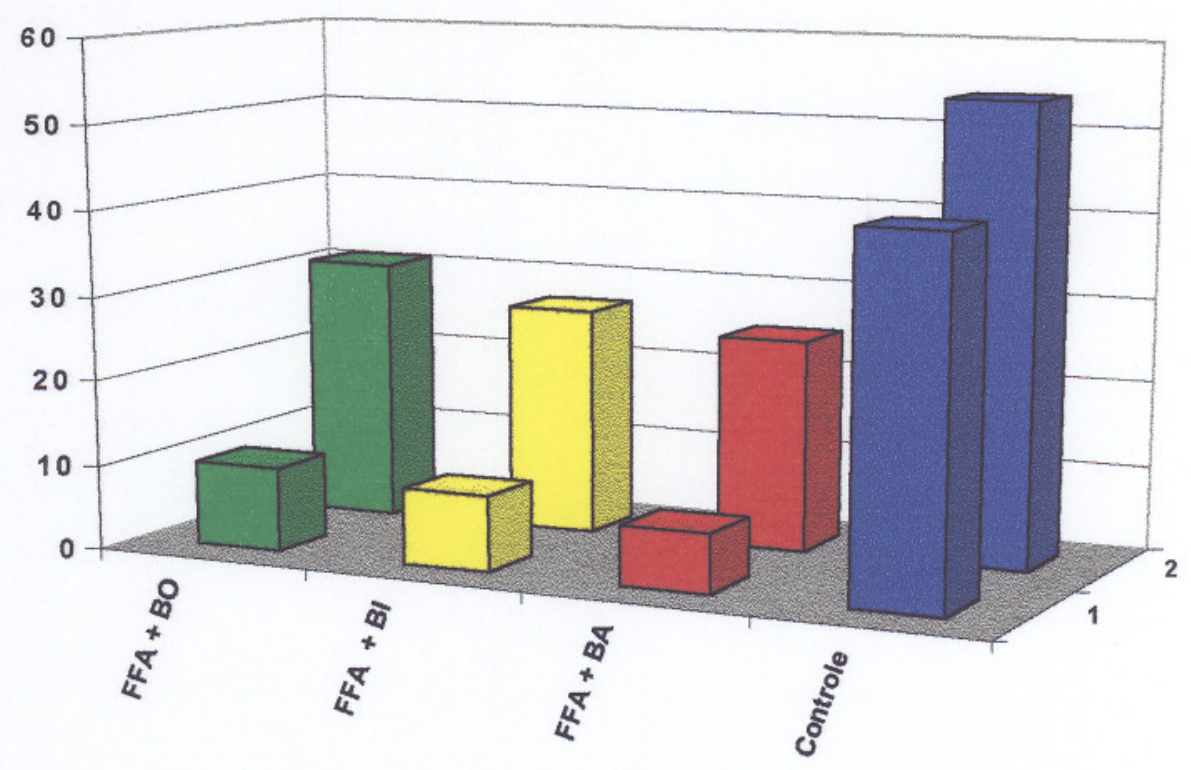

Figura 60- Tempo de queima das espécies sugi (1) e pinus (2) submetidas ao teste de Índice de Oxigênio. 
Os palitos submetidos ao teste de índice de oxigênio foram observados no microscópio eletrônico de varredura, fazendo-se o recobrimento com banho de ouro.

O índice de oxigênio da espécie sugi tratada mostrou-se superior em relação à sem tratamento. No caso do pinus, o índice de oxigênio da amostra sem tratamento mostrou-se superior às amostras tratadas. Isto significa que a amostra sem tratamento necessita de maior quantidade de oxigênio para queimar do que as tratadas. $O$ comportamento diferenciado entre as duas espécies pode ser atribuída à diferença nas concentrações de lignina e extrativos. A lignina é a principal responsável pelo aumento da temperatura de ignição. As determinaçōes foram efetuadas somente com amostras submetidas à lixiviação. Muitos extrativos voláteis foram lixiviados.

O tempo de queima relacionado na tabela 9 e na figura 60 é o tempo em que a chama e depois a brasa (enquanto persistir a cor rubra) permanecem acesas, de acordo com o tipo de material, de no mínimo 3 segundos ou, $50 \mathrm{~mm}$ de extensão, segundo os critérios da ASTM D 2863-77. Em nosso caso, escolhemos o mínimo de $50 \mathrm{~mm}$ de extensão.

As amostras sem tratamento permanecem queimando por longo tempo, evolvem maior quantidade de fumaça e liberam cinzas, como pode ser visto nas micrografias da figura 61 . No caso do sugi a chama se apaga rapidamente mas a brasa demora a ser consumida. No caso do pinho tanto a chama como a brasa demoram a se apagar.

Com as amostras tratadas de sugi, a chama se apaga rapidamente e quase não forma brasa. A chama se apaga rapidamente também com as amostras de pinus tratadas, porém, a brasa persiste um tempo um pouco maior. 


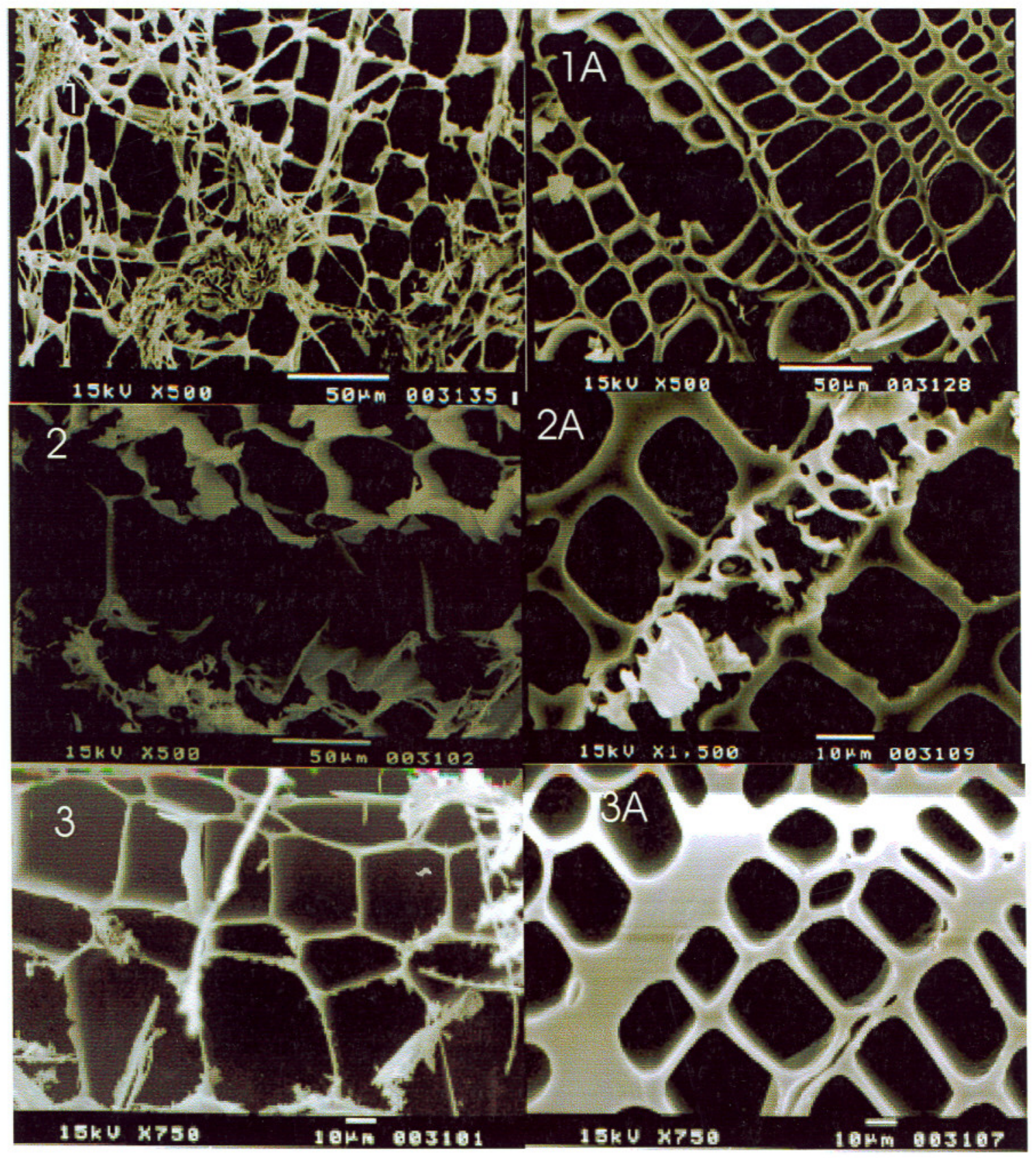

Figura 61- Micrografias de madeiras submetidas ao Teste de Índice de Oxigênio.

1 Sugi sem tratamento

2 Pinus sem tratamento

3 Pinus sem tratamento
$1 A$ Sugi tratado com FFA + BA

$2 A$ Pinus tratado com FFA + BA

$3 \mathrm{~A}$ Pinus tratado com FFA + BA 
Observa-se também pelas micrografias que as amostras tratadas apresentam a parede celular preservada e reforçada. Este aumento da parede celular é devido às ligações intercruzadas com polímero de FFA e com o boro. Os anéis furânicos se carbonizam e formam uma barreira de produtos carbonáceos na superfície do compósito, isolando-o da superfície inflamante. Assim, evitam a formação de muita fumaça e cinzas, provenientes dos produtos de degradação. Pouca fumaça é evolvida devido ao baixo peso molecular dos produtos voláteis liberados nestas temperaturas. E também porque o boro reduz os voláteis em combustão.

Os compostos de boro formam um filme vitreo na superfície do compósito, inibindo a transferência de vapores combustiveis e mantendo a formação do carvão devido às resinas de FFA, como pode ser observado pelas figuras 63 e 65 .

No caso dos tratamentos FFA + BI e FFA + BO, para a espécie sugi, o início da combustão torna-se acelerado com altas chamas mas depois que estas se apagam a brasa não persiste por muito tempo, ao contrário das amostras sem tratamento em que a brasa persiste por longo tempo. Este tratamento é considerado do tipo retardante de queima sem chama. 


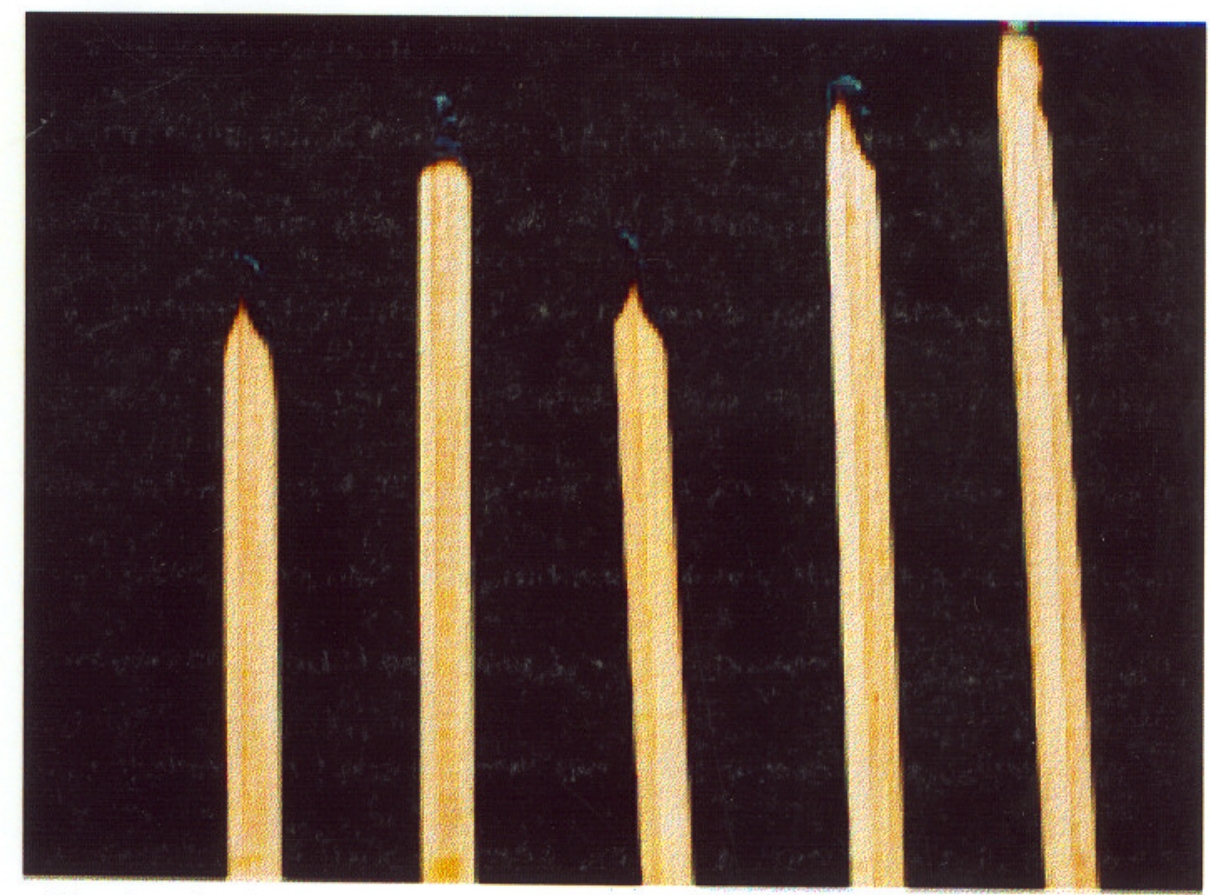

Figura 62- Aparência visual do Sugi sem tratamento após Teste de Índice de Oxigênio.

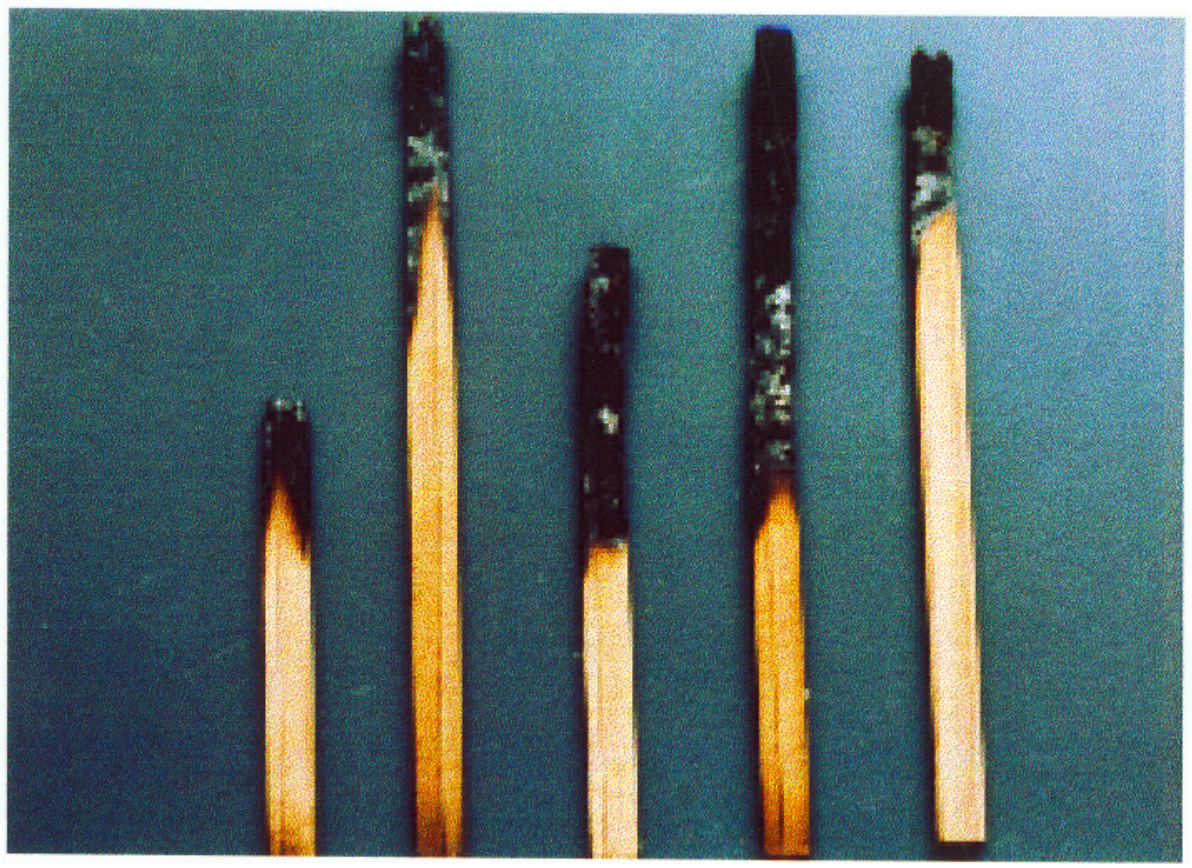

Figura 63- Aparência visual do Sugi tratado com FFA + BA após o Teste de Índice de Oxigênio. 


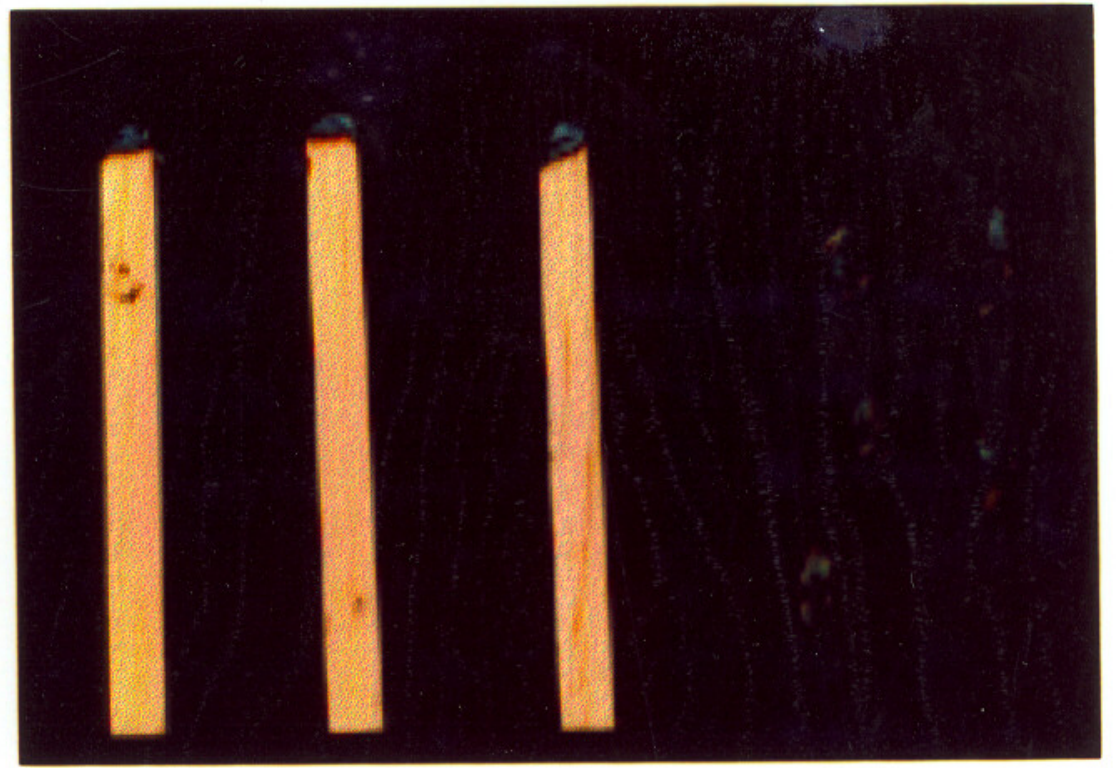

Figura 64- Aparência visual do Pinus sem tratamento após Teste de Índice de Oxigênio.

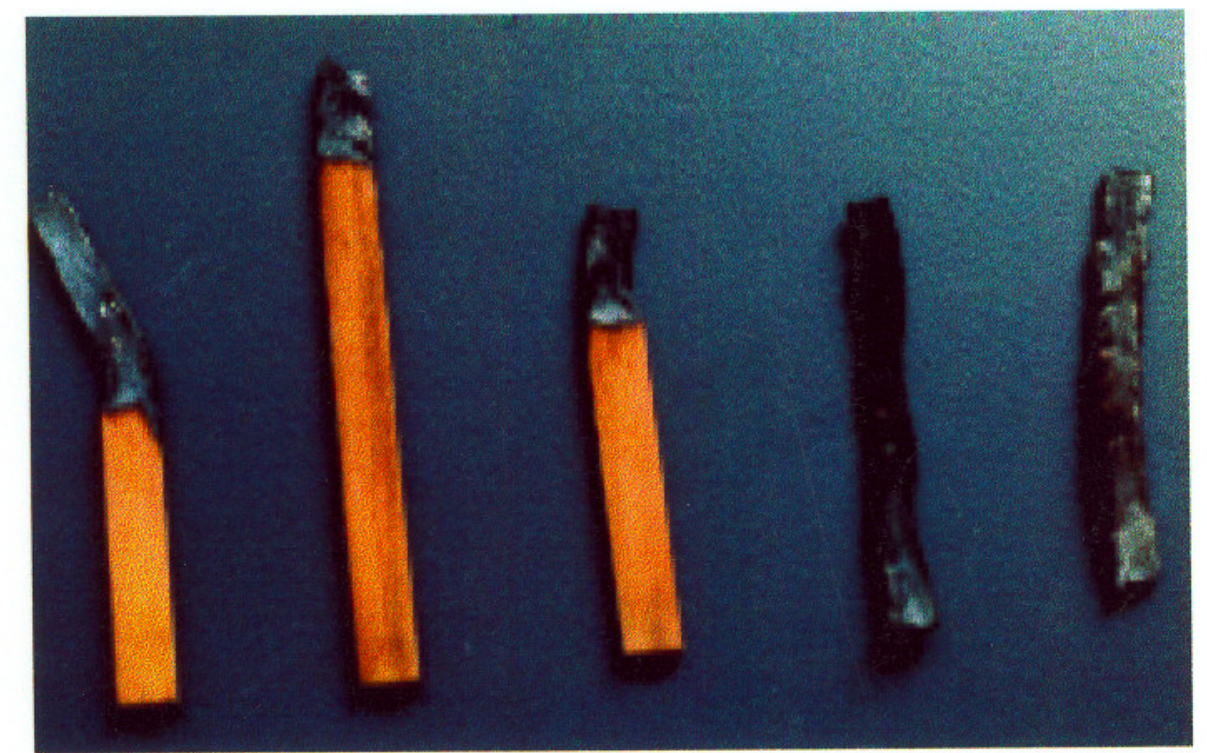

Figura 65- Aparência visual do Pinus tratado com FFA + BA após o Teste de Índice de Oxigênio. 


\subsection{Teste de Exposição às Condições Climáticas}

\section{Preparo das Amostras}

Amostras de sugi (Criptomeria japonica) e pinus (Pinus caribaea var hondurensis) com medidas superficiais de $100 \times 25 \mathrm{~mm}$ e $5 \mathrm{~mm}$ de espessura foram impregnadas com FFA e FFA + compostos de boro, conforme procedimento descrito no capítulo anterior. As concentrações constam na tabela 3.

A cor das amostras tratadas e sem tratamento foram medidas. Depois, as amostras foram dispostas em um suporte de aluminio, com um ângulo de inclinação de $45^{\circ}$, para exposição às condições climáticas durante um período de 24 semanas, de janeiro a junho de 1998, no campus de Uji da Universidade de Kyoto, na província de Kyoto, Japão. Uji localiza-se a $20 \mathrm{~m}$ acima do nível do mar. Suas coordenadas são: latitude $33^{\circ} 0^{\prime} \mathrm{N}$ e longitude $135^{\circ} 48^{\prime} \mathrm{E}$. Nesta região a temperatura média anual está entre 13 e $21^{\circ} \mathrm{C}$. A umidade relativa média é de $67 \%$. A média anual de precipitação é de $1558 \mathrm{~mm}$, sendo que os meses de junho e setembro apresentam até $250 \mathrm{~mm}$ de precipitação. E a insolação total é de 1867 horas (Outline of the Yoshino Forestry; AmeDas Information of Japan weather Agency).

As variações na cor das amostras foram medidas mensalmente. Antes de medir a variação de cor, as amostras foram fotografadas para registrar variações de cor visíveis a olho nu, assim como a ocorrência de trincas e fissuras.

Utilizou-se a leitura direta por meio de um medidor de cor e diferença de cor modelo Z - 1001 DP, da Nippon Denshoku Kogyo Co. Ltd., pertencente ao Departamento de Agricultura da Universidade da Provincia de Kyoto. Ele é composto de um colorímetro fotoelétrico. Primeiro, a amostra é irradiada com lâmpada de 
xenônio. A luz refletida é coletada e transformada em índices numéricos dos sistemas $L a b$, ou $L^{*} a^{*} b^{*}$, ou $X Y Z$ ou UWW, conforme o caso. Utilizou-se o sistema $L^{*} a^{*} b^{*}$, onde a cor é representada conforme o esquema da figura 66.

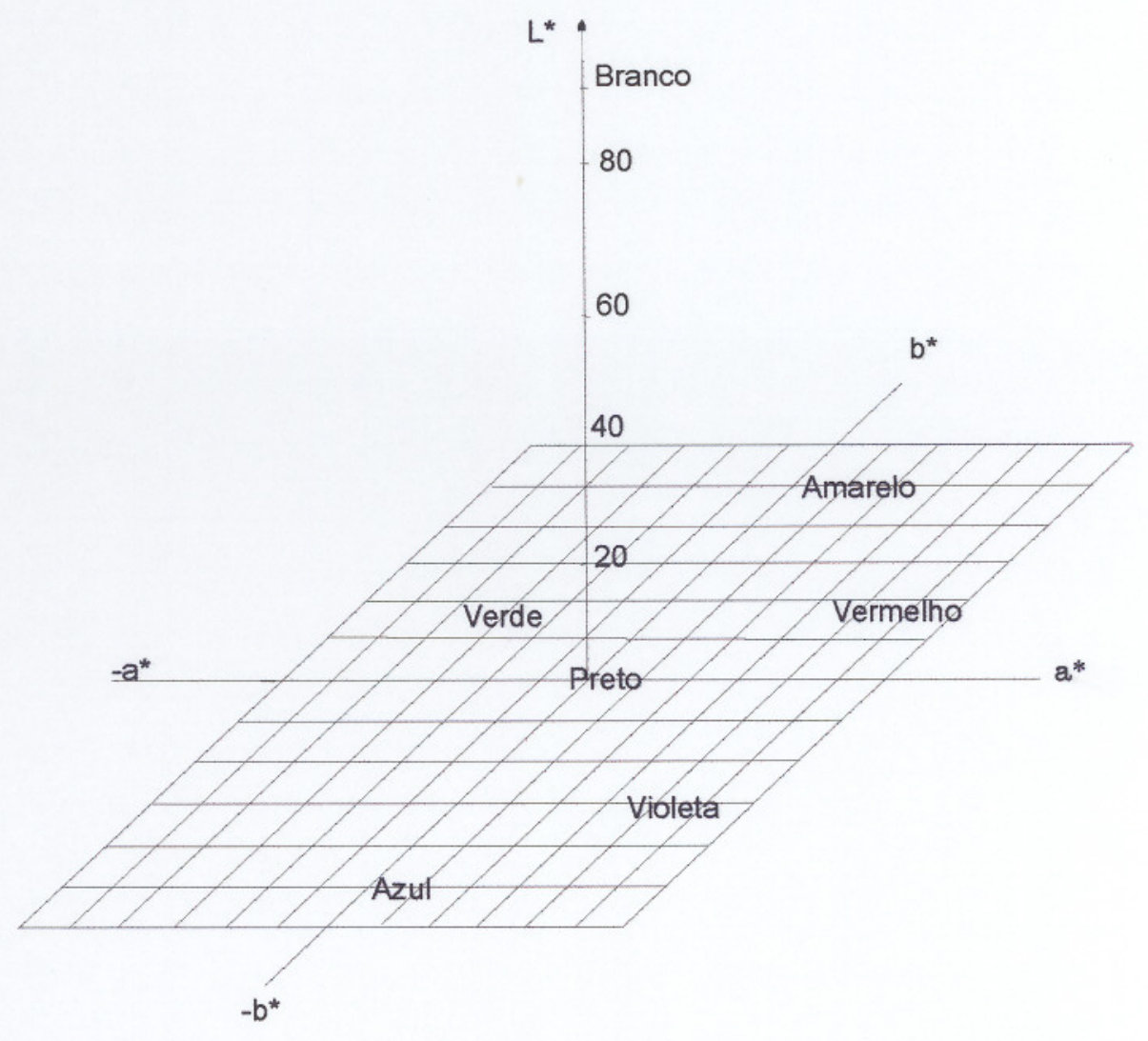

Figura 66- Representação do sistema $L^{*} a^{*} b^{*}$ para determinar a qualidade tricromática.

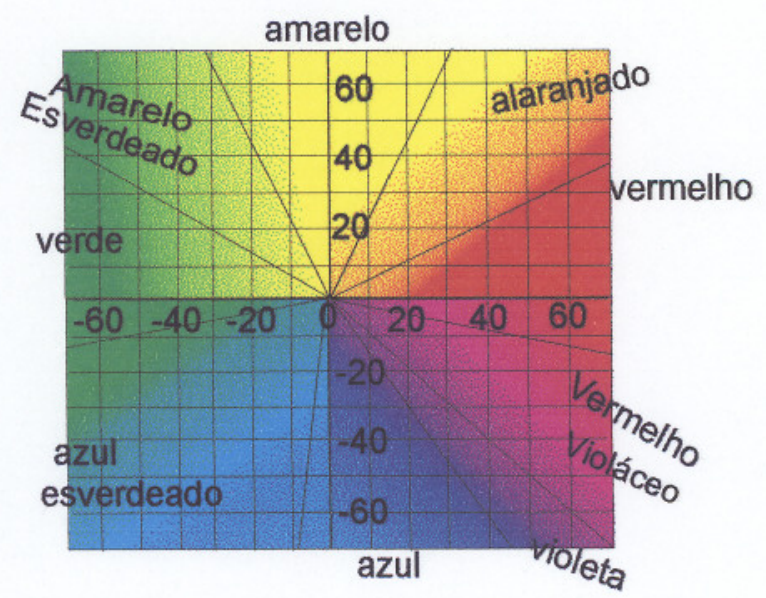

Figura 67- Detalhe da representação das cores nos planos $a^{*}$ e b*. 


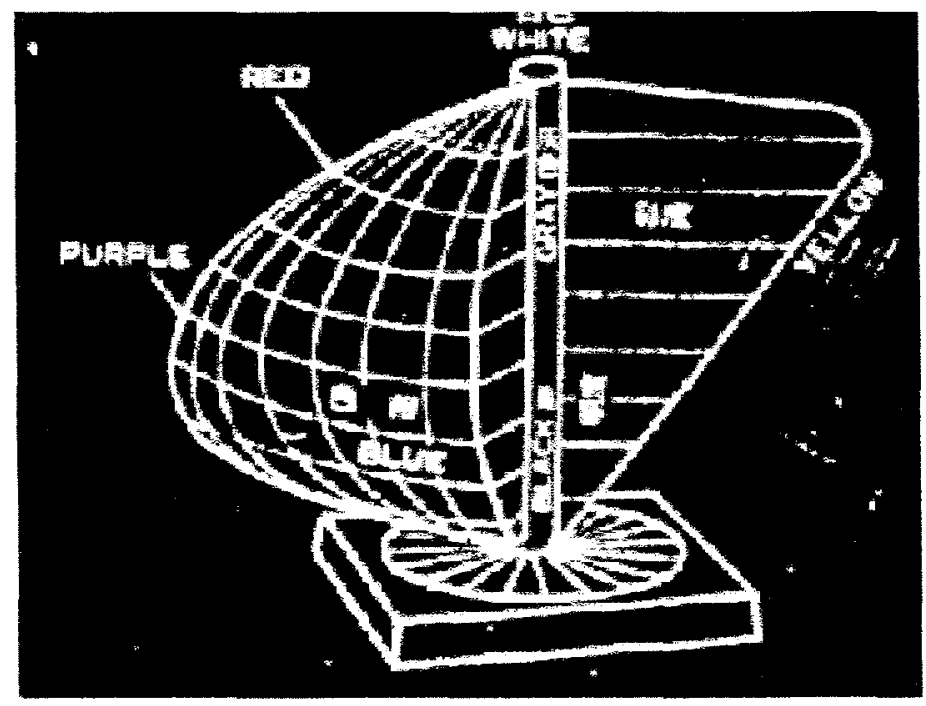

Figura 68- Representação tridimensional das cores no sistema $L^{*} a^{*} b^{*}$.

As medidas das cores foram feitas em triplicata, em três pontos da amostra. Fazendo-se a média dos nove pontos de cada valor nos eixos $x, y$ e $z$, calcula-se os valores de $L^{*}$, $a^{*}$ e $b^{*}$ de cada amostra.

Cálculos de $L^{*}, a^{*}$ e $b^{*}$ :

$$
\begin{aligned}
& L^{*}=116(Y / 100)^{1 / 3} \\
& a^{*}=500\left[(X / 98)^{1 / 3}-(Y / 100)^{1 / 3}\right\rfloor \\
& b^{*}=200\left[(Y / 100)^{1 / 3}-(Z / 118.1)^{1 / 3}\right\rfloor
\end{aligned}
$$

A diferença média da cor $\left(\Delta E^{\star}=\Delta E\right)$ é calculada de acordo com a equação:

$$
\left.\Delta E=\left\{(\Delta L)^{2}+(\Delta a)^{2}+(\Delta b)^{2}\right\}^{1 / 2}\right\}
$$

onde: $a$ e b são índices cromáticos $\left(a=a^{*}\right.$ e $\left.b=b^{*}\right)$.

$$
L=L^{*} \text { é a saturação. }
$$


Após 24 meses, a média da variação total de cor $\left(\Delta \mathrm{E}^{*}\right)$ foi calculada. Os resultados estão apresentados na tabela 10 e figura 69.

Tabela 10- Variação total de cor ao final de 24 semanas de exposição às condições climáticas.

\begin{tabular}{|c|c|c|c|}
\hline Madeira & Tipo de tratamento & $\Delta \mathrm{E}^{*}$ & $\mathrm{SD}$ \\
\hline Sugi & Controle & 49,75 & 5,4 \\
\hline & FFA + BA & 30,99 & 3,8 \\
\hline & FFA + BI & 32,13 & 4,5 \\
\hline Pinho & FFA + BO & 33,71 & 3,3 \\
\hline & Controle & 66,66 & 3,0 \\
\hline & FFA + BA & 22,91 & 4,4 \\
\hline & FFA + BI & 30,99 & 3,7 \\
\hline & FFA + BO & 32,45 & 3,8 \\
\hline & FFA & 37,42 & 4,1 \\
\hline
\end{tabular}

Cada leitura é uma média de 4 amostras.

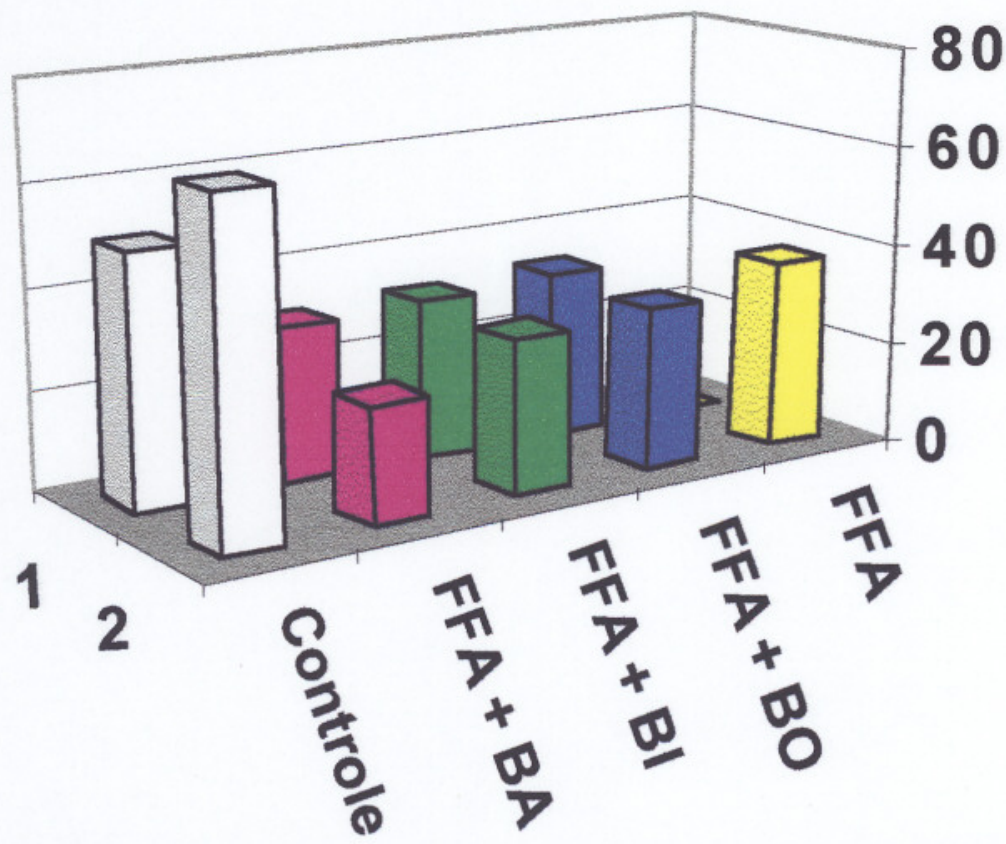

$\Delta \mathbf{E}$

Figura 69- Variação total de cor após 24 semanas de exposição às condições climáticas. 


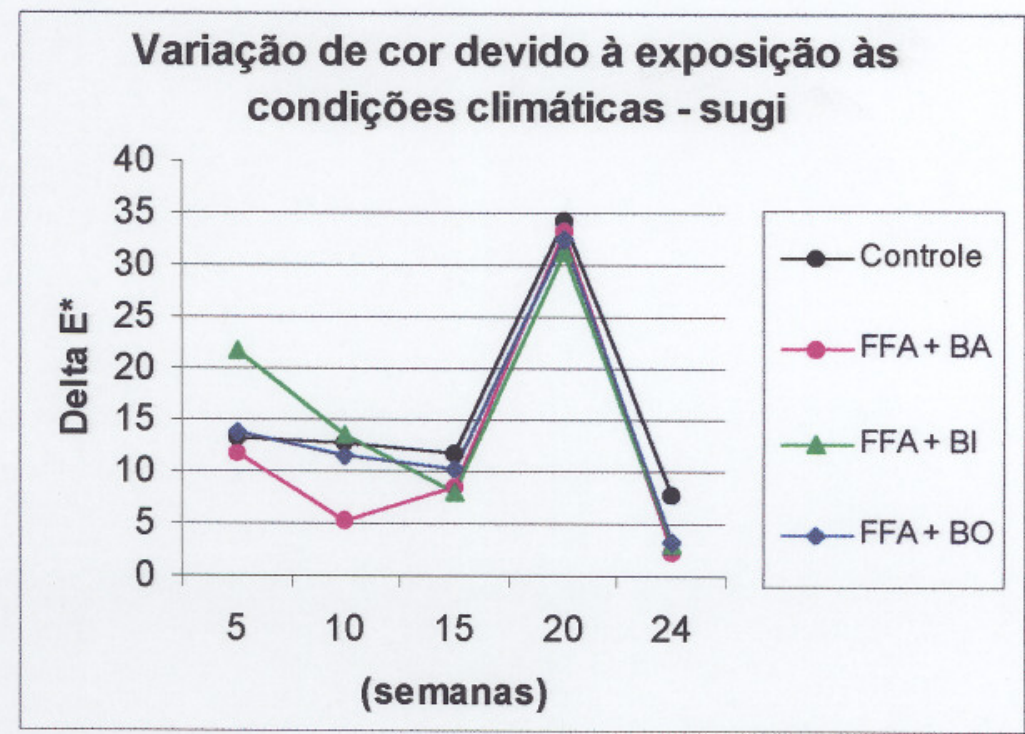

Figura 70- Variação de cor da espécie sugi exposta às condições climáticas ao longo de 24 semanas.

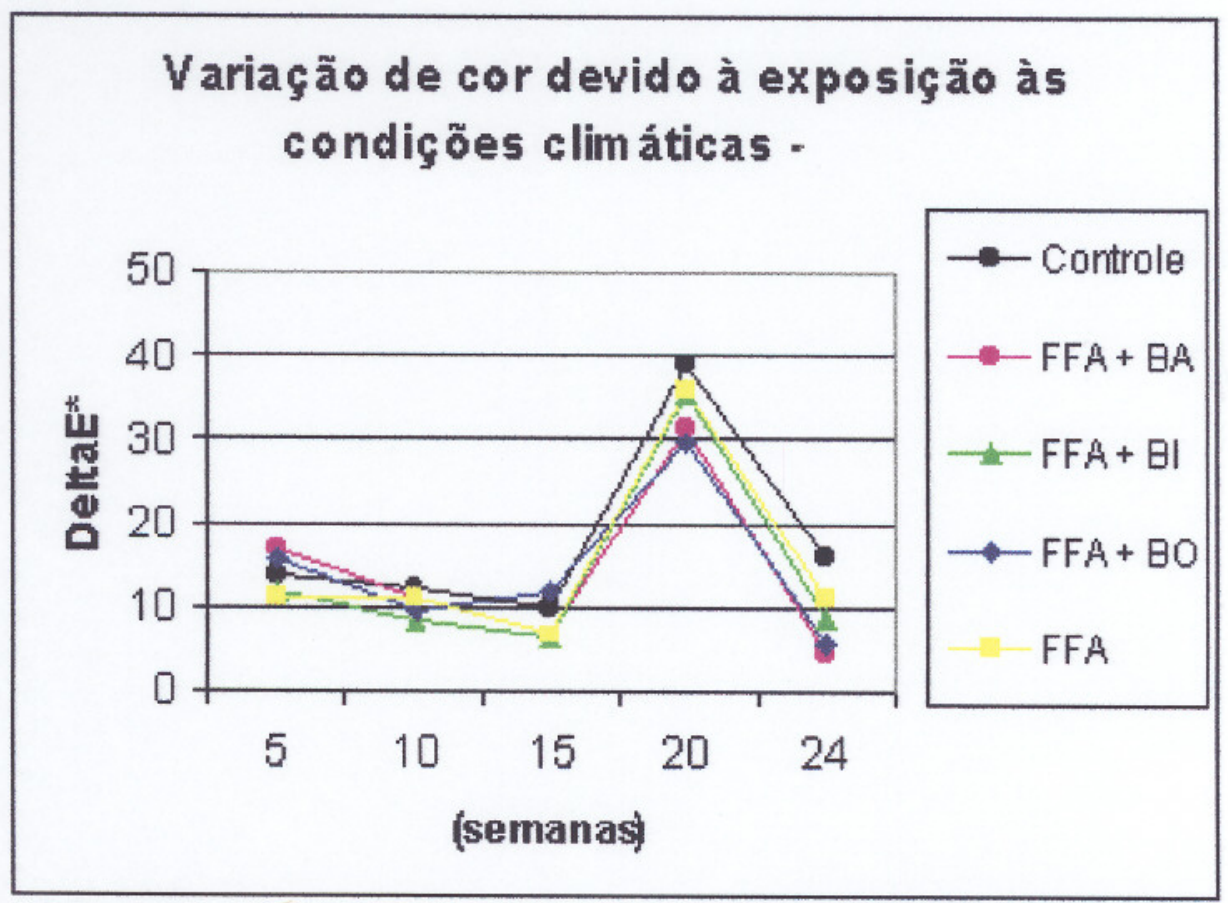

Figura 71- Variação de cor da espécie pinus exposta às condições climáticas ao longo de 24 semanas. 


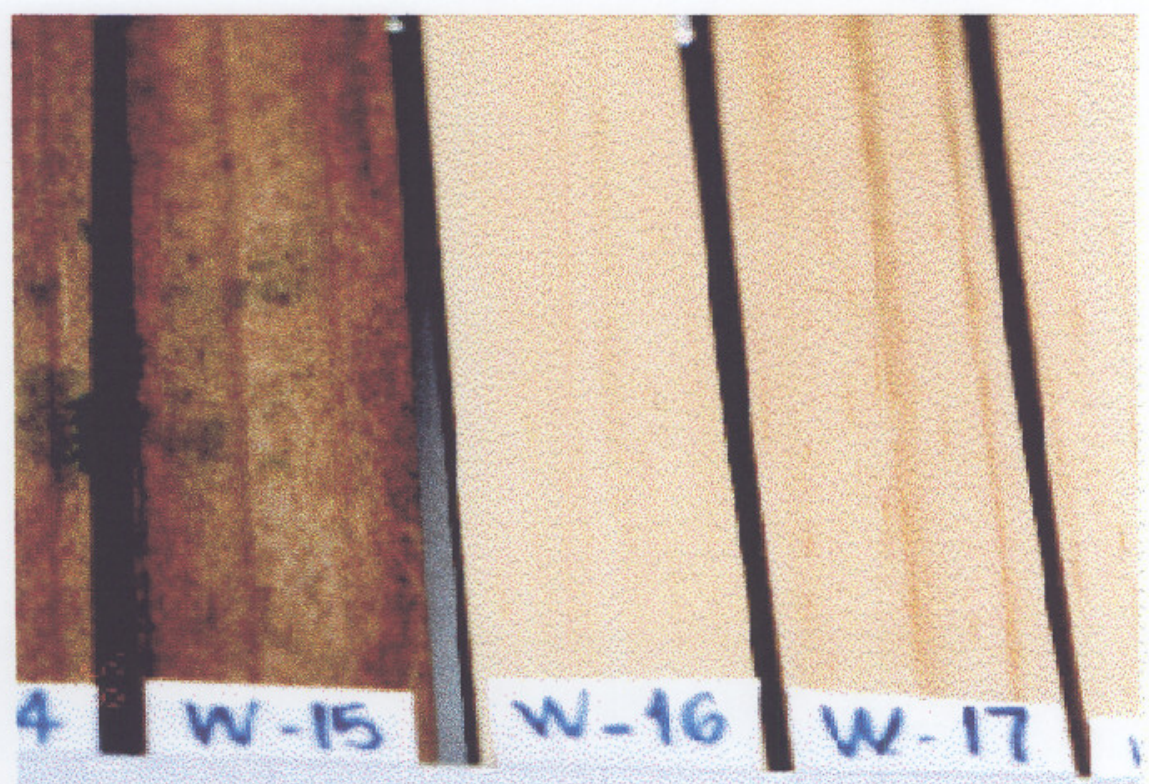

Figura 72- Aparência visual de amostras de pinus tratada com FFA (W-15) e sem tratamento (W-16 e W-17), antes da exposição às condições climáticas.

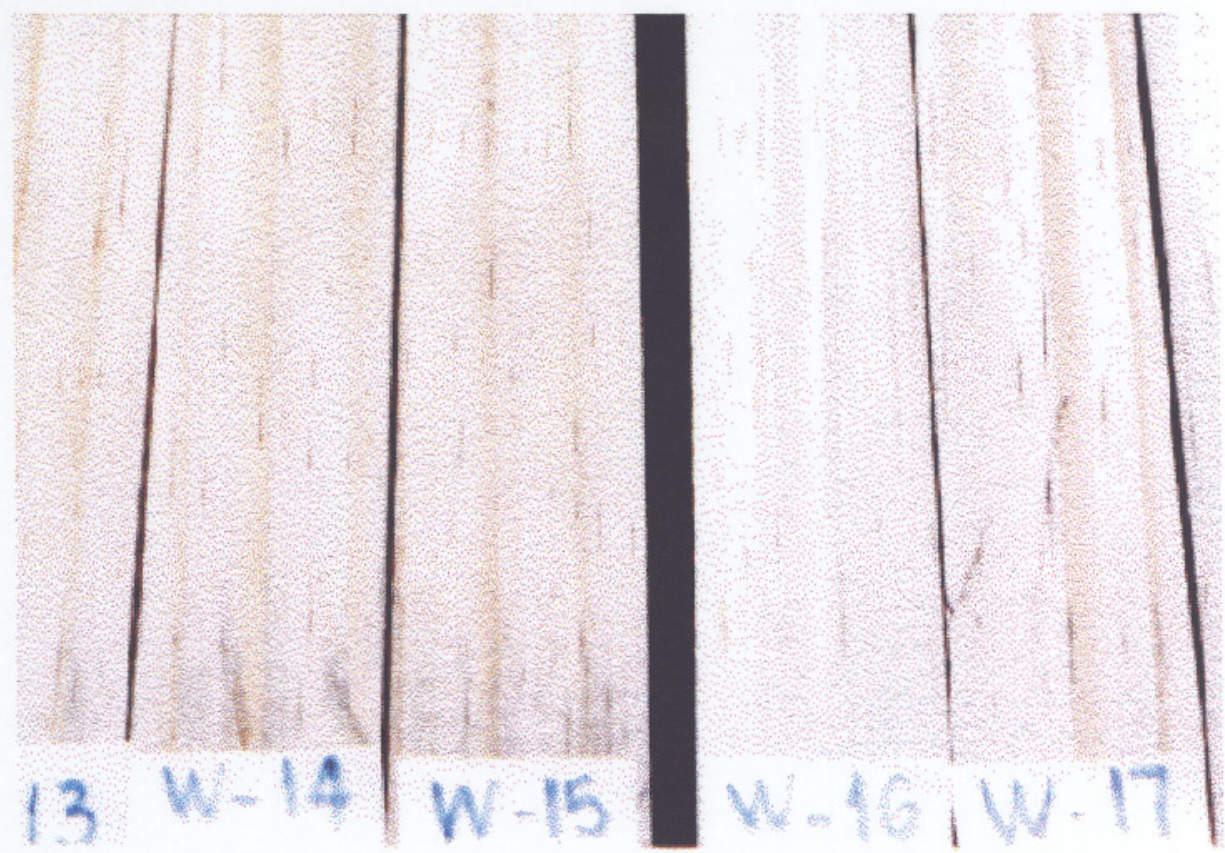

Figura 73- Aparência visual de amostras de pinus tratadas com FFA $(\mathrm{W}-14$ e W-15) e sem tratamento $(\mathrm{W}$-16 e W-17), após 24 semanas de exposição às condições climáticas. 


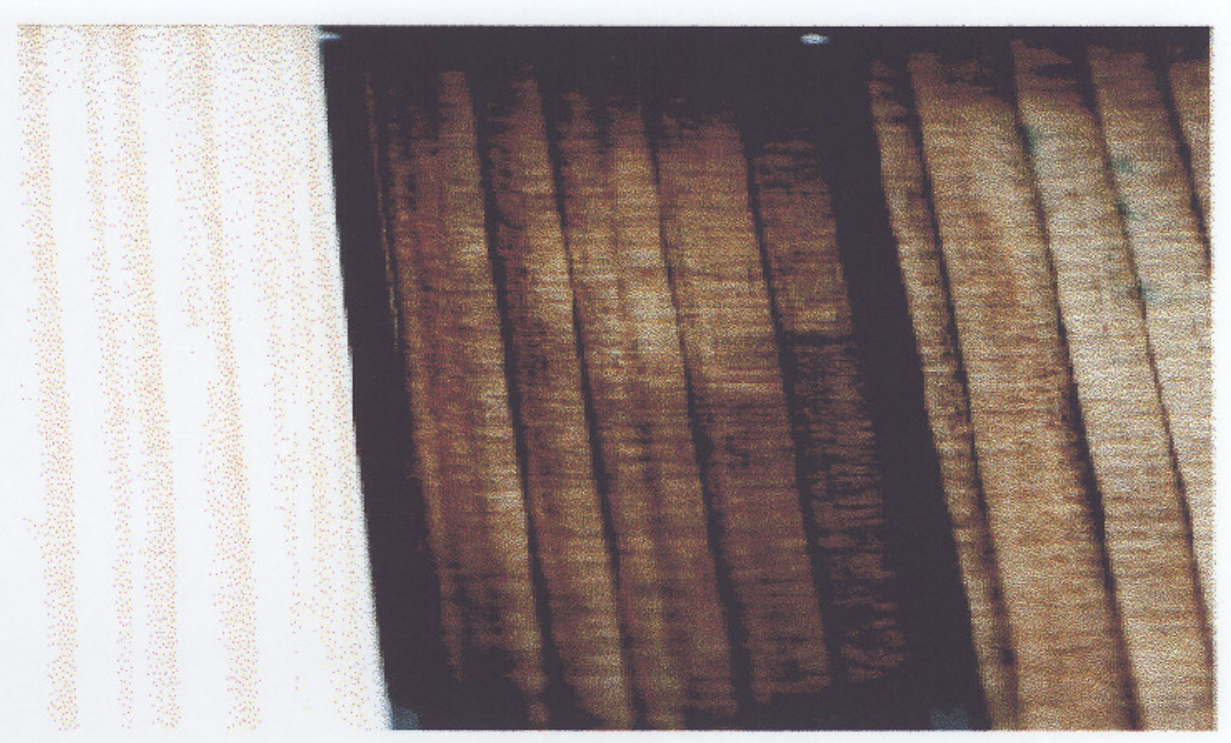

Figura 74- Aparência visual de amostras de sugi sem tratamento e tratada com FFA + BA, antes da exposição às condições climáticas.

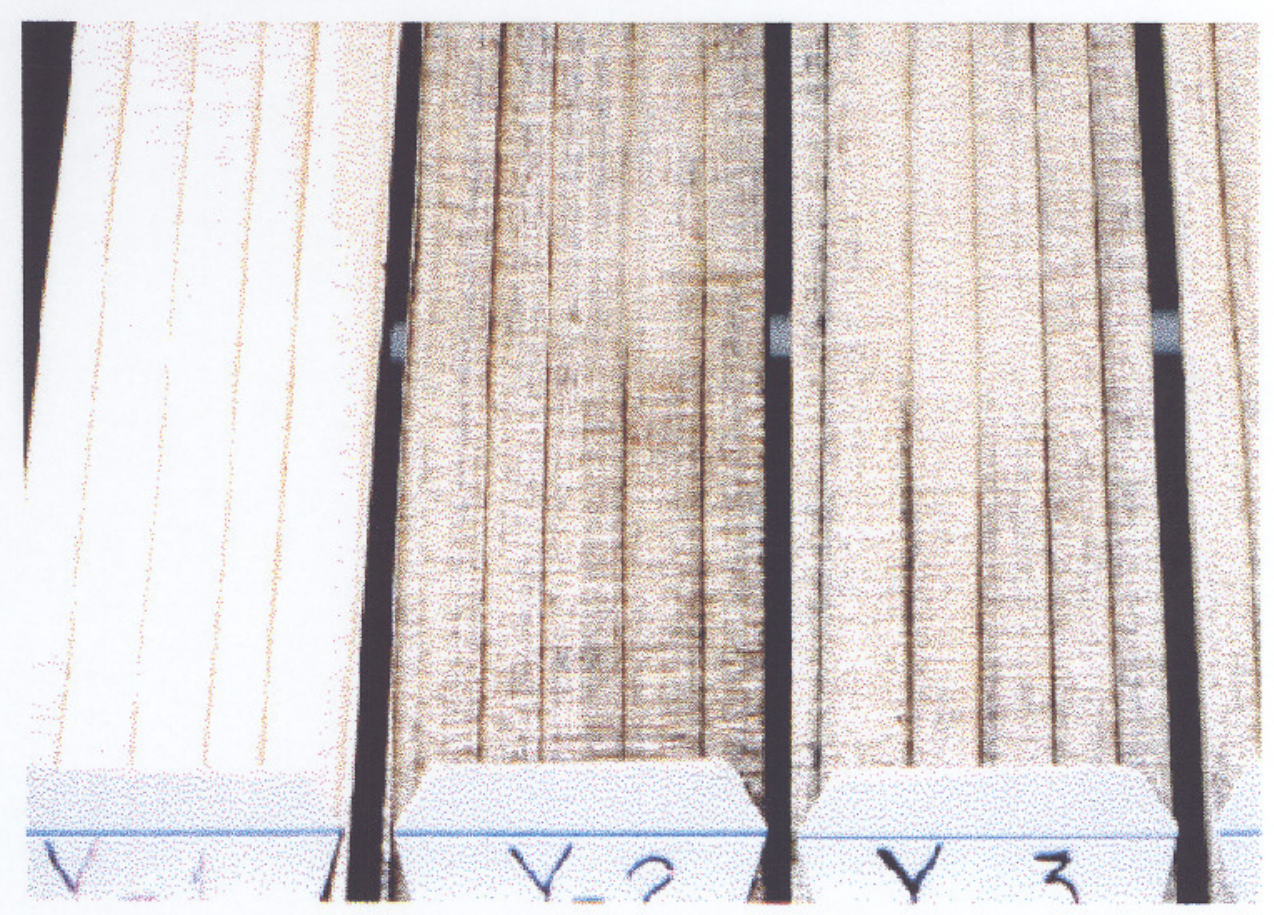

Figura 75- Aparência visual de amostras de sugi sem tratamento e tratada com FFA + BA, após 24 semanas de exposição às condições climáticas 


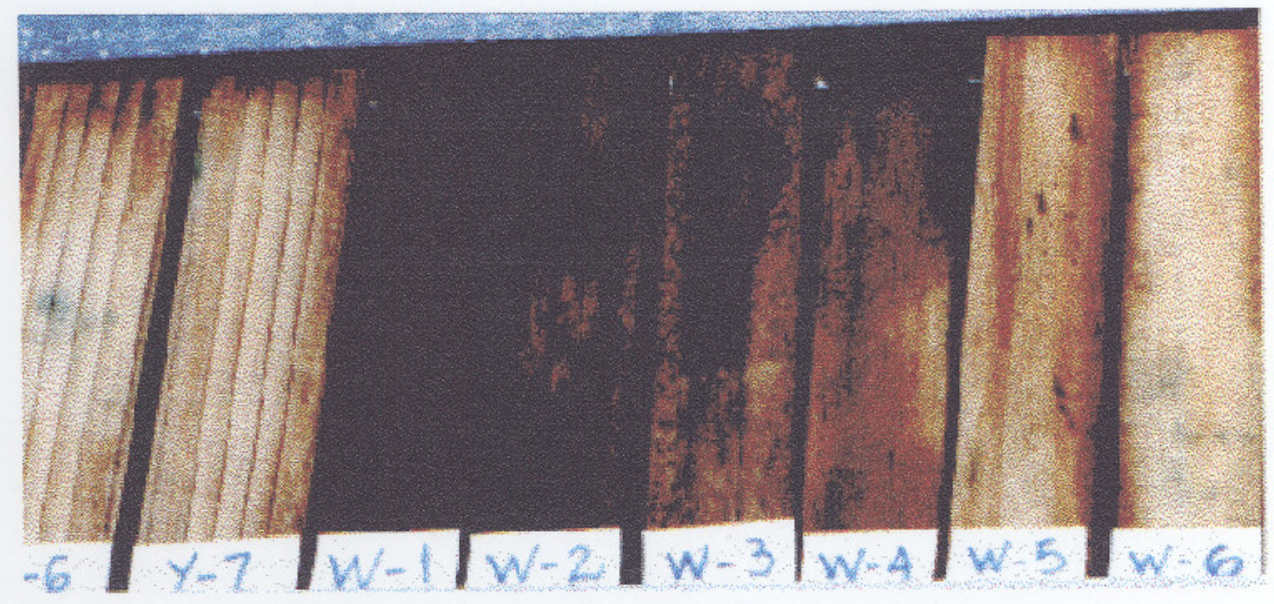

Figura 76- Aparência visual de amostras de sugi tratadas com FFA + $\mathrm{BO}(\mathrm{Y}-6$ e $\mathrm{Y}-7)$ e de pinus tratadas com FFA + BA (W-1 a W- 4), FFA + $\mathrm{BI}(\mathrm{W}-5$ e W-6), antes da exposição às condições climáticas.

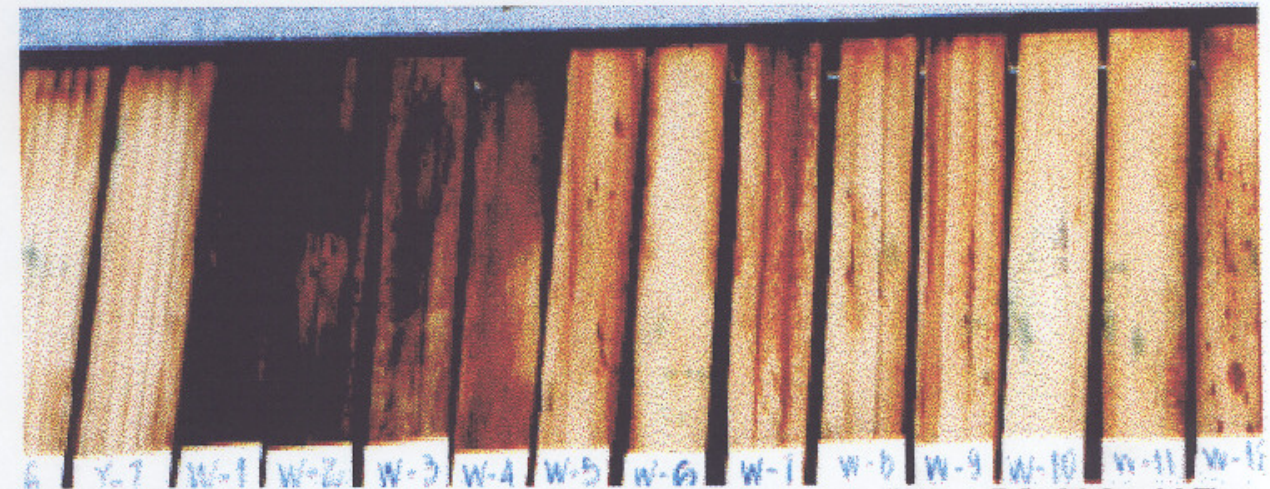

Figura 77-Aparência visual de amostras de sugi tratadas com FFA + $\mathrm{BO}(\mathrm{Y}-6$ e $\mathrm{Y}-7)$ e de pinus tratadas com FFA + BA (W-1 a W- 4), FFA + BI (W-5 a W-8), FFA + BO (W-9 a W-12), após 8 semanas de exposição às condições climáticas.

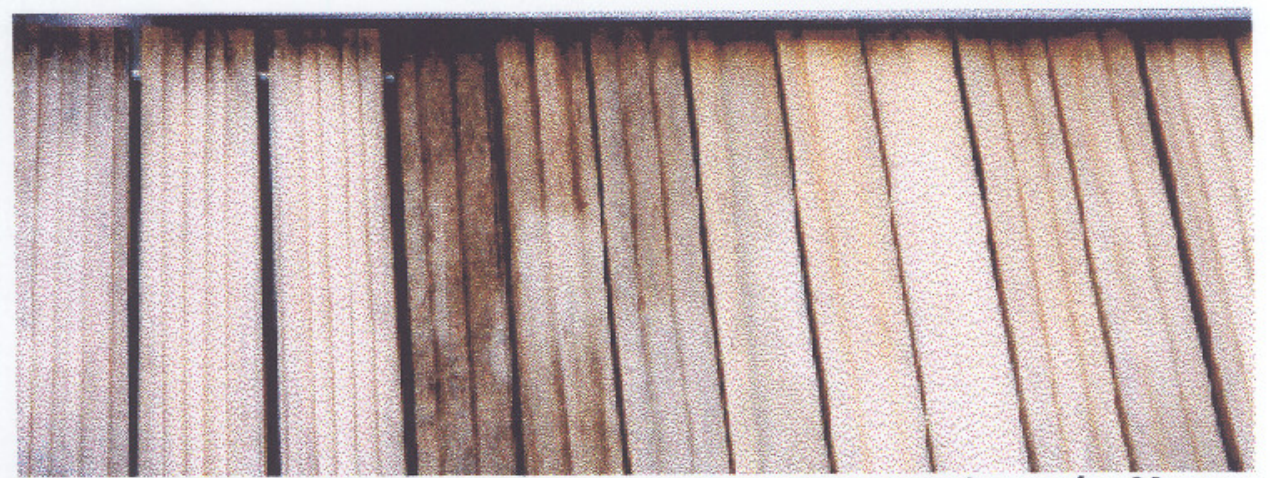

Figura 78- Aparência visual de amostras de sugi e pinus tratadas após 20 semanas de exposição às condições climáticas. 


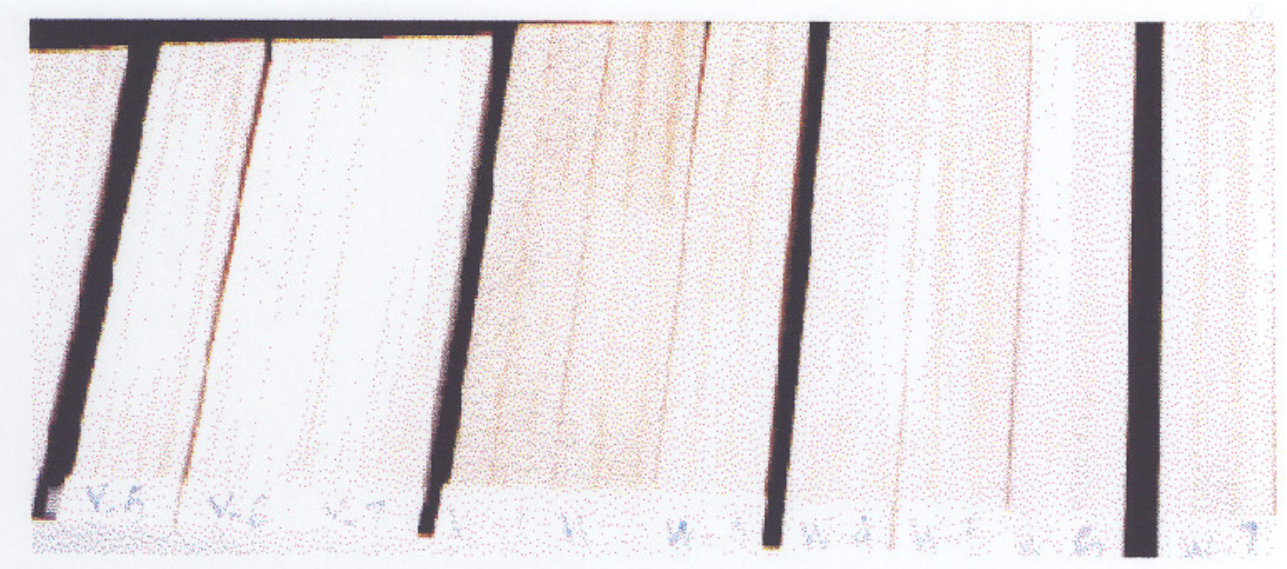

Figura 79- Aparência visual de amostras de sugi tratadas com FFA + BO ( $Y-5$ a $Y-7)$ e de pinus tratadas com FFA + BA (W -1 a W- 4), FFA + BI ( W-5 a W-7), após 24 semanas de exposição às condições climáticas.

Amostras de sugi e pinho variaram de cor devido à exposição às condições climáticas. As variações de cor ao longo de 24 semanas de teste estão apresentadas nas figuras 70 e 71. A variação total de cor $(\Delta E)$ está apresentada na tabela $10 . A$ maior variação ocorreu com a amostra de pinus sem tratamento $(\Delta \mathrm{E}=66,66)$ que variou do amarelo claro ao incolor. E o sugi sem tratamento variou do bege ao incolor $(\Delta \mathrm{E}=49,75)$.

As amostras tratadas com FFA ou FFA-composto de boro variaram do marrom escuro ao amarelo claro e incolor. O tratamento que apresentou maior estabilidade de cor foi $F F A+B A(\Delta E=22,91)$ para o pinus. $O$ pinus possui maior quantidade de extrativos que o sugi e a formação de complexos do BA com alguns extrativos, principalmente com o tanino, e com a lignina, é o responsável pela maior fixação da cor. Além disso, pode estar havendo a formação de peroxoboratos que restauram a cor da madeira pela decomposição das estruturas cromofóricas do sistema. Porém, estas amostras tratadas com FFA + BA foram as que, durante as 24 semanas de exposição, mais fissuras apresentaram. 
Os outros tratamentos apresentaram $\Delta E$ em torno de 32 , o que, para superficies sem acabamento, pode ser considerado um bom resultado.

O processo foi acompanhado de aparecimento de fissuras e, principalmente no caso do sugi, da transformação da superfície tornando-se frágil, celulósica. Ficou claro que houve degradação da lignina, lixiviação da superfície e perda de material.

Pelos resultados obtidos podemos concluir que os tratamentos com FFA + compostos de boro conferem maior proteção ao pinus que ao sugi. 


\section{Capítulo IV}

\section{Conclusões}

O presente trabalho oferece uma contribuição para o estudo do melhor aproveitamento da madeira, fazendo a impregnação de polímeros para o melhoramento de algumas propriedades tidas como indesejáveis. Foi utilizado um polímero obtido de rejeitos agrícolas, que oferece vantagens como proporcionar estabilidade dimensional, ter ação inseticida e fungicida, e também ser retardante de fogo. Esta resina de álcool furfurílico, quando completamente curada, utilizando-se para isso ácidos fortes como catalisadores, torna-se negra e infusível. A madeira assim tratada seria resistente a ataques de ácidos e álcalis, teria as propriedades mencionadas anteriormente, porém, teria suas fibras enfraquecidas. Além disso, a madeira seria de difícil descarte após seu uso.

Os compostos de boro são conhecidos há muito tempo como agentes retardantes de fogo, biologicamente resistentes, e de baixo impacto ambiental, para tratamento de madeiras. O uso externo destes compostos, porém, é limitado pela facilidade com que são lixiviadas da madeira. 
O álcool furfurílico foi usado como agente de fixação do boro, para retardar sua taxa de lixiviação da madeira, sem, contudo, estacioná-lo completamente, pois de sua mobilidade depende sua ação biocida. Assim, o FFA formou complexos solúveis com os boratos, ou apenas manteve-os aprisionado, liberando-os aos poucos, prolongando seus efeitos como inseticida e fungicida.

Observaram-se comportamentos diferenciados da mobilidade do boro em diferentes combinações com FFA ao longo de um processo de lixiviação cíclica e o efeito destas combinações quando impregnadas na madeira com o objetivo de melhorar sua performance contra deterioração biológica, contra as intempéries e contra a flamabilidade.

$A$ análise dos resíduos de lixiviação demonstrou que a combinação FFA+BA não é eficaz como processo de fixação do boro porque ao final de dez ciclos quase que o total de $100 \%$ do boro adicionado sofreu lixiviação. Porém, esta mobilidade permitida ao boro o torna eficaz como biocida. As demais combinações FFA + BO e FFA + BI apresentaram taxa de mobilidade do boro bem mais retardada e a quantidade de boro lixiviada ao final dos ciclos foi bem menor. $E$, analisando os cromatogramas de cada tratamento, observou-se no caso das combinações FFA + BO e FFA + BI a formação de um outro pico de boro após o sexto ou sétimo ciclo, o que pode indicar a presença de um composto diferente seis ou sete vezes mais estável que o que aparece primeiro. Também se observou que em todas as combinações a mobilidade do boro foi retardada em comparação com o tratamento somente com BA. E, mesmo após ter sido submetido a dez severos ciclos de lixiviação, o boro ainda está presente, ao contrário do tratamento somente com BA onde, ao final do terceiro ciclo, o boro já se toma não detectável (concentração abaixo de 1 ppm). 
Os efeitos dos tratamentos da madeira com FFA combinado com compostos de boro podem ser assim resumidos:

a) Resistência aos ataques de térmitas:

As combinações mostraram-se mais eficazes que o tratamento somente com - Ácido Bórico e somente com o Álcool Furfurílico quando submetidos à lixiviação.

b) Resistência aos ataques de fungos:

As amostras de pinus submetidas a tratamento apresentaram resistência levemente superior aos fungos TYP que aos fungos COV em todos os tratamentos, enquanto que as amostras de sugi tratadas apresentaram resistência levemente superior aos fungos da podridão branca COV que aos TYP, em todos os tratamentos. A diferença pode ser creditada à diferença no conteúdo de lignina entre as espécies. As combinaçōes FFA-compostos de boro não demonstraram ser mais eficazes que o tratamento somente com o FFA quando submetidos à lixiviação (tanto no caso do sugi como no caso do pinus).

c) Resistência à flamabilidade:

Os tratamentos apresentaram retardamento da queima sem chama, pouca evolução de cinzas e fumaça, e aumento da formação de carvão a baixas temperaturas. $O$ índice de oxigênio não se tomou muito maior, sendo que no caso do pinus tomou-se menor que a amostra sem tratamento. $O$ tempo de queima, porém, tornou-se a metade no caso do pinho, e um quinto no caso do sugi.

d) Resistência à Degradação por Raios Ultravioleta: 
Com a exposiçãa às condições climáticas, constatou-se que os tratamentos com as combinações não são desejáveis para fixar a cor. Para isto é necessário que a madeira seja pintada ou receba outro tratamento externo. $\mathrm{Na}$ combinação FFA + BA, o BA forma complexo com a lignina e o tanino, tornando a madeira mais resistente à variação de cor e menos susceptivel à lixiviação superficial. Além disso, peroxoboratos (que restauram a cor) podem estar sendo formados. $O$ branqueamento da superfície e o aparecimento de fissuras (principalmente no caso do sugi) indicam que a lignina sofreu forte degradação. Isto é um indício de que a lignina não estava ligada, ou que a ligação não era forte.

Sugestões para trabalhos futuros:

- Estudo dos complexos de boro formados, e se outros mais aparecerão, se continuarmos os ciclos de lixiviação.

- Teste de resistência aos térmitas em campo (em andamento), e com espécies comuns no Brasil.

- Outros testes com a combinação FFA + compostos de boro de resistência ao fogo (p. e. o "Heat Release Rate" - HRR), para determinar com maior acuracidade outras propriedades além de retardante de queima sem chama.

- Análise por espectroscopia de infravermelho para determinar as variações de lignina nas superfícies de madeiras expostas às condiçōes climáticas (em andamento).

- Um estudo para determinar a melhor cobertura para a utilização externa ou em contato com o solo. 


\section{Referências Bibliográgficas}

PIZZI, A. A New Approach to Non-Toxic, Wide Spectrum, Ground Contact Wood Preservatives. Part I. Approach and Reaction on Mechanisms. Holzforschung, vol. 47, p. 253-260, 1993.

DUNLOP, A.P. ; PETERS, F. N. The Furans. American Chemical Society, New York; 1953, p. 783-785.

STAMM, Alfred J. Dimensional Stabilization of Wood with Furfuryl Alcohol Resin in Wood Technology : Chemicals Aspects. American Chemical Society, New York, 1977.

FENGEL, D. ; WENEGER, G. Wood - Chemistry, Ultrastructure, Reactions, Berlin/New York, Walter de Gruyter, 1989, 613p.

BAILEY, I. W.; Kerr, T. J. Arnold Arbor. 18, p. 196-205, 1953. In: Käärik, A. A. Decomposition of Wood.

SAKA, S. Structure and Chemical Composition of Wood as a Natural Composite Material. In: SHIRAISHI, N.; KAJITA, H.; NORIMOTO, M. eds. Recent Research on Wood and Wood-Based Materials. Current Japanese Materials Research, vol. 11, p.1-20, Elsevier, London/New York, 1993.

SJÖSTRÖM, E. Wood Chemistry - Fundamentals and Applications. Academic Press, Orlando, FL, 1981, 223 p.

ROWELL, R. M. Wood Preservation and Stabilization by Chemical Modification of Wood Substance. In: Chemical Aspects of Wood Technology. Swedish Forest 
Products Research Laboratory. STFI Series A, No. 772, p. 32-49, Stockholm, 1982

HIGUCHI,T. Lignin Structure and Morphological Distribution in Plant Cell Walls. In:

KIRK, T. K.; HIGUCHI, T.; CHANG, H. -m. eds. Lignin Biodegradation:

Microbiology, Chemistry and Potential Applications. Vol. I, CRC Press, Boca Raton, Florida, 1978. ISBN 0-8493-5459-5

HILLIS, W. E. Secondary Changes in Wood. In: The Structure, Biosynthesis, and Degradation of Wood. Recent Advances in Phytochemistry. Vol. 11, Plenum Press, New York, 1977, p. 247-309.

STAMM, A. J. Wood and Cellulose Science. Ronald Press, New York, 1964, 549p.

ROWELL, R. M.; BANKS, W. B. Water Repellency and Dimensional Stability of Wood. USDA, General Technical Report FPL-50, Forest Service, Forest Products Laboratory, Madison, WI, 1985, 24p.

SOUZA, M. F.; SOUZA, D. P. F. Glass Phase Expelling During Liquid Phase Sintering of YSZ. Materials Research, vol. 1, p. 53-58, 1998.

OHMAE, K.; NORIMOTO, M.; MINATO, K. Dimensional Change of Wood by

Chemical Treatment. Preliminary Notes. In: Bulletin of the Wood Research Institute, Kyoto University, No. 84, Kyoto, 1997.

NORIMOTO, M. ; GRIL, Joseph Structure and Properties of Chemically Treated

Woods. In: SHIRAISHI, N.; KAJITA, H.; NORIMOTO, M. eds. Recent Research on Wood and Wood-Based Materials. Current Japanese Materials Research, vol. 11, p. 135-54, Elsevier, London/New York, 1993.

OHMAE, K.; NORIMOTO, M. Dimensional Change of Wood by Chemical

Treatment. $47^{\text {th }}$ Annual Meeting of the Japan Wood Research Society, Kochi, Japan, April, 1997.

YUSUF, S. Properties Enhancement of Solid Wood by Cross-Linking Formation.

Ph. D. Thesis, Wood Research Institute, Kyoto University, 1996. 
ROWELL, R. M.; KONKOL, P. Treatments that Enhance Physical Properties of Wood. USDA, General Technical Report FPL-55, Forest Service, Forest Products Laboratory, Madison, WI, 1987.

ROWELL. R. M. Distribution of Bonded Chemicals in Southem pine Treated with Alkalene Oxides. Wood Science, vol. 10 (4), p. 193-197, 1978.

ROWELL, R. M. et al. Effects of Alkylene Oxide Treatments on Dimensional Stability of Wood. Wood Science, vol. 9(1), p. 51-4, 1976.

GALPERIN, A. S. et al. Manufacturing and Properties of Modified Wood. A Review of 25 Years Work. Holzforschung, vol. 49, No. 1, 1995.

RYU, Jae Y.; Imamura, Y.; Takahashi, M. Biological Resistance of Phenolic Resin Treated Wood Incorporating Boric Acid Impregnation. In: Chemical Modification of Lignocellulosics. Rotorua, New Zealand, Nov. 6-7, 1992.

KUMAR, S. Chemical Modification of Wood. Wood and Fiber Science, vol 26(2), p. 270-80, 1994.

GOMES, O. F. Estudo das Ligações Cavilhadas Impregnadas com Resinas Estirênicas Empregadas em Estruturas de Madeiras. Tese(Doutorado), Escola de Engenharia de São Carlos, USP, 1996.

HAZER, B.; ORS, Y.; ALMA, M. H. Improvement of Wood Properties by Impregnation with Macromonomeric Initiators (Macroinimers). Joumal of Applied Science, vol. 47, p. 1097-103, 1993.

ROWELL, R. M.; ELLIS, W. D. Chemical Modification of Wood: reaction of Methyl Isocyanate with Southern Pine. Wood Science, vol. 12(1), p. 52-8, 1979.

GOLDSTEIN, I.S. The Impregnation of Wood to Impart Resistance to Alkali and Acid. Forest Products Journal, vol. 5 , p.265-267, 1961.

SHIMADA, M. Biochemical Mechanisms for the Biodegradation of Wood. In: SHIRAISHI, N.; KAJITA, H.; NORIMOTO, M. eds. Recent Research on Wood and Wood-Based Materials. Current Japanese Materials Research, vol. 11, p. 
207-22, Elsevier, London, 1993.

SCHEFFER, T. C. Microbiological Degradation and the Causal Organisms. In: NICHOLAS, D. D. ed. Wood Deterioration and its Prevention by Preservative Treatments. Vol. 1. Degradation and Protection of Wood. Syracuse University Press, New York, 1973, p. 31-106.

WILCOX, W. W. Degradation in Relation to Wood Structure. In: NICHOLAS, D. D. ed. Wood Deterioration and its Prevention by Preservative Treatments. Vol. 1. Degradation and Protection of Wood. Syracuse University Press, New York, 1973.

SHIMADA, M.; TAKAHASHI, M. In: HON, D. N. -S.; SHIRAISHI, N. eds. Wood and Cellulosic Chemistry. Marcel Dekker, 1991, p. 621.

SHIMADA, M.; AKAMATSU, Y.; TAKAHASHI, M. Proceedings of the International Symposium of Wood and Pulping Chemistry. Melbourne, Australia, April 29 May-3, 1991.

KÄÄRIK, A. Decomposition of Wood. In: KIRK, T. K.; HIGUCHI, T.; CHANG, H. m. Lignin Biodegradation: Microbiology, Chemistry, and potentials Applications. Vol. I, CRC Press, Boca Raton, Florida, 1978, p. 129-174.

SMULSKI, S. Preservative Treated Wood. Wood Science Specialists Inc., 1996. http://www.umass.edu/bmatwt/preserve.html

TAKAHASHI, M. Wood Preserving Techniques to Prevent Biodeterioration. In: SHIRAISHI, N.; KAJITA, H.; NORIMOTO, M. eds. Recent Research on Wood and Wood-Based Materials. Current Japanese Materials Research, vol. 11, p. 207-22, Elsevier, London, 1993.

TAKAHASHI, M.; IMAMURA, Y.; TANAHASHI, M. Effect of Acetylation on Decay Resistance of Wod Against Brown, White-Rot and Soft-Rot Fungi. The International Research Group on Wood Preservation. Doc. IRGMP/3540, 1989. MINATO, K. et al. Resistance of Formaldehyde-treated Wood to Biological Attacks. 
Mokuzai Gakkaishi, vol. 38, No. 11, p. 1050-56, 1992.

YASUDA, R.; MINATO, K. Chemical Modification of Wood by Non-Formaldehyde

Cross-Linking Reagents. Wood Science and Technology, vol.29, p. 243-51, 1995.

Wood Industry Handbook. Forest Industry Experiment Unit. Maruzen Co., $3^{\text {rd }}$ ed., 1982, p. 195. (em Japonês)

BORTOLETTO Jr., G. Indicações para a Utilização da Madeira de seis espécies e variedades de Pinus na Construção Civil. Dissertação de Mestrado, EESC, USP, São Carlos, 1993.

WEHR, J. P. P. Métodos Práticos de Tratamento Preservativo de Moirões Roliços de Pinus caribaea Morelet var hondurensis Bar et Golf. Dissertação de Mestrado. Escola Superior de Agricultura Luiz de Queiroz - USP, 1985, 226p.

PIZZI, A. The Chemistry and Kinetic Behavior of Cu-Cr-As/B Wood Preservatives I. Fixation of Chromium on Wood. Journal of Polymer science: Polymer Chemistry Edition, vol. 19, p. 3093-121, John Wiley, New York, 1981.

YOSHIDA, S. Degradation and Synthesis of Lignin and Its related Compounds by Fungal Ligninolytic Enzymes. In: Kyoto University Bulletin of the Wood Research Institute No. 84, 1997.

YOSHIMURA, T. Ph. D. Thesis. Faculty of Agriculture, Kyoto University, Japan, 1995.

IMAMURA, Y.; NISHIMOTO, K. Bending Creeps Tests of Wood-Based Materials under Fungal Attack. J. Soc. of Material Science, vol. 34, p. 985-9, Japan, 1985. IMAMURA, Y. et alii Distribution of Polymer in the Cell Walls and its Effect on Decay Resistance in Wood-Plastic Composite. Biocontrol Science, 1998. KANG, H. -Y.; SAMESHIMA, K.; TAKAMURA, N. Termite Resistance Test of Hardwoods of Kochi Prefecture Growth. IV. Isolation and Identification of a Termiticidal Component of Litsea coreana leveille Wood. Mokuzai Gakkaishi, 
vol. 40, No. 1, p. 64-71, 1994.

SIILVA, D.; HILLS, W. E. The Contribution of Silica to the Resistance of Wood to Marine Borers. Holzforschung, vol. 34, p. 95-97, 1980.

LEÃO, A. L. Fire Retardants in Lignocellulosics Composites. In: LEÃO, A. L. ; CARVALHO, F. X.; FROLLINI, E. eds. Lignocellulosic - Plastics Composites. USPIUnesp, São Paulo, 1997.

SU, W. - S. et al. Combustion Behavior of Boron-Alkali Metal Treated Wood Using Thermographic Analysis. Mokuzai Gakkaishi, vol. 13, No. 1, p. 82-89, 1997.

SU, W. -S. Ph. D. Thesis. Wood research Institute, Kyoto University, 1997.

YALINKILIC, M. K. et al. Oxygen Index Levels and Thermal Analysis of Wood

Treated with Melamine Formaldehyde-Boron Combinations. $28^{\text {th }}$ Annual Meeting of International Research Group on Wood preservation, Doc. IRG?WP 97-30135, Vancouver, Canada, may 28-30, 1997.

LEITHEISER, R. H. et al. Fire Retardants Furan Resins. European Conference on Flammability and Fire Retardants, Copenhagen, Demark, July 13-14, 1978.

BOZER, K. B.; LONDRIGAN, M. E.; AKERBERG, D. W. Effectiveness of Flame Retardant Additives in Furan Resins. Annual Conference of the Reinforced Plastics/Composites Institute, vol. 33, Section 6B, p. 1-9, 1978.

BOZER, K. B.; BROWN, L. H. High Temperature and Combustion Properties of Furan Composites. 27 $7^{\text {th }}$ Annual Technical Conference of the Reinforced Plastics/Composites Institute, The Society of the Plastics Industry, 1972.

ROWELL, R. M.; FEIST, W. C.; ELLIS, W. D. Weathering of Chemically Modified Southern Pine. Wood Science, vol. 13(4), p. 202-208, 1981.

AmeDas Information of Japan Weather Agency Bulletin (1987) (em Japonês).

HON, D. -S.; MINEMURA, N. Color and Discoloration. In: HON, D. -S.; SHIRAISHI, N. eds. Wood and Cellulosic Chemistry. Marcel Dekker, New york, 1991. 
EVANS, P. D.: THAY, P. D.; SCHMALZL, K. J. Degradation of Wood Surfaces During Natural Weathering. Effects on Lignin and Cellulose and on the Adhesion of Acrylic Latex Primers. Wood science and Technology, vol. 30, p. 411-22, 1996.

EVANS, P. D.; SCHMALZL, K. J. A Quantitative Weathering Study of Wood Surfaces Modified by Cromium VI and Iron III Compounds. Part I. Loss in Zerospan Tensile Strength and Weight of Thin Wood Veneers. Holzforschung, vol. 43, p. 289-292, 1989.

LEE, J. D. Concise Inorganic Chemistry. Chapman \& Hall, London, $5^{\text {th }}$ edition, p. 359-62, 1996.

YUSUF, S. et al. Weathering Properties of Chemically Modified Wood with some Cross-Linking Agents. Second Pacific Rim Bio-Based Composites Symposium, Vancouver, Canada, Nov. 6-9, 1994.

ABE, Z.;ODA, K.; MATSUMURA, J. The Color Change of Sugi(Cryptomeria japonica) Heartwood from Reddish Brown to Black. I. The Color Change and Its Causes. Mokuzai Gakkaishi, vol. 40, No. 10, p. 1119-1125, 1994.

GANDINI, A.; BELGACEM, M. N. Furans in Polymer Chemistry:-Synthesis and Properties of Materials. In "Progress in Polymer Science". Saint Martin d'Heres, 1996.

BATISTA, P. S. Estudo da Formação e das Propriedades Ópticas dos Oligômeros do Álcool Furfurílico em Sistemas Capilares. Dissertação de Mestrado, IFSC, DFCM-USP - São Carlos, 1998.

GERRARD, R. T. The Organic Chemistry of Boron. Academic Press, New York, 1961, p. 17.

JOLLY, WILLIAM L. A Química dos Não Metais. Trad.: Giesbrecht, E.; Perrier, M.; Vicentini, G. Edgard Blücher, São Paulo, 1966. 
PIZZI, A.; BAECKER, A. A New Boron Fixation Mechanism for Environmental Friendly Wood Preservatives. Holzforschung, vol. 50, p. 507-10, 1996.

PEYLO, A.; WILLEITNER, $H$. The Problem of Reducing the Leachability of Boron by Water Repellents. Holzforschung, vol. 49, p. 211-16, 1995.

LAKS, P. E.; MANNING, M. J. Inorganic Borates as Preservative System for Wood Composites. Proceedings of Second Pacific Rim Bio-Based Composites Symposium, Vancouver, Canada, Nov. 6-9, 1994.

YALINKILIC, M. K. et alii. A New Process for in situ Polymerization of Vinyl Monomers in Wood to Delay Boron Leaching. $29^{\text {th }}$ Annual Meeting of the International Research Group on Wood Preservation, Maastricht, The Netherlands, June 14-19, 1998.

KOLLMANN, F. F. P.; KUENZI, E.; STAMM, A. J. Principles of Wood Science and Technology. II. Wood Based Materials. Springer-Verlag, Berlin, Heidelberg, New York, 1975. 
This standard was revised in 8,1977

\section{J APANESE I NDUSTRIAL STANDARD}

\section{Method of Test for Decay of Wood$$
\text { JIS Z } 2119_{-1963}
$$

This English version does not give the numerical values in terms of S/ units which, in the recently issued Japanese text, are given in braces ofter the volues in customary units as a transitional step.

Reference to the original Japanese text is recommended if necessary.

\section{Translated and Published}

by

Japanese Standards Association 
JAPANESE INDUSTRIAL STANDARD

Method of Test for Decay of Wood
J I S

Z 2119-1963

\section{General}

1.1 Scope This standard specifies method of test for decay of wood.

1.2 The decay resistance of wood shall be denoted by the decay resistance ratio.

1. 3 Moreover, items on method of test other than those specified here shall comply with JIS Z 2101 -General Rules for Testing Wood.

\section{Test Fungus}

2. 1 The fungus shown in 2. 2, after being cultured by the method shown in $2.3 \sim 2.5$, shall be used as the test fungus.

2. 2 The fungus shall be of the following two kinds and as the fungus stamms (') prescribed.

$$
\begin{aligned}
\text { Coriolellus palustris - Forestry Experiment Station Fungus } \\
\text { Species No. } 0507
\end{aligned}
$$

Note $\left({ }^{l}\right) \quad$ Standard fungus stamms for decay resistance test which are separated by Forestry Experiment Station, Ministry of Agriculture and Forestry, Japan

2. 3 The culture bottle shall be of cylindrical wide-mouthed glass container having $50 \sim 100 \mathrm{~cm}^{2}$ of bottom area and $500 \sim 800 \mathrm{ml}$ of total content.

2. 4 The culture medium shall be sterilized by dry heating in the culture bottle filled with about $350 \mathrm{~g}$ of quartz sand $\left({ }^{2}\right)$ and about $100 \mathrm{ml}$ of culture fluid $\left({ }^{4}\right)$ separately sterilized $\left({ }^{3}\right)$ shall be given germless and gently hereto by flattening over the surface of the quartz sand.

Notes $\left({ }^{2}\right) \quad$ Quartz sand (Reagent Extra Pure, Grain Size $20 \sim 30$ meshes) shall be washed well with water and air dried before using.

$\left({ }^{3}\right) \quad$ Method of sterilization shall be carried out so as to pass superheated steam at $1 \mathrm{~kg} / \mathrm{cm}^{2}$ of steam pressure for about 30 minutes or steam of ordinary pressure for 30 minutes a day through continuous three days.

(4) Culture fluid shall contain $4 \%$ of glucose (Reagent Extra Pure), $0.3 \%$ of peptone and $1.5 \%$ of malt extract (manufactured by Difco).

2. 5 The method of culture for the test fungus shall be carried out so as to insert ore piece of wood for inoculation $\left(^{5}\right)$ near the centre of surface of the culture medium under 2.4 carefully by not letting miscellaneous fungi invade and to 
culture at a temperature of $26 \pm 2^{\circ} \mathrm{C}$ and $70 \%$ humidity. After the mycelium is grown well on the culture medium in $10 \sim 15$ days the test fungi shall be submitted to the test.

Note $\left({ }^{5}\right) \quad$ To inoculate the wood piece for inoculation with the test fungus on an agar medium, culture at a temperature of $26 \pm 22^{\circ} \mathrm{C}$. When the mycelium spreads widely let the mycelium absorb water. well, insert a chip of sterilized beech (about $10 \times 10 \mathrm{~mm}$, about $1 \mathrm{~mm}$ thick) so as not to let miscellaneous fungi invade and culture for $4 \sim 5$ days to increase the test fungi.

\section{Specimen}

3. 1 The specimen shall be taken out of test block and control block. The control block shall be made of sapwood of beech.

3. 2 The specimen shall be taken out air-dried wood, as a rule, to make into a cube of $20 \pm 1 \mathrm{~mm}$ in side length with two radial surfaces.

3. 3 The test block to be used for this test shall be taken the average width of annular rings and specific gravity in dry condition in compliance generally with JIS Z 2102-Method of Measuring Average Width of Annual Rings, Moisture Content and Specific Gravity of Wood. Provided that the specific gravity in dry condition shall be determined with the constant weight $\left(w_{1}\right)$ specified in 3.4 .

3. 4 The specimen shall be dried at $60 \pm 2^{\circ} \mathrm{C}$ until constant weight $\left(W_{l}\right)$ is attained.

3. 5 The specimen shall be weighed to the nearest $0.01 \mathrm{~g}$.

\section{Tests}

4. 1 The test shall be carried out on the test block and control block at the same time.

4. 2 Decaying Manipulation The specimen shall be so taken as to place three pieces per culture bottle upon the test fungus under 2.1 by being placed vertically in fibre direction and shall be decayed for about 60 days at a temperature of 26 $\pm 2^{\circ} \mathrm{C}$ and relative humidity not less than $70 \%$.

\subsection{Decreasing Rate of Decay Weight The specimen, at the end of decay in} 4.2, shall be carefully free from mycelium adhered to the surface, air-dried for about 20 hours, dried at $60 \pm 2^{\circ} \mathrm{C}$, until the constant weight $\left(W_{2}\right)$ is attained and the percentage of loss in weight is calculated in each species of the fungus from the following formula:

$$
\text { Percentage of loss in weight }|\%\rangle=\frac{W_{1}-W_{2}}{W_{1}} \times 100
$$

Moreover, the specimen for correction taken out of the test block and control block shall be placed vertically in fibre direction upon the culture medium under 2.4 for the same period at a temperature of $26 \pm 2^{\circ} \mathrm{C}$ and relative humidity not less than $70 \%$, and the percentage of $108 \mathrm{~s}$ in weight is obtained in the same method as above-mentioned. By the use of the loss in weight without decay, the percentage of loss in weight shall be corrected. 
3.

Z $2119-1963$

4. 4 The relative decay resistance shall be calculated from the following to the nearest 0.1 :

$$
\text { Relative decay resistance }=\frac{A}{A_{0}}
$$

where,

$$
\begin{aligned}
& A_{0}=100-\text { Corrected percentage of loss in weight in control block } \\
& A=100-\text { Corrected percentage of loss in weight in test block }
\end{aligned}
$$

4. 5 The test result shall be reported, besides the relative decay resistance, the course of fungus in each test block, and visual evidence of decay at the end of test. 


\section{Standard Mothod for MEASURING THE MINIMUM OXYGEN CONCENTRATION TO SUPPORT CANDLE-LIKE COMBUSTION OF PLASTICS (OXYGEN INDEX)"}

Wis Standard is issued under the fixed desiznation D 2863: the number immediutely folluwing the desiznation indicates the Ir of original aduption or, in the case of revision, the year of last reviajon. A number in parentheses indicatea the year of last spproval.

Is merhod has been approved for use by ogencies of the Department of Defense and for listing in the DoD Index of Specifications 4 Standards.

\section{Seope}

1.1 This method describes a procedure for Fasuring the minimum concentration of ygen in a nowing mixture of oxygen and fogen that will just support flaming combus-

.2 This method has been found applicable testing various forms of plastics materials ivding film and cellular plastic.

3 Caution-During the course of comfon, gases or vapors, or both, are evolved th may be hazardous to personnel. Adee precautions should be taken to protect Sperator.

TE I-Although this method has been found able for testing other materials, the accuracy of hethod has not been determined for these matefor for specimen geometries and test conditions th those recommended herein.

This standard should be used to measure escribe the properties of materials, products. imblies in respohse to heat and Jlame under plled laboratory conditions and should not it to describe or appraise the fire hazard or "sk of materials, products, or assemblies actual fire conditions. However, results of At may be used as elements of a fire risk Went which takes into account all of the Which are pertinent to an assessment of hazard of a particular end use. 3

ifcable Documents

"tole.

ISTM Standards:

8 Conditioning Plastics and Electrical Wulating Materials for Testing ${ }^{2}$

H1 Measurement of Gaseous Fuel mples"
D 2444 Test for Impact Resistance of Thermoplastic Pipe and Fittings by Means of a Tup (Falling Weight)

\section{Siznificance}

3.I This method provides for the measuring of the minimum concentration of oxygen in a nowing mixture of oxygen and nitrogen that will just support naming combustion of plastics. Correlation with burning characteristics under actual use conditions is not implied.

\section{Definition}

4.1 oxygen index-the minimum concentration of oxygen, expressed as volume percent, in a mixture of oxygen and nitrogen that will just support flaming combustion of a material initially at room temperature under the conditions of this method.

\section{Summary of Method}

S.1 The minimum concentration of oxygen in a mixture of oxygen and nitrogen flowing upward in a test column that will just support combustion is measured under equilibrium conJitions of candle-like burning. The equilibrium is established by the relation het ween the heat generated from the combustion of the specimen and the heat lost to the surroundings as mea-

\footnotetext{
"This method is under Ihe intictielin of 1 OTM CommitIU D.ID on Plastics and is the direct responsibility of Subcommittee D20.30 on Thermal Properties.

Cument edition approved iuly 1, 1977. Published Seprember 1977. Originally publinhed as D 2863-70. Lat previous edition D 2863 - 76.

- Annual Book of ASTM Standards, Parts 22, 30, 35, and 39.

Annual Book of ASTM Standards, Part 26.

- Annual Book of ASTM Standards, Part 34.
} 
sured by one or the other of two arbitrary criteria, namely, a time of burning or a length of specimen burned. This point is approached frum both sides of the critical oxygen concentration in order to establish the oxygen index.

\section{Apparalus}

6.1 Test Column, consisting of a heat-resistant glass tube of $75 \mathrm{~mm}$ minimum inside diameter and $450 \mathrm{~mm}$ minimum height. The bottom of the column or the base to which the tube is altached shall contain noncombustible material to mix and distribute evenly the gas mixture entering at this base. Glass beads 3 to 5 $\mathrm{mm}$ in diameter in a bed $8010100 \mathrm{~mm}$ deep have been found suitable (an example is shown in Fig. 1).

Note 2-A column with a 95-mm inside diameter and $210 \mathrm{~mm}$ high with a restricted upper opening (diameler $=50 \mathrm{~mm}$ ) has been found to give equivalent results.

NOTB 3-It is helpful to place a wire screen above the noncombustible material to catch falling fragments and aid in keeping the base of the column clean.

6.2 Specimen Holder-Any small holding device that will support the specimen at its base and hold it vertically in the center of the column is acceptable. For physically self-supporting specimens, a typical arrangement (Fig. 1) consists of a laboratory thermometer clamp inseried into the end of a glass tube held in place by glass beads or otherwise firmly supported. For other forms, such as film and thin sheet, the frame shown in Fig. 2 shall be used and held in place by the above tube. The test specimen must be held securely along both upright edges by the frame, using clips or other means.

6.3 Gas Supply-Commercial grade (or bet(er) oxygen and nitrogen shall be used. If an air supply is used with oxygen or nitrogen, it must be clean and dry.

6.4 Flow Measurement and Control Devices-Suitable flow measurement and control devices shall be available in each line that will allow monitoring the volumetric flow of each gas into the column within $1 \%$ in the range being used. After the flow is measured in each line, the lines should be joined to allow the gases to mix before being fed into the column.

Nore 4-One satisfactory flow control system consists of calibrated jeweled orifices (3), pressure regulating devices, and gas gages. An equally satisfactory system consists of needle valves and rotam. eters meeting the requirements of 6.4 .
6.5 Ignition Source-The igniter shall be a lube with a small orifice (1 $103 \mathrm{~mm}$ in diameter) having a hydrogen, propane, or other gas name at the end that can be inserted into the open end of the column to ignite the test specimen. A suitable flame may be from 61025 $\mathrm{mm}$ long.

6.6 Timer-A suitable timer capable of indicating at least $10 \mathrm{~min}$ and accurate at $5 \mathrm{~s}$ shall be used.

6.7 Soot, Fumes, and Heat Removal-To ensure the removal of toxic fumes, sool, heat, and other possible noxious products, the col. umn shall be installed in a hood or other facilities providing adequate exhaust.

Notr 5-If soot-generating specimens are being tested, the glass column becomes coated on the inside with soot and should be cleaned as often as necessan for good visibility.

\section{Test Specimens}

7.1 A sufficient number of specimens (nor. mally 5 to 10 ) shall be cut from the material to be tested. Specimen dimensions shall be determined from Table 1.

7.1.1 The specimens shall be tested in the as-received condition unless otherwise agreed upon.

7.1.2 Moisture content of some materials has been shown to affect the oxygen index. Where a material is suspected to be affected by retained moisture, the specimens should be conditioned in accordance with Procedure A of Method D 618.

Nore 6-If non-standard size specimens are used, a difference in oxygen index may result.

7.1.3 For Type C specimens, comparisons should only be made between materials of similar densities.

Notr 7-For certain types of cellular plastics, the direction of anisotropy may have an effect and should be evaluated unless a particular direction has previously been agreed upon.

7.1.4 Type D materials shall be tested in the as-received thickness, but comparisons may be made only between material of the same thickness.

7.1.5 The edges of the specimens shall bo relatively smooth and free from fuzz or burrs of material left from machining.

\section{Procedure}

8.1 Calibrate the flowmeasuring systemt using a water-sealed rolating drum meter (wet) 
test meter) in accordance with Method D 1071 or by equivalent calibration devices. It is recommended that this calibration be repeated at least every 6 months.

Nore 8-One step in the calibration should be to check carefully for leaks at all ioints.

8.2 The test shall be conducted at room temperature conditions in accondance with Method D 618.

8.3 Clamp the specimen vertically in the approximate center of the column with the top of the specimen at least $100 \mathrm{~mm}$ below the top the open column.

Norr 9-If a restricted opening column is used (see Note 3), the top of the apecimen should be at Heast $40 \mathrm{~mm}$ below the opening.

8.4 Select the desired initial concentration of kygen based on experience with similar mateials. If there is no experience with similar haterial, light a specimen in the air and note he burning. If the specimen burns rapidly, start a concentration of about $18 \%$, but if the Jecimen goes out, select a concentration of bout $25 \%$ or higher depending on the diffility of ignition and time of burning.

8.5 Set the now valves so that the desired fial concentration of oxygen is nowing fough the column. The gas now rate in the Jumn shall be $4 \pm 1 \mathrm{~cm} / \mathrm{s}$ as calculated at hodard temperature $\left(0^{\circ} \mathrm{C}\right)$ and pressure $01.3 \mathrm{kPa}$ ) from the total flow of gas in $4 / 5$, divided by the area of the column in *.

3.6 Allow the gas to now for $30 \mathrm{~s}$ to purge system.

7 Ignite the entire top of the specimen with ignition flame so that the specimen is well ited. Remove the ignition flame and start the iter.

7.1 Type A, B, and C apecimens are well fod when the entire top is burning.

1.2 Type D specimens are well lighted if inon occurs before any portion of the flame passes the 2-cm reference mark on the 18. This method is not applicable to matethat shrink below the $2-\mathrm{cm}$ mark before ton.

of 10 -Certain Type D materials have been to shrink excessively at oxygen concentrations the critical value but burn al values above the al value. Care should be taken in testing such tials.

The concentration of oxygen is too high must be reduced if the specimen burns in accordance with one of the following criteria:

$\begin{array}{cccc}\text { Type } & \text { A and B } & \text { C } & \text { D } \\ \text { Criteria for } & \text { at least } & \text { at least } & \text { past the loo } \\ \text { burning } & 3 \mathrm{~min} & 3 \mathrm{~min} & \text { mm refer- } \\ & \text { or } & \text { or } & \text { ence mark }\end{array}$

8.8.1 Do not adjust the oxygen concentration after igniting the specimen.

8.9 The concentration of oxygen must be raised if the naming of the specimen extinguishes before meeting the criterion in 8.8 .

Nom 11-When testing Type $D$ specimens, the support frame may come within $12 \mathrm{~mm}$ of the glass chimney. It has been found that the chimney may become quite hot and cause a decrease in oxygen index. Where this is found, it is suggested that the glass chimney be allowed to come back to room temperature before running the next test specimen. Certain laboratories accomplish this by atternating two chimneys.

8.10 Adjust the oxygen concentration, insert a new specimen, or if the previous specimen is long enough, turn it end for end or cut off the burned end, then purge and re-ignite.

8.11 Continue repeating 8.6 through 8.10 until the critical concentration of oxygen is determined. This is the lowest oxygen concentration that will meet the criterion of 8.8. At the next lower oxygen concentration that will give a difference in oxygen index of $0.2 \%$ or less, the specimen should not meet the criterion of 8.8 .

Nots 12-The critical oxygen concentration has been found to be dependent on the temperature of the specimen at ignition and the temperature of the gas mixture.

Nort 13-For material having consistent burning characteristics, the difference in oxygen concentration between burning as defined in 8.8 and extinguishing as defined in 8.9 , will be reproducible within 0.1 to $0.3 \%$ depending on the sensitivity of the flow measuring equipment and upon the particular oxygen concentration involved. Some materials, however, exhibit erratic burning characteristics because of inhomogeneity, char formation, dripping. bending. etc., which cause less reproducible results. In such cases, the critical concentration may be determined by a statistical testing mothod."

8.12 Perform the lest at least three times by starting at a slightly different now rate still within the $3105-\mathrm{cm} / \mathrm{s}$ limits and again per-

- Such a atiatical method as the Bruceton Suircase Method at the $F_{\text {on }}$ mean failure value may be used. See the equalions in Method D 2444. Also see bixon, W. J. and Massey, F. J., Jr., Introduction 10 Stotisticol Analysis, (2nd Edition), MoGraw.Hill Book Co., Inc., New York, N. Y. 1957. Chapter 19, or Nalrella, Mary, "Experimental Statistics," Section 10-4, National Bureau of Siandards Hondbook 91. 1963. Other procedures, such as using ten specimens at cach oxygen concenlration tried, have also proved successful. 
forming steps 8.5 through 8.11 .

8.13 Rourine Inspection Tesis-For routine inspection or specification purposes, a specified number of specimens may be tested at a specified oxygen concentration, all other conditions being controlled as in 8.1 to 8.7 . The specification should be written in terms of the maximum number of specimens burning according to 8.8 .

Note 14-Such a specification might read, for example "Not more than __ of _._ specimens shall burn at least $3 \mathrm{~min}$ or $50 \mathrm{~mm}$ at an oxygen level of _._.

\section{Calculations}

9.1 Calculate the oxygen index, $n$, of the material for each replicate in 8.12, as follows:

$$
n_{1} \%=\left(100 \times O_{2}\right) /\left(O_{2}+N_{2}\right)
$$

where:

$\mathrm{O}_{2}=$ volumetric flow of oxygen, $\mathrm{cm}^{3} / \mathrm{s}$, at the concent ration determined in 8.11 , and

$N_{1}$ = corresponding volumetric flow rate of nitrogen, $\mathrm{cm} \% \mathrm{~s}$.

9.1.1 If air is used and either oxygen or nitrogen is added as required, calculate . assuming that air contains $20.9 \%$ oxygen as follows:

$$
n_{1} w_{0}=\left(100 \times O_{2}\right)+(20.9 \times A) /\left(O_{2}+N_{1}+A\right)
$$

where:

$A=$ volumetric flow rate of air, $\mathrm{cm}^{3} / \mathrm{s}$.

$\mathrm{O}_{2}=$ volumet ric llow rate of oxygen, and

$N$, volumetric flow rate of nitrogen.

\section{Report}

10.1 The report shall include the following:
10.1.1 Description of the material tested including the type, density, and general direc. tion of anisotropy (for Type $C$ specimens) source, manufacturers code number, form, pre. vious history, and conditioning (if any),

10.1.2 Test specimen dimensions,

10.1.3 Individual oxygen index values found for each of the tests, and average oxygen index value.

10.1.4 Description of any unusual behavior such as charring, dripping, bending, etc., and

10.1.5 The caveat contained in 1.4 herein shall be incorporated in its entirety in the test report issued.

\section{Precision}

11.I From a statistically designed round. robin testing program $(4,5)$ on Type $A$ speci mens in which 18 laboratories checked five materials, the following was determined:

11.1.1 The standard deviation of the mean of three replicates (for comparing laboratory-to. laboratory) was $0.4 \mathrm{fnr}$ materials with an oxygen index below $21 \%$ and 0.7 to 1.4 for materials with an oxygen index above $21 \%$ The higher value was for a material that exhibits the erratic behavior mentioned in Note 14.

11.1.2 The standard deviation within a labo. ratory ranged from 0.1 for clean burning mate. rials to 1.0 for erratic materials.

11.2 In a later statistically designed round. robin testing program (6) on Types B, C, and D specimens in which 29 laboratories studied 12 materials, the results in Table 2 were found.

\section{REFERENCES}

(1) Fenimore, C. P., and Martin, F. J. “Candle-type Test for Flammability of Polymers," Modern Plastics, MOPLA, Vol 43, November 1966, p. 141.

(2) Goldblum, K. B., "Oxygen Index: Key to Precise Flammability Ratings," Society of Plastic's Engineers Journal, SPEJA, Vol 25, February 1969, p. 50.

(3) Andersen, J. W., and Friedman, R., "An Accurate Gas Metering System for Laminar Flow Studies," Revien of Scientific Insiruments,
RSINA, Vol 20, 1949, p. ol.

(4) Isaacs, J. L.. "The Development, Standardiza. tion and Utilication of the Oxygen Index Flammability Test." General Electric TIS Report 69-MAL-13. August 1969, Louisville, Ky.

(5) Supporting data for this method may be obtained from ASTM Headquarters by requesting RR: D-20-102.

(6) Supporting data for this method may be obtained from ASTM Headquarters by requesting RR: D.20-1031. 


\section{Afll 02863}

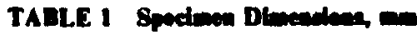

\begin{tabular}{|c|c|c|c|c|}
\hline Type & Plastic Form & Width & Thickness & Length \\
\hline $\mathbf{A}$ & $\begin{array}{l}\text { Physically self-supporting } \\
\text { Alternute for self-supporting } \\
\text { nexible plastica }\end{array}$ & $\begin{array}{l}6.5 \pm 0.5 \\
6.5 \pm 0.5\end{array}$ & $\begin{array}{l}3.0 \neq 0.5 \\
2.0 \neq 0.25\end{array}$ & $\begin{array}{l}70 \text { to } 150 \\
70 \text { to } 150\end{array}$ \\
\hline $\begin{array}{l}\text { C } \\
\text { D }\end{array}$ & $\begin{array}{l}\text { Cellular plastic } \\
\text { Film or thin shoet }\end{array}$ & $\begin{aligned} 12.5 & \neq 0.5 \\
52 & \neq 0.5\end{aligned}$ & $\begin{array}{l}12.5 \pm 0.5 \\
\text { as received }\end{array}$ & $\begin{array}{l}12510150 \\
140 \pm 5\end{array}$ \\
\hline
\end{tabular}

TABLE 2 Prectaion Rewalts

\begin{tabular}{|c|c|c|}
\hline Type & $\begin{array}{l}\text { Laboralory-To- } \\
\text { Laboratory } \\
\text { Standard } \\
\text { Deviation }\end{array}$ & $\begin{array}{l}\text { Within Laboratory } \\
\text { Standand Deviation }\end{array}$ \\
\hline $\begin{array}{l}\mathbf{B} \\
\mathbf{C} \\
\mathbf{D}\end{array}$ & $\begin{array}{ll}0.5 \text { to } & 1.1 \\
0.410 & 1.5 \\
0.5 \text { to } & 1.4\end{array}$ & $\begin{array}{l}\text { below } 0.2 \\
0.1 \text { to } 0.3 \text { (est.) } \\
\text { below } 0.6\end{array}$ \\
\hline
\end{tabular}


49f D 2863

GLASS COLUMN IMMMAUM OMENSION $45 \mathrm{CM}$ H. $\times 7.5 \mathrm{~cm}$ 1.0.1

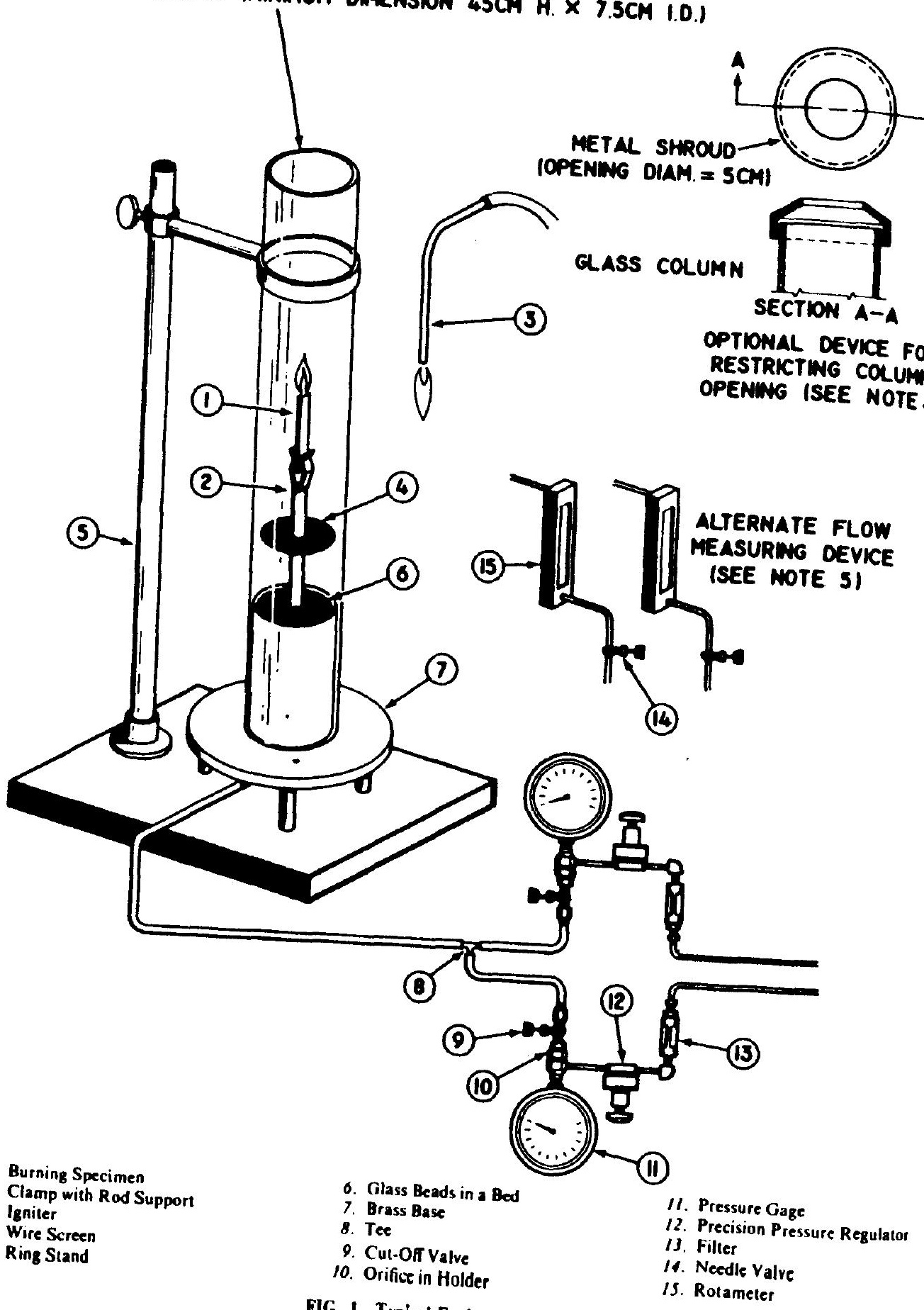

FIC. I Typical Equipment L.ayour. 
